\title{
MODULATION OF PRIMARY MERISTEM ACTIVITY BY GIBBERELLINS THROUGH DELLA-TCP INTERACTION IN ARABIDOPSIS
}

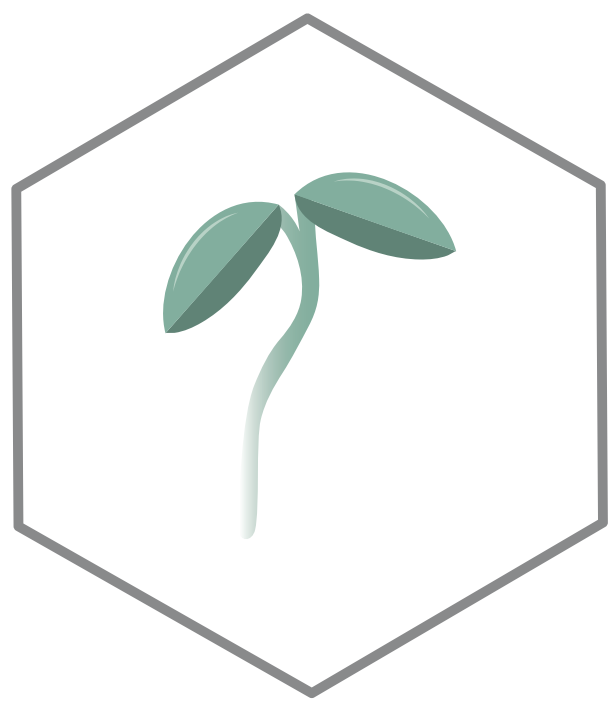

AMELIA FELIPO BENAVENT

ADVISORS

MIGUEL ÁNGEL BLÁZQUEZ RODRÍGUEZ DAVID ALABADÍ DIEGO

IGNACIO RUBIO SOMOZA 


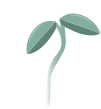

9

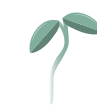

of

9

$\infty$
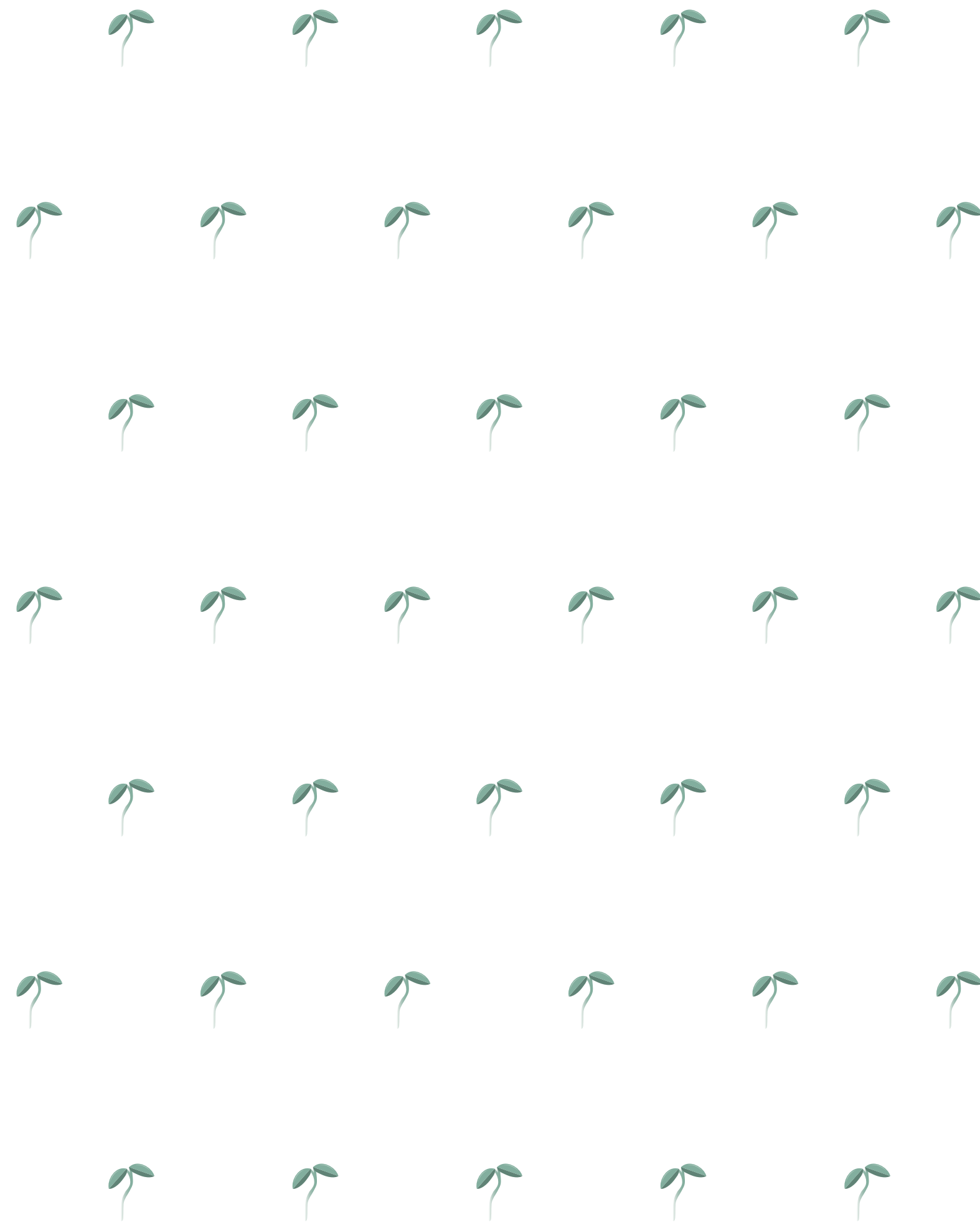


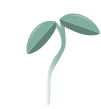

9

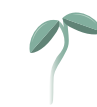

of

9

$\infty$
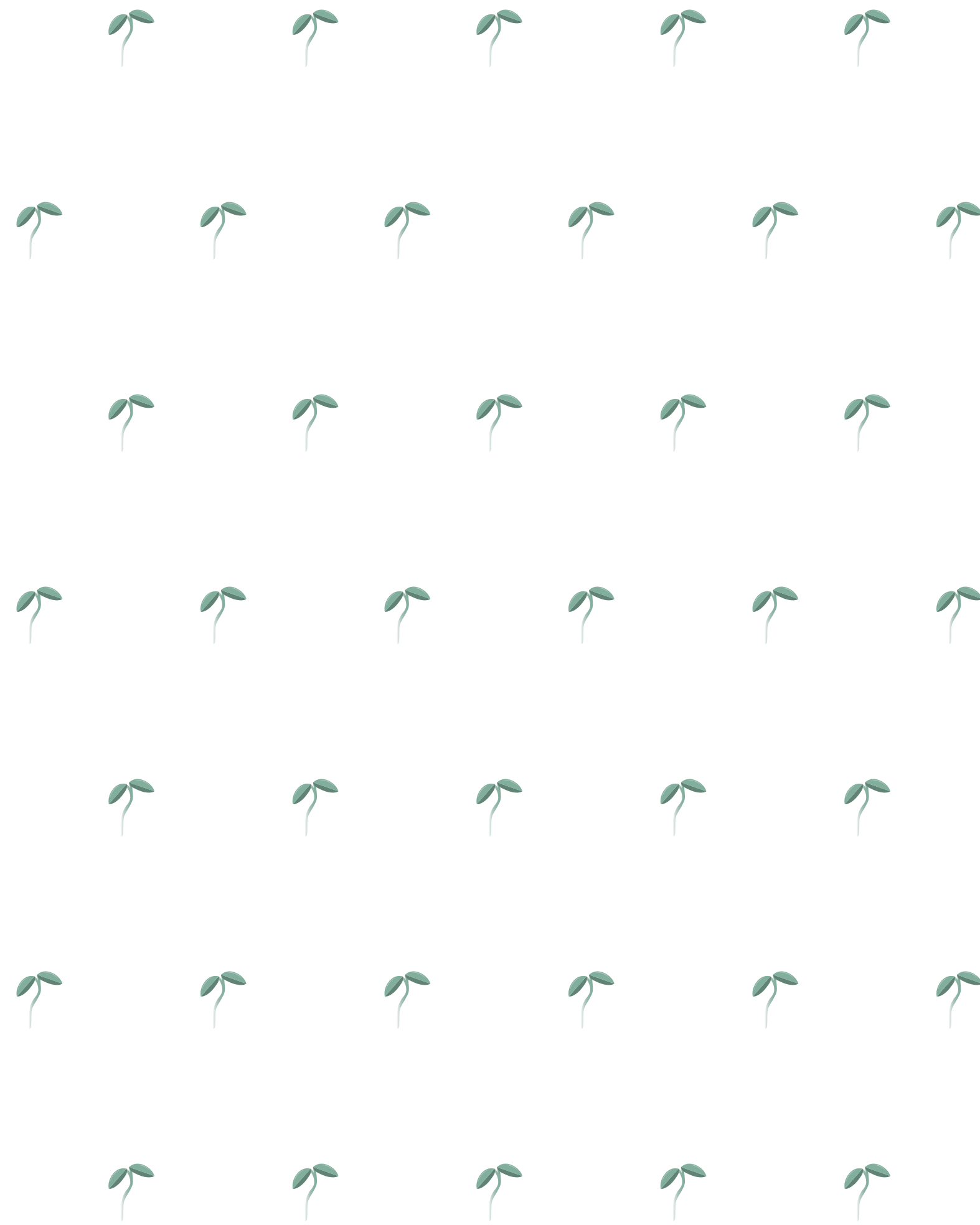



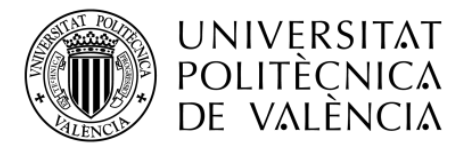

BIOTECHNOLOGY DEPARTMENT

PhD Thesis

\section{Modulation of primary meristem activity by gibberellins through DELLA- TCP interaction in Arabidopsis}

Amelia Felipo Benavent

Advisors:

Miguel Ángel Blázquez Rodríguez

David Alabadí Diego

Ignacio Rubio Somoza

March 2017 

El Dr. Miguel Ángel Blázquez Rodríguez, Profesor de Investigación del CSIC, el Dr. David Pablo Alabadí Diego, Científico Titular del CSIC, ambos pertenecientes al Instituto de Biología Molecular y Celular de Plantas (IBMCP, UPV-CSIC) de Valencia, y el Dr. Ignacio Rubio Somoza, Investigador Junior del Centre for Research in Agricultural Genomics (CRAG) de Barcelona,

CERTIFICAN que Amelia Felipo Benavent, ha realizado bajo su dirección en el Instituto de Biología Molecular y Celular de Plantas, el trabajo titulado "Modulation of primary meristem activity by gibberellins through DELLA-TCP interaction in Arabidopsis", y que autorizan su presentación para optar al grado de Doctor en Biotecnología.

Y para que así conste, firman el presente certificado en Valencia a 4 de febrero de 2017.

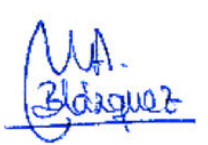

Dr. Miguel Ángel

Blázquez Rodríguez

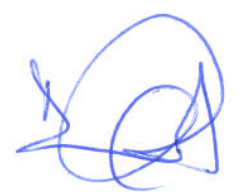

Dr. David Pablo

Alabadí Diego

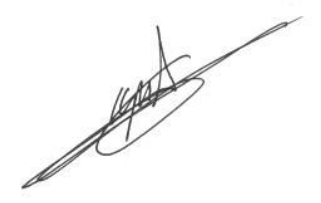

Dr. Ignacio Rubio Somoza 

Para mis abuelos 



\section{Agradecimientos}

Después de más de cinco años el momento agridulce ha llegado y toca dejar atrás esta etapa, que siempre recordaré con cariño. Ante todo, gracias a todos los que os habéis cruzado en mi camino este tiempo, porque de todos vosotros me llevo algo, una amistad, una enseñanza o unas risas.

En primer lugar, quiero dar las gracias a Miguel y David, por guiarme estos años con tanto humor y apoyarme cuando lo he necesitado. He tenido suerte con vosotros. También por confiar en mí y empujarme hacia retos que me han hecho crecer como profesional y como persona. Estoy muy contenta con la formación que me habéis dado y sobre todo por la pasión por el trabajo que trasmitís. Gracias por este aprendizaje, lo llevaré siempre conmigo.

A Nacho, por darme la oportunidad de trabajar con él y aprender tanto a su lado. Por estar siempre dispuesto a ayudarme en mi carrera científica, con sus sabios consejos y agudas observaciones, que me ayudan a ver otros puntos de vista y ser mejor profesional. También a nuestros colaboradores: Detlef Weigel en Alemania, Antonio y Robert Sablowski en Gran Bretaña y Simona Masiero en Italia, porque trabajar con ellos ha sido muy enriquecedor.

A Asier y Marta, no tengo palabras. O mejor dicho, tengo demasiadas, y si empiezo no paro. Soy muy afortunada de teneros. Gracias por ser mis remos.

A mis amigos y compañeros pasados y presentes del 2.07 y aledaños. A Juan Camilo y Moe, gracias por los cafés y la amistad. A Cris Úrbez, Francesca, Eugenio y David "nuevo", por cuidarme, animarme y siempre estar ahí cuando os necesitaba. A mis grandes colegas Jorge, Rodri, Noel y Marco, que me han hecho sentir como un tío más y ya puedo decir que estoy inmunizada para lo que venga después. Sobre todo a Noel, por su ayuda con los experimentos. Mención especial para Ma Ángeles y Juan, que son el alma del IBMCP, y me alegro de que retrasaran su jubilación y haber compartido con ellos estos años. A Nora y Paco, por ser unas grandes personas, siempre dispuestas a echar una mano. En definitiva, a todas las personas que a lo largo de estos años han compartido conmigo en mayor o menor grado momentos, charlas de pasillo, boleras, karaokes, horchatas, torrás, fiestas... Todo lo vivido con vosotros me ha llevado a ser la persona que hoy soy, disfrutando los buenos momentos y aprendiendo de los malos. 
Quiero agradecer a mis viejos amigos, sobre todo a mis biotecnólogas, que hayan estado conmigo todo este tiempo. Han demostrado que no importa el tiempo que pase, la distancia o las responsabilidades laborales y familiares, siempre están ahí para lo que haga falta.

Por último, quiero dar las gracias a mi familia entera. Por muchísimas cosas, pero sobretodo, por su cariño y los valores que me han llevado hasta aquí y me permitirán seguir adelante pase lo que pase.

Ha sido una gran aventura,

¡Gracias! 


\section{Summary}

Plant development is an iterative process of organ formation from the primary meristems of the plant. Meristem activity is driven by dynamic transcriptional programs that determine cell fate and identity as cells are displaced trough the meristematic tissue to initiate organ primordia. This regulatory network includes members of the TCP and KNOX family of transcription factors, and integrates external and intrinsic cues to efficiently adapt meristem activity to an ever-changing environment. However, how this integration occurs is not clear yet.

DELLA proteins have been proposed to modulate transcriptional circuits in plants in response to environmental signals. Although they do not show DNA binding capacity, DELLAs regulate transcription through physical interaction with a large number of DNA-binding transcription factors and other transcriptional regulators. Given the observed interaction between DELLAs and several members of the TCP family of transcription factors, we have explored the relevance of this interaction in the regulation of primary meristems. We have confirmed that DELLAs interact with members of both Class I and Class II TCPs, and prevent their ability to regulate downstream targets. In the embryonic roots, DELLAs maintain a dormant meristem by impairing TCP14/15-dependent activation of cell-cycle genes. On the other hand, DELLAs participate in the establishment of the shoot apical meristem domain that keeps an indeterminate fate, through the control of KNAT1 gene expression by the TCP2/4-AS1 regulatory module. In summary, this Thesis provides a mechanistic framework to eventually explain environmental regulation of meristem activity. 


\section{Resumen}

El desarrollo de las plantas es un proceso iterativo de formación de órganos a partir de los meristemos primarios de la planta. La actividad meristemática está dirigida por programas transcripcionales dinámicos que determinan el destino y la identidad celular conforme las células son desplazadas a través del tejido meristemático para iniciar el primordio del órgano. Esta red regulatoria incluye miembros de las familias de factores de transcripción TCP y KNOX, e integra señales externas e intrínsecas para adaptar eficientemente la actividad meristemática al medio ambiente, siempre cambiante. Sin embargo, la manera en que esta integración ocurre no se ha desvelado todavía.

Se ha propuesto que en plantas, las proteínas DELLA modulan los circuitos transcripcionales en respuesta a señales medioambientales. Aunque no muestran capacidad de unión al ADN, las DELLAs regulan la transcripción a través de su interacción física con un gran número de factores de transcripción capaces de unirse al ADN y otros reguladores transcripcionales. Dada la interacción observada entre las DELLA y varios miembros de la familia de factores de transcripción TCP, hemos explorado la relevancia de esta interacción en la regulación de los meristemos primarios. Hemos confirmado que las DELLA interaccionan con miembros de las dos clases de TCPs (Clase I y Clase II) e impiden su capacidad de regular dianas aguas abajo. En la raíz del embrión, las DELLAs mantienen el meristemo durmiente al impedir la activación de los genes de ciclo celular dependiente del módulo TCP14/15. Por otro lado, las DELLAs participan en el establecimiento del meristemo apical del tallo, que mantiene un estado indiferenciado, a través del control el módulo TCP2/4-AS1, el cual regula la expresión del gen KNAT1. En resumen, esta Tesis aporta un marco mecanístico para explicar, con el tiempo, la regulación medioambiental de la actividad meristemática. 


\section{Resum}

El desenvolupament de les plantes consiteix en un procés iteratiu de formació d'órgans a partir dels meristems primaris. L'activitat meristemàtica està diridida per programes transcripcionals dinàmics que determinen el destí i la identitat cel.lular a mesura que les cèl.lules es van allunyant del meristem per formar els primordis d’órgans. Esta xarxa de regulació inclou membres de les famílies de factors de transcripció TCP i KNOX, i integra senyals externes i intrínseques per adaptar d'una manera eficient l'activitat del meristem als canvis del medi ambient. No obstant, no es coneix de quina manera la planta fa esta integració.

S'ha proposat que les proteïnes DELLA modulen estes xarxes transcripcionals en resposta a senyals del medi. Estes proteïnes no tenen capacitat d'unir-se a I'ADN, però regulen la transcripció mitjançant la interacció amb factors de transcripció i altres reguladors transcripcionals. Donada la interacció entre les proteïnes DELLA i alguns membres de la família de factors de transcripció TCP, hem explorat la rellevància d'esta interacció a la regulació dels meristems primaris. Hem confirmat que les DELLA interaccionen amb membres de les dos classes de TCPs (Classe I i Classe II) i els impedeixen regular les seues dianes. A l'arrel de l'embrió, les DELLA mantenen el meristem dorment al impedir l'activació de gens del cicle cel.lular depenent del mòdul TCP14/15. Per una altra banda, les DELLA particípen a l'establiment del meristem apical de la tija, al que mantenen en un estat indiferenciat, mitjançant el control del mòdul TCP2/4-AS1, que regula l'expressió de KNAT1. En resum, esta Tesi aporta un marc mecanístic per poder explicar, més endavant, la regulació mediambiental de l'activitat meristemàtica. 

Abbreviations 

A. tumefaciens

ABA

ACT8

AD

ALC

Arabidopsis

ARR

AS1

bHLH

BiFC

BME3

BP

BR

BZR1

CDKs

cDNA

ChIP

CIN

CK

Co-IP

Colo

CYC

CZ

DBD

E. coli

EDZ

EMSA

ET

GA

GA200X

GA2ox

GA3OX

GAI

GFP

GGDP

GID
Agrobacterium tumefaciens

ABscisic Acid

ACTINE8

Activation Domain

ALCATRAZ

Arabidopsis thaliana

ARABIDOPSIS RESPONSE REGULATOR

ASYMMETRIC LEAVES1

BASIC HELIX-LOOP-HELIX

Bimolecular Fluorescence Complementation

BLUE MICROPYLAR END 3

BREVIPEDICELLUS

Brassinosteroid

BRASSINAZOLE RESISTANT1

Cyclin-Dependent Kinases

complementary DNA

Chromatin ImmunoPrecipitation

CINCINNATA

Cytokinin

Co-ImmunoPrecipitation

Columbia 0

CYCLIN

Central Zone

DNA binding domain

Escherichia coli

Elongation-Differentiation Zone

Electrophoretic Mobility Shift Assay

Ethylene

Gibberellin

GA20-OXIDASE

GA2-OXIDASE

GA3-OXIDASE

GIBBERELLIC ACID INSENSITIVE

GREEN FLOURESCENT PROTEIN

GERANYLGERANYL DIPHOSPHATE

GIBBERELLIN INSENSITIVE DWARF 


\begin{tabular}{|c|c|}
\hline GO & Gene Ontology \\
\hline GUS & B-glucoronidase \\
\hline$H D A$ & HISTONE DEACETYLASE \\
\hline IAA & auxin/Indol Acetic Acid \\
\hline$I D D$ & INDETERMINATE DOMAIN \\
\hline IPT & ISOPENTENYL TRANSFERASE \\
\hline JA & Jasmonic Acid \\
\hline$J A Z$ & JASMONATE ZIM-DOMAIN \\
\hline KN1 & KNOTTED1 \\
\hline KNAT & KNOTTED1-LIKE HOMEOBOX IN ARABIDOSIS THALIANA \\
\hline KNOX & KNOTTED1-LIKE HOMEOBOX \\
\hline KRP2 & KIP-RELATED PROTEIN 2 \\
\hline LD & Long Day \\
\hline Ler & Landsberg erecta \\
\hline LHR & Leucine Heptad Repeats \\
\hline LOX & LIPOXYGENASE \\
\hline Luc & Luciferase \\
\hline mRNA & messenger RNA \\
\hline N. benthamiana & Nicotiana benthamiana \\
\hline No-O & Nossen-0 \\
\hline OD & Optical Density \\
\hline OSH1 & Oryza sativa homeobox1 \\
\hline$P_{0}$ & Plastochron 0 \\
\hline PAC & Paclobutrazol \\
\hline PCNA & PROLIFERATING CELL NUCLEAR ANTIGEN \\
\hline PCR & Polymerase Chain Reaction \\
\hline PD & Physiological Dormancy \\
\hline PIF & PHYTOCHROME INTERACTING FACTOR \\
\hline PKL & PICKLE \\
\hline PM & Proximal Meristem \\
\hline PZ & Peripheral Zone \\
\hline QC & Quiescent Center \\
\hline qRT-PCR & quantitative-Real Time PCR \\
\hline RAM & Root Apical Meristem \\
\hline RBR1 & RETINOBLASTOMA-RELATED 1 \\
\hline RGA & RESPRESSOR OF ga1-3 \\
\hline$R G L$ & RGA LIKE \\
\hline
\end{tabular}




$\begin{array}{cl}\text { rTCP } & \text { dominant miR319-resistant gene version of CIN-TCP } \\ \text { RZ } & \text { Rib Zone } \\ \text { SA } & \text { Salicylic Acid } \\ \text { SAM } & \text { Shoot Apical Meristem } \\ \text { SCF } & \text { SKP1, CULLIN, F-BOX } \\ \text { SIM } & \text { SIAMESE } \\ \text { SL } & \text { Strigolactone } \\ \text { SLY1 } & \text { SLEEPY1 } \\ \text { SPL } & \text { SQUAMOSA PROMOTER BINDING-LIKE } \\ \text { STM } & \text { SHOOT MERISTEMLESS } \\ \text { TCA Cycle } & \text { Tricarboxylic acid cycle } \\ \text { TCP } & \text { TEOSINTE BRANCHED1, CYCLOIDEA, PROLIFERATING CELL FACTOR } \\ \text { TF } & \text { Transcription Factor } \\ \text { TR } & \text { Transcriptional Regulator } \\ \text { TZ } & \text { Transition Zone } \\ \text { VAL } & \text { VP1/ABI3-LIKE } \\ \text { Y2H } & \text { Yeast Two-Hybrid } \\ \text { YFP } & \text { YELLOW FLUORESCENT PROTEIN }\end{array}$



Table of contents 



\section{General Introduction}

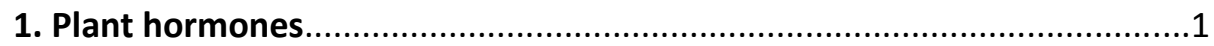

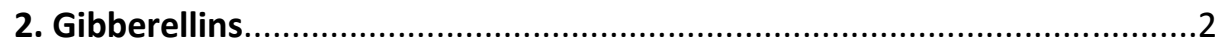

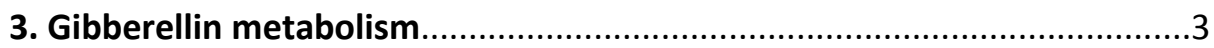

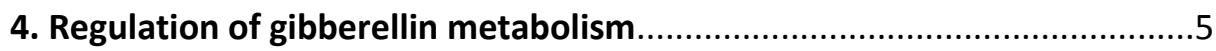

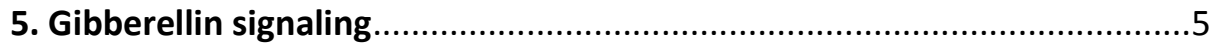

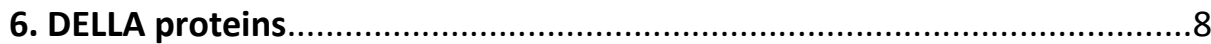

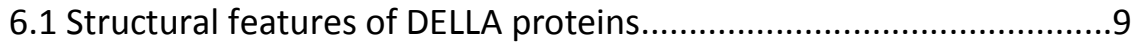

6.2 Mechanisms of action of DELLA proteins.........................................10

7. The role of DELLAs in the primary meristems: interaction with TCPs.......11

7.1 Looking for suitable DELLA interactors regulating meristem

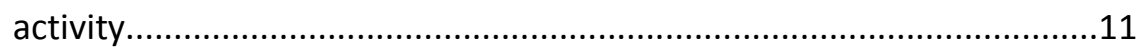

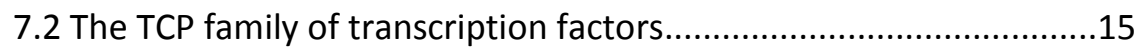

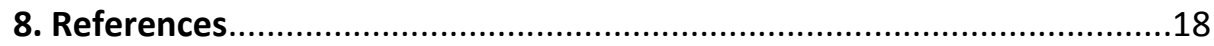

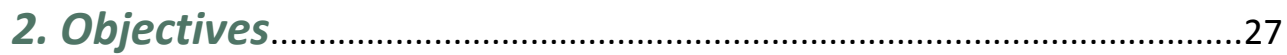

\section{Introduction of Chapter I:}

DELLAs' role on the vegetative shoot apical meristem

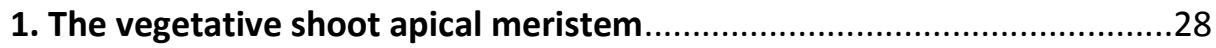

2. The TCP/KNAT1 module of regulation..................................................30

3. The role of gibberelin in the vegetative shoot apical meristem...............35

4. Proposal of the hypothesis: DELLAs function in the SAM........................36

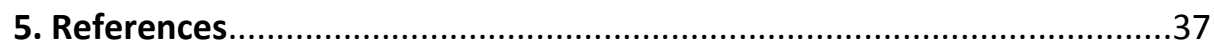

\section{Results and Discussion Chapter I:}

DELLAs regulate the shoot apical meristem through the activity of CINTCPs and KNAT1

1. GAI and RGA interact with CIN-TCP family members .41

2. DELLAs do not regulate CIN-TCPs transcriptionally .44

2.1. Chemical approach. 
2.2 Genetic approach.

3. DELLAs inactivate CIN-TCPs upon interaction..........................................

4. Effect of the interaction in a known target of TCPs in the shoot apical

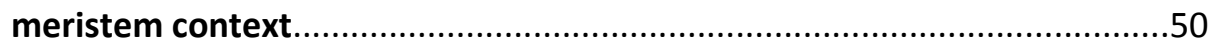

5. Effect of the interaction in a downstream target: a KNOX gene................54

6. DELLAs and KNAT1 expression patterns...............................................55

7. Localization of KNAT1 and RGA proteins in the vegetative shoot apical

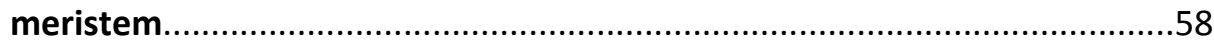

8. The GA/KNAT1 balance regulates cell expansion in the shoot apical

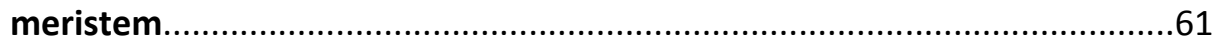

9. Unraveling KNAT1 function at the genomic level...................................65

9.1 Comparison with literature data...................................................67

9.2 Analysis of the KNAT1 targets found in the RNA-sequencing

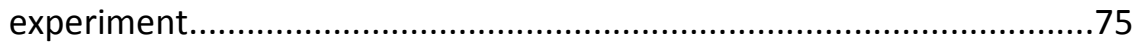

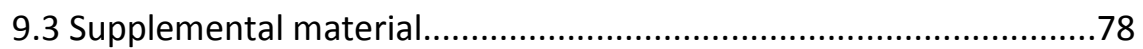

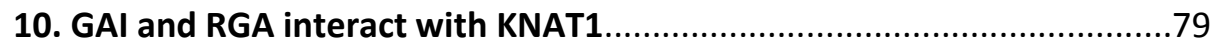

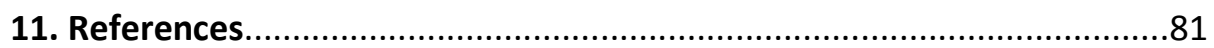

\section{Introduction of Chapter II:}

\section{DELLAs' role on the germination process}

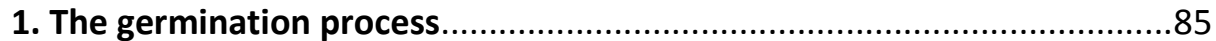

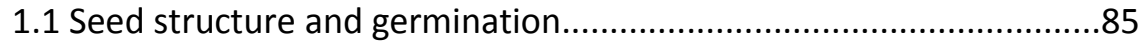

1.2 Dormancy and dormancy releasing mechanisms.............................86

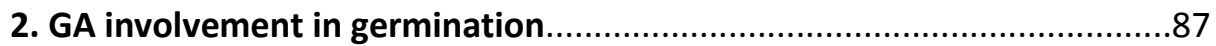

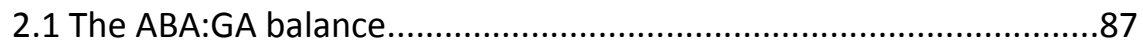

2.2 GA implication in the molecular networks regulating germination

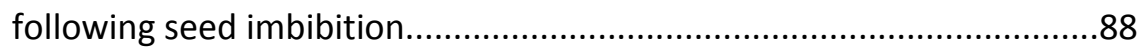

3. GAs role in cell division in the RAM during germination ........................90

4. Class I TCPs involvement in germination ..............................................94

5. Proposal of the hypothesis: DELLAs function in the RAM.........................96

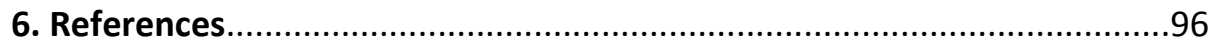




\section{Results and Discussion Chapter II:}

Regulation of the root apical meristem by DELLAs trough Class I-TCPs

1. TCP14 and TCP15 are required for the promotion of the germination by

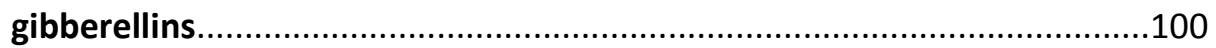

2. TCP15 is expressed in developing embryos........................................102

3. DELLAs do not regulate TCP14 and TCP15 transcriptionally..................104

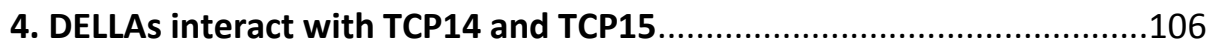

5. GAI inactivates TCP14 upon interaction..............................................108

6. Role of TCP14 and TCP15 regulating cell division in the root apical

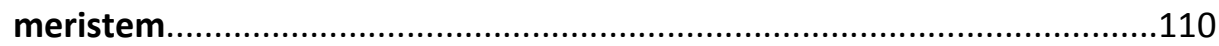

7. Role of TCP14 and TCP15 regulating root growth in later stages of development

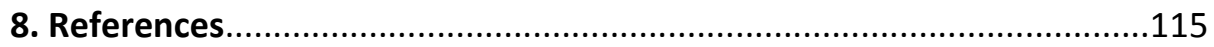

\section{General Discussion}

1. The DELLA-TCP interaction, an example of cell-type specific signaling..119

2. DELLA function in meristems: a possible link with the environment.....120

3. References

8. Conclusions .124

\section{Material and Methods}

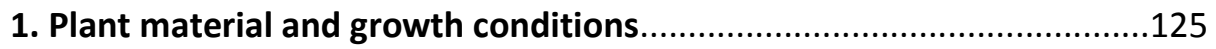

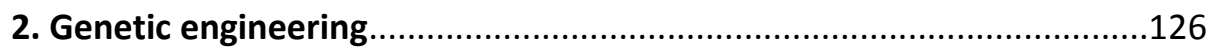

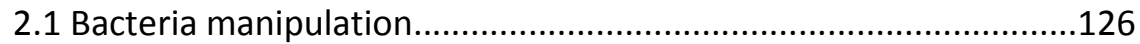

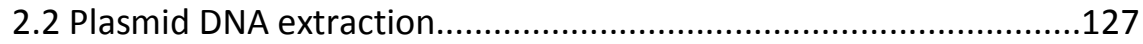

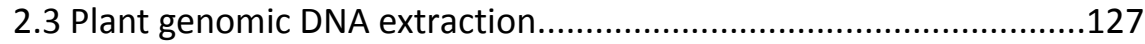

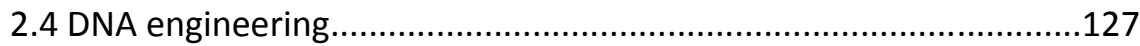

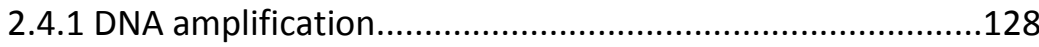

2.4.2 DNA digestion, ligation and phosphorylation....................128 


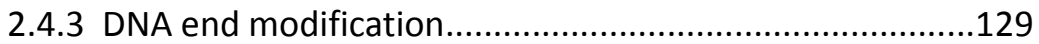

2.5 Electrophoresis and fragment purification.....................................129

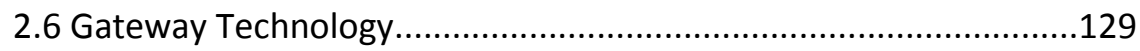

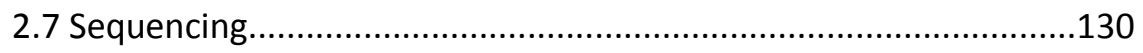

2.8 Constructs and oligos used in the Thesis......................................130

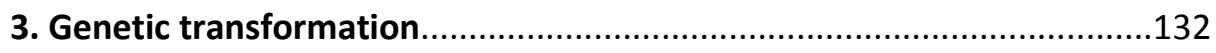

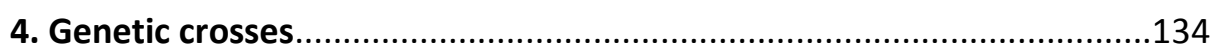

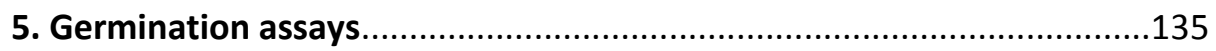

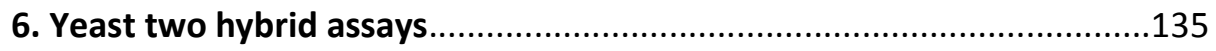

7. Bimolecular Fluorescence Complementation assay..............................135

8. Co-immunoprecipitation assays......................................................136

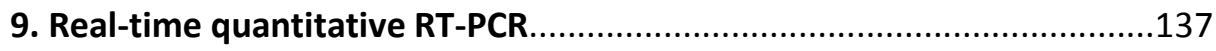

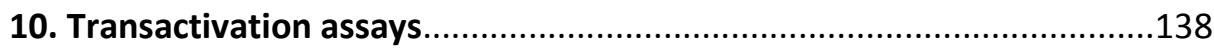

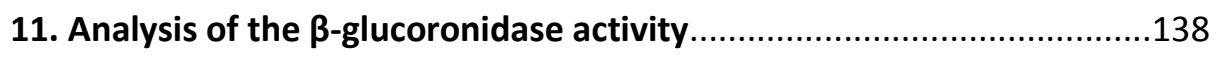

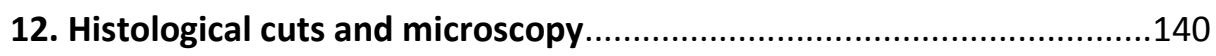

13. Cell measurements in the shoot apical meristem..............................141

14. Root length and cell measurements in the root apical meristem.........142

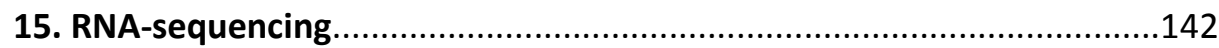

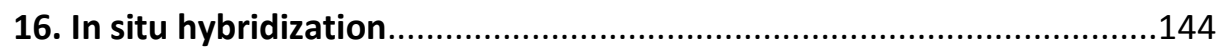

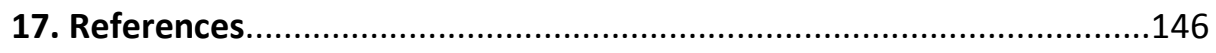


1. General Introduction 



\section{Plant hormones}

Plants are sessile organisms that ensure their survival by adjusting their growth and developmental processes in accordance to environmental conditions. This trait is called "plasticity" and implies the perception and integration of external environmental conditions (such as changes in light quality and quantity, temperature, moisture, nutrient access, herbivorous feeding, etc.) with the intrinsic genetic programs of the plant (1). An important factor contributing to plasticity are hormones.

Phytohormones are small endogenous signaling molecules that can be produced in each cell and act locally or are transported to other cells or tissues. They play a dual role in the plant: as mediators that coordinate endogenous developmental processes and integrating environmental cues to conduct adaptive responses. Nine classes of phytohormones have been identified for the moment: the five classical hormones discovered in the mid $20^{\text {th }}$ century [gibberellin (GA), auxin (IAA), cytokinin (CK), abscisic acid (ABA) and ethylene (ET)] and other hormones more recently recognized [jasmonic acid (JA), salicylic acid (SA), brassinosteroid (BR) and strigolactone (SL)] (2).

In the last decades, intense research in this field has unraveled the molecular mechanisms controlling the metabolism, perception and signal transduction of each hormone, although their mechanism of action is not completely understood. Specific roles for each hormone have been assigned. Nevertheless, increasing evidence shows that the interconnection between hormonal pathways to perform overlapping functions is common in plants $(3,4)$. These interconnections can lead to different outputs: additivity, synergism, antagonism or co-regulation (modulation of outcomes for a determined process mediated through independent pathways) (5).

In this context, current research is focused in finding out the molecular mechanisms by which hormones act, their underlying interactions and their relation with environmental and endogenous signals, such as the circadian clock. 


\section{Gibberellins}

In this Thesis, we will focus on the role of GAs regulating Arabidopsis thaliana (Arabidopsis) primary meristems.

GAs were first discovered while studying the bakanae disease in rice caused by the fungus Gibberella fujikuroi, which produced big losses due to the elongation and fall over of infected plants. It was discovered that the fungus secretes a substance, they called gibberellin, responsible for this tallness (6). Since then, GAs have been broadly identified in plants, and also in some fungi and bacteria, as tetracyclic diterpenoids (6). Currently, there are $136 \mathrm{GAs}$ identified, although only a few have biological activity in plants $\left(\mathrm{GA}_{1}, \mathrm{GA}_{3}, \mathrm{GA}_{4}\right.$ and $\left.\mathrm{GA}_{7}\right)(7$, 8).

In general, GAs are considered the "growth hormones", since they promote and are involved in the regulation of diverse key developmental processes during the life cycle of the plant (9-22), such as stem elongation or root growth (Figure 1.1). They also play an essential role integrating environmental cues and driving adaptive responses, for example temperature and light mediated growth $(23,24)$. Recent research has provided evidence of the individual function of GAs in these developmental processes, but also demonstrated that GA activities overlap with all other hormones at different levels (2). In the following sections of the Introduction, I will elaborate on key aspects of GA metabolism and the molecular events that occur from GA perception to the activation of the transcriptional networks for its signaling transduction, focusing on the pivotal signaling element, the DELLA proteins.

Remarkably, the study of GAs has been linked intimately with agriculture. For instance, several practical uses have derived from GA application, the application of GA inhibitors, or the biotechnological manipulation of GA synthesis and signaling, such as changing the stalk length of seedless grapes, or increasing sugar yield in sugarcane (25). Furthermore, during the "Green Revolution", certain varieties of rice and wheat were selected for increased yield, given that they decreased losses by lodging and were more resistant to pathogens. Later investigation demonstrated that these varieties were indeed GA insensitive mutants. 


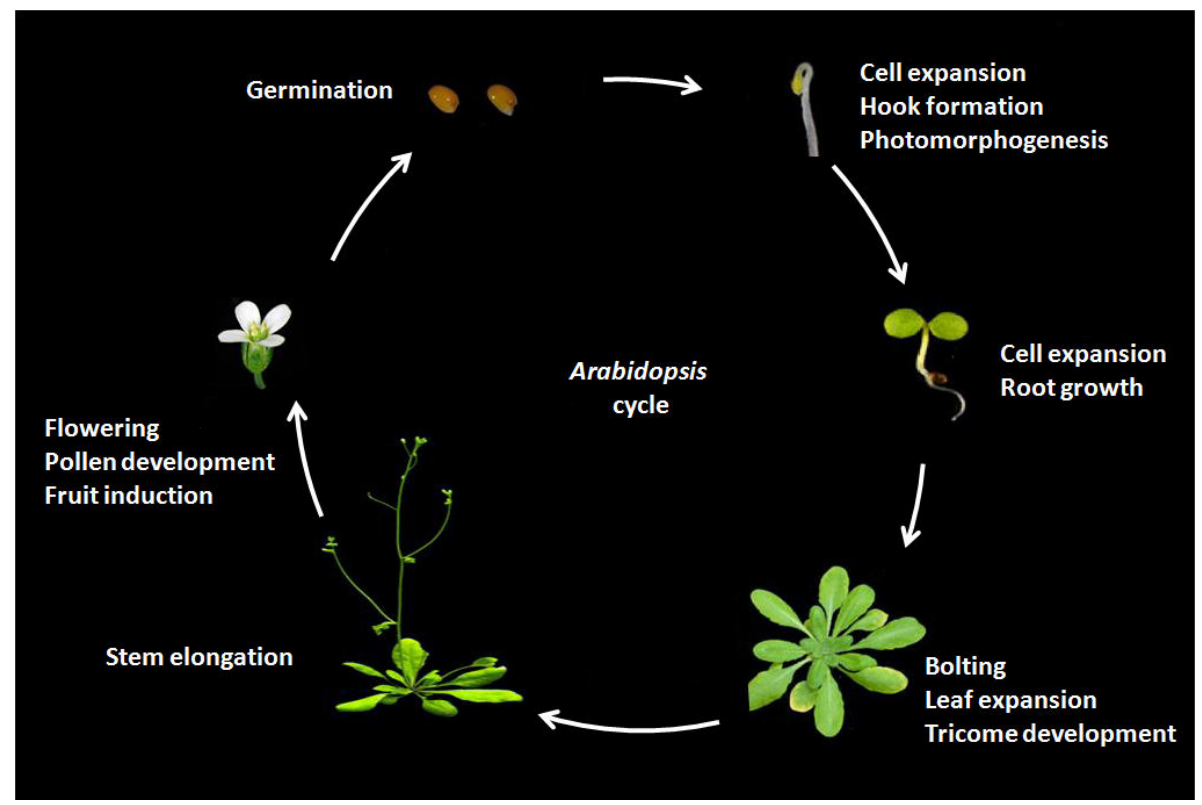

Figure 1.1. GAs regulate several developmental processes during the life cycle of the plant.

\section{Gibberellin metabolism}

As it has been above mentioned, GAs are diterpenoid acids that are synthesized by the terpenoid pathway in the plastid and then modified in the endoplasmic reticulum and cytosol until they reach their active form. In brief, GA synthesis occurs in three stages (each one in a different cellular compartment). We will focus on the last step of biosynthesis, which is the one that is regulated by a feedback mechanism in response to developmental and environmental cues.

In the plastid is where the first reactions take place, converting the geranylgeranyl diphosphate (GGDP) in ent-kaurene. This occurs in two steps catalyzed by two different terpene synthases $(26,27)$. Remarkably, the GA deficient ga1 and ga2 mutants of Arabidopsis are deficient in the first and the second step, respectively. In a second stage, that takes place in the plastid membrane and endoplasmic reticulum, the ent-kaurene is transformed to $\mathrm{GA}_{12}$ or $\mathrm{GA}_{53}$ by the action of two cytochrome P450 monooxygenases. $\mathrm{GA}_{12}$, in turn can be converted to $\mathrm{GA}_{53}$ by further hydroxylation (Figure 1.2). 
In the cytosol, the last stage in the production of biologically active GAs is catalyzed by two oxoglutarate-dependent dioxygenases, GA20-oxidase (GA20ox) and GA3-oxidase (GA3ox) (Figure 1.2). $\mathrm{GA}_{12}$ and $\mathrm{GA}_{53}$ are the inactive precursors of all biologically active GAs (27), and are converted in parallel pathways through three consecutive oxidations by GA20ox, leading to the production of $\mathrm{GA}_{9}$ and $\mathrm{GA}_{20}$, which are further oxidized by GA3ox to form the bioactive $G A s \mathrm{GA}_{4}$ and $\mathrm{GA}_{1}$ (27-29). This route is conserved in all plants, and in some of them there are alternative pathways to form the minority, biologically active compounds $\mathrm{GA}_{3}$, $\mathrm{GA}_{5}$, and $\mathrm{GA}_{6}$; which can be derived from the precursor $\mathrm{GA}_{20}$ (Figure 1.2).

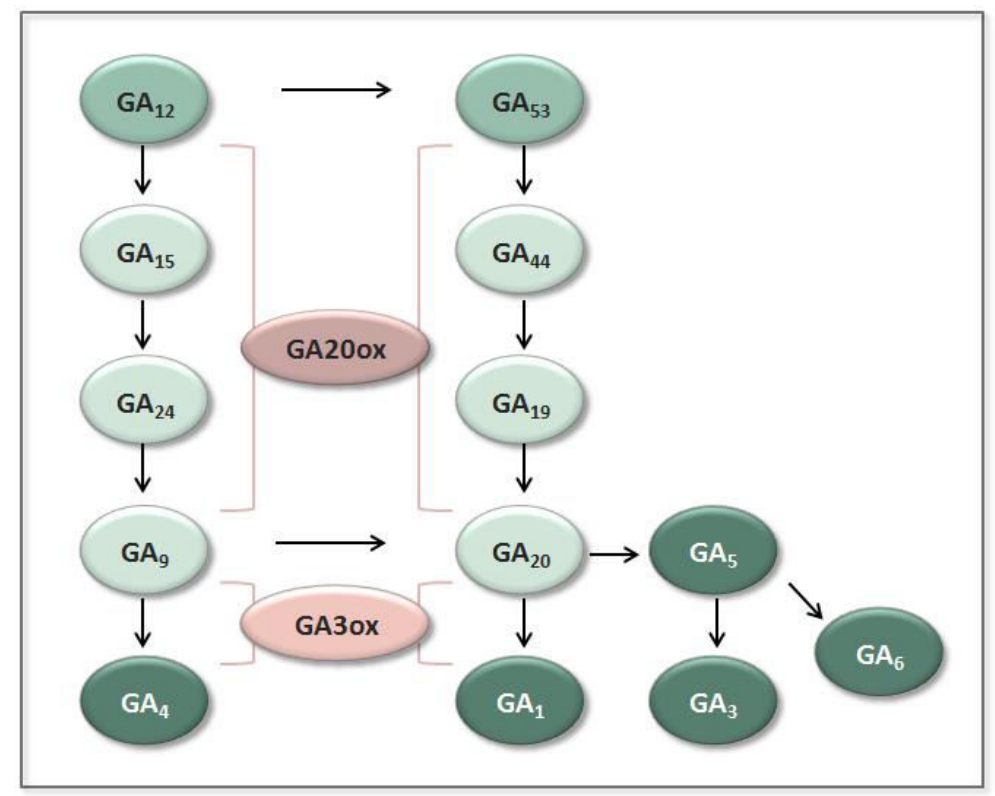

Figure 1.2. Reactions taking place in the last stage of GA biosynthesis in the cytosol. Two oxoglutarate-dependent dioxygenases, GA20ox and GA3ox (enzymes in mauve) catalyze the formation of different bioactive GAs (dark green) from the inactive precursors $G_{12}$ and $G A_{53}$ (medium green). Inactive GAs are shown in light blue.

GA homeostasis does not only rely only on their synthesis but also on a delicate balance with their inactivation. Several mechanisms for GA inactivation have been reported. The best characterized is the addition of an hydroxyl group to GAs by the GA2-oxidase (GA2ox) (Figure 1.2) (27). This inactivation is irreversible, given that the resulting molecules are immediately degraded. This mechanism is biologically important because the expression of GA2ox genes is 
transcriptionally regulated in response to environmental and developmental cues and it constitutes the main GA-deactivation pathway.

\section{Regulation of gibberellin metabolism}

To ensure their survival, plants need to respond effectively to environmental changes. That means being able to promptly and precisely regulate hormone homeostasis according to those changes. The Arabidopsis genome contains small gene families encoding the cytosolic enzymes GA20ox (five genes), GA3ox (four genes) and GA2ox (eight genes) (30). Remarkably, plants regulate transcriptionally the expression levels of members of these gene families by a feedback mechanism in order to regulate GA levels.

Then, when bioactive GA level is high, most of the biosynthetic GA20ox and GA3ox genes are down-regulated through this GA-mediated feedback mechanism $(27,28)$. In contrast, GA2ox genes are up-regulated by GA treatment (31). In a low GA level situation, the inverse regulation takes place. In some situations, however, the plant needs a higher level of GA, and this self-regulation does not occur. This is the case during germination, where the GA3ox2 gene is uncoupled from the feedback and its continuous expression allows the constant production of bioactive GAs (32). Moreover, GA levels in the plant are also influenced by different elements: endogenous factors such as the circadian clock, GAs and other hormones such as BRs (33), IAA (34) or ET (19); and environmental conditions such as light (35-37), temperature $(24,38)$, pathogens, etc.

\section{Gibberellin signaling}

During the past twenty years, intense research has been made to unravel the molecular mechanisms of GA signaling, and most of its components have been identified by genetic screenings in Arabidopsis and rice and by the subsequent biochemical analysis of GA response mutants. It was also found that this signaling pathway is widely conserved among dicots and monocots (39).

In brief, GA signaling consists in three key elements: the soluble GA receptor GIBBERELLIN INSENSITIVE DWARF1 (GID1), the transcriptional regulators DELLA proteins (DELLA) and the F-box proteins SLEEPY1 (SLY1) in Arabidopsis and 
GIBBERELLIN INSENSITIVE DWARF2 (GID2) in rice (40) that mediate the GAdependent degradation of DELLAs.

GA receptors were discovered while studying the GA-insensitive rice mutant gibberellin insensitive dwarf1 (gid1) (41). In Arabidopsis, three orthologous genes have been found (GID1A, GID1B and GID1C $(42,43))$ and they seem to have overlapping functions, since only the triple knockout mutant presents the dwarf phenotype characteristic of GA signaling deficiency $(42,44)$. Accordingly, the three genes are expressed in all tissues, but at different levels $(42,43)$, and the proteins localize to the nucleus and the cytoplasm (44).

DELLAs are the master negative regulators of the GA signaling pathway, since these proteins down-regulate all GA responses (45). They were discovered through the study of the Arabidopsis gai-1 (qibberellic acid insensitive-1) mutant (13), a dominant version resistant to GA-dependent degradation. Over the years the five DELLAs in Arabidopsis have been identified: GAI, RGA (Repressor of qa13), RGL1 ( of these proteins in section 6 of the Introduction, as they are the main protagonists of this Thesis.

The current model of GA signaling it is well established in the literature. Basically, DELLA proteins restraint all GA functions, whereas the GA signal overcomes this DELLA-mediated restriction by promoting DELLA degradation by the proteasome (40) (Figure 1.3).

The signaling cascade starts when a bioactive GA binds the nuclear receptor GID1 (41). Crystallization studies demonstrated that GID1 contains a GA-binding pocket and a flexible N-terminal extension (47). Upon formation of the GA-GID complex, the flexible domain closes the pocket, changing the three-dimensional conformation of the complex. This new conformation allows the $\mathrm{N}$-terminal part of the DELLA proteins to bind the lid of the complex, generating a GA-GID1-DELLA complex (48). Remarkably, the N-terminal part of DELLAs, that contains the DELLA and TVHYNP motifs (see section 6.1 of the Introduction), is essential for the interaction with GID1 because their deletion results in an inability of DELLAs to interact, despite the presence of GA (44). 
The resulting GA-GID1-DELLA complex induces conformational changes in the C-terminal half of the DELLA, called GRAS domain, that triggers its recognition by the F-box protein SLY1/GID2 (49). SLY is part of a SCF (NKP1, CULLIN1, F-BOX)dependent E3 ubiquitin ligase complex that catalyzes the attachment of polyubiquitin chains to target proteins for their subsequent degradation by the 265 proteasome $(42,50,51)$. The union of both complexes lead to the polyubiquitination of DELLA and its subsequent degradation by the $26 \mathrm{~S}$ proteasome, thereby relieving their GA function-restraining effects $(42,44,52,53)$ (Figure 1.3).

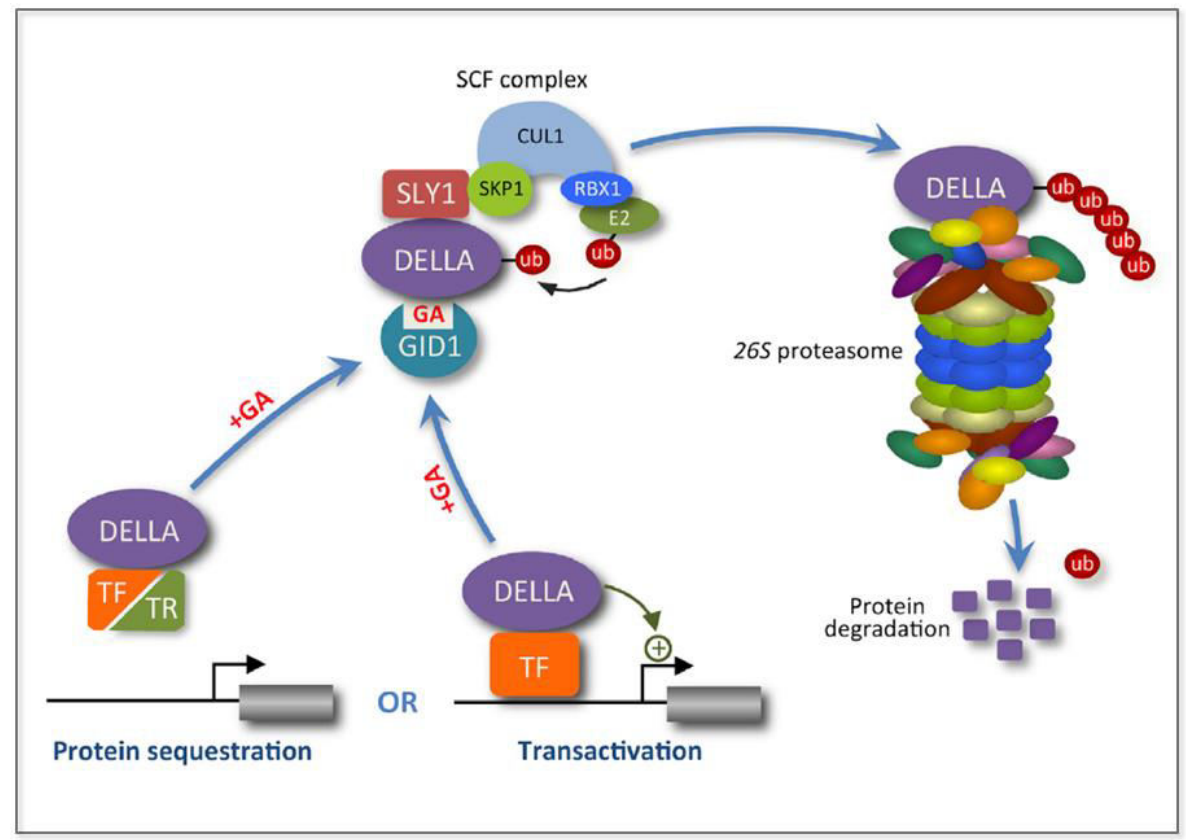

Figure 1.3. The GA signaling pathway. When GA level is low, DELLAs repress GA responses by two different mechanisms: (1) by protein sequestration, interacting with and inhibiting the activity of transcription factors (TF) or regulatory proteins (TR), or (2) by transactivation, activating the transcription of target genes associated with TF. On the other hand, when GA concentrations increase, GA binds to GID1 receptor, forming the GA-GID1-DELLA complex. This complex interacts with the $\mathrm{SCF}^{\mathrm{SLY} 1}$ complex through DELLA, which is consequently polyubiquitylated and degraded by the 265 proteasome. This leads to the activation of GA responses. Extracted from Davière and Achard, 2015 (2).

Thus, GA promotes its responses, such as growth, by mediating the proteasome-dependent destabilization of DELLA proteins; on the contrary, in absence of GAs, DELLAs accumulate and repress GA responses (54). In the 
following section, the mechanism by which DELLAs perform its repressing function is described.

\section{DELLA proteins}

Now, we will focus on the key signaling component of the pathway, the DELLA proteins, which are the most extensively studied elements of the GA signaling pathway. Several observations gathered during the last decades have led to the current model of GA and DELLA action (Figure 1.3). della mutants in Arabidopsis and rice results in a constitutive activated GA response $(15,55-58)$, with a slender or tall phenotype in these loss of function mutants. Inversely, DELLA gain of function mutants such as gai-1 in Arabidopsis, present the phenotype of GA deficiency that includes dwarfism among other features $(59,60)$. Besides, exogenous GA treatments were associated with DELLA protein destabilization to rescue dwarfism of a GA-deficient mutant ga1 (54).

DELLAs are highly conserved proteins among plant species, and several of them carry a single DELLA gene, such as tomato (61), grapevine (62), rice (56), barley (63) and wheat (45). Interestingly, that only DELLA is sufficient to regulate all GA responses in those species. On the other hand, the Arabidopsis DELLA gene has undergone amplification, and, as it has been previously mentioned, the Arabidopsis genome encodes five DELLAs: GAI, RGA, RGL1, RGL2 and RGL3 (39). Those DELLA genes have undergone sub-functionalization. Thus, distinct but overlapping functions have been reported for the five DELLAs, and it has been proposed that the functional diversification of DELLA genes is based on their differential expression patterns (64). Therefore, the differential transcriptional regulation of DELLA genes is the cause for the differential roles in Arabidopsis.

In particular, RGA and GAI are the major players during vegetative growth, since they control cell expansion and cell division in hypocotyls, shoot and root; and in induction of flowering $(55,65-70)$. RGA, RGL1 and RGL2 together modulate flower development $(57,58)$ and RGL2 is the main DELLA inhibiting seed germination $(15,58,71)$. Finally, RGL3 contributes to plant fitness during environmental stress $(72,73)$. 


\subsection{Structural features of DELLA proteins.}

It is well established in the literature that DELLAs are nuclear proteins and belong to the plant-specific GRAS family of transcription regulators (74). GRAS proteins are characterized by a conserved C-terminal GRAS domain involved in protein-protein interactions and transcriptional regulation of specific targets. Additionally, and in contrast with other GRAS proteins, DELLAs present a distinctive $\mathrm{N}$-terminal domain that mediates interaction with the GA-loaded GID1 receptor, as mentioned earlier (Figure 1.4) (39).

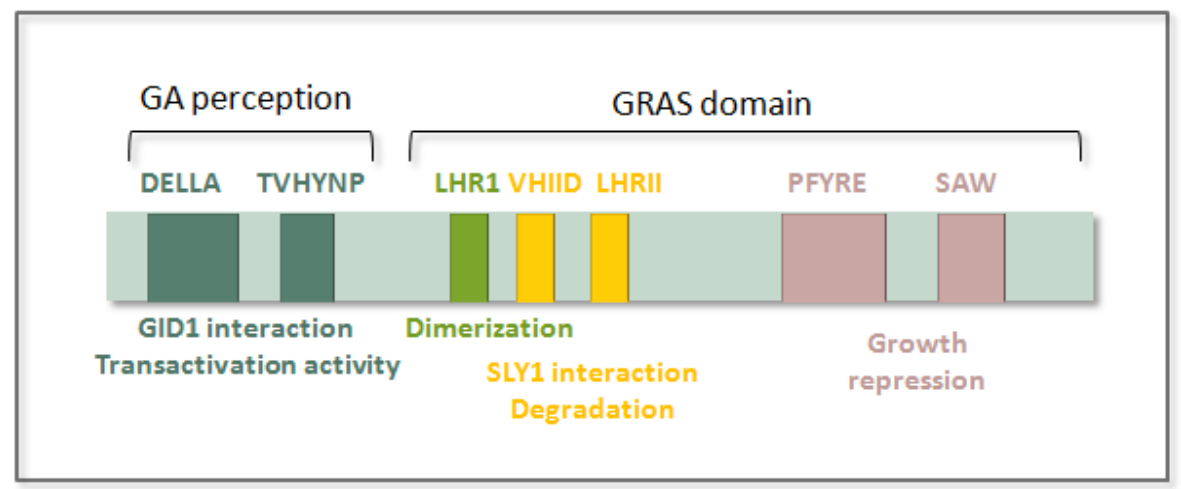

Figure 1.4. Structural features of the DELLA proteins. The important motifs of DELLA proteins and their associated functions are shown in the same color. Modified from Davière and Achard, 2015 (2).

The GRAS domain contains two leucine heptad repeats (LHRI and LHRII) and three conserved motifs, VHIID, PFYRE and SAW (Figure 1.4) (2). The VHIID and LHRs domains have been implicated in dimerization of the protein (75) and in their interaction with the F-box protein SLY1 in Arabidopsis and subsequent degradation (76). On the other hand, the function of PFYRE and SAW is still unknown, although it has been involved in growth repression (2).

DELLAs are distinguished from the rest of the GRAS family by its specific Nterminal sequence containing two conserved domains: the TVHYNP domain and the DELLA domain, which presents conserved amino acid sequences Asp-Glu-LeuLeu-Ala (DELLA) that gives them their name. It has been demonstrated that mutations or deletions on DELLA or TVHYNP regions result in protein versions unable to interact with GID1. Thus, these versions are resistant to GA-promoted 
degradation, the DELLA protein is stabilized and this leads to semi-dominant GAinsensitive dwarf phenotypes such as rga- $\Delta 17$ and gai- $1(41,42,44)$. Furthermore, recent research has demonstrated that the N-terminal DELLA/TVHYNP domain of the rice DELLA possesses transactivation activity, indicating additional functions for this domain that can be conserved in other species (Figure 1.4) (77).

\subsection{Mechanisms of action of DELLA proteins}

Since their discovery, DELLAs have been involved in the regulation of a great variety of developmental processes during the whole life of the plant (see section 2 of the Introduction). However, the mechanisms by which DELLAs repress GA responses were just recently unraveled, defining two different manners of regulation and mediated by protein-protein interactions in both cases.

It has been found that an important function of DELLAs relies on their ability to interact with key regulatory proteins such as transcription factors (TFs) or transcriptional regulators (TR) to modulate plant development. This first mechanism is called "protein sequestration", since DELLAs impair the DNA binding ability of their target TFs upon interaction (2), as in the case of PHYTOCHROME INTERACTING FACTORS (PIFs) $(68,69)$ or BRASSINAZOLE-RESISTANT1 (BZR1) (78). DELLAs also interact with and inhibit the activity of TRs such as JASMONATE ZIMDOMAIN (JAZ) proteins (79) (Figure 1.3). By this mechanism, DELLAs have been found to regulate a great variety of processes. They control hypocotyl elongation by interacting with PIFs $(64,68,69)$ and $\operatorname{BZR1}(78,80)$; floral transition with SQUAMOSA PROMOTER BINDING-LIKE (SPL) (81); fruit patterning with ALCATRAZ (ALC) (82), plant defense with JAZ proteins $(73,79)$, etc. Remarkably, the list of DELLA interactors is still growing, highlighting the high promiscuity of these proteins. The great number and variety of DELLA interactors provide a molecular explanation for the fact that GAs regulate a wide variety of physiological processes (39). Therefore, DELLAs are central players and integrators of GAdependent processes in a context-dependent manner.

On the other hand, DELLAs operate in the chromatin either as transactivation factors, as in the case of the interaction with ARABIDOPSIS RESPONSE REGULATOR 1 (ARR1) (83); or as co-repressors, as described for the interaction with SPL15 (84). Thus, DELLAs regulate the transcription of downstream genes to repress GA responses (Figure 1.3) (85). For instance, recent transcriptome analyses indicate 
that the DELLA protein RGA is able to activate the transcription of target genes (83, 86-89). However, there is no evidence for direct binding of DELLAs to DNA, since DELLAs do not present a DNA binding domain, and chromatin precipitation assays show only a moderate enrichment of promoter targets. Thus, it has been proposed that the association of DELLAs with their target promoters might be rather indirect, including other elements (39).

Acccordingly, several studies strongly support this idea. Just in the last four years, DELLAs have been found to associate with the promoter of target genes trough the interaction with two families (up to now) of TFs, INDETERMINATE DOMAIN (IDD) and type-B ARR factors $(83,90)$. Therefore, these TFs are intermediate proteins between DELLA and DNA, allowing DELLAs to enhance the expression of target genes. In this sense, experiments in rice suggest that the transactivation activity may reside in the N-terminal DELLA/TVHYNP domain (Figure 1.4) (77). Besides, DELLAs have been found to interact with the core subunit of the chromatin remodeling factor SWI/SNF, resulting in an increased transcription of DELLA target genes in Arabidopsis (91).

\section{The role of DELLAs in the primary meristems: interaction with TCPs}

7.1 Looking for suitable DELLA interactors regulating meristem activity

According to literature, the levels of bioactive GAs are modulated in different tissues and developmental stages to regulate plant growth in an environmentaldependent manner. In particular, they seem to be decisive in two different biological contexts, as elaborated below.

The first developmental challenge plants have to overcome to ensure their survival is the germination process and GAs play a crucial regulatory role at this stage promoting embryo growth and reducing the physical restraint imposed by the endosperm and testa. Remarkably, activation of embryo growth, especially in the radicle allows radicle protrusion trough the covering layers, what constitutes the final step of the process (see introduction of Chapter II) (66). This implies the activation of the root apical meristem. 
After germination, during the vegetative growth, GAs are needed to promote stem elongation, leaf expansion and root growth, among other processes (92); and they are present mainly in rapidly developing tissues, such as the shoot tips, expanding leaves and petioles near elongating internodes, for example (93-95).

GA activity seems to be focused on regions where new cells and tissues are formed, where they can promote morphogenesis or cell growth. Importantly, this observation made us think that the GA signaling pathway might be involved in the regulation of the primary meristems of the plant: the root apical meristem (RAM) and the shoot apical meristems (SAM). As GAs perform their activity by promoting DELLA degradation, and DELLA proteins are the main regulatory elements of the pathway, we will focus on the role of DELLAs in the regulation of primary meristems of Arabidopsis. In particular, the aim of this Thesis is to unravel the regulatory role of DELLAs in the meristem in two different situations: in the SAM during vegetative growth (Chapter I), and in the RAM during germination (Chapter III.

Since DELLAs are known to repress GA responses trough the interaction with other proteins, mainly TFs, understanding the GA-mediated control of meristems would require the identification of its downstream transcriptional mediators. Therefore, the first step in our research was the identification of DELLA interactors capable to regulate jointly meristem activity. As a matter of fact, at the beginning of this Thesis, we took advantage of unpublished work in our laboratory, which unveiled a great amount of these interactors. In this work, that was published later on (96), the TF interactome of the Arabidopsis DELLA protein GAl was determined by yeast two-hybrid assays ( $\mathrm{Y} 2 \mathrm{Hs}$ ). 


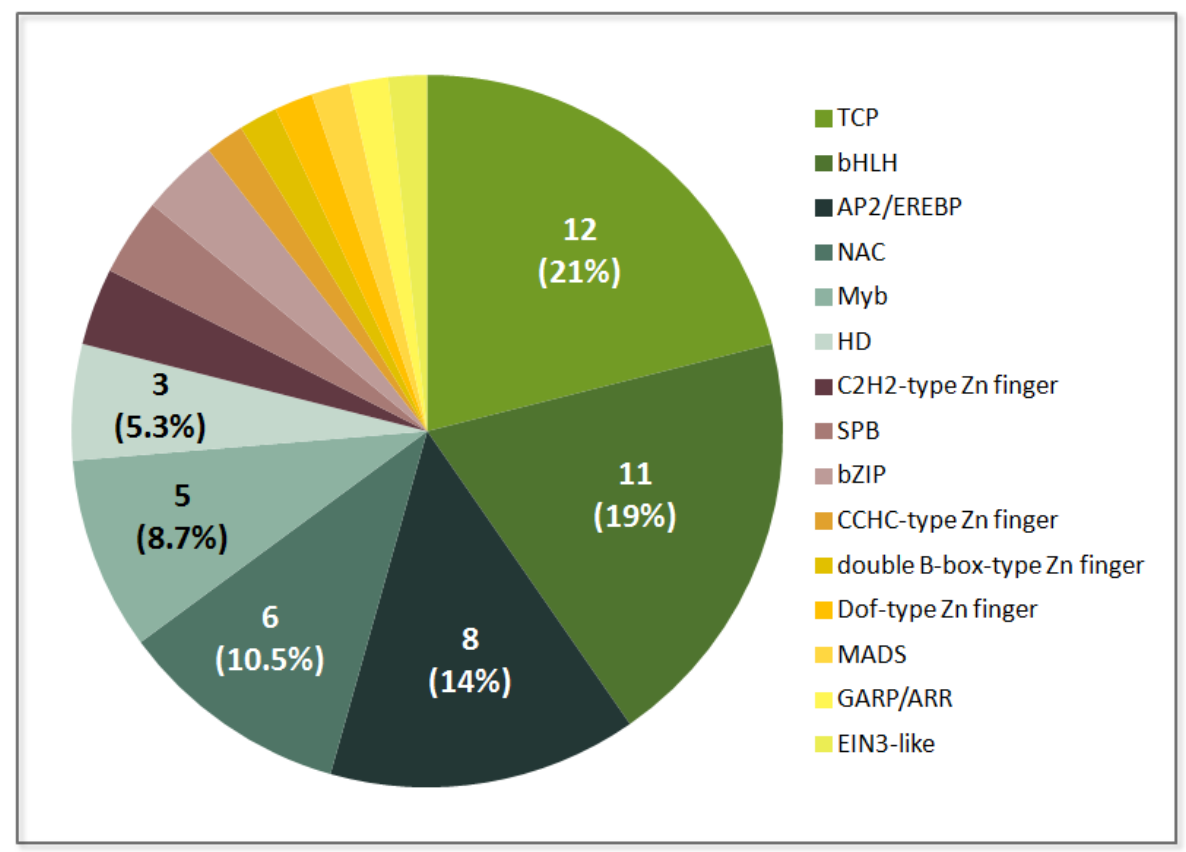

Figure 1.5. TF interactome of the DELLA protein GAI in Arabidopsis. The $\mathrm{Y} 2 \mathrm{H}$ screening unraveled 57 interactors of GAl, that belonged to 15 different families of transcription factors (different sections in the circle). The number of interacting members and the percentaje of interactors that the family represents over the total 57 are shown. Mauve and yellow sections represent families with 2 and 1 interactors respectively. Data extracted from Marín-de la Rosa et al., 2014 (96).

To do so, a library of approximately 1,200 TFs of Arabidopsis (97) was screened using the GRAS domain of GAI (M5GAI) as bait, and 57 novel interactors were found. Among the TFs found, there were two known interactors of GAI, PIF3 and PIF4 $(68,69)$, showing the reliability of the screening. The interactors found belonged to 15 out of 39 families of TFs represented in the library. This diversity is in accordance with the great variety of DELLA interactors reported in the literature (98) and demonstrates that there is not a strong bias to any particular family of TFs. Nevertheless, it is remarkable that approximately $21 \%$ of the interactors found belonged to the TEOSINTE BRANCHED1, CYCLOIDEA, PROLIFERATING CELL FACTOR (TCP) family of transcription factors (Figure 1.5); and $19 \%$ to their structurally close proteins basic helix-loop-helixes (bHLHs). Other categories were less represented (96). 


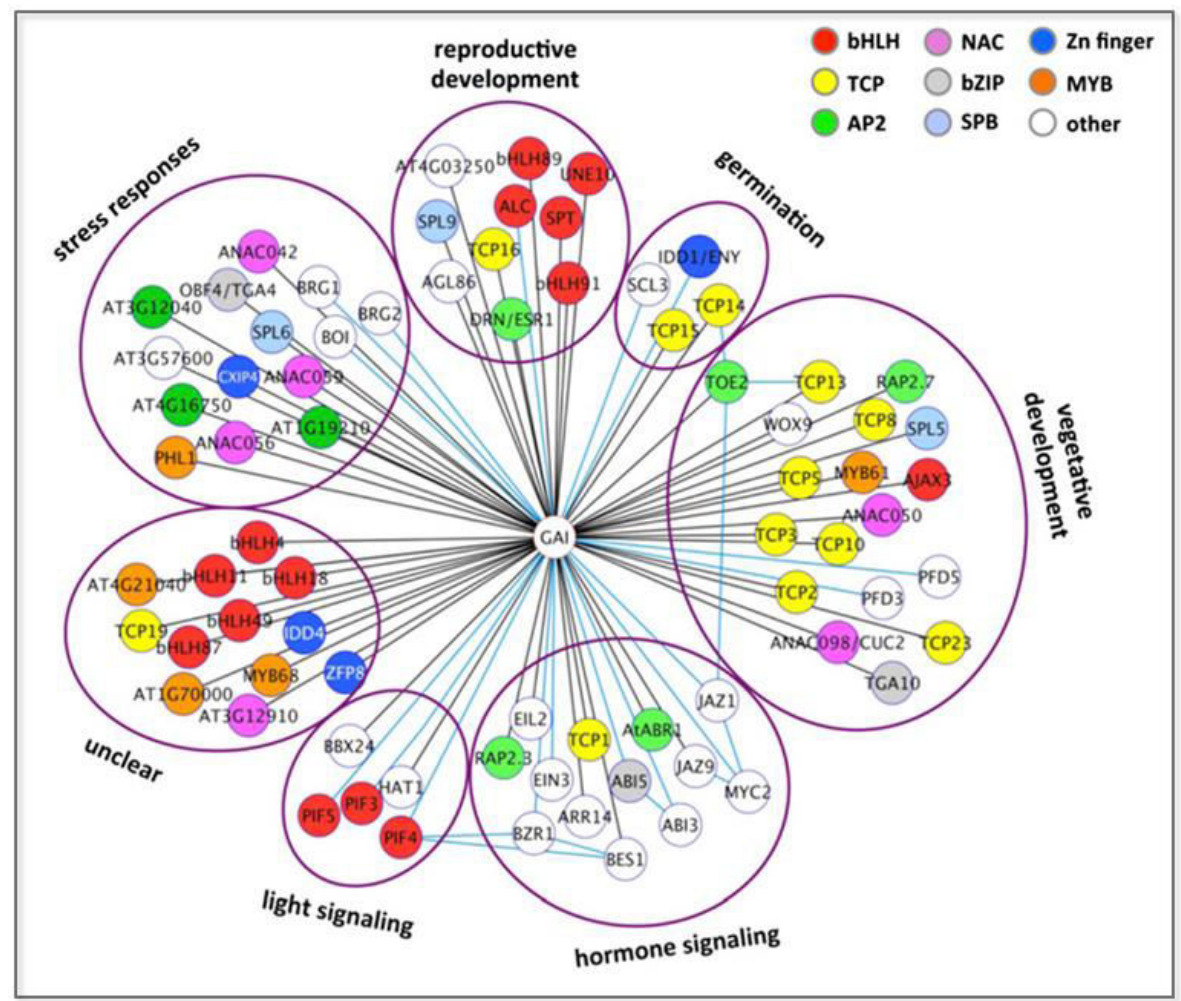

Figure 1.6. TF interactome of the DELLA protein GAI: biological processes. The graph shows all GAI partners found in the $\mathrm{Y} 2 \mathrm{H}$ screening grouped by the biological processes in which they are involved. The most abundant TF families are represented in different colors (see legend in the figure). Notice the TCP (yellow) enrichment in the functional categories "germination" and "vegetative development". Extracted from Marín-de la Rosa et al., 2014 (96).

The GAI partners were also grouped based on the biological processes in which they participate (Figure 1.6) (96). Among the four partners of GAI associated with germination, two were TCPs (TCP14 and TCP15); and in the vegetative development category, seven out of eighteen (approximately 39\%) belonged also to this family of TFs (TCP2, TCP3, TCP5, TCP8, TCP10, TCP13 and TCP23) (96). Besides the physical interaction, DELLAs and their TCP partners identified in the $\mathrm{Y} 2 \mathrm{H}$ screening seemed to have a functional connection, as indicated by the co-expression analysis they performed (96).

Notably, out of the 23 members of the TCP family present in the library, 12 were identified as GAI partners. That constitutes a $52 \%$ of GAl interactors over the total TCP members present. However, due to the high-throughput approach followed in the screening, it is possible that not all the interactions were 
identified, and that more members of the family constitute reliable GAI partners (see section 1 of Results and Discussion of Chapter I) (96).

Taking into account that TCP is the family of TFs for which more members have been found to interact with GAI by $\mathrm{Y} 2 \mathrm{H}$, and the enrichment in TCPs of the biological processes aim of our study (germination and vegetative development), we thought that the TCP family of TFs represent a promising target for additional research. Therefore, in this Thesis, we decided to focus in the study of the relevance of DELLA-TCP interaction in the control of SAM and RAM activity during vegetative development and germination.

\subsection{The TCP family of transcription factors}

The family was first discovered in 1999, and takes its name from its founding members: IEOSINTE BRANCHED1 (TB1), CYCLOIDEA (CYC) and PROLIFERATING CELL NUCLEAR ANTIGEN FACTOR1 (PCF1). TCP proteins are plant-specific TFs, closely linked historically to the control of cell proliferation and growth, therefore shaping plant morphology. They are known to have profound effects on the growth patterns of meristems and lateral organs, they regulate the transcription of cell cycle regulators such as cyclins and they are involved in the regulation of diverse growth-related processes, such as embryonic growth, branching, leaf development, floral and pollen development, germination, cell cycle regulation, etc $(99,100)$.

The family is characterized by a non-canonical basic helix-loop-helix (bHLH) motif, the TCP domain, which is responsible of DNA-binding and protein-protein interactions (dimerization). This domain is closely related to the canonical bHLH that can be found in bHLH proteins such as PIFs, but the basic region of the TCP is longer and contains helix-breaking amino acids (100).

In Arabidopsis, the TCP family is a group of 24 phylogenetically related members, and according to differential features within the TCP domain, can be distinguished in two types, class I and class II, whereas class II can be further subdivided in two groups: CYC/TB1 and CINCINNATA (CIN) (Figure 1.7) (101). In particular, sequence alignment of the conserved TCP domain of several TCP proteins reveals three differential features between the two classes: a 3-residue insertion in the basic region of the class II but not in the class I TCP domain (101), 
the residue compositions in the loop and hydrophilic faces of helices I and II, and the length of helix II (99).

Besides, outside the TCP domain, a subset of five CIN-TCPs (indicated with an asterisk in Figure 1.7) possess a microRNA miR319 recognition sequence in their mRNA. In fact, the function of this class II TCP genes seems to be tightly controlled post-transcriptionally by this microRNA. This is not surprising given the strong effects on proliferation and growth of these CIN-TCPs, which at some developmental stages and tissues need to be finely tunned, for example in the SAM (100).

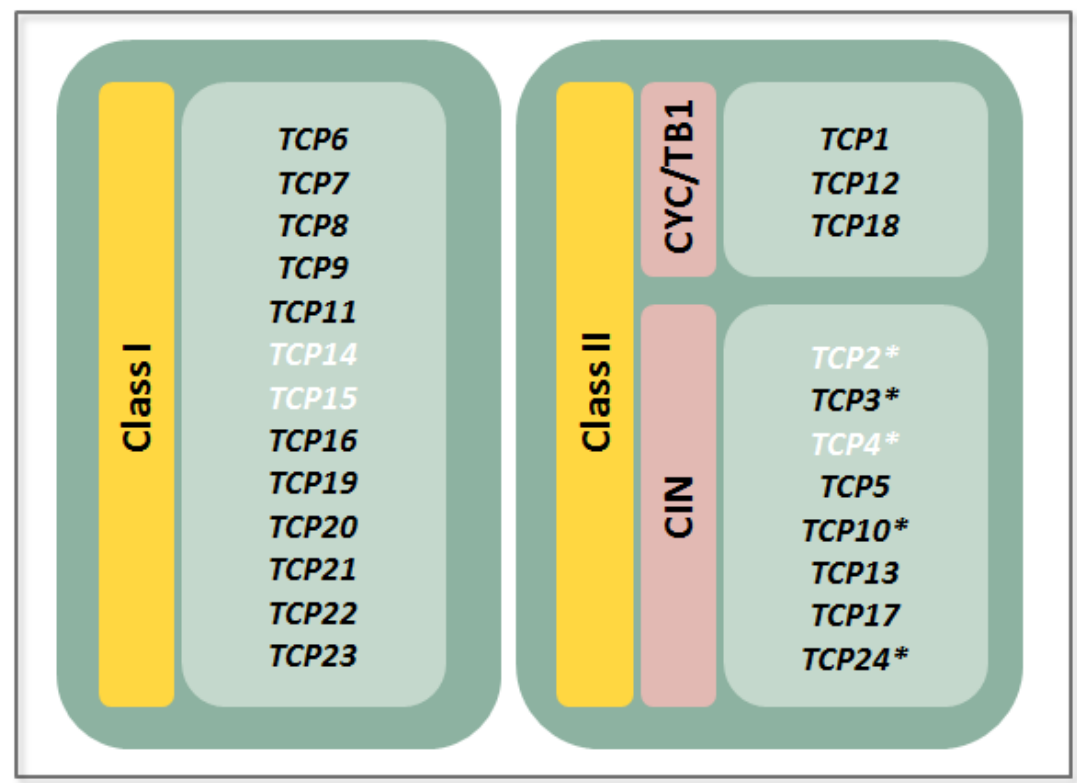

Figure 1.7. Classification of the Arabidopsis TCP family of transcription factors. The 24 members of the family in Arabidopsis are divided in two classes based on differences within their TCP domain. Class II TCPs can be further subdivided in two groups: CYC/TB1 and CIN. The five miR319-targeted CIN-TCPs are indicated with asterisks, and the TCPs target of our study in this Thesis are shown in white: the CIN-TCPs TCP2 and TCP4 in Chapter I and Class I TCPs TCP14 and TCP15 in Chapter II.

Research on TCPs has been always hindered by two characteristics: the considerable functional redundancy of its members and, in the case of CIN-TCP genes, their post-transcriptional down-regulation by miR319 (102). 
Several studies reported that single, double and even triple tcp mutants and CIN-TCP over-expressor lines do not show strong phenotypes different from wild type plants, preventing functional gene analysis (excluding a delay in flowering in the tcp4 mutant (103)). Nevertheless, two strategies have been used to overcome these difficulties. First, dominant-negative genetic approaches have been used, consisting in the fusion of EAR or SRDX repression domains with TCP coding sequences. This strategy has generated loss of function lines with strong mutant phenotypes $(70,104,105)$. Second, some molecular strategies have been used to manipulate the regulatory effect of miR319 in CIN-TCPs. It was discovered that miR319 over-expressing lines and the jaw-D mutant (that is an activation tag dominant mutant of miR319) simultaneously down-regulated the five target CINTCPs $(102-104,106,107)$. Inversely, the enhancement of CIN-TCPs expression has been possible, among other strategies, by inactivating miR319 (miR319 mimicry, MIM319) (108-110). Another successful way to obtain gain of function lines is by introducing synonym mutations within the microRNA target sequence in the TCP coding regions. Thus, the resulting TCPs escape miR319 regulation without altering their protein sequence. Those miR319-resistant gene versions of CIN-TCPs (rTCPs) were placed under the control of their natural promoters or ectopic promoters $(102,104,108,111)$. These versions lead to reductions in growth, fusion of cotyledons, lack of shoot apical meristem development and lethality, what remarks the importance of regulating these TCP genes for plant viability $(102,112)$.

In fact, the tcp2 tcp3 tcp4 tcp10 tcp24 quintuple loss of function mutant, jaw$D$ plants, or plants expressing a fusion of any of the CIN TCPs to the dominant SRDX (EAR) repressor domain have similar phenotypes, with wavy petals and leaves due to excessive proliferation in the margin regions $(113,114)$. Although these approaches have been very useful to generate interesting, informative phenotypes, their results are usually interpreted with caution as they often lead to interference with several TCPs, especially when constitutive, ectopic or highly active promoters are used (115).

As for the DNA-binding properties of TCPs, intense research has been made, though a complete understanding of this feature is still lacking. Several DNAbinding site selection assays have unraveled the consensus-binding site of both 
classes of TCPs: class I TCPs is "GTGGGCCCAC" (116) whereas class II is "GTGGTCCCA" (117).

\section{References}

1. Casal JJ, Fankhauser C, Coupland G, Blazquez MA. Signalling for developmental plasticity. Trends in plant science. 2004;9(6):309-14.

2. Daviere JM, Achard P. A Pivotal Role of DELLAs in Regulating Multiple Hormone Signals. Molecular plant. 2015.

3. Kuppusamy KT, Walcher CL, Nemhauser JL. Cross-regulatory mechanisms in hormone signaling. Plant molecular biology. 2009;69(4):375-81.

4. Vanstraelen M, Benkova E. Hormonal interactions in the regulation of plant development. Annual review of cell and developmental biology. 2012;28:463-87.

5. Chandler JW. Auxin as compere in plant hormone crosstalk. Planta. 2009;231(1):1-12.

6. Takahashi N, Kitamura H, Kawarada A, Seta Y, Takai M, Tamura S, et al. Biochemical Studies on "Bakanae" Fungus. Bulletin of the Agricultural Chemical Society of Japan. 2014;19(4):267-81.

7. Yamaguchi S. Gibberellin metabolism and its regulation. Annual review of plant biology. 2008;59:225-51.

8. Hedden P, Thomas SG. Gibberellin biosynthesis and its regulation. The Biochemical journal. 2012;444(1):11-25.

9. Fleet CM, Sun TP. A DELLAcate balance: the role of gibberellin in plant morphogenesis. Current opinion in plant biology. 2005;8(1):77-85.

10. Pimenta Lange MJ, Lange T. Gibberellin biosynthesis and the regulation of plant development. Plant biology. 2006;8(3):281-90.

11. Wilson RN, Heckman JW, Somerville CR. Gibberellin Is Required for Flowering in Arabidopsis thaliana under Short Days. Plant physiology. 1992;100(1):403-8.

12. Garcia-Martinez JL, Lopez-Diaz I, Sanchez-Beltran MJ, Phillips AL, Ward DA, Gaskin $\mathrm{P}$, et al. Isolation and transcript analysis of gibberellin 20-oxidase genes in pea and bean in relation to fruit development. Plant molecular biology. 1997;33(6):1073-84.

13. Peng J, Harberd NP. Gibberellin deficiency and response mutations suppress the stem elongation phenotype of phytochrome-deficient mutants of Arabidopsis. Plant physiology. 1997;113(4):1051-8.

14. Blazquez MA, Green R, Nilsson O, Sussman MR, Weigel D. Gibberellins promote flowering of arabidopsis by activating the LEAFY promoter. The Plant cell. 1998;10(5):791-800. 
15. Lee S, Cheng H, King KE, Wang W, He Y, Hussain A, et al. Gibberellin regulates Arabidopsis seed germination via RGL2, a GAI/RGA-like gene whose expression is up-regulated following imbibition. Genes \& development. 2002;16(5):646-58.

16. Ogawa M. Gibberellin Biosynthesis and Response during Arabidopsis Seed Germination. The Plant Cell Online. 2003;15(7):1591-604.

17. Alabadi D, Gil J, Blazquez MA, Garcia-Martinez JL. Gibberellins repress photomorphogenesis in darkness. Plant physiology. 2004;134(3):1050-7.

18. Yu H, Ito T, Zhao Y, Peng J, Kumar P, Meyerowitz EM. Floral homeotic genes are targets of gibberellin signaling in flower development. Proceedings of the National Academy of Sciences of the United States of America. 2004;101(20):7827-32.

19. Achard P, Baghour M, Chapple A, Hedden P, Van Der Straeten D, Genschik $P$, et al. The plant stress hormone ethylene controls floral transition via DELLAdependent regulation of floral meristem-identity genes. Proceedings of the National Academy of Sciences of the United States of America. 2007;104(15):6484-9.

20. Ubeda-Tomas S, Swarup R, Coates J, Swarup K, Laplaze L, Beemster GT, et al. Root growth in Arabidopsis requires gibberellin/DELLA signalling in the endodermis. Nature cell biology. 2008;10(5):625-8.

21. Achard P, Gusti A, Cheminant S, Alioua M, Dhondt S, Coppens F, et al. Gibberellin signaling controls cell proliferation rate in Arabidopsis. Current biology : CB. 2009;19(14):1188-93.

22. Nelissen H, Rymen B, Jikumaru $Y$, Demuynck K, Van Lijsebettens $M$, Kamiya $\mathrm{Y}$, et al. A local maximum in gibberellin levels regulates maize leaf growth by spatial control of cell division. Current biology : CB. 2012;22(13):1183-7.

23. Alabadi D, Blazquez MA. Molecular interactions between light and hormone signaling to control plant growth. Plant molecular biology. 2009;69(4):409-17.

24. Stavang JA, Gallego-Bartolome J, Gomez MD, Yoshida S, Asami T, Olsen JE, et al. Hormonal regulation of temperature-induced growth in Arabidopsis. The Plant journal : for cell and molecular biology. 2009;60(4):589-601.

25. Silverstone AL, Sun T. Gibberellins and the Green Revolution. Trends in plant science. 2000;5(1):1-2.

26. Lange T. Molecular biology of gibberellin synthesis. Planta. 1998;204(4):409-19.

27. Hedden P, Phillips AL. Gibberellin metabolism: new insights revealed by the genes. Trends in plant science. 2000;5(12):523-30.

28. Yamaguchi S, Kamiya Y. Gibberellin biosynthesis: its regulation by endogenous and environmental signals. Plant \& cell physiology. 2000;41(3):251-7. 
29. Nilsson L, Muller R, Nielsen TH. Dissecting the plant transcriptome and the regulatory responses to phosphate deprivation. Physiologia plantarum. 2010;139(2):129-43.

30. Eriksson S, Bohlenius $\mathrm{H}$, Moritz T, Nilsson O. GA4 is the active gibberellin in the regulation of LEAFY transcription and Arabidopsis floral initiation. The Plant cell. 2006;18(9):2172-81.

31. Thomas SG, Phillips AL, Hedden P. Molecular cloning and functional expression of gibberellin 2- oxidases, multifunctional enzymes involved in gibberellin deactivation. Proceedings of the National Academy of Sciences of the United States of America. 1999;96(8):4698-703.

32. Yamaguchi S, Smith MW, Brown RG, Kamiya Y, Sun T. Phytochrome regulation and differential expression of gibberellin 3beta-hydroxylase genes in germinating Arabidopsis seeds. The Plant cell. 1998;10(12):2115-26.

33. Bouquin T, Meier C, Foster R, Nielsen ME, Mundy J. Control of Specific Gene Expression by Gibberellin and Brassinosteroid. Plant physiology. 2001;127(2):450-8.

34. Ross JJ, O'Neill DP, Smith JJ, Kerckhoffs LH, Elliott RC. Evidence that auxin promotes gibberellin A1 biosynthesis in pea. The Plant journal : for cell and molecular biology. 2000;21(6):547-52.

35. Toyomasu T, Kawaide H, Mitsuhashi W, Inoue Y, Kamiya Y. Phytochrome regulates gibberellin biosynthesis during germination of photoblastic lettuce seeds. Plant physiology. 1998;118(4):1517-23.

36. O'Neill DP, Ross JJ, Reid JB. Changes in gibberellin A(1) levels and response during de-etiolation of pea seedlings. Plant physiology. 2000;124(2):805-12.

37. Garcia-Martinez JL, Gil J. Light Regulation of Gibberellin Biosynthesis and Mode of Action. Journal of plant growth regulation. 2001;20(4):354-68.

38. Yamauchi Y, Ogawa M, Kuwahara A, Hanada A, Kamiya Y, Yamaguchi S. Activation of gibberellin biosynthesis and response pathways by low temperature during imbibition of Arabidopsis thaliana seeds. The Plant cell. 2004;16(2):367-78.

39. Daviere JM, Achard P. Gibberellin signaling in plants. Development. 2013;140(6):1147-51.

40. Achard P, Genschik P. Releasing the brakes of plant growth: how GAs shutdown DELLA proteins. Journal of experimental botany. 2009;60(4):1085-92.

41. Ueguchi-Tanaka $M$, Ashikari $M$, Nakajima $M$, Itoh $H$, Katoh E, Kobayashi $M$, et al. GIBBERELLIN INSENSITIVE DWARF1 encodes a soluble receptor for gibberellin. Nature. 2005;437(7059):693-8.

42. Griffiths J, Murase K, Rieu I, Zentella R, Zhang ZL, Powers SJ, et al. Genetic characterization and functional analysis of the GID1 gibberellin receptors in Arabidopsis. The Plant cell. 2006;18(12):3399-414.

43. Nakajima M, Shimada A, Takashi Y, Kim YC, Park SH, Ueguchi-Tanaka M, et al. Identification and characterization of Arabidopsis gibberellin receptors. The Plant journal : for cell and molecular biology. 2006;46(5):880-9. 
44. Willige BC, Ghosh S, Nill C, Zourelidou M, Dohmann EM, Maier A, et al. The DELLA domain of GA INSENSITIVE mediates the interaction with the GA INSENSITIVE DWARF1A gibberellin receptor of Arabidopsis. The Plant cell. 2007;19(4):1209-20.

45. Peng J, Richards DE, Hartley NM, Murphy GP, Devos KM, Flintham JE, et al. 'Green revolution' genes encode mutant gibberellin response modulators. Nature. 1999;400(6741):256-61.

46. Silverstone AL, Ciampaglio CN, Sun T. The Arabidopsis RGA gene encodes a transcriptional regulator repressing the gibberellin signal transduction pathway. The Plant cell. 1998;10(2):155-69.

47. Shimada A, Ueguchi-Tanaka M, Nakatsu T, Nakajima M, Naoe Y, Ohmiya $\mathrm{H}$, et al. Structural basis for gibberellin recognition by its receptor GID1. Nature. 2008;456(7221):520-3.

48. Murase K, Hirano Y, Sun TP, Hakoshima T. Gibberellin-induced DELLA recognition by the gibberellin receptor GID1. Nature. 2008;456(7221):459-63.

49. Hirano K, Asano K, Tsuji H, Kawamura M, Mori H, Kitano H, et al. Characterization of the molecular mechanism underlying gibberellin perception complex formation in rice. The Plant cell. 2010;22(8):2680-96.

50. Lechner E, Achard P, Vansiri A, Potuschak T, Genschik P. F-box proteins everywhere. Current opinion in plant biology. 2006;9(6):631-8.

51. Ariizumi T, Lawrence PK, Steber CM. The role of two f-box proteins, SLEEPY1 and SNEEZY, in Arabidopsis gibberellin signaling. Plant physiology. 2011;155(2):765-75.

52. Ueguchi-Tanaka M, Nakajima M, Katoh E, Ohmiya H, Asano K, Saji S, et al. Molecular interactions of a soluble gibberellin receptor, GID1, with a rice DELLA protein, SLR1, and gibberellin. The Plant cell. 2007;19(7):2140-55.

53. Schwechheimer $C$. Understanding gibberellic acid signaling--are we there yet? Current opinion in plant biology. 2008;11(1):9-15.

54. Silverstone AL, Jung HS, Dill A, Kawaide H, Kamiya Y, Sun TP. Repressing a repressor: gibberellin-induced rapid reduction of the RGA protein in Arabidopsis. The Plant cell. 2001;13(7):1555-66.

55. Dill A, Sun T. Synergistic derepression of gibberellin signaling by removing RGA and GAI function in Arabidopsis thaliana. Genetics. 2001;159(2):777-85.

56. Ikeda A, Ueguchi-Tanaka M, Sonoda $Y$, Kitano $H$, Koshioka M, Futsuhara $Y$, et al. slender rice, a constitutive gibberellin response mutant, is caused by a null mutation of the SLR1 gene, an ortholog of the height-regulating gene GAI/RGA/RHT/D8. The Plant cell. 2001;13(5):999-1010.

57. Cheng $H$, Qin L, Lee S, Fu X, Richards DE, Cao D, et al. Gibberellin regulates Arabidopsis floral development via suppression of DELLA protein function. Development. 2004;131(5):1055-64. 
58. Tyler L, Thomas SG, Hu J, Dill A, Alonso JM, Ecker JR, et al. Della proteins and gibberellin-regulated seed germination and floral development in Arabidopsis. Plant physiology. 2004;135(2):1008-19.

59. Wilson RN, Somerville CR. Phenotypic Suppression of the GibberellinInsensitive Mutant (gai) of Arabidopsis. Plant physiology. 1995;108(2):495-502.

60. Dill A, Jung HS, Sun TP. The DELLA motif is essential for gibberellin-induced degradation of RGA. Proceedings of the National Academy of Sciences of the United States of America. 2001;98(24):14162-7.

61. Marti C, Orzaez D, Ellul P, Moreno V, Carbonell J, Granell A. Silencing of DELLA induces facultative parthenocarpy in tomato fruits. The Plant journal : for cell and molecular biology. 2007;52(5):865-76.

62. Zhong GY, Yang Y. Characterization of grape Gibberellin Insensitive1 mutant alleles in transgenic Arabidopsis. Transgenic research. 2012;21(4):725-41.

63. Chandler PM, Marion-Poll A, Ellis M, Gubler F. Mutants at the Slender1 locus of barley cv Himalaya. Molecular and physiological characterization. Plant physiology. 2002;129(1):181-90.

64. Gallego-Bartolome J, Minguet EG, Marin JA, Prat S, Blazquez MA, Alabadi D. Transcriptional diversification and functional conservation between DELLA proteins in Arabidopsis. Molecular biology and evolution. 2010;27(6):1247-56.

65. Richards DE, King KE, Ait-Ali T, Harberd NP. HOW GIBBERELLIN REGULATES PLANT GROWTH AND DEVELOPMENT: A Molecular Genetic Analysis of Gibberellin Signaling. Annual review of plant physiology and plant molecular biology. 2001;52:67-88.

66. Olszewski N, Sun TP, Gubler F. Gibberellin signaling: biosynthesis, catabolism, and response pathways. The Plant cell. 2002;14 Suppl:S61-80.

67. King KE, Moritz T, Harberd NP. Gibberellins are not required for normal stem growth in Arabidopsis thaliana in the absence of GAI and RGA. Genetics. 2001;159(2):767-76.

68. Feng S, Martinez C, Gusmaroli G, Wang Y, Zhou J, Wang F, et al. Coordinated regulation of Arabidopsis thaliana development by light and gibberellins. Nature. 2008;451(7177):475-9.

69. de Lucas $M$, Daviere JM, Rodriguez-Falcon $M$, Pontin $M$, Iglesias-Pedraz $\mathrm{JM}$, Lorrain $\mathrm{S}$, et al. A molecular framework for light and gibberellin control of cell elongation. Nature. 2008;451(7177):480-4.

70. Daviere JM, Wild M, Regnault T, Baumberger N, Eisler H, Genschik P, et al. Class I TCP-DELLA interactions in inflorescence shoot apex determine plant height. Current biology : CB. 2014;24(16):1923-8.

71. Cao D, Hussain A, Cheng $H$, Peng J. Loss of function of four DELLA genes leads to light- and gibberellin-independent seed germination in Arabidopsis. Planta. 2005;223(1):105-13. 
72. Achard P, Renou JP, Berthome R, Harberd NP, Genschik P. Plant DELLAs restrain growth and promote survival of adversity by reducing the levels of reactive oxygen species. Current biology : CB. 2008;18(9):656-60.

73. Wild M, Daviere JM, Cheminant S, Regnault T, Baumberger N, Heintz D, et al. The Arabidopsis DELLA RGA-LIKE3 is a direct target of MYC2 and modulates jasmonate signaling responses. The Plant cell. 2012;24(8):3307-19.

74. Bolle $\mathrm{C}$. The role of GRAS proteins in plant signal transduction and development. Planta. 2004;218(5):683-92.

75. Itoh $\mathrm{H}$. The Gibberellin Signaling Pathway Is Regulated by the Appearance and Disappearance of SLENDER RICE1 in Nuclei. The Plant Cell Online. 2002;14(1):57-70.

76. Dill A, Thomas SG, Hu J, Steber CM, Sun TP. The Arabidopsis F-box protein SLEEPY1 targets gibberellin signaling repressors for gibberellin-induced degradation. The Plant cell. 2004;16(6):1392-405.

77. Hirano K, Kouketu E, Katoh H, Aya K, Ueguchi-Tanaka M, Matsuoka M. The suppressive function of the rice DELLA protein SLR1 is dependent on its transcriptional activation activity. The Plant journal : for cell and molecular biology. 2012;71(3):443-53.

78. Gallego-Bartolome J, Minguet EG, Grau-Enguix F, Abbas M, Locascio A, Thomas SG, et al. Molecular mechanism for the interaction between gibberellin and brassinosteroid signaling pathways in Arabidopsis. Proceedings of the National Academy of Sciences of the United States of America. 2012;109(33):13446-51.

79. Hou X, Lee LY, Xia K, Yan Y, Yu H. DELLAs modulate jasmonate signaling via competitive binding to JAZs. Developmental cell. 2010;19(6):884-94.

80. Bai MY, Shang JX, Oh E, Fan M, Bai Y, Zentella R, et al. Brassinosteroid, gibberellin and phytochrome impinge on a common transcription module in Arabidopsis. Nature cell biology. 2012;14(8):810-7.

81. Yu S, Galvao VC, Zhang YC, Horrer D, Zhang TQ, Hao YH, et al. Gibberellin regulates the Arabidopsis floral transition through miR156-targeted SQUAMOSA promoter binding-like transcription factors. The Plant cell. 2012;24(8):3320-32.

82. Arnaud N, Girin T, Sorefan K, Fuentes S, Wood TA, Lawrenson T, et al. Gibberellins control fruit patterning in Arabidopsis thaliana. Genes \& development. 2010;24(19):2127-32.

83. Marin-de la Rosa N, Pfeiffer A, Hill K, Locascio A, Bhalerao RP, Miskolczi P, et al. Genome Wide Binding Site Analysis Reveals Transcriptional Coactivation of Cytokinin-Responsive Genes by DELLA Proteins. PLoS genetics. 2015;11(7):e1005337.

84. Hyun Y, Richter R, Vincent C, Martinez-Gallegos R, Porri A, Coupland G. Multi-layered Regulation of SPL15 and Cooperation with SOC1 Integrate Endogenous Flowering Pathways at the Arabidopsis Shoot Meristem. Developmental cell. 2016;37(3):254-66. 
85. Ogawa $\mathrm{M}$, Kusano $\mathrm{T}$, Katsumi $\mathrm{M}$, Sano $\mathrm{H}$. Rice gibberellin-insensitive gene homolog, OsGAI, encodes a nuclear-localized protein capable of gene activation at transcriptional level. Gene. 2000;245(1):21-9.

86. Zentella R, Zhang ZL, Park M, Thomas SG, Endo A, Murase K, et al. Global analysis of della direct targets in early gibberellin signaling in Arabidopsis. The Plant cell. 2007;19(10):3037-57.

87. Zhang ZL, Ogawa M, Fleet CM, Zentella R, Hu J, Heo JO, et al. Scarecrowlike 3 promotes gibberellin signaling by antagonizing master growth repressor DELLA in Arabidopsis. Proceedings of the National Academy of Sciences of the United States of America. 2011;108(5):2160-5.

88. Gallego-Bartolome J, Arana MV, Vandenbussche F, Zadnikova P, Minguet EG, Guardiola V, et al. Hierarchy of hormone action controlling apical hook development in Arabidopsis. The Plant journal : for cell and molecular biology. 2011;67(4):622-34.

89. Gallego-Bartolome J, Alabadi D, Blazquez MA. DELLA-induced early transcriptional changes during etiolated development in Arabidopsis thaliana. PloS one. 2011;6(8):e23918.

90. Yoshida H, Hirano K, Sato T, Mitsuda N, Nomoto M, Maeo K, et al. DELLA protein functions as a transcriptional activator through the DNA binding of the indeterminate domain family proteins. Proceedings of the National Academy of Sciences of the United States of America. 2014;111(21):7861-6.

91. Sarnowska EA, Rolicka AT, Bucior E, Cwiek P, Tohge T, Fernie AR, et al. DELLA-interacting SWI3C core subunit of switch/sucrose nonfermenting chromatin remodeling complex modulates gibberellin responses and hormonal cross talk in Arabidopsis. Plant physiology. 2013;163(1):305-17.

92. Yaxley JR, Ross JJ, Sherriff LJ, Reid JB. Gibberellin biosynthesis mutations and root development in pea. Plant physiology. 2001;125(2):627-33.

93. Chung $\mathrm{CH}$, Coolbaugh RC. ent-Kaurene Biosynthesis in Cell-Free Extracts of Excised Parts of Tall and Dwarf Pea Seedlings. Plant physiology. 1986;80(2):544-8.

94. Choi Y-H, Yoshizawa K, Kobayashi M, Sakurai A. Distribution of Endogenous Gibberellins in Vegetative Shoots of Rice. Plant and Cell Physiology. 1995;36(6):997-1001.

95. Aach H, Bode $H$, Robinson DG, Graebe JE. ent-Kaurene synthase is located in proplastids of meristematic shoot tissues. Planta. 1997;202(2):211-9.

96. Marin-de la Rosa N, Sotillo B, Miskolczi P, Gibbs DJ, Vicente J, Carbonero $P$, et al. Large-scale identification of gibberellin-related transcription factors defines group VII ETHYLENE RESPONSE FACTORS as functional DELLA partners. Plant physiology. 2014;166(2):1022-32.

97. Castrillo G, Turck F, Leveugle M, Lecharny A, Carbonero P, Coupland G, et al. Speeding cis-trans regulation discovery by phylogenomic analyses coupled with screenings of an arrayed library of Arabidopsis transcription factors. PloS one. 2011;6(6):e21524. 
98. Locascio A, Blazquez MA, Alabadi D. Genomic analysis of DELLA protein activity. Plant \& cell physiology. 2013;54(8):1229-37.

99. Manassero NG, Viola IL, Welchen E, Gonzalez DH. TCP transcription factors: architectures of plant form. Biomolecular concepts. 2013;4(2):111-27.

100. Martin-Trillo M, Cubas P. TCP genes: a family snapshot ten years later. Trends in plant science. 2010;15(1):31-9.

101. Li S. The Arabidopsis thaliana TCP transcription factors: A broadening horizon beyond development. Plant signaling \& behavior. 2015;10(7):e1044192.

102. Palatnik JF, Allen E, Wu X, Schommer C, Schwab R, Carrington JC, et al. Control of leaf morphogenesis by microRNAs. Nature. 2003;425(6955):257-63.

103. Schommer C, Palatnik JF, Aggarwal P, Chetelat A, Cubas P, Farmer EE, et al. Control of jasmonate biosynthesis and senescence by miR319 targets. PLoS biology. 2008;6(9):e230.

104. Koyama T, Mitsuda N, Seki M, Shinozaki K, Ohme-Takagi M. TCP transcription factors regulate the activities of ASYMMETRIC LEAVES1 and miR164, as well as the auxin response, during differentiation of leaves in Arabidopsis. The Plant cell. 2010;22(11):3574-88.

105. Guo Z, Fujioka S, Blancaflor EB, Miao S, Gou X, Li J. TCP1 modulates brassinosteroid biosynthesis by regulating the expression of the key biosynthetic gene DWARF4 in Arabidopsis thaliana. The Plant cell. 2010;22(4):1161-73.

106. Yanai O, Shani E, Russ D, Ori N. Gibberellin partly mediates LANCEOLATE activity in tomato. The Plant journal : for cell and molecular biology. 2011;68(4):571-82.

107. Zhou M, Li D, Li Z, Hu Q, Yang C, Zhu L, et al. Constitutive expression of a miR319 gene alters plant development and enhances salt and drought tolerance in transgenic creeping bentgrass. Plant physiology. 2013;161(3):1375-91.

108. Rubio-Somoza I, Weigel D. Coordination of Flower Maturation by a Regulatory Circuit of Three MicroRNAs. PLoS genetics. 2013;9(3):e1003374.

109. Franco-Zorrilla JM, Valli A, Todesco M, Mateos I, Puga MI, Rubio-Somoza I, et al. Target mimicry provides a new mechanism for regulation of microRNA activity. Nature genetics. 2007;39(8):1033-7.

110. Reichel M, Millar AA. Specificity of plant microRNA target MIMICs: Crosstargeting of miR159 and miR319. Journal of plant physiology. 2015;180:45-8.

111. Li S, Zachgo S. TCP3 interacts with R2R3-MYB proteins, promotes flavonoid biosynthesis and negatively regulates the auxin response in Arabidopsis thaliana. The Plant journal : for cell and molecular biology. 2013;76(6):901-13.

112. Ori N, Cohen AR, Etzioni A, Brand A, Yanai O, Shleizer S, et al. Regulation of LANCEOLATE by miR319 is required for compound-leaf development in tomato. Nature genetics. 2007;39(6):787-91.

113. Koyama T, Furutani M, Tasaka M, Ohme-Takagi M. TCP transcription factors control the morphology of shoot lateral organs via negative regulation of 
the expression of boundary-specific genes in Arabidopsis. The Plant cell. 2007;19(2):473-84.

114. Koyama T, Ohme-Takagi M, Sato F. Generation of serrated and wavy petals by inhibition of the activity of TCP transcription factors in Arabidopsis thaliana. Plant signaling \& behavior. 2011;6(5):697-9.

115. Nicolas M, Cubas P. TCP factors: new kids on the signaling block. Current opinion in plant biology. 2016;33:33-41.

116. Viola IL, Reinheimer R, Ripoll R, Manassero NG, Gonzalez DH. Determinants of the DNA binding specificity of class I and class II TCP transcription factors. The Journal of biological chemistry. 2012;287(1):347-56.

117. Kosugi S, Ohashi Y. DNA binding and dimerization specificity and potential targets for the TCP protein family. The Plant journal : for cell and molecular biology. 2002;30(3):337-48. 
2. Objectives 



\section{Objectives}

DELLAs have been involved in the regulation of a great variety of biological processes during the life cycle of the plant. However, little is known about their role modulating meristem activity. In this Thesis, we decided to focus in the regulation exerted by DELLAs on the primary meristems of Arabidopsis thaliana in two different processes: regulating the RAM during germination and the SAM during the vegetative phase. Thanks to the GAI TF interactome, TCP TFs were identified as suitable partners of DELLA in this regulation. Therefore, the two specific objectives pursued in this work are:

1. Investigating the regulation of SAM by DELLAs in the vegetative phase through their interaction with CIN-TCPs, and more particularly, with TCP2 and TCP4 (Chapter I). Previous evidence shows that CIN-TCPs and GAs promote cell differentiation in organ primordia. Accordingly, we hypothesized that DELLAs would promote the meristematic state of cells by inhibiting CIN-TCP activity through their physical interaction.

2. Exploring the regulation of the RAM during the germination process by DELLA interaction with the class I TCPs TCP14 and TCP15 (Chapter II). Cell division in the RAM has been found to be essential for completing germination, and TCP14 and TCP15 have been involved in promoting cell progression. Besides, TCP14 has a role promoting germination, whereas DELLAs are known to repress this process. With these data, we propose that DELLAs interact with these TCPs inhibiting their role favoring germination. 



\section{Introduction of Chapter I:}

DELLAs' role on the vegetative shoot apical meristem 



\section{The vegetative shoot apical meristem}

Plant development is an iterative process of organ initiation from meristems. The shoot apical meristem (SAM) is established during embryogenesis, and remains active during the whole life cycle of the plant, making it able to generate organs throughout every stage of its development. It is the structure from which all the aboveground organs originate, and generates simple leaves during the vegetative phase of Arabidopsis. It harbors a pool of self-renewing, undifferentiated pluripotent stem cells that are located in the central region of the meristem, a highly regulated microenvironment termed the stem cell niche (1); and their daughters, that fill the periphery and transition to differentiation and determinate growth to generate leaves at this stage (2). A great advantage of this continual organ initiation is that plant architecture is able to be flexible and respond to changing environmental conditions, contributing to their plasticity.

The SAM is a dome-shaped structure that is organized in distinct cell layers and subdivided into different zones or functional domains (Figure 3.1). In Arabidopsis, the SAM is defined by three cell layers (L1 to L3). An external L1 overlies the $\mathrm{L} 2$, both growing in a two-dimensional way by anticlinal cell division (originating cell walls are perpendicular to the apex surface) and constituting thr tunica layers $(3,4)$; and the most inner layer, $L 3$, that constitutes the corpus and grows in a three-dimensional manner (with periclinal and anticlinal cell divisions) (Figure 3.1). Each layer generates different tissues. In general, epidermis is formed from the $L 1$ layer while gametes from the $L 2$ and internal tissue of organs from the $L 3$ and further corpus cells.

More importantly for our study, there are three functional domains in the Arabidopsis SAM, characterized by different transcriptional and developmental programs directing each of them (5): the central zone (CZ), the peripheral zone (PZ) and the rib zone (RZ). The CZ includes L1, L2 and L3 cells, and is where the stem cells are located. The organizing center $(O C)$ is formed by a small group of cells and sustains the stem cells above. It is known that stem cells from the $\mathrm{CZ}$ divide at a slow rate and the progeny produced from its division are used to replenish the stem cells themselves and are also displaced into the PZ, which is a ring of cells that surround the $\mathrm{CZ}$. This $\mathrm{PZ}$ is characterized by high mitotic activity: cells start to divide more rapidly and it is where lateral organs are initiated. The 
site of incipient organ formation is called the Plastochron $0\left(\mathrm{P}_{0}\right)$, used to index leaves at a point in development. Cells in the PZ undergo sequential differentiation as they distance from the $\mathrm{CZ}$ and give rise to organ primordia (Figure 3.1) $(6,7)$. On the other hand, daughter cells can also be displaced to the RZ that generates the inner tissues of the stem.

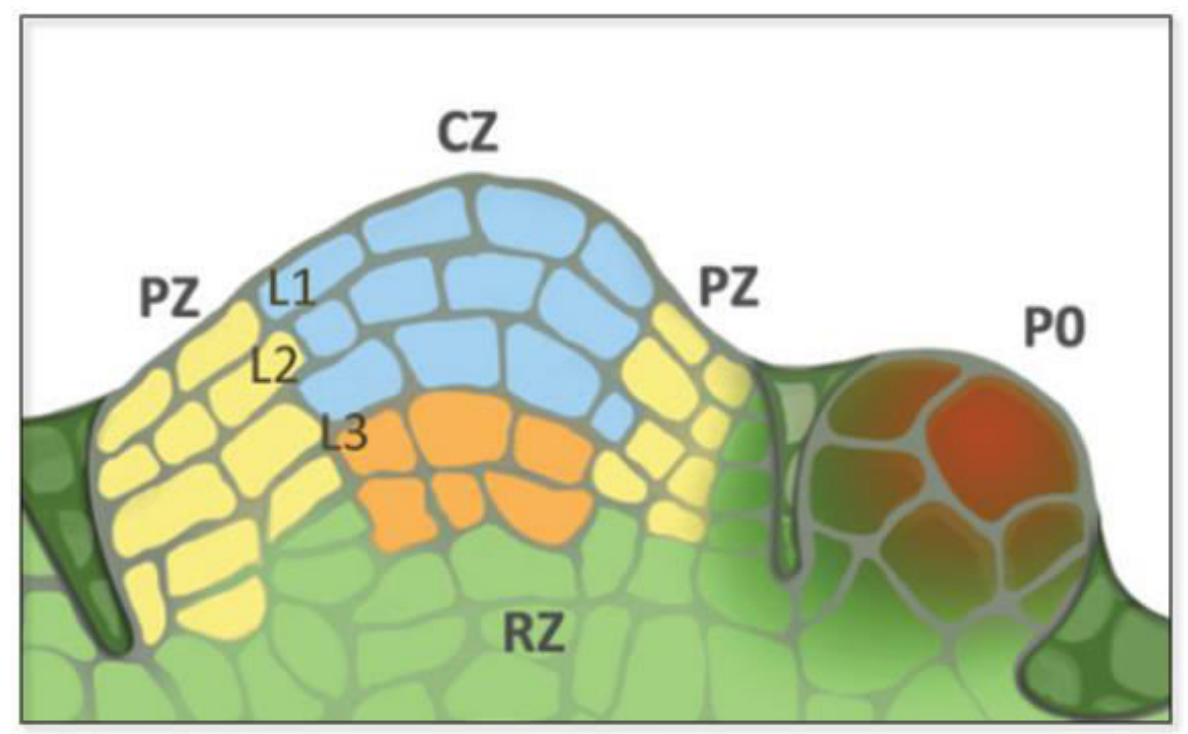

Figure 3.1. Layers and functional domains of the Arabidopsis shoot apical meristem. Cells from the SAM are disposed in three layers: L1, L2 and L3. Regarding functional domains, SAM architecture is organized in a central zone (CZ, blue), where the stem cell niche and the organizing center (orange) are localized; the peripheral zone (PZ, yellow) and the rib zone (RZ). The molecular events driving meristem maintenance are in tight coordination with organ differentiation processes. Leaf primordia in PO developmental stage is indicated. Extracted from Bustamante et al., 2015 (1).

In this line, stem cell maintenance is accomplished by the balance between self-replacement and organ initiation. Therefore, unraveling the molecular mechanisms of meristem function, including meristem maintenance, is currently a major area of interest in plant development. As cells are passively displaced from the $\mathrm{CZ}$ to the periphery by cell division and growth, they need to integrate the information of its own position within the meristem and the transcriptional program directing its fate or identity and act accordingly. Thus, this changing nature of the SAM depends on two factors: intercellular communication by plasmodesmata to assess their position relative to the neighboring cells; and principally, dynamic transcriptional programs within all the area of the meristem 
able to drive changes in cell fate and identity as cells are displaced through the meristematic tissue to initiate organ primordia and organogenesis $(1,8)$.

A key aspect for Chapter I of this Thesis is the transition of cells from the undifferentiated to differentiated state as they are displaced from the $\mathrm{CZ}$ to the periphery to form the organ primordia. This process is essential for plant development and implies a tight coordination of pro-meristematic and prodifferentiation regulators. In other words, there is a balance between the maintenance of the undifferentiated fate of cells in the shoot meristem and the promotion of cellular differentiation in organ primordia. The establishment of a boundary between both situations is essential for organogenesis and meristem maintenance. Unraveling the molecular mechanisms that establish this boundary is still a goal for current research, and we provide evidence in this Thesis that DELLAs might be involved in this point.

It is noteworthy that genes related to this regulation of the SAM and organ primordia are highly conserved among different plant species and their mutation result in severe developmental defects (9). This is the case for Knotted1-like homeobox (KNOX) genes, which are fundamental for meristem maintenance (10), and indirect targets of TCPs $(11,12)$. Given these data, we decided to focus our research on the role of DELLAs in this TCP/KNOX regulatory network. In the following section, an outline of this pathway is provided.

\section{The TCP/KNAT1 module of regulation}

KNOX genes constitute a small family of TALE homeobox genes found in all green plant lineages, and they are divided in two subclasses based on sequence similarity within the homeodomain, phylogenetic analysis and other aspects such as expression pattern $(13,14)$. Class I KNOX genes are the most widely studied and are expressed within the SAM (15), whereas Class II genes show diverse expression patterns and less known functions (16). As their function is involved in meristem maintenance and their expression primarily confined in the SAM, in this Thesis we focus on Class I KNOX genes. 


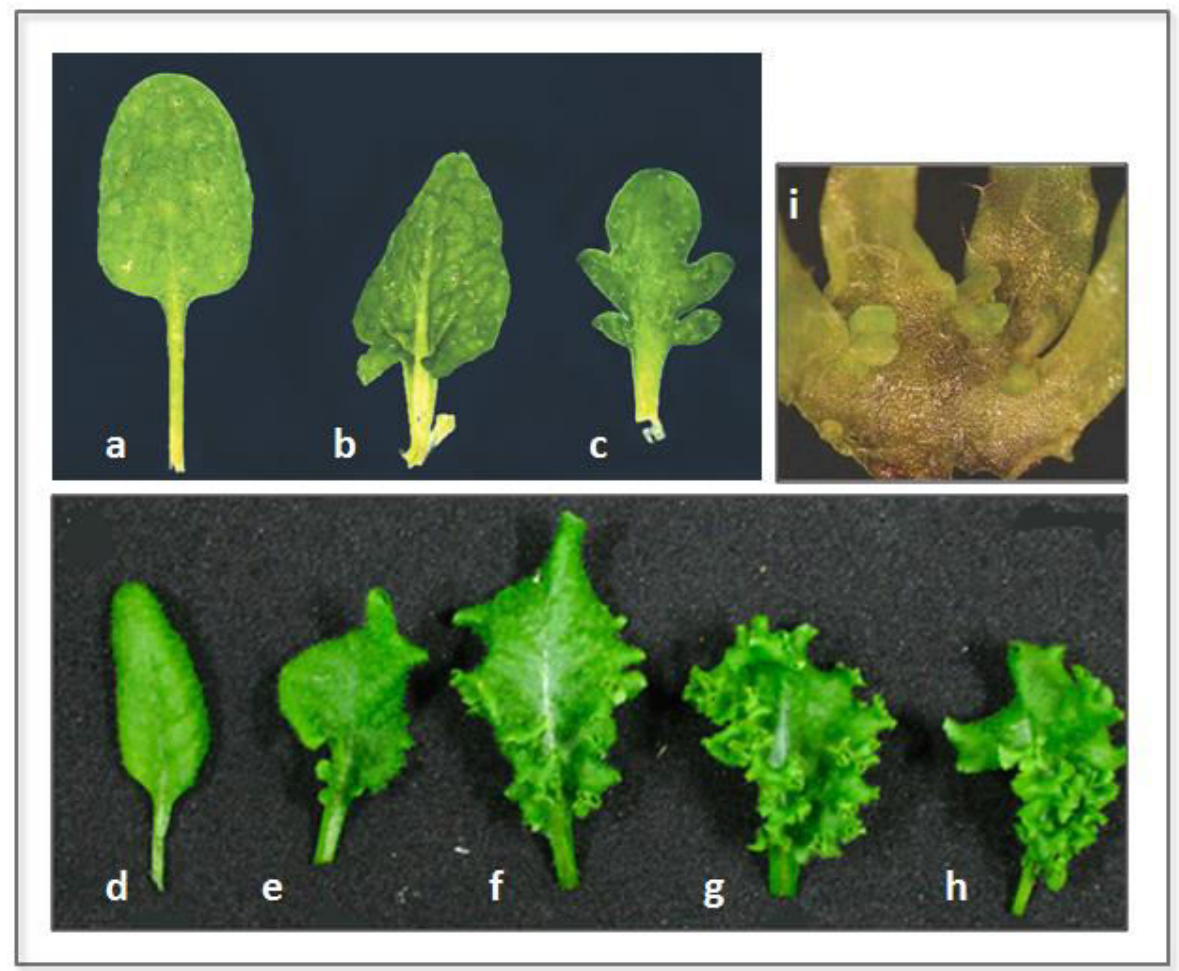

Figure 3.2. Leaf-phenotypes of Arabidopsis thaliana mutants defective in proper downregulation of class I KNOX gene expression in the leaf primordia. A representative leaf of each genotype is shown: WT (Ler)(a), as1-1 (b), 35s::KNAT1 (c), WT (Col0) (d), tcp3/4/10 (e), tcp3/4/5/10 (f), tcp3/4/5/10/13 (g), and 35S:miR319 tcp3/4/5/10/13 (h). Close-up of vegetative leaf of a severely lobed 35S::KNAT1 plant with ectopic shoot meristems in the sinus region (i). Extracted from Tsukaya, 2005 (a-c) (17), Koyama et al., 2010 (d-h) (11) and Chuck et al., 1996 (18).

The Arabidopsis genome encodes four class I KNOX (KNOXI) genes: SHOOT MERISTEMLESS (STM), Kn1-like in Arabidopsis thaliana1 (KNAT1) [also called BREVIPEDICELLUS (BP]), KNAT2 and KNAT6. STM and KNAT1 are the most extensively studied and more relevant for meristem function, since single mutations in KNAT2 and KNAT6 genes do not apparently affect shoot development $(19,20)$. In contrast, stm-1 development is arrested at the seedling stage, showing fused cotyledons and consumed meristem (15). On the other hand, the architecture of the KNAT1 mutant, named $b p-1$, is altered. They are plants with reduced height, irregularly shortened internodes, reduced apical dominance, and their pedicels are shorter and point downward. Cell wall defects are manifest in ectopic lignin accumulation in epidermis and cortex and in precocious lignifications in young plants, indicating a role of KNAT1 preventing 
premature cell differentiation and promoting meristem maintenance (21) (Figure 3.2). It is important to remember that we will focus our attention on KNAT1, since it constitutes an indirect target of TCPs and can be relevant in our research (Figure 3.3).

In Arabidopsis, the expression of class-I KNOX genes is confined to meristem cells and excluded from the leaf founder cells in organ primordia $\left(P_{0}\right)$; thus, they have been considered good markers for meristem versus lateral organ cell fate (22). The study of KNOX genes has allowed unraveling key aspects of the regulation of cell fate and tissue differentiation. These homeodomain transcription factors maintain the stem cells in the SAM in its un-differentiated state. Several reports support this affirmation. First, it has been demonstrated that KNOX activity is required to impede stem cells from adopting differentiated cell fates in maize and Arabidopsis, where mutants in KNOX genes KNOTTED1 (KN1) and STM fail to establish and maintain a $\operatorname{SAM}(23,24)$. Second, in plants with simple leaves (Arabidopsis, maize and tobacco), KNOX genes are expressed exclusively in the meristem and their ectopic expression in differentiated tissues (such as leaves) alter drastically their development (25-27), producing differential growth at the leaf margin, creating new meristems in leaves and novel 'meristemleaf' boundaries that lead to the formation of lobes $(18,25,26)$ (Figure 3.2). Third, in plants with dissected leaves, such as tomato, KNOX are also expressed in leaf primordia, further supporting their role in the control of cell fate (differentiation or un-differentiation) on the leaf margins (15).

In this context, defining a boundary between KNOX-expressing and non expressing cells is crucial for a correct initiation of lateral organs and plant development (15). The establishment of this boundary requires the repression of KNOX genes outside the SAM and involves the coordination of the antagonistic actions of meristem determinants, such as KNAT1, and pro-differentiation determinants (KNAT1 negative regulators) (Figure 3.3).

In this sense, several negative regulators of $K N O X$ genes have been reported to confine KNOX activity in the SAM and to exclude it from organ primordia (15). Among them, we will pay attention to ASYMMETRIC LEAVES1 (AS1), whose expression is directly activated by TCPS, and therefore, interesting for our research. 
AS1 is a MYB-type TF specifically expressed in the shoot lateral organs, that is, with a complementary expression pattern to that of the KNOX genes. Thus, AS1 promotes cell differentiation through the repression of KNOX expression (28). AS1 mutation in Arabidopsis inhibits cell differentiation and induces ectopic expression of KNAT1 in organ primordia, producing asymmetric leaves with lobed margins and occasional ectopic meristems (29-31), a phenotype that resembles the alterations in leaf patterning observed in transgenic plants over-expressing KNAT1 (25). As for the mechanism of KNAT1 repression, it has been reported that AS1 can bind the KNAT1 promoter alone or interacting with the LOB domain protein AS2. Then, chromatin remodeling factors that make promoter regulatory sequences un-accessible are recruited: the histone deacetylase HDA6 (by AS1) and POLYCOMB-REPRESSIVE COMPLEX 2 (by AS1-AS2) $(32,33)$.

In this regulatory interplay between pro-meristematic (KNAT1) and prodifferentiation (AS1) factors in the SAM to establish the boundary of KNOXexpressing and non-expressing cells, CIN-TCPs play an important role:

Koyama et al., 2010 (11), demonstrated the mechanism by which CIN-TCPs promote cell differentiation in organ primordia in the SAM context: activating AS1 expression, and therefore, indirectly repressing KNOX genes such as KNAT1 (11) (Figure 3.3). A microarray experiment using a $\beta$-estradiol inducible TCP3SRDX line identified $A S 1$ as a putative direct target of CIN-TCPs. Further chromatin immunoprecipitation (ChIP) and transient expression assays demonstrated that CIN-TCPs are able to bind AS1 promoter and activate its transcription (11). These results indicate that TCPs are located upstream of AS1 in the regulatory network controlling the boundary of KNAT1-expressing vs non-expressing cells; or, in other words the SAM vs the differentiating cells (Figure 3.3).

Several observations implicate CIN-TCPS in the regulation of the differentiation of cells in the SAM boundary and confirm its role promoting cellular differentiation. Plants with reduced expression of CIN-TCPs, such as TCP mutants (11), the Arabidopsis jaw-d mutant (which over-expresses miR319 that down-regulates five out of eight CIN-TCPs) and plants over-expressing TCP-SRDX in which all TCP target genes are repressed; exhibit a wavy-leaf phenotype, irregular vasculature, undifferentiated cells and ectopic formation of shoot 
meristems in cotyledons; resembling the phenotype of 35S::KNAT1 $(25,34)$. And contrarily, over-expression of CIN-TCPs harboring mutations that prevent the binding of the miR319 (microRNA-resistant versions of TCPs) produces defects in the formation of a functional SAM and the fusion of cotyledons (34-36), also in tomato (37).

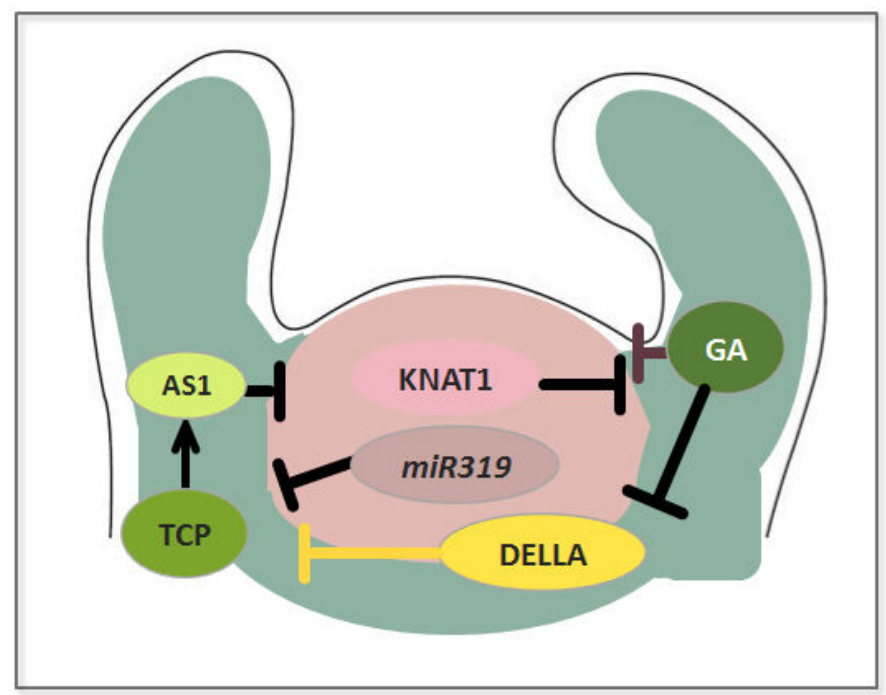

Figure 3.3. Regulatory network controlling the un-differentiate state of stem cells in the SAM and cell differentiation in organ primordia. The factors involved in the pathway are localized in their expression domains: pro-meristematic factors (in mauve, KNAT1 and miR319) in the SAM (mauve zone); and pro-differentiation factors (in green, CIN-TCPs, AS1 and GA) in organ primordia (blue zone). The working hypothesis is represented in yellow: DELLA-CIN-TCP physical interaction would inhibit TCP activity, therefore promoting KNAT1 expression in the SAM.

It is important to take into account that the microRNA miR319 downregulates five out of eight CIN-TCPS, as we have already mentioned. Interestingly, the precursor of this microRNA was more abundant in the SAM, and its expression decreased drastically in leaves (34). A complementary pattern of expression was found for the CIN-TCP TCP4 by in situ hybridization assays. TCP4 expression in the vegetative phase is restricted to leaf primordia, cotyledons and leaves with the highest levels near the tip, whereas TCP signal is excluded from the SAM. These domains of expression are consistent with the repressive effect of miR319 on CINTCPs in the SAM (34). This way, miR319 would impair the pro-differentiation effects of CIN-TCPs in the SAM, favoring meristem identity (Figure 3.3). 
All in all, these reports show that there is an interplay between TCPs and AS1 promoting differentiation in organ primordia through KNAT1 inhibition, and meristem maintenance by KNAT1 and miR319. This regulatory network establishes the boundary between the KNOX-expressing and non-expressing cells (Figure 3.3). The implication of GAs on this pathway is presented in the following section.

\section{The role of gibberelin in the vegetative shoot apical meristem}

Several lines of evidence implicate plant hormones (including GAs) in the fine-tuning mechanism that determines cell fate and maintenance of stem cells. KNOX proteins favor meristem activity, in part by regulating the balance between both CK and GA activities. Specifically, low levels of GAs and high levels of the cell division promoter CKs seem to be necessary for meristem maintenance, while higher levels of GAs are associated to primordia outgrowth, mostly for cell expansion and differentiation (38-41). KNOX are known to guarantee this balance by repressing GA biosynthesis and inducing GA inactivation, while promoting $\mathrm{CK}$ synthesis in the SAM (42).

First, KNOX genes have been shown to repress the transcription of the GA biosynthetic genes GA20ox in several plant species $(39-41,43)$. Second, KNOX proteins activate the transcription of GA2ox genes, which encode GA catabolic enzymes, at the meristem-leaf primordia boundary $(39,44,45)$. In this sense, it has been proposed that this localized GA2ox expression protects the stem cells in the SAM from the possible diffusion of GA from the adjacent organ primordia (40). Therefore, KNOX action is directed to exclude GAs from the SAM region (Figure 3.3), where the GA pro-differentiation effect could lead to detrimental impacts on SAM activity. In fact, genetic evidence supports this idea. The Ofucosyltransferase SPINDLY (SPY) is a negative regulator of GA responses, because mutation of this gene phenocopies plants treated with an overdose of bioactive GA and results in insensitivity to a GA inhibitor during seed germination $(46,47)$. Therefore, it is known that the Arabidopsis mutant spindly is characterized by constitutive activated GA signaling, and the combination of this mutant with weak $\mathrm{stm}$ alleles enhances its phenotypic defects (39). 
And the third way by which KNOX regulates the CK/GA balance is by activating CK biosynthesis, as KNOX-overexpressing plants have elevated levels of CK (41) due to higher expression of CK biosynthetic gene ISOPENTENYL TRANSFERASE7 (IPT7) $(40,41)$. In this line, over-expression of CK biosynthetic IPT genes and exogenous application of $C K$ can partially rescue the meristem defects of stm mutants (41), confirming that CK is required in the SAM for its correct activity (38).

This GA/CK balance reflects the complex way in which hormones are integrated in the regulatory network controlling the SAM that may serve to buffer the apex against hormone perturbations caused by the normal course of development or as a response to environmental changes (38). In fact, when this $\mathrm{CK} / \mathrm{GA}$ balance is reversed, for instance combining spindly with an over-expressor of the CK catabolic enzyme CKX3, the SAM function is abolished (40).

To sum up, in the SAM, high CK/low GA balance promotes indeterminate growth, whereas in organ primordia (PO) high GA and low CK concentrations promote lateral organ initiation. As far as GAs are concerned, they are excluded from the SAM by KNOX and located in organ primordia (Figure 3.3) (in fact the biosynthetic gene GA20ox1 is expressed there (39)), where they promote differentiation and cell elongation via reorienting microtubules (48). In fact, the lack of GAs in the SAM could be involved in maintaining the isodiametric shape that characterizes meristem cells (39).

\section{Proposal of the hypothesis: DELLAs function in the SAM}

The aim of this part of the Thesis (Chapter I) is to unravel the role of DELLAs regulating the vegetative SAM. As it has already been presented, in the meristem there is a balance between factors that promote a meristematic state in the central zone and factors that favor cell differentiation in external regions (primordia). Importantly, KNAT1 expression is a distinctive trait in meristematic cells, and the establishment of the boundary between KNAT1-expressing and nonexpressing cells defines cell fate and it is relevant for plant development. Currently, the mechanisms that determine the KNAT1 expression domain remain to be understood. 
Here, we challenge the hypothesis that DELLAs participate in the maintenance of the SAM by defining the KNAT1 expression boundary at the transcriptional level, given that GAs do not accumulate in the SAM and that DELLAs interact with upstream regulators of KNAT1 (the CIN-TCPs module).

\section{References}

1. Bustamante M, Matus JT, Riechmann JL. Genome-wide analyses for dissecting gene regulatory networks in the shoot apical meristem. Journal of experimental botany. 2016;67(6):1639-48.

2. Tsuda K, Kurata N, Ohyanagi H, Hake S. Genome-wide study of KNOX regulatory network reveals brassinosteroid catabolic genes important for shoot meristem function in rice. The Plant cell. 2014;26(9):3488-500.

3. Shapiro BE, Tobin C, Mjolsness E, Meyerowitz EM. Analysis of cell division patterns in the Arabidopsis shoot apical meristem. Proceedings of the National Academy of Sciences of the United States of America. 2015;112(15):4815-20.

4. Barton MK. Twenty years on: the inner workings of the shoot apical meristem, a developmental dynamo. Developmental biology. 2010;341(1):95-113. 5. Yadav RK, Girke T, Pasala S, Xie M, Reddy GV. Gene expression map of the Arabidopsis shoot apical meristem stem cell niche. Proceedings of the National Academy of Sciences of the United States of America. 2009;106(12):4941-6.

6. Reddy GV, Heisler MG, Ehrhardt DW, Meyerowitz EM. Real-time lineage analysis reveals oriented cell divisions associated with morphogenesis at the shoot apex of Arabidopsis thaliana. Development. 2004;131(17):4225-37.

7. Heisler MG, Ohno C, Das P, Sieber P, Reddy GV, Long JA, et al. Patterns of auxin transport and gene expression during primordium development revealed by live imaging of the Arabidopsis inflorescence meristem. Current biology : CB. 2005;15(21):1899-911.

8. Pautler M, Tanaka W, Hirano HY, Jackson D. Grass meristems I: shoot apical meristem maintenance, axillary meristem determinacy and the floral transition. Plant \& cell physiology. 2013;54(3):302-12.

9. Sluis A, Hake S. Organogenesis in plants: initiation and elaboration of leaves. Trends in genetics : TIG. 2015;31(6):300-6.

10. Hay A, Tsiantis M. KNOX genes: versatile regulators of plant development and diversity. Development. 2010;137(19):3153-65.

11. Koyama T, Mitsuda N, Seki M, Shinozaki K, Ohme-Takagi M. TCP transcription factors regulate the activities of ASYMMETRIC LEAVES1 and miR164, as well as the auxin response, during differentiation of leaves in Arabidopsis. The Plant cell. 2010;22(11):3574-88. 
12. Hay A, Barkoulas M, Tsiantis M. ASYMMETRIC LEAVES1 and auxin activities converge to repress BREVIPEDICELLUS expression and promote leaf development in Arabidopsis. Development. 2006;133(20):3955-61.

13. Kerstetter R, Vollbrecht E, Lowe B, Veit B, Yamaguchi J, Hake S. Sequence analysis and expression patterns divide the maize knotted1-like homeobox genes into two classes. The Plant cell. 1994;6(12):1877-87.

14. Mukherjee K, Brocchieri L, Burglin TR. A comprehensive classification and evolutionary analysis of plant homeobox genes. Molecular biology and evolution. 2009;26(12):2775-94.

15. Hake S, Smith HM, Holtan H, Magnani E, Mele G, Ramirez J. The role of knox genes in plant development. Annual review of cell and developmental biology. 2004;20:125-51.

16. Zhong R, Lee C, Zhou J, McCarthy RL, Ye ZH. A battery of transcription factors involved in the regulation of secondary cell wall biosynthesis in Arabidopsis. The Plant cell. 2008;20(10):2763-82.

17. Tsukaya $\mathrm{H}$. Leaf shape: genetic controls and environmental factors. The International journal of developmental biology. 2005;49(5-6):547-55.

18. Chuck G, Lincoln C, Hake S. KNAT1 induces lobed leaves with ectopic meristems when overexpressed in Arabidopsis. The Plant cell. 1996;8(8):1277-89.

19. Belles-Boix E, Hamant O, Witiak SM, Morin H, Traas J, Pautot V. KNAT6: an Arabidopsis homeobox gene involved in meristem activity and organ separation. The Plant cell. 2006;18(8):1900-7.

20. Byrne ME, Simorowski J, Martienssen RA. ASYMMETRIC LEAVES1 reveals knox gene redundancy in Arabidopsis. Development. 2002;129(8):1957-65.

21. Smith HMS. The Interaction of Two Homeobox Genes, BREVIPEDICELLUS and PENNYWISE, Regulates Internode Patterning in the Arabidopsis Inflorescence. The Plant Cell Online. 2003;15(8):1717-27.

22. Smith LG, Greene B, Veit B, Hake S. A dominant mutation in the maize homeobox gene, Knotted-1, causes its ectopic expression in leaf cells with altered fates. Development. 1992;116(1):21-30.

23. Vollbrecht E, Reiser L, Hake S. Shoot meristem size is dependent on inbred background and presence of the maize homeobox gene, knotted1. Development. 2000;127(14):3161-72.

24. Long JA, Moan El, Medford JI, Barton MK. A member of the KNOTTED class of homeodomain proteins encoded by the STM gene of Arabidopsis. Nature. 1996;379(6560):66-9.

25. Lincoln C, Long J, Yamaguchi J, Serikawa K, Hake S. A knottedl-like Homeobox Gene in Arabidopsis 1s Expressed in the Vegetative Meristem and Dramatically Alters Leaf Morphology When Overexpressed in Transgenic Plants. The Plant cell. 1994;6:1859-76. 
26. Sinha NR, Williams RE, Hake S. Overexpression of the maize homeo box gene, KNOTTED-1, causes a switch from determinate to indeterminate cell fates. Genes \& development. 1993;7(5):787-95.

27. Vollbrecht E, Veit B, Sinha N, Hake S. The developmental gene Knotted-1 is a member of a maize homeobox gene family. Nature. 1991;350(6315):241-3.

28. Guo M, Thomas J, Collins G, Timmermans MC. Direct repression of KNOX loci by the ASYMMETRIC LEAVES1 complex of Arabidopsis. The Plant cell. 2008;20(1):48-58.

29. Byrne ME, Barley R, Curtis M, Arroyo JM, Dunham M, Hudson A, et al. Asymmetric leaves1 mediates leaf patterning and stem cell function in Arabidopsis. Nature. 2000;408(6815):967-71.

30. Ori N, Eshed Y, Chuck G, Bowman JL, Hake S. Mechanisms that control knox gene expression in the Arabidopsis shoot. Development. 2000;127(24):552332.

31. Semiarti E, Ueno $Y$, Tsukaya H, Iwakawa H, Machida C, Machida Y. The ASYMMETRIC LEAVES2 gene of Arabidopsis thaliana regulates formation of a symmetric lamina, establishment of venation and repression of meristem-related homeobox genes in leaves. Development. 2001;128(10):1771-83.

32. Luo L, Ando S, Sasabe M, Machida C, Kurihara D, Higashiyama T, et al. Arabidopsis ASYMMETRIC LEAVES2 protein required for leaf morphogenesis consistently forms speckles during mitosis of tobacco BY-2 cells via signals in its specific sequence. Journal of plant research. 2012;125(5):661-8.

33. Lodha M, Marco CF, Timmermans MC. The ASYMMETRIC LEAVES complex maintains repression of KNOX homeobox genes via direct recruitment of Polycomb-repressive complex2. Genes \& development. 2013;27(6):596-601.

34. Palatnik JF, Allen E, Wu X, Schommer C, Schwab R, Carrington JC, et al. Control of leaf morphogenesis by microRNAs. Nature. 2003;425(6955):257-63.

35. Koyama T, Furutani M, Tasaka M, Ohme-Takagi M. TCP transcription factors control the morphology of shoot lateral organs via negative regulation of the expression of boundary-specific genes in Arabidopsis. The Plant cell. 2007;19(2):473-84.

36. Nag A, King S, Jack T. miR319a targeting of TCP4 is critical for petal growth and development in Arabidopsis. Proceedings of the National Academy of Sciences of the United States of America. 2009;106(52):22534-9.

37. Ori N, Cohen AR, Etzioni A, Brand A, Yanai O, Shleizer S, et al. Regulation of LANCEOLATE by miR319 is required for compound-leaf development in tomato. Nature genetics. 2007;39(6):787-91.

38. Galinha C, Bilsborough G, Tsiantis M. Hormonal input in plant meristems: A balancing act. Seminars in cell \& developmental biology. 2009;20(9):1149-56.

39. Hay A, Kaur H, Phillips A, Hedden P, Hake S, Tsiantis M. The Gibberellin Pathway Mediates KNOTTED1-Type Homeobox Function in Plants with Different Body Plans. Current Biology. 2002;12:1557-65. 
40. Jasinski S, Piazza P, Craft J, Hay A, Woolley L, Rieu I, et al. KNOX action in Arabidopsis is mediated by coordinate regulation of cytokinin and gibberellin activities. Current biology : CB. 2005;15(17):1560-5.

41. Yanai O, Shani E, Dolezal K, Tarkowski P, Sablowski R, Sandberg G, et al. Arabidopsis KNOXI proteins activate cytokinin biosynthesis. Current biology : CB. 2005;15(17):1566-71.

42. Tsuda K, Hake S. Diverse functions of KNOX transcription factors in the diploid body plan of plants. Current opinion in plant biology. 2015;27:91-6.

43. Ori N, Juarez MT, Jackson D, Yamaguchi J, Banowetz GM, Hake S. Leaf senescence is delayed in tobacco plants expressing the maize homeobox gene knotted1 under the control of a senescence-activated promoter. The Plant cell. 1999;11(6):1073-80.

44. Sakamoto $\mathrm{T}$, Kobayashi $\mathrm{M}$, Itoh $\mathrm{H}$, Tagiri $\mathrm{A}$, Kayano $\mathrm{T}$, Tanaka $\mathrm{H}$, et al. Expression of a gibberellin 2-oxidase gene around the shoot apex is related to phase transition in rice. Plant physiology. 2001;125(3):1508-16.

45. Bolduc $\mathrm{N}$, Hake $\mathrm{S}$. The maize transcription factor KNOTTED1 directly regulates the gibberellin catabolism gene ga2ox1. The Plant cell. 2009;21(6):164758.

46. Qin F, Kodaira KS, Maruyama K, Mizoi J, Tran LS, Fujita Y, et al. SPINDLY, a negative regulator of gibberellic acid signaling, is involved in the plant abiotic stress response. Plant physiology. 2011;157(4):1900-13.

47. Zentella R, Sui N, Barnhill B, Hsieh WP, Hu J, Shabanowitz J, et al. The Arabidopsis O-fucosyltransferase SPINDLY activates nuclear growth repressor DELLA. Nature chemical biology. 2017.

48. Shibaoka H, Nagai R. The plant cytoskeleton. Current opinion in cell biology. 1994;6(1):10-5. 



\section{Results and Discussion of Chapter}

I: DELLAs regulate the shoot apical meristem through the activity of CIN-TCPs and KNAT1 



\section{GAI and RGA interact with CIN-TCP family members}

Previous work using a yeast two hybrid $(\mathrm{Y} 2 \mathrm{H})$ screen with the GRAS domain of GAI as bait (M5GAI) against an arrayed library of approximately 1,200 TFs from Arabidopsis had identified 12 members of the TCP family as interactors (1). As stated above, 6 of these members are included in the class I TCPs (for example TCP14 and 15, Chapter II) and other 6 in the class II. Among them, 5 belong to the CIN subclass (TCP2, TCP3, TCP5, TCP10 and TCP13).

Given that out of the five DELLA genes in Arabidopsis (2), GAI and RGA are the two most strongly expressed in the shoot apex (3), our first aim was to further characterize the interaction of CIN-TCPs with these two DELLA proteins in particular. We carried out $\mathrm{Y} 2 \mathrm{H}$ assays with the GRAS domain from GAI and we found that this DELLA protein was able to interact with all the CIN-TCP family members tested, as expected (1) (Figure 4.1A). Taking TCP2 and TCP4 as a model, we found that they are able to interact with the GRAS domain of RGA (called RGA52) as well (Figure 4.1B). According to these results it seems reasonable to think that RGA is also able to interact with the other members of the CIN-TCP subclass.

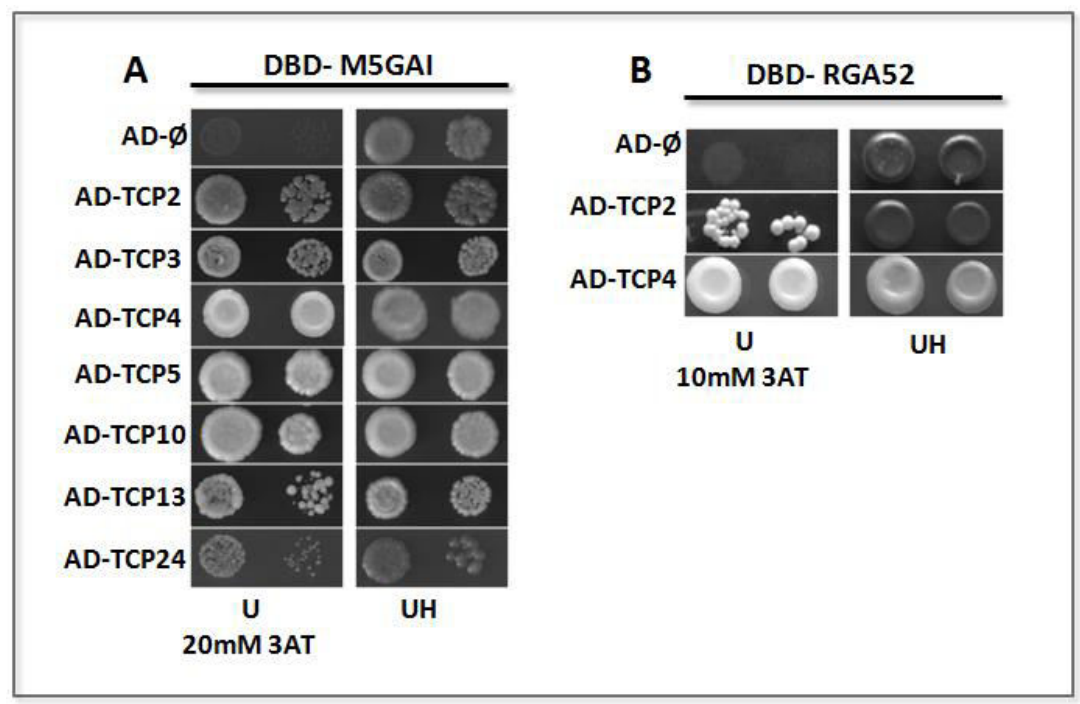

Figure 4.1. DELLA proteins interact with CIN-TCP family members. $\mathrm{Y} 2 \mathrm{H}$ assay of the interaction between (A) a truncated version of GAI (M5GAI) and seven members of the CIN-TCP family; and (B) a truncated version of RGA (RGA52) and TCP2 and TCP4. (DBD, DNA binding domain; $A D$, activation domain; $A D-\phi$, activation domain empty vector; $U$, uracil; $H$, histidine; 3-AT, 3aminotriazol). 
The identification of protein regions involved in a particular interaction might provide useful information regarding its effects on the activity of the TF. For instance, this sort of analysis showed that the interacting surface between PIFs and DELLAs includes the bHLH domain, providing this way the first hints pointing that the interaction would have a negative effect on the activity of the TF $(4,5)$. To determine the domains involved in the interaction between DELLAs and CINTCPs, we generated truncated versions of both TCP2 and GAI. We split TCP2 in roughly two halves, with the $\mathrm{N}$-terminal one including the TCP domain (Figure 4.2A). This domain is a 59 amino acid non-canonical basic helix-loop-helix (bHLH) motif responsible of DNA binding and protein-protein interactions (6). In fact, this motif is very similar to the bHLH of PIF3 and PIF4 $(4,5)$. However, none of the deleted versions were able to interact with M5GAI. These results indicate either that both parts of the protein are needed to support the interaction in the native TCP protein, or that none of the truncated versions are expressed or folded correctly.

On the other hand, we tested the ability of TCP2 to interact with different regions of $\mathrm{M} 5 \mathrm{GAl}$, and remarkably all of them were able to interact, although the interaction seems weaker than with M5GAI (Figure 4.2.B). Similar results were obtained when we assayed TCP4 with the same deletions of M5GAl (Figure 4.2C). The interaction involves different regions of the GRAS domain, and none of them seems to be essential. This behaviour is not typical among the DELLA interactors, for which certain specificities in the domains involved in the interaction have been described. For instance, the LHR1 motif is essential for the interaction of GAI with BZR1, PIF4, and JAZ1 (4, 5, 7-11). However, ARR1 interacts with GAl even when the LHR1 motif is not present, but further deletion of the VHIID motif abolishes the union (12).

Next, we confirmed that the interaction also occurs in planta. For that purpose we decided to use two complementary techniques: Bimolecular Fluorescence Complementation ( $\mathrm{BiFC}$ ) and co-immunoprecipitation (co-IP). Both assays were performed in Nicotiana benthamiana leaves. As shown in the BiFC assay in Figure 4.3A, the fluorescence of the reconstituted YFP can be seen in the nuclei of epidermal cells co-expressing YFC-GAl and YFN-TCP4 and YFN-TCP2, while in the control it remains undetected. We also demonstrated the DELLA-CINTCP interaction by co-IP (Figure 4.3B). The c-myc-M5GAI protein was effectively 
pulled down by anti-HA antibody coated beads only from extracts of leaves coexpressing HA-TCP2, demonstrating the interaction between both proteins.

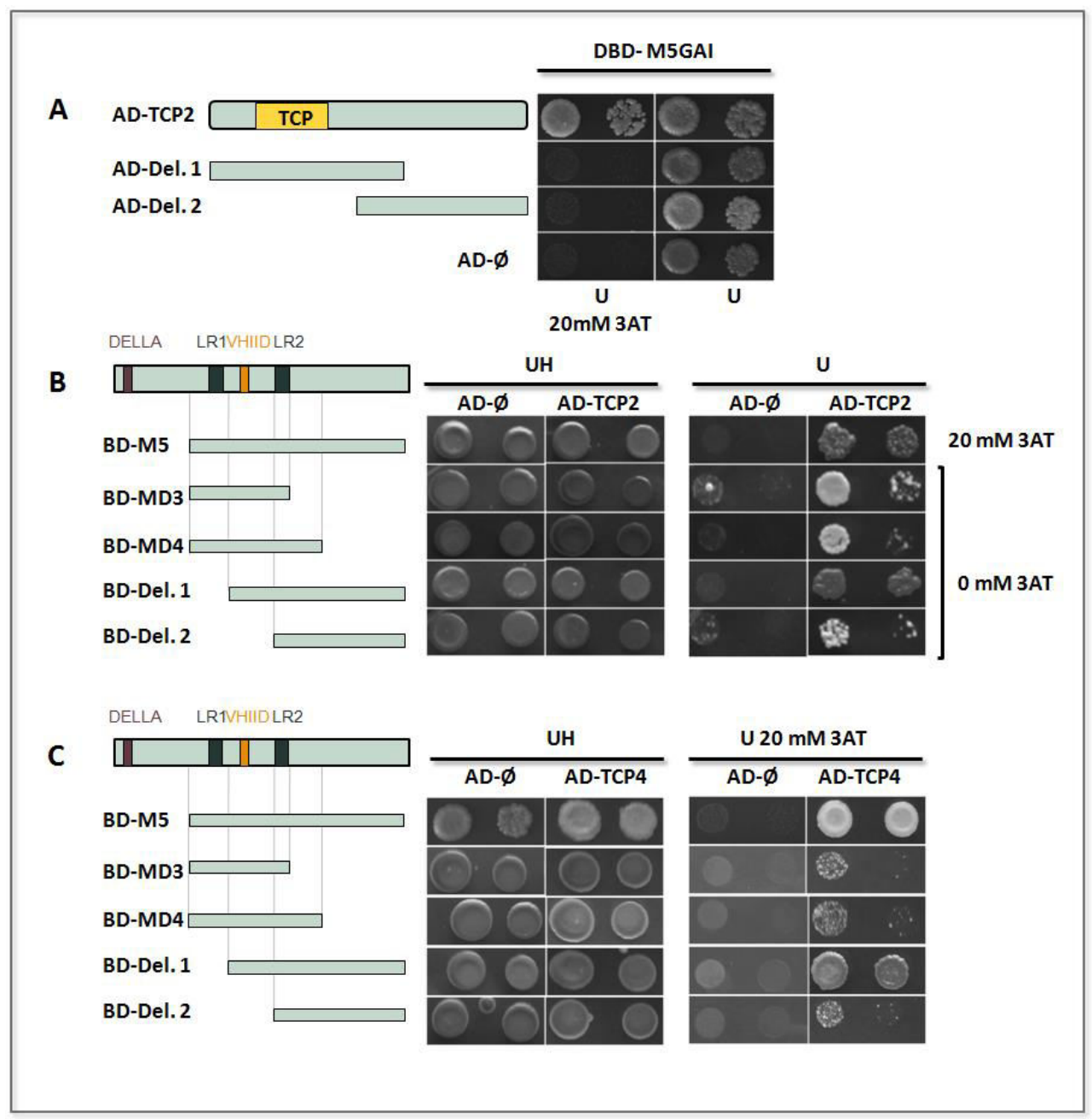

Figure 4.2. Domains involved in CIN-TCP-DELLA interaction. $\mathrm{Y} 2 \mathrm{H}$ assay of the interaction between (A) M5GAl and truncated versions of TCP2, (B) TCP2 and truncated versions of GAl and (C) TCP4 and truncated versions of GAl. The different domains are indicated in colors. (DBD, DNA binding domain; $A D$, activation domain; $A D-\phi$, activation domain empty vector; $U$, uracil; $H$, histidine; 3-AT, 3-aminotriazol).

All in all, those findings indicate that the DELLA-CIN-TCP interaction takes place in planta and that DELLAs can potentially regulate the activity of these TFs post-translationally. Moreover, the fact that there are 8 members of the CIN-TCP family and 5 different DELLAs suggests the possibility of an extensive and 
combinatorial module of regulation involving different pairs of proteins that could interact depending on their expression patterns, the physiological contexts and/or environmental conditions, for instance.

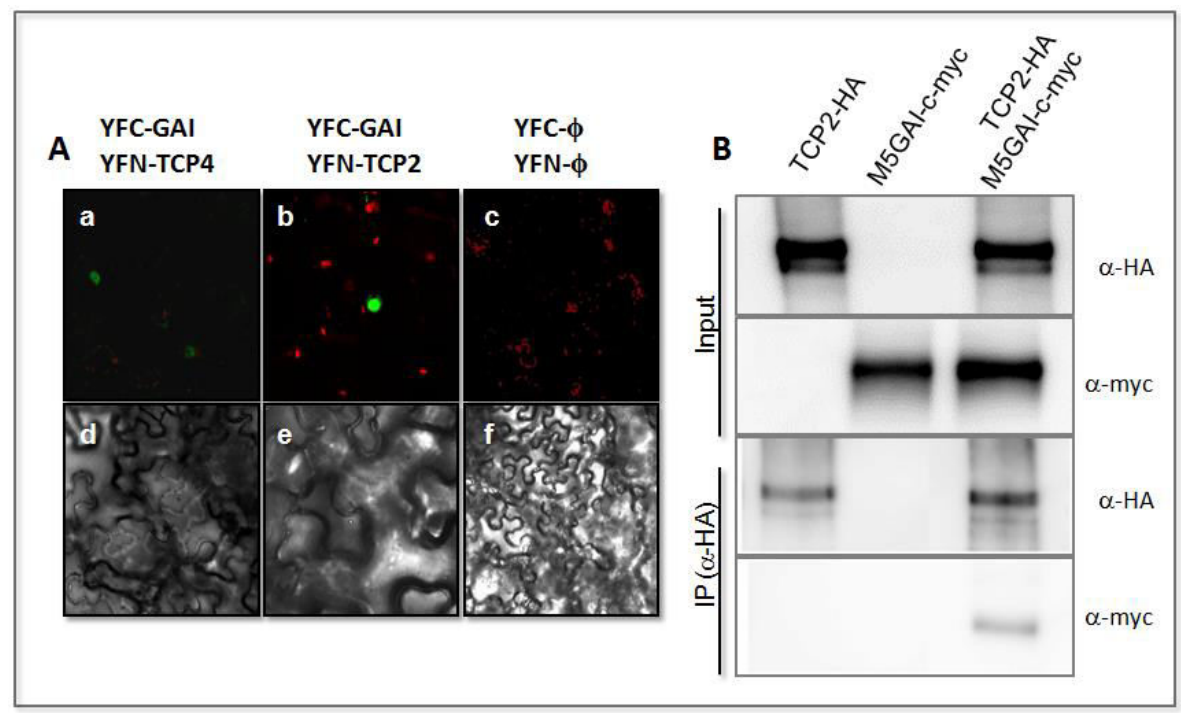

Figure 4.3. CIN-TCPs and DELLA proteins interact in planta. (A) Bimolecular fluorescence complementation analysis showing the interaction of $\operatorname{TCP} 4(a, d)$ and $\operatorname{TCP} 2(b, e)$ proteins with GAI in nuclei of $N$. benthamiana leaf cells. Empty vectors of each construction were used as a negative control (c, f). The lower panel shows the bright field of each picture. (B) Co-IP of M5GAI-myc and TCP2-HA expressed in N. benthamiana leaves. TCP2 was immunoprecipitated using anti-HA $(\alpha-H A)$ conjugated paramagnetic beads, and TCP2 and M5GAl were detected in immunoblots using anti-HA and anti-myc, respectively. Note that M5GAl was coimmunoprecipitated with TCP2. The sizes of the bands correspond to the expected sizes of the fusion proteins.

\section{DELLAs do not regulate CIN-TCPs transcription}

Besides the role of DELLAs regulating CIN-TCPs by physical protein-protein interaction, we wanted to check whether they are also modulating CIN-TCPs at the transcriptional level. To this end, we tried two different approaches, one chemical and one genetic.

\subsection{Chemical approach}

Treatments with GAs and with their biosynthesis inhibitor paclobutrazol (PAC) are widely used to decrease and increase, respectively, the level of DELLA 
proteins in plants (see General Introduction). For this reason, we first treated wild type plants with PAC for 18 and 24 hours, and analyzed TCP2 expression. As it can be seen in Figure 4.4, TCP2 mRNA level does not significantly change in plants treated with PAC respect to the control.

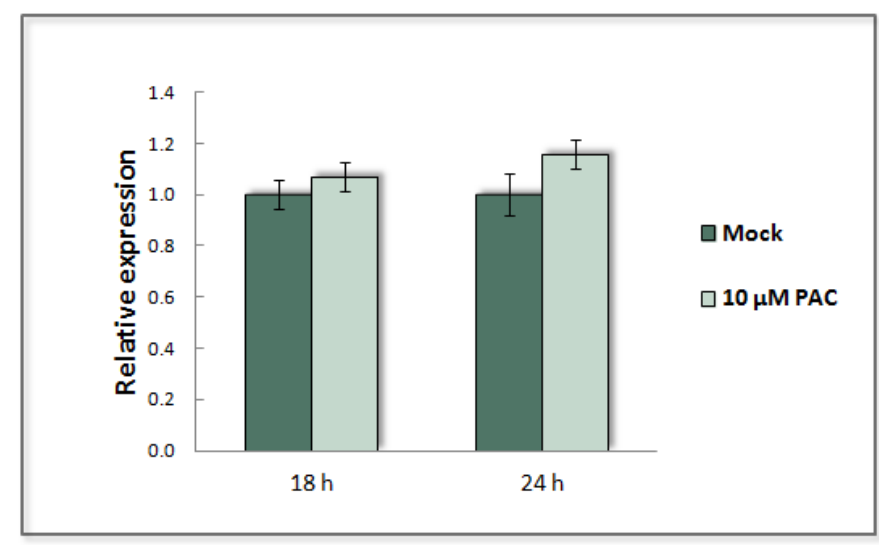

Figure 4.4. Chemical treatments with PAC do not affect TCP2 mRNA level in wild type plants. RT-qPCR experiment indicating TCP2 mRNA level in seven-day-old wild-type (Ler) seedlings treated with $10 \mu \mathrm{M}$ PAC for 18 and 24 hours (light green bars) or mock-treated (dark green bars).

We further corroborated those findings in two types of genetic resources that we prepared as part of this work. On the one side, we used the transgenic lines $p T C P 2:: T C P 2-G F P$ and $p T C P 4:: T C P 4-G F P$ that express a translational fusion of the TCP protein with the GFP under the control of the their endogenous promoters (see Material and Methods). On the other side, we used miR319resistant versions of the TCPs ( $\mathrm{TTCP}$ ) uncoupling then their expression from the down regulation imposed by the microRNA, pTCP2::rTCP2-GFP and pTCP4::rTCP4GFP (see Material and Methods). Therefore, we evaluated TCP2 (Figure 4.5B) and TCP4 (Figure 4.5C) expression in these transgenic lines in response to GA and PAC treatments. We treated 7 day old seedlings of each genotype with $10 \mu \mathrm{M}$ PAC for 18 hours, and then half of them were treated with $100 \mu \mathrm{M} \mathrm{GA}$ for 5 hours whereas the other half remained in PAC for 5 hours (Figure 4.5A). None of the transgenic lines presented significant changes in one condition respect to the other, suggesting that, as in the wild type (Figure 4.4), DELLAs do not regulate $T C P 2$ and TCP4 transcriptionally. 


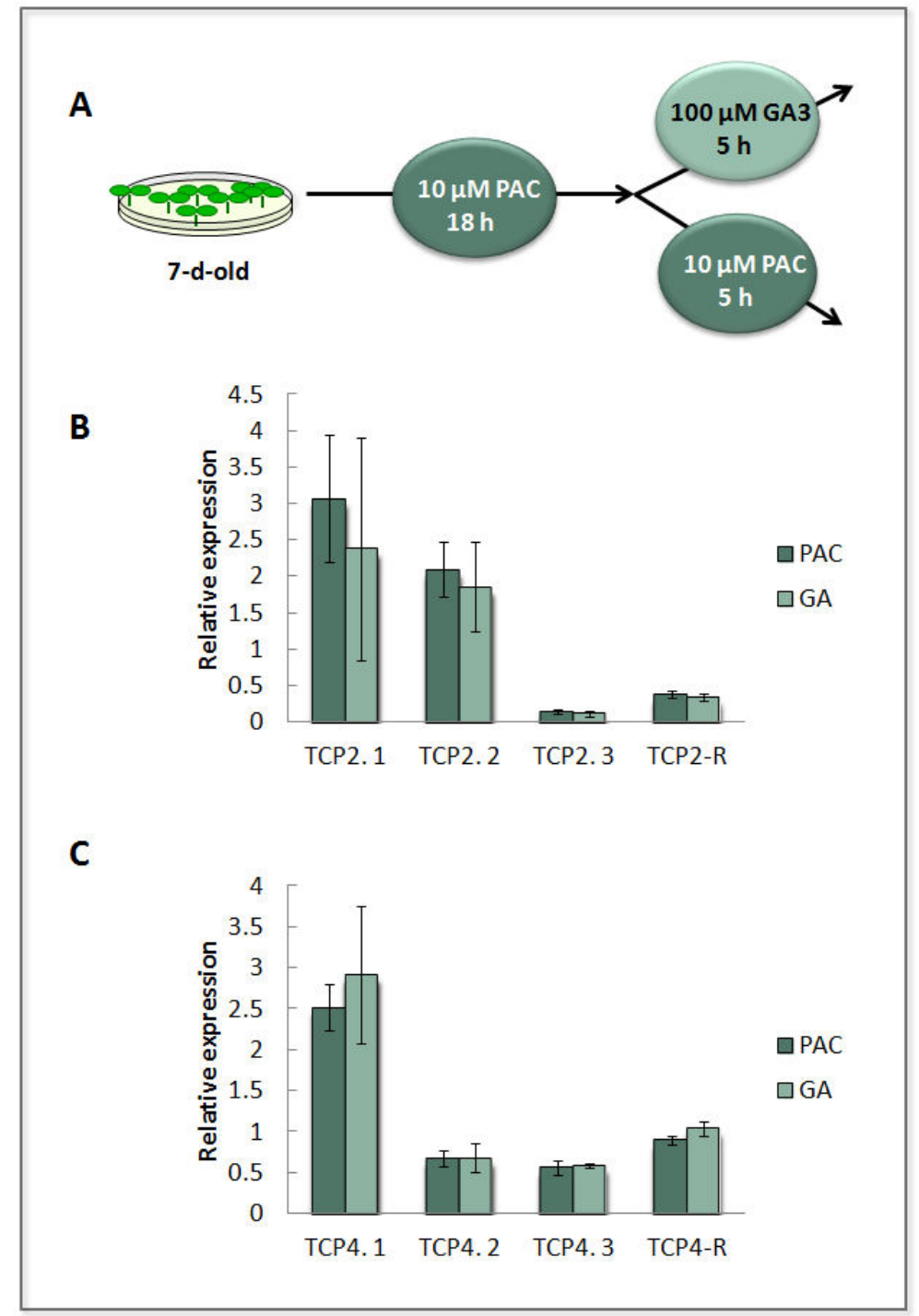

Figure 4.5. Chemical treatments with PAC and GA do not affect CIN-TCP mRNA level in transgenic lines. (A) Scheme of the experimental setting. Seven-day-old seedlings of each genotype are treated with $10 \mu \mathrm{M}$ PAC for 18 hours, then half of them are treated with $100 \mu \mathrm{M} \mathrm{GA_{3 }}$ for 5 hours whereas the other half remain in PAC. Samples are collected and RT-qPCR analysis is performed. A transgenic line carrying the empty vector was used as a control of the experiment. (B) mRNA level of TCP2 in three homozygous lines of the pTCP2::TCP2-GFP (TCP2.1, TCP2.2 and TCP2.3) and the microRNA-resistant $p$ TCP2::rTCP2-GFP (TCP2-R) after PAC (dark green bars) or GA (light green bars) treatment. (C) TCP4 expression level in three different $p$ TCP4::TCP4-GFP (TCP4.1, TCP4.2 and TCP4.3) and pTCP4::rTCP4-GFP (TCP4-R) lines following the same treatments in (B). 


\subsection{Genetic approach}

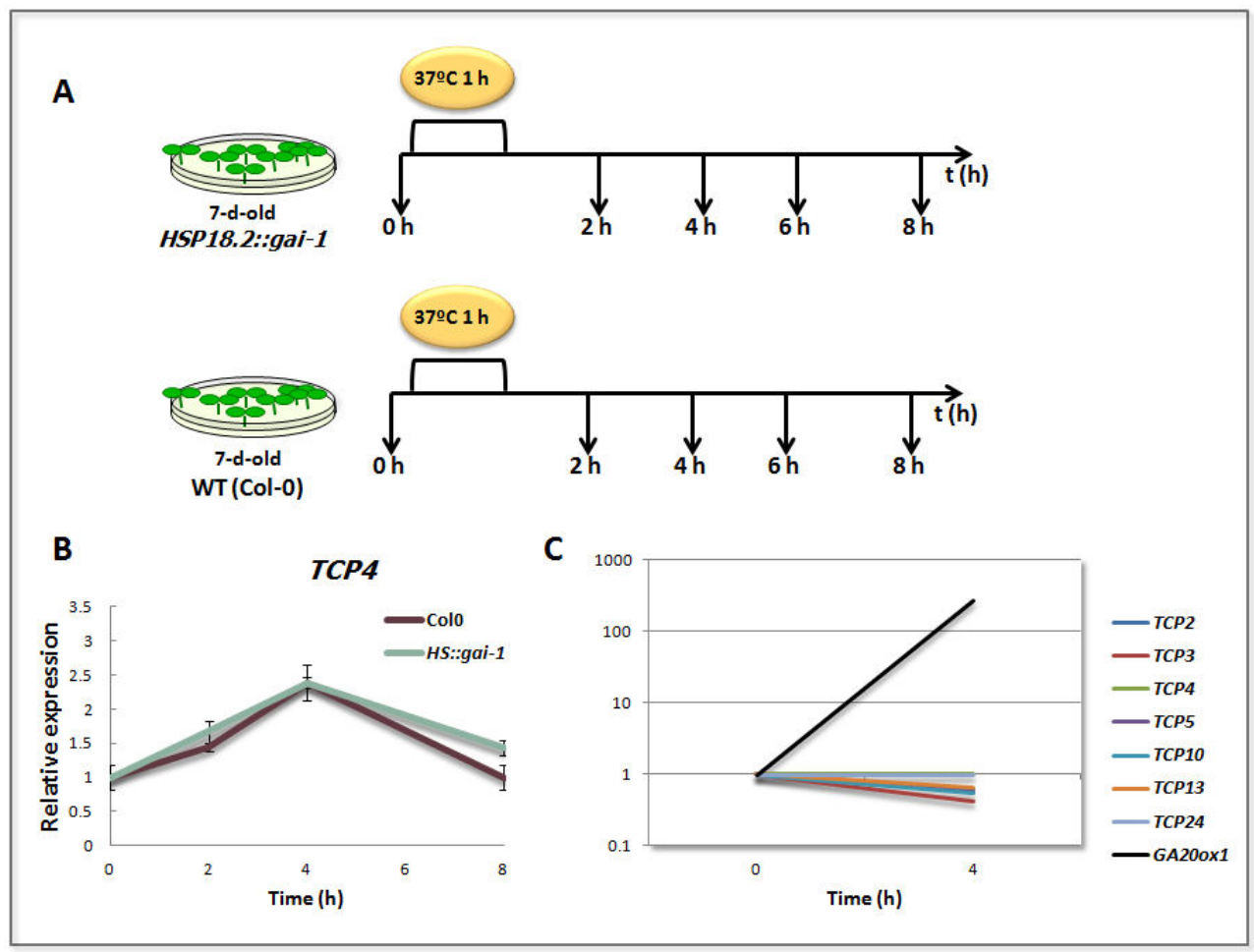

Figure 4.6. DELLA induction does not affect CIN-TCPs mRNA level. (A) Diagram of the experimental setting. In the transgenic line (HSP18.2::gai-1), the dominant version of the DELLA protein GAI (gai-1) is induced by a heat shock (1 hour at 37으). Samples were collected at several time points before and after the heat shock and RT-qPCR analysis was performed. Wild-type (Col-0) plants followed the same procedure as a control. Seven-day-old seedlings of each genotype were used. (B) mRNA level of TCP4 in the control (purple) and the transgenic line (HS::gai-1, green) within all the time-course. (C) Fold change of the mRNA level of several CIN-TCPs 4 hours after gai-1 induction. Data was normalized first to time cero and then to the control line for each time point. GA20ox1 gene is used as a positive control.

To further confirm our previous results, we used a genetic approach. To this end, we used the HS::gai-1 transgenic line that expresses the dominant gain-offunction version of GAl (gai-1) under the control of a temperature inducible promoter (13). We subjected 7-day-old seedlings of control and transgenic lines to 37 ㅇ $\mathrm{C}$ for one hour to induce gai-1 expression. This line has been demonstrated to accumulate gai-1 quickly after the treatment (14), so we decided to test the expression of TCP4 before the heat shock and shortly after it (Figure 4.6A and B). We did not observe differences between the transgenic line and the control 
(Figure 4.6B). Next, we evaluated the expression of several CIN-TCPs at the $4 \mathrm{~h}$ time point, using the expression of the GA20ox1, a bona fide GAl early target (see General Introduction), as a control (Figure 4.6C). As it can be seen in the graph, the expression of none of the CIN-TCPs was severely altered upon gai-1 induction, whereas expression of GA200x1 clearly increased validating the approach.

All in all, these experiments demonstrate that CIN-TCP expression is not altered in response to changes of DELLA levels, indicating that DELLAs regulate CIN-TCP activity post-translationally through the physical interaction of the proteins. These results are in line with a whole body of investigation starting last decade, showing that DELLAs regulate TFs and other transcriptional regulators by interacting with them (15).

\section{DELLAs inactivate CIN-TCPs upon interaction}

DELLAs regulate its TF targets away of the chromatin by a sequestration mechanism or in the context of the target genes (15). Upon interaction, DELLAs can interfere with the DNA-binding capacity of their targets, and so, inhibit their activity by a sequestration mechanism. This is the case for example of the bHLH transcription factors PIFs $(4,5)$. On the other hand, DELLAs can operate in the chromatin as transactivation factors, which is the case of the interaction with ARR1 (12), or can be co-repressors, as described for the interaction with SPL15 (16).To test the effect of DELLA on TCP-mediated regulation of gene expression, we performed transactivation assays in Nicotiana benthamiana leaves.

For this purpose, we designed a synthetic promoter with 6 repeated copies of the Class II TCP consensus binding site (GTGGTCCCA) (17) with a 6-nucleotide spacer (AAAAAA). We cloned the synthetic promoter in a vector under the control of a minimal Cauliflower mosaic $35 \mathrm{~S}$ promoter and the translational enhancer omega to control the expression of the LUCIFERASE (LUC) reporter gene (Figure 4.7A). Then, we co-expressed the synthetic promoter with a translational fusion of TCP4 with the transcriptional activator VP16, taking the basal expression level of the promoter as a control (Figure 4.7B.1). As it can be seen in the graph, VP16TCP4 transcriptional activity caused an increase in the LUC activity respect to the control. Notably, this activation of LUC was partially reversed when GAI was coexpressed, whereas GAI alone did not alter the activity of the reporter. To test whether these results can be extended to other CIN-TCPS, we performed the 
same experiment with VP16-TCP2, with similar results (Figure 4.7C.1). As TCP4 and TCP2 proteins were tagged with HA and the GAI with myc, we could perform a western blot of the same samples. The protein levels of TCPs and GAI were similar in all conditions, ruling out the possibility that changes in LUC activity were due to differences in the expression of the effectors rather than in their activity (Figure 4.7B.2, 4.7C.2).

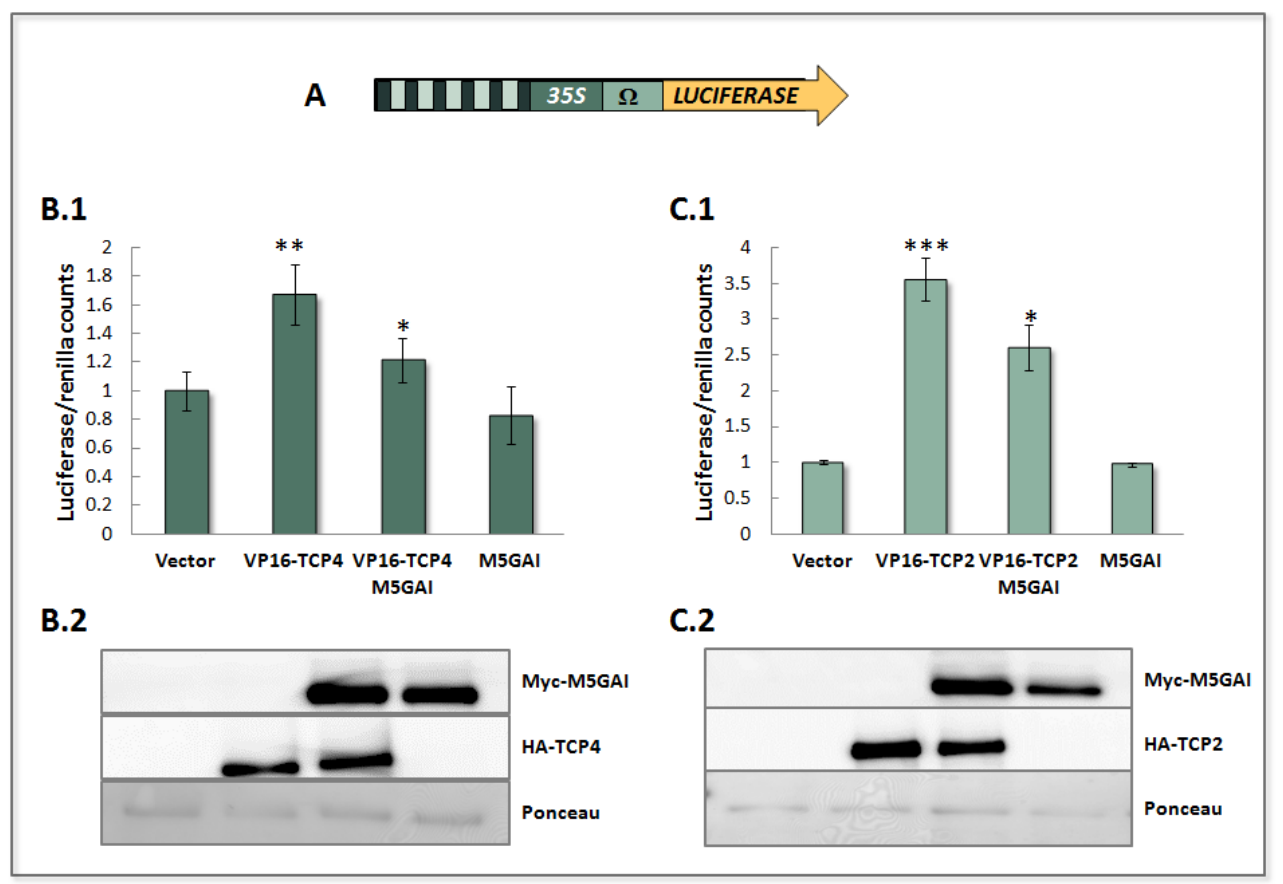

Figure 4.7. GAI inactivates CIN-TCPs upon interaction. (A) Design of the synthetic promoter used for the transient expression assays in $N$. benthamiana leaves. It consist of six repeated copies of the CIN-TCP consensus binding site (dark green boxes) separated by a 6nucleotide spacer (AAAAAA, light green boxes) placed it upstream of a minimal 355 promoter (dark green box) and the translational enhancer omega (medium green box) to control the expression of the Luciferase reporter gene (orange arrow). Renilla Luciferase under $35 \mathrm{~S}$ promoter in the same construct was used as control. (B.1, C.1) Transient expression assays for TCP4 (B.1) and TCP2 (C.1). (Vector, infiltration with the synthetic promoter alone used as a negative control; VP16, transcriptional activator). (B.2, C.2) Western blots corresponding to the transient expression assays for TCP4 (B.2) and TCP2 (C.2). TCPs and M5GAl were detected in immunoblots using anti-HA and anti-myc, respectively. Ponceau was used as a load control. Statistic differences are shown ( $P$ value $<0.05)$.

Altogether, these results indicate that DELLAs inhibit CIN-TCP transcriptional activity upon interaction, probably by preventing the binding to their target 
promoters, in a similar way that they do with PIFs and other TFs $(4,5,15)$. Furthermore, these observations are in line with the studies made with Class I TCPs that are described in Chapter II. What is more, recent work in the laboratory of Patrick Achard demonstrated that DELLAs impair TCPs capacity to bind their target promoters and so, their transcriptional activity (3).

\section{Effect of the interaction in a known target of TCPs in the shoot apical meristem context}

Once we had demonstrated the negative effect of DELLA-CIN-TCP interaction on CIN-TCP transcriptional activity, we investigated whether this regulation occurs in the SAM context. CIN-TCPs are expressed in the primordia (18), where they bind to AS1 promoter and activate its transcription (19). AS1, in turn, represses KNAT1 expression (20-22). In fact, CIN-TCP level in the meristem remain low by the action of miR319 that down-regulates 5 out of 8 CIN-TCPs (18). This way, we have TCPs and AS1 promoting differentiation in organ primordia through KNAT1 inhibition and meristem maintenance by KNAT1 and miR319 (Figure 4.8).

In this context, we wanted to evaluate the effect of the DELLA-CIN-TCP interaction in a known target of TCPs in the SAM context, AS1, i.e. whether DELLAimposed CIN-TCP inhibition reduces AS1 expression. It is important to take into account that induction of gai-1 expression in etiolated HS::gai-1 seedlings caused a decrease in AS1 expression (14), which is in line with our hypothesis. Then, we evaluated whether AS1 expression was also altered upon gai-1 accumulation in our experimental conditions. To do so, we took advantage of our previous experiment with the $H S::$ gai-1 line (section 2.2 of the Results of this Chapter). As it can be observed in Figure 4.9A, AS1 mRNA level continuously decreased in the transgenic line after the heat treatment. 


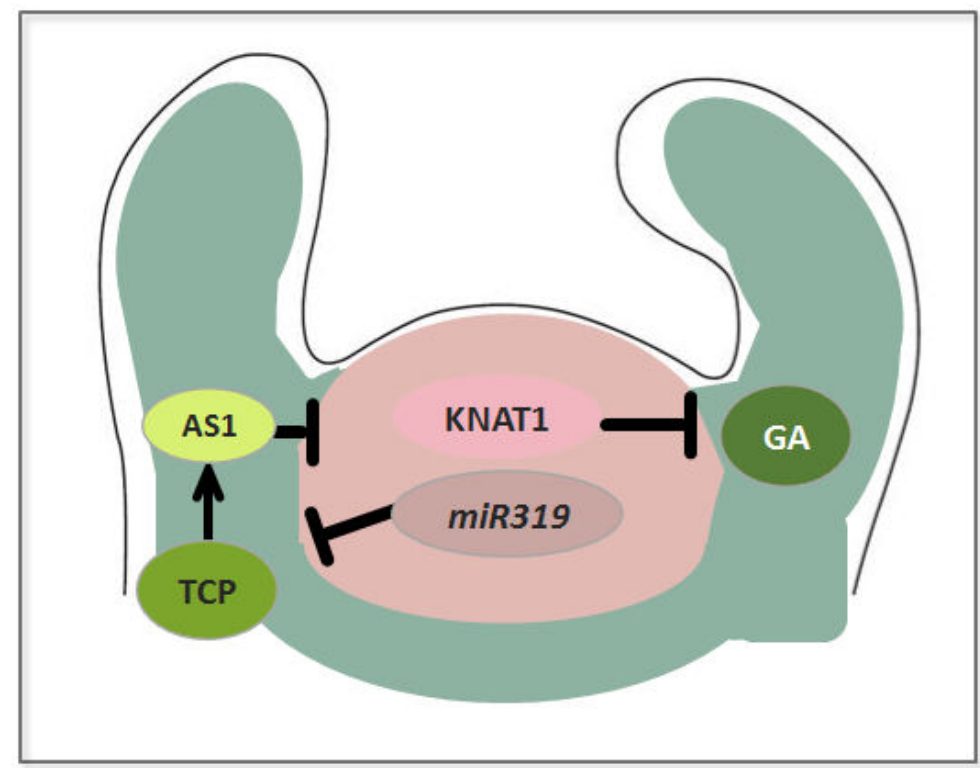

Figure 4.8. Interplay of pro-meristematic (mauve) and pro-differentiation (green) regulators in the transition from the in-determinate SAM to differentiated lateral organs.

To additionally confirm that the effect of DELLA-CIN-TCP interaction on AS1 expression is indeed taking place within the SAM context, we used another strategy to test our hypothesis, we evaluated AS1 expression pattern using the pAS1::GUS transgenic line (23). First, we treated 8 day old seedlings of the pAS1::GUS line with $10 \mu \mathrm{M}$ PAC for 18 hours and then half of the samples followed a $100 \mu \mathrm{M} \mathrm{GA}$ treatment whereas the other half remained in PAC for 5 hours. Seedlings subjected to mock treatment were used as a control (Figure 4.9B, $\mathrm{a}, \mathrm{d}$ and $\mathrm{g}$ ). A significant decrease in AS1 expression can be observed after the PAC treatment, and this effect is reversed when plants were treated with GA. In fact, the expression domain of AS1 after the GA treatment seems to be expanded compared to the mock.

Next, we tested our hypothesis genetically. We analyzed AS1 expression in pAS1::GUS p35S::GAI and in pAS1::GUS pTCP2::rTCP2-GFP transgenic lines in response to the same treatments. In seedlings of the pAS1::GUS p35S::GAI transgenic line (Figure 4.9B, b, e and h), a decrease in the staining could be noticed even in the mock condition and hyper sensibility to the PAC treatment was observed. This effect was reverted by the GA treatment, although to a lesser 
extent than in the wild type background line. In contrast, AS1 expression in mock condition was increased in pAS1::GUS pTCP2::rTCP2-GFP, a transgenic line expressing a microRNA-resistant version of TCP2. Remarkably, this line was more resistant to the PAC treatment and GAs further expanded the AS1 expression domain (Figure 4.9B, $c$, f and i).

Although it is possible that other mechanisms can be involved, these results are in agreement with our hypothesis, which is that DELLAs regulate AS1 expression through the inhibition of CIN-TCPs. 


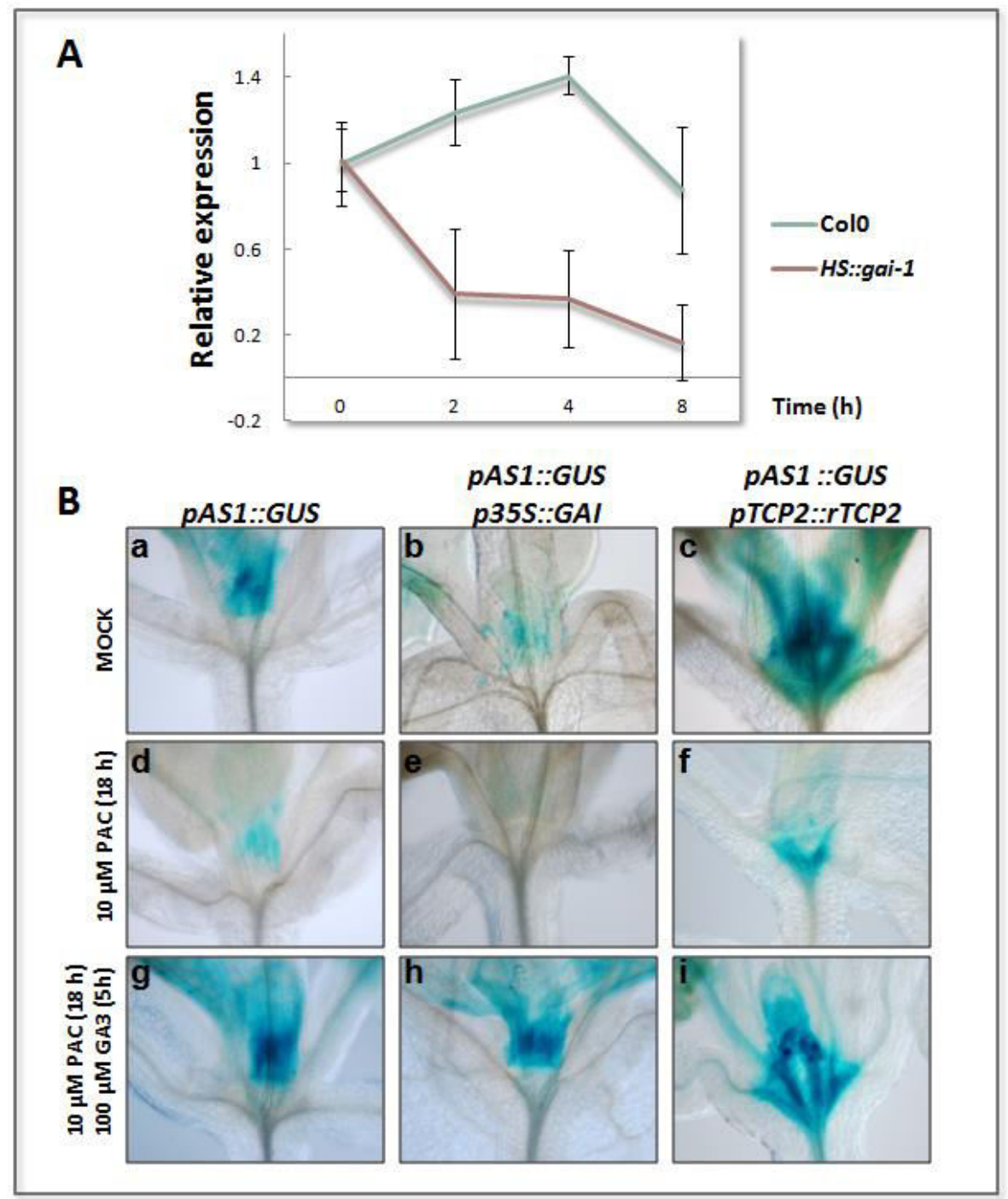

Figure 4.9. DELLAs regulate AS1 expression through the inhibition of CIN-TCPs. (A) AS1 mRNA level continuously decreases in the transgenic line (HS::gai-1, purple line) when the dominant version of the DELLA protein GAI (gai-1) is induced by a heat shock (for a diagram of the experimental setting see Figure 4.6A). Wild-type (Col-0) plants followed the same procedure as a control (light green line). Seven-day-old seedlings of each genotype were used. (B) The expression pattern of AS1 depends on the activity of DELLA proteins. The transgenic lines pAS1::GUS $(\mathrm{a}, \mathrm{d}, \mathrm{g})$; pAS1::GUS p35S::GAl (b, e, h) and pAS1::GUS pTCP2::rTCP2 (c, $\mathrm{f}, \mathrm{i})$ are used to carry out GUS staining assays. AS1 expression pattern is evaluated in three different conditions: mock (a, b, c); plants treated with PAC for $18 \mathrm{~h}(\mathrm{~d}, \mathrm{e}, \mathrm{f})$ and plants in PAC for $18 \mathrm{~h}$ followed by a GA treatment for $5 \mathrm{~h}(\mathrm{~g}, \mathrm{~h}$, i). Seven to ten-day-old seedlings of each genotype were used in both experiments. Images are representative of four independent biological repeats including 20 seedlings per genotype. 


\section{Effect of the interaction in a downstream target: a KNOX} gene

According to previous results, the inhibition that DELLAs exert on CIN-TCP activity upon interaction seems to have a regulatory role in the SAM given the known role that CIN-TCPs and AS1 exert in this tissue. The fact that DELLAs impair the function of these pro-differentiation factors suggests that DELLAs would act as pro-meristematic factors in this scenario. This idea is line with the current knowledge that GAs promote cell differentiation in organ primordia and that they are excluded from the SAM (see Introduction of Chapter I). Therefore, we investigated whether the DELLA-CIN-TCP module could be affecting the activity of the pro-meristematic KNOX genes. Since KNAT1 is a known target of AS1, we evaluated whether AS1 regulation by DELLAs has consequences in KNAT1 expression. We used the pKNAT1::GUS transgenic line (24) to check whether KNAT1 expression depends on the level of DELLA proteins. To do so, two different approaches were taken. On the one hand, we tested our hypothesis genetically. The pKNAT1::GUS p35S::GAl transgenic line was generated, and GUS staining assays in these seedlings as well as in the pKNAT1::GUS line were carried out (Figure 4.10, a-f). On the other hand, pKNAT1::GUS seedlings were subjected to chemical treatments: plants were treated with PAC to induce DELLA accumulation and with a PAC plus GAs to reduce DELLA levels. Seedlings in mock were used as a control of the normal KNAT1 expression domain (Figure 4.10, d-I). Interestingly, KNAT1 was over-expressed and its expression domain seemed to be expanded in response to high DELLA level (pKNAT1::GUS p35S::GAl and plants treated with PAC), whereas KNAT1 expression decreased when DELLA levels were low (GA treatment), which is in agreement with our hypothesis.

According to these results, it is reasonable to think that DELLAs might regulate KNAT1 expression through the inhibition of CIN-TCPs (and consequently AS1) within the SAM context. Therefore, DELLAs would act favoring meristem maintenance through the promotion of KNAT1 expression. 


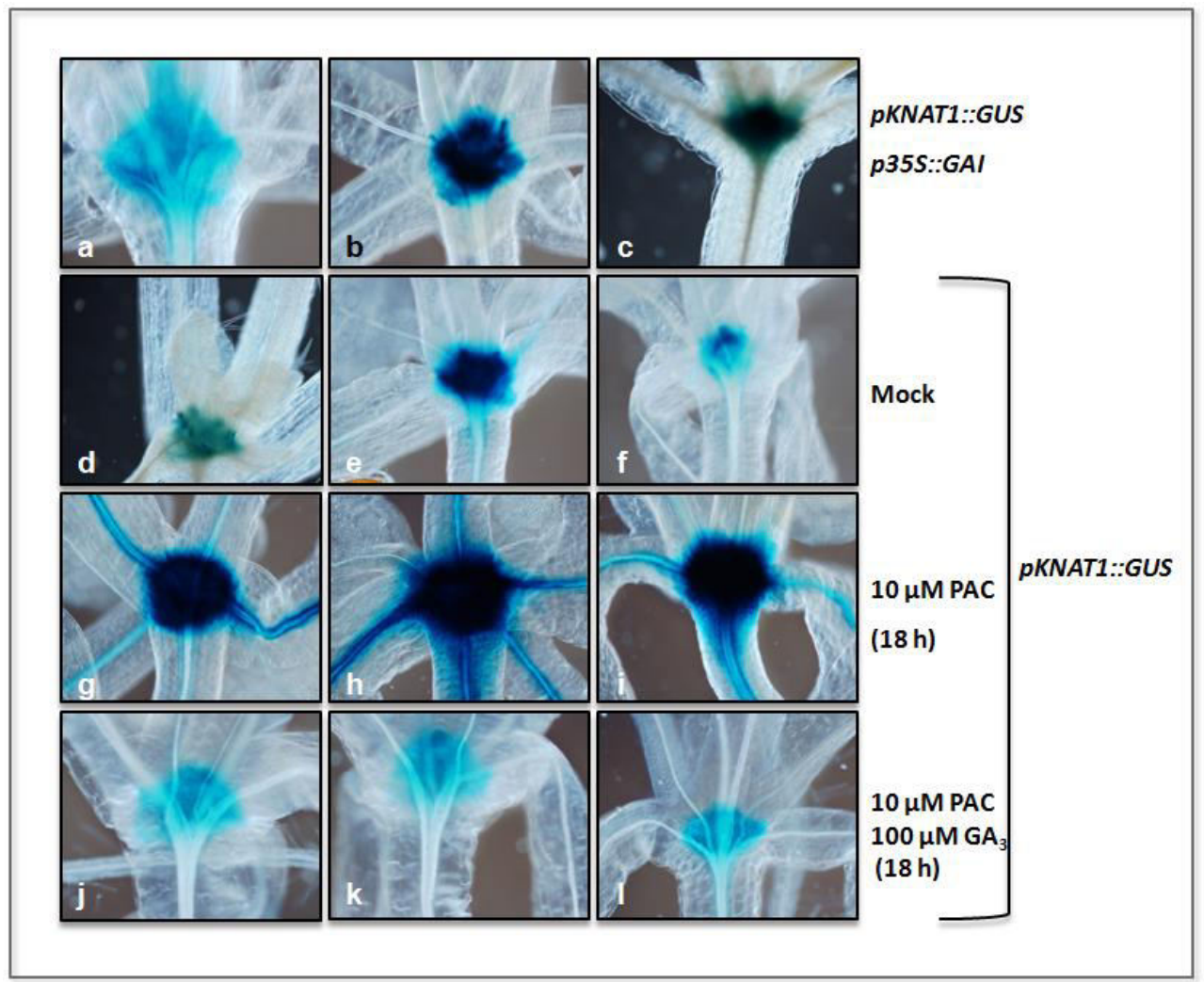

Figure 4.10. DELLAs regulate KNAT1 expression. The expression pattern of KNAT1 depends on the activity of DELLA proteins. The transgenic lines pKNAT1::GUS (d-I) and pKNAT1::GUS p35S::GAl (a-c) are used to carry out GUS staining assays in seven to ten-day-old seedlings. KNAT1 expression pattern is evaluated in mock (a-f), $10 \mu \mathrm{M}$ PAC (g-i) and $10 \mu \mathrm{M}$ PAC plus $100 \mu \mathrm{M} \mathrm{GA}$ for 18 hours. Three seedlings per genotype or treatment are shown. Images are representative of three independent biological repeats including 15 seedlings per genotype.

\section{DELLAs and KNAT1 expression patterns}

Our results indicate that DELLAs promote KNAT1 expression, in agreement with the inhibition by DELLAs of negative regulators of KNAT1. However, for this effect to be biologically relevant, it needs to be placed in the context of the spatial accumulation of the corresponding proteins. For that reason, our next aim was to unravel the specific location of these transcripts and proteins in the vegetative SAM.

Our first step was to assess GAI, RGA and KNAT1 expression patterns. To do so, we used GUS reporter lines lines pKNAT1::GUS (24), pGAl::GUS and pRGA::GUS 
(25); we carried out GUS staining assays in 7 to 10 day old seedlings of the three genotypes (Figure 4.11). As it can be seen in the figure, GAI and RGA are expressed in the meristematic zone, cotyledons and primary leaves, and also in the root vasculature and especially near the root tip. However, KNAT1 expression pattern seem to be restricted to the shoot apex meristematic zone. Focusing on this zone (Figure 4.11B), it can be seen that the overlapping zone is located in the vegetative meristem. Besides, the observed expression pattern of KNAT1 is in agreement with the literature, that establishes that in species with simple leaves, such as Arabidopsis, Class I KNOX gene expression, such as that of KNAT1, is only found in the shoot meristem and subtending stem and is not found during any stage of leaf development. KNAT1 expression disappears in the meristem cells that are destined to be the next leaf (26). 


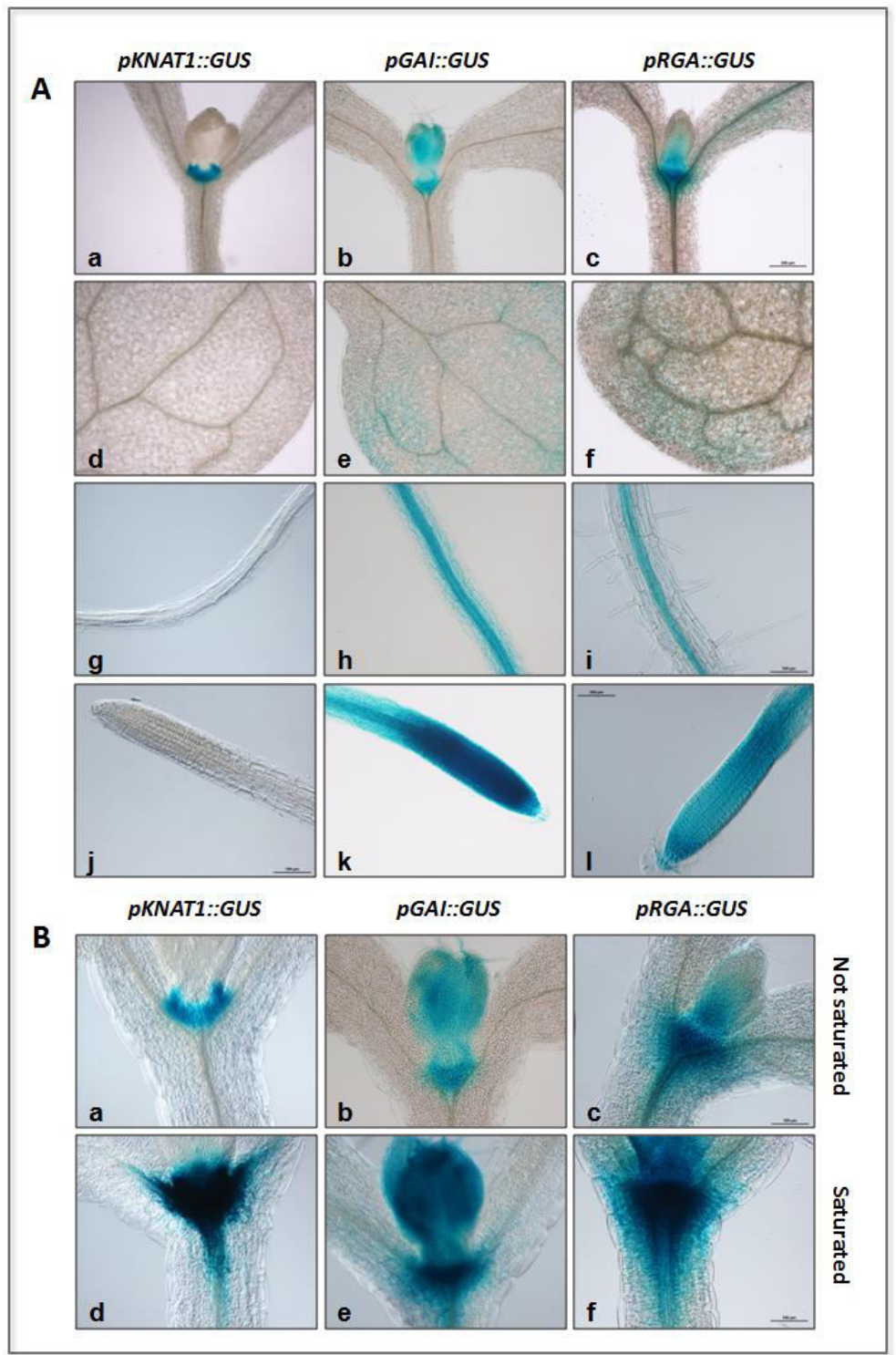

Figure 4.11. DELLAs and KNAT1 expression patterns overlap. The expression domains of $\operatorname{KNAT1}$ (A. a, d, g, j; B. a, d), GAl (A. b, e, h, k; B. b, e) and RGA (A. c, f, i, l; B. c, f) were evaluated by GUS staining assays in seven to ten-day-old seedlings. (A) Meristem zone (a, b, c); cotyledon (d, e, f); middle part of the root $(g, h, i)$ and root tip $(j, k, l)$ are shown. (B) Zoom on the vegetative meristem in not saturated $(a, b, c)$ and saturated $(d, e, f)$ conditions. Images are representative of three independent biological repeats including 15 seedlings per genotype. 


\section{Localization of KNAT1 and RGA proteins in the vegetative shoot apical meristem}

As described previously, there is a complex regulation between the promeristematic and pro-differentiation factors in the apical meristem (see Introduction of Chapter I). Stem cells in the central zone of the SAM undergo cell division and their daughter cells are displaced towards the periphery where they can start the differentiation process. In this situation, the boundaries between the cells expressing or not expressing KNOX genes become very important for plant development. Once we have established that DELLAs and KNAT1 expression patterns overlap in the meristematic region, our next goal was to precisely localize the proteins in the SAM. Localizing DELLA and KNAT1 proteins in this region would provide us with important information about their possible function in this regulatory network.

To this end, we generated $p R G A:: R G A-G F P$ pKNAT1::KNAT1-CFP transgenic lines and analyzed the localization of both proteins in the vegetative SAM. For confocal microscopy observations, we established collaboration with Dr. Antonio Serrano-Mislata and Prof. Robert Sablowski in the John Innes Centre in Norwich, UK. As it can be seen in Figure 4.12, RGA (green) and KNAT1 (blue) indeed colocalized in the SAM but not uniformly. Thus, $p R G A:: R G A-G F P$ signal was clearly weaker in the central region, becoming stronger towards the periphery, while pKNAT1::KNAT1-CFP fluorescence accumulated preferably in the central zone of the shoot apical meristem.

These results point out the idea that DELLA proteins would primarily perform a role in the boundary regions of the SAM, where the DELLA-CIN-TCP interaction could take place. For instance, in situ hybridization experiments demonstrated that TCP4 is mainly expressed in leaf primordia of Arabidopsis seedlings (18), suggesting that this boundary region could be where DELLA and CIN-TCP expression patterns mostly overlap. The activity of KNAT1 preventing GA accumulation in the boundary region will facilitate the presence of DELLAs. Then, in that frontier, DELLAs would inhibit the CIN-TCP/AS1 module, therefore promoting KNAT1 expression in a region where its negative regulators start to be present and probably establishing the boundary zone from which KNAT1 expression gets progressively stronger towards the center of the meristem. DELLAs, therefore, may help establishing the boundary between the meristematic 
and the differentiation zone in the SAM guaranteeing the proper spatial KNAT1 expression pattern.

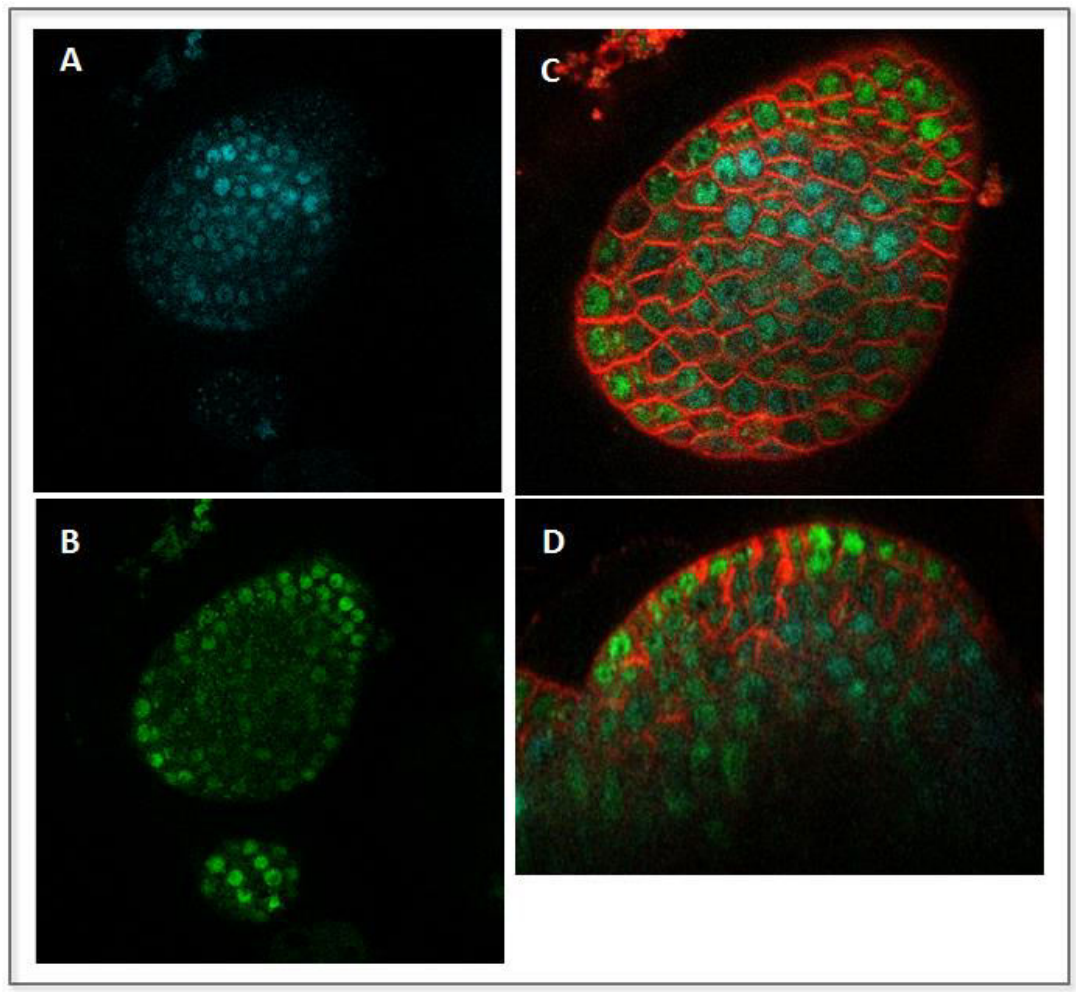

Figure 4.12. Localization of RGA-GFP and KNAT1-CFP proteins in the SAM. Fluorescence of $p R G A:: R G A-G F P$ pKNAT1::KNAT1-CFP lines, green and blue, respectively, was detected by confocal microscopy of shoot apices stained with FM4-64 (red). Meristems were from 9 day-old F1 seedlings grown at $22^{\circ} \mathrm{C}$ and continuous light. (A,B) Splitted channels of the same stack for detection of KNAT1-CFP (a) and RGA-GFP (b). (C) Merge of both signals. (D) Orthogonal view, merged channels. Images are representative of three independent biological repeats.

Thus, our results suggest that there is a mutual negative regulation between KNAT1 and GAs to maintain meristem homeostasis, which is represented in Figure 4.13. The localization of the RGA and KNAT1 in the SAM implies a complex regulation between pro-meristematic and pro-differentiation factors in this context. It is also highlighted the possible role of DELLAs in the boundary of the meristem, where they would ensure KNAT1 expression by inhibiting its negative regulators (CIN-TCPs and AS1). 


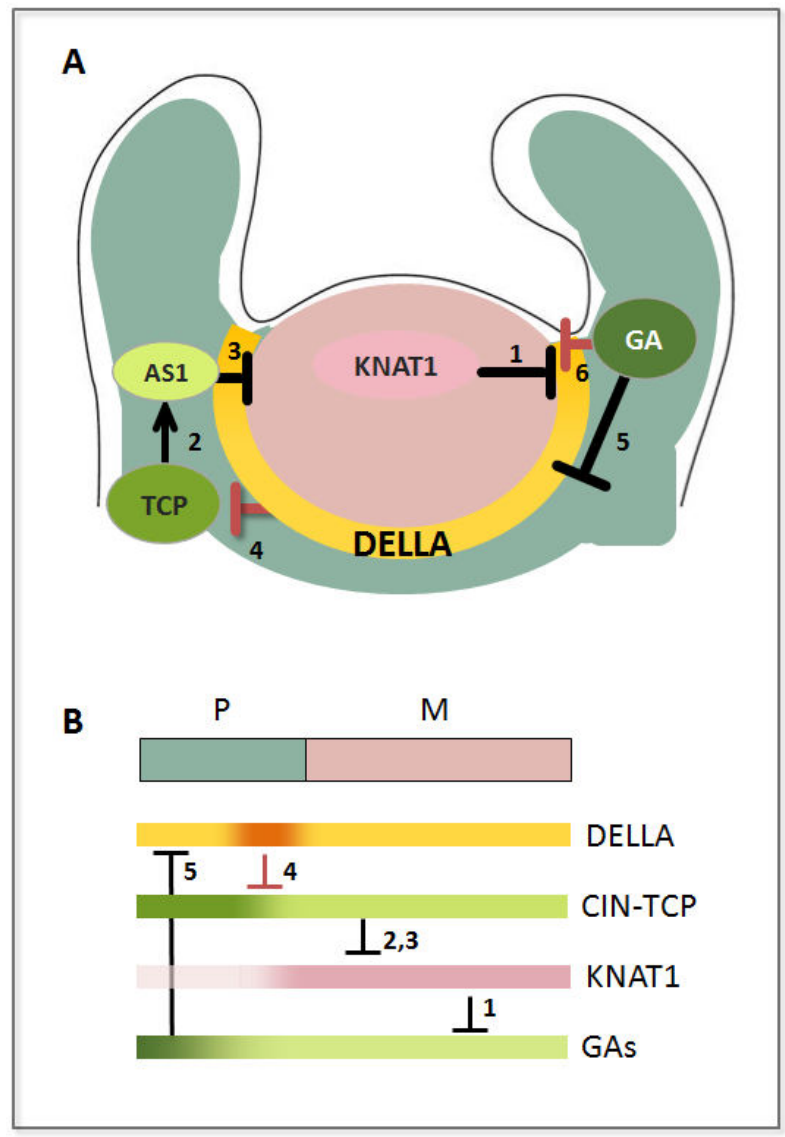

Figure 4.13. Summary of the molecular and genetic interactions observed at the SAM. Graphical (A) and schematic (B) representation of the GA/KNAT1 regulatory module. The promeristematic factor KNAT1 (in mauve) is found in the un-differentiated zone (mauve zone (M)), where it represses GA biosynthesis and promotes its deactivation (1). On the other hand, prodifferentiation factors GAs, CIN-TCPs and AS1 (in green) are located in the primordia (blue zone (P)), where they promote cell specification by repressing KNAT1 expression. CIN-TCPs are known to activate AS1 expression (2), which is a known repressor of KNAT1 (3). Results in this Thesis indicate that DELLAs (in yellow) interact with CIN-TCPs, probably in the meristematic-differentiation frontier, inhibiting CIN-TCP transcriptional activity, and therefore, they could guarantee KNAT1 expression in that boundary, where its negative regulators star to be present (4). As higher level of GAs (that lead to DELLA degradation (5)) is found in the primordia, DELLA function could be specially relevant controlling the extent of KNAT1 expression in the boundary of the un-differentiated zone. This way, there is a mutual negative regulation between KNAT1 and GA (6) that could help to modulate the interplay between meristematic and differentiation factors to maintain meristem homeostasis. In (B), intensity of the color indicates accumulation of the protein or molecule. Lines and arrows in black indicate literature data; in red, results of this Thesis. 
On the other hand, it is remarkable that, as depicted in Figure 4.12, RGA protein accumulation decreased towards the center of the meristem. This suggests that there should be other mechanisms that operate in the center of the meristem taking over the role of DELLAs. For instance, the presence of miR319 causes a down-regulation of CIN-TCPS (18). Other interesting question derived from this observation was how RGA levels decreased in the center of the SAM. Since KNAT1 guarantees a GA-free environment in the meristem, transcriptional but not post-transcriptional regulation of DELLAs should be important in this zone. Therefore, there must be factors in the meristematic zone that could inhibit DELLA expression.

\section{The GA/KNAT1 balance regulates cell expansion in the shoot apical meristem}

Once we have established that there seem to be a mutual negative interaction between KNAT1 and GAs in the meristem context to balance meristem homeostasis, our next aim was to unravel the SAM characteristics regulated by this GA/KNAT1 balance.

It has been described that GAs play a relevant role in the transition from vegetative to reproductive meristem, which is characterized by an increase in the size of the meristem (27). In this line, although a lot of recent work has been focused on unraveling the molecular pathways involving KNOX genes such as KNAT1 (28), no attention has been paid to its possible role in the regulation of meristem size. Taking into account these observations and our previous results indicating the regulation that DELLAs exert on KNAT1, we wondered whether the GA/KNAT1 module could regulate meristem size.

To this purpose, we measured the cell number, and cell and meristem volume of 9 day old wild type and KNAT1 mutant seedlings (called $b p-1$ (29)) treated or not with GAs. Remarkably, thanks to our collaboration, we used a novel technique implemented in the laboratory of Prof. Sablowski (30). To track cell number and volume, we used confocal imaging of vegetative apices and then a package of Python scripts and Fiji macros were applied to the images to landmark, segment, locate and measure cells in 3D, covering all the volume of the meristem (Figure 4.14A). Another step of manual treatment of the data was applied to delete cells that were incorrectly segmented. 


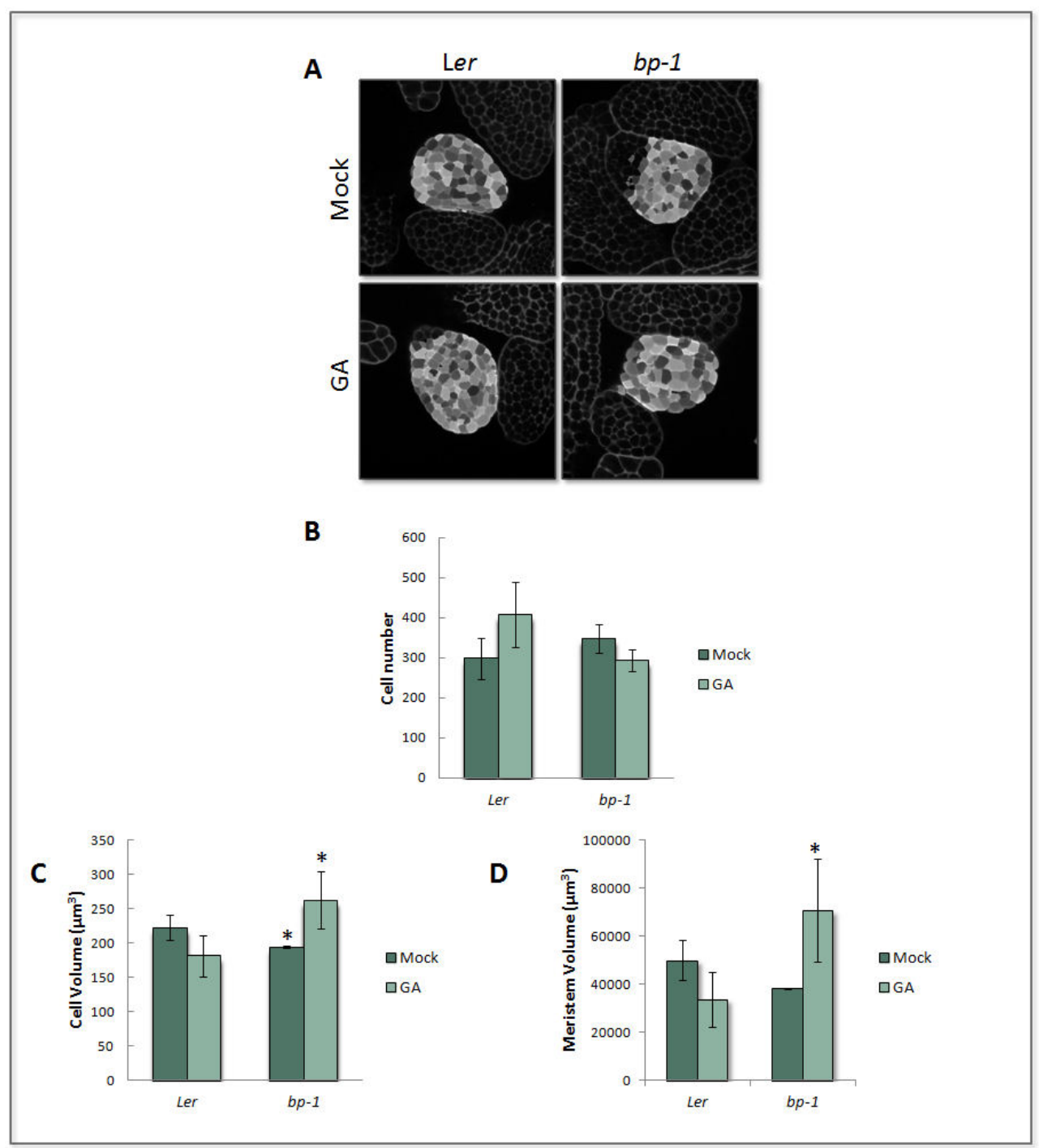

Figure 4.14. The GA/KNAT1 module regulate SAM size. Confocal microscopy images of vegetative meristems of 9 day old seedlings grown in continuous light of the depicted genotypes were in silico analyzed. GA-treated plants were maintained in $50 \mu \mathrm{M} \mathrm{GA}$ since sowing. (A) Stack of each condition at the same point of the Z-axis (stack 30). Confocal microscopy image and in silico segmentation image overlap is shown. (B) Cell number, (C) cell volume and (D) meristem volume of the indicated genotypes and conditions are depicted. Three to five replicates per apex were analyzed. Statistic differences between mock conditions in both genotypes and between the GA and the mock condition in each genotype are shown ( $P$-value<0.05). 
As it can be seen in Figure 4.14B, neither KNAT1 nor GA treatment affected cell number in the meristem, suggesting that none of these factors regulates cell division in the context of SAM development. However, cell and meristem volume seem to be modulated by both factors. Meristem cells in the KNAT1 mutant ( $b p-1)$ were slightly smaller than in the wild type (Figure 4.14C). Furthermore, GA treatment does not affect cell volume in the wild type, whereas it has an impact on cells of the $b p-1$ mutant, as their cell volume is increased. This higher cell volume is reflected in an increased meristem volume in $b p-1$ (Figure 4.14D). The fact that the $b p-1$ mutant presents a slightly smaller meristem than the wild type indicates that KNAT1 could contribute to cell volume. This result is in line with the observation that KNAT1 expression increases during the transition from vegetative to reproductive meristem (eFP Browser (31)), in parallel with a significant increase in meristem size (27).

On the other hand, KNAT1 renders the meristem insensitive to GAs, since only the $b p-1$ mutant (deficient in KNAT1 activity) responded to applied GAs (Figure $4.14 \mathrm{C}$ and $\mathrm{D}$ ). In this sense, it is important to remember that KNAT1 represses GA biosynthesis and promotes GA deactivation in the SAM (see Introduction of this Chapter), excluding GAs from that zone. This way KNAT1 would protect the meristem from the effect of GAs, maintaining an adequate meristem volume. On the other hand, results in this Thesis indicate that GAs have a negative effect on KNAT1 expression, probably due to the fact that the DELLACIN-TCP interaction inhibits the transcriptional activity of TCPs and therefore, promotes KNAT1 transcription. Hence, in the SAM, there is a balance between GA and KNAT1 to maintain meristem homeostasis in relevant aspects, such as meristem size (Figure 4.15).

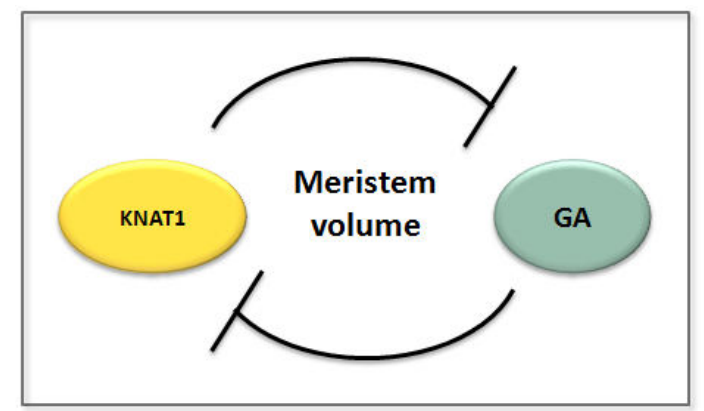

Figure 4.15. The GA/KNAT1 regulatory module ensures meristem homeostasis in relevant aspects such as meristem volume. 
Interestingly, KNAT1 seems to have a dual role in the regulation of cell expansion, and consequently, meristem size. On the one hand, it could promote cell expansion, as meristem volume of the mutant is significantly smaller than the wild type (Figure 4.14.1). On the other hand, it renders the meristem insensitive to GAs, which could be important to prevent excessive growth under conditions when GA flow towards the SAM increases, such as during the transition to flowering (27). All in all, these data strongly supports the idea that DELLAs and KNAT1 constitute an important regulatory network in the SAM context destined to maintain a correct meristem size by controlling cell expansion by a feedback mechanism (Figure 4.15).

Additionally, we evaluated whether DELLAs are found in inflorescence meristems, and therefore, the KNAT1/DELLA module of regulation could be taking place also in this stage. To do so, we performed in situ assays in inflorescences of three to four week old plants to evaluate the endogenous expression of the DELLA GAI (Figure 4.16). According to our results, GAl expression can be also found in the inflorescence meristem, suggesting that the mechanism described can be also functional at that stage and organ after the induction of flowering. In this line, KNAT1 expression in inflorescence meristems has also been described $(26,31)$. 


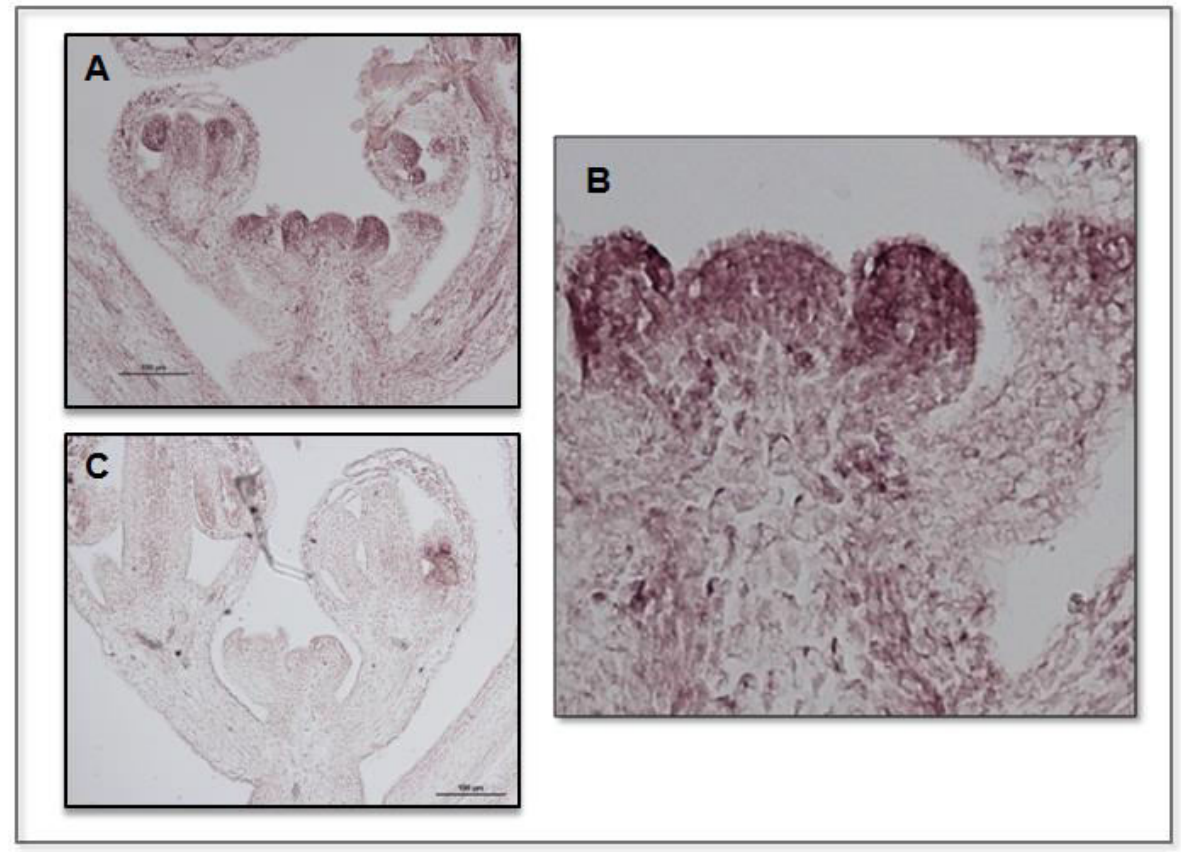

Figure 4.16. DELLA $G A I$ is expressed in inflorescence meristems. In situ hybridization of $G A l$ in longitudinal slices of inflorescences of 3 to 4 weeks Col-0 plants. Antisense (a, b) and sense (c) probes are shown. A zoom of the shoot apical meristem can be observed in (b).

\section{Unraveling KNAT1 function at the genomic level}

Previous results point out the importance of KNAT1 modulating meristem size. Although the implications of this gene in plant development have been extensively studied, information about its specific downstream targets or the molecular processes regulated by KNAT1 is still lacking (28). To further unveil possible KNAT1 biological functions, a RNA-sequencing (RNA-seq) experiment was done. Additionally, to test a possible implication of DELLAs in the KNAT1-driven regulation, the experiment was done in response to different DELLA levels. 


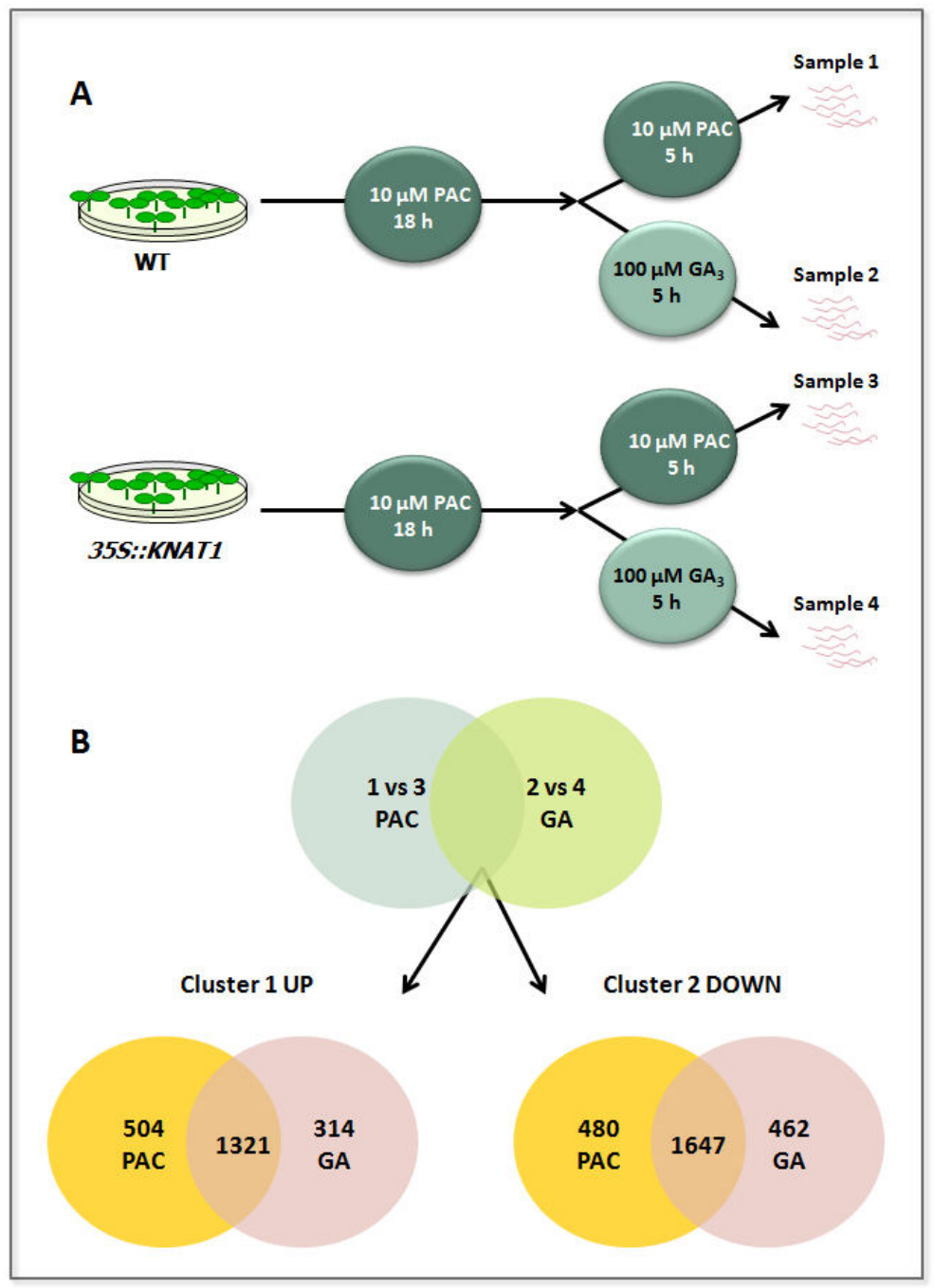

Figure 4.17. RNA-seq experiment. (A) Diagram of the experimental setting. Seven day old seedlings of wild type (No-O) and 35S::KNAT1 genotypes were treated with $10 \mu \mathrm{M}$ of PAC for 18 hours. Then, half of them followed a $100 \mu \mathrm{M} \mathrm{GA}_{3}$ treatment whereas the other half remained in PAC for 5 hours. Samples (named as sample 1 to 4) were collected and RNA-seq data was obtained. Three biological replicates were used for the analysis. (B) Scheme of the in silico analysis, which compared samples in the same chemical treatment (sample 1 versus sample 3 and sample 2 versus sample 4) to highlight KNAT1 targets. This initial cluster is subdivided in two: targets up-regulated by the presence of KNAT1 over-expressor were organized in Cluster 1 and the KNAT1 down-regulated targets in Cluster 2. Each cluster renders three different datasets of KNAT1 targets: DELLA-presencedependent targets (504 UP and 480 down), DELLA-absence-dependent targets (314 UP and 462 DOWN) and KNAT1 targets that are independent of DELLA presence or absence, that is the overlapping zone of both previous datasets (1321 UP and 1647 DOWN). 
In particular, we treated seedlings of the KNAT1 over-expressor transgenic line 35S::KNAT1 (32) and its wild-type control No-O with PAC for 18 hours to ensure the accumulation of DELLAs. At that point, half of them were subjected to GA treatment whereas the other half remained in PAC. This way it is possible to compare between two different situations, one with a high level of DELLA (PAC) and other where the degradation of DELLA is promoted (GA). As a result, 4 different samples were obtained and processed to obtain sequencing data for each one of them (see Material and Methods) (Figure 4.17.A). Regarding the in silico analysis, samples in the same chemical treatment (sample 1 versus 3 and sample 2 versus 4) were compared to detect KNAT1 targets in each condition. Thus, the differential expression of these targets is due to the presence of the KNAT1 over-expressor, not to the chemical compound. To simplify the analysis, this initial clustering is further subdivided in two attending to the up-regulation (Custer 1 ) or down-regulation (Cluster 2) of the targets in response to KNAT1 over-expression (Figure 4.17.B). Thus, for each cluster, this analysis renders three different sets of KNAT1 targets. First, targets altered only when DELLAs are present (PAC, DELLA-presence-dependent targets) that include 504 up- and 480 down-regulated genes. Second, a set of differentially expressed targets only when DELLAs are absent (GA, DELLA-absence-dependent targets), that renders 314 upand 462 down-regulated targets. Finally, a third set of genes that are KNAT1 targets independently of the presence or absence of DELLAs, that is the overlapping zone of both previous datasets (KNAT1 DELLA-independent targets), with 1321 up- and 1647 down-regulated genes (Figure 4.17.B). The complete datasets can be found in the Supplemental Folders "Cluster 1 " and "Cluster 2".

Once the sequencing data was obtained and organized, we pursued three different goals in the following analysis, which we elaborate in the next sections. First, we compare our results with literature data, and then we analyze the DELLAindependent and DELLA- dependent KNAT1 targets found in our RNA-seq experiment.

\subsection{Comparison with literature data}

KNOX genes have been studied for decades and, despite the deep appreciation for the importance of these genes in plant development, we know very little about the genes under KNOX regulation. To gain further understanding of KNOX gene function and possible KNAT1 biological roles, we decided to carry 
out a bibliographical research on genome-wide studies in KNOX genes and compare this data with our results. Remarkably, two recent articles from the group of Dr. Hake have investigated on this topic $(33,34)$. In both articles, RNAseq and ChIP-sequencing technologies are combined to identify genes differentially expressed in response to the KNOX genes KNOTTED1 (KN1) in maize (34) and Oryza sativa homeobox1 (OSH1) in rice (33). As a result, we could obtain three datasets: one from the maize ChIP-seq experiment, one from the ChIP-seq in rice and finally, one from the RNA-seq in rice.

As the genomic data was found in different species from Arabidopsis, before the comparison with our data we carried out a plant comparative genomic study with the tool PLAZA (35). This bioinformatic platform integrates numerous types of information (e.g. gene families, phylogenetic trees and genomic homology) along with structural and functional annotation, and, with this information, it provides the most probable ortholog among two species. Using this tool, we searched for the orthologs in Arabidopsis of the targets of KNOX genes in maize and rice. As the methodology holds some limitations, not all the targets were assigned, and sometimes the same Arabidopsis gene was assigned to various original targets (duplications). Nevertheless, a considerable amount of orthologs were found (Table 4.1). The complete datasets can be found in the Supplemental File "PLAZA orthologs".

\begin{tabular}{|c|c|c|c|c|c|}
\hline \multicolumn{6}{|c|}{ Table 4.1. Comparative genomic study with PLAZA } \\
\hline & & Original targets found & Assigned orthologs & Duplications & Unique targets in Arabidopsis \\
\hline Maize & ChIP-seq & 277 & 277 & 62 & 215 \\
\hline \multirow{2}{*}{ Rice } & RNA-seq & 1473 & 1192 & 282 & 910 \\
\hline & ChIP-seq & 4662 & 4324 & 3715 & 609 \\
\hline
\end{tabular}

Once the different data sets of orthologs are available, our aim in this first analysis was to evaluate which functions of KNAT1 could be shared with other KNOX genes in other species. To do so, we searched for common targets among the orthologs of these published studies and our candidates in the RNA-seq. In particular, we included all the KNAT1 targets found in our analyses, independently of the DELLA level. That is 504+1321+314 in Cluster 1 and 480+1647+462 in Cluster 2, meaning a total of 4728 genes. To find the common targets among all 4 datasets (ours and the three published ones) we used the bioinformatic tool Venny (36), that provides a graphical Venn diagram and the different lists of common and unique targets (Figure 4.18.A). Remarkably, among all the targets 
found in our RNA-seq experiment, 125 (2,6\% of our total dataset), $163(3,4 \%)$ and $31(0,65 \%)$ were shared with the ChIP-seq and RNA-seq in rice and the ChIP-seq in maize respectively. In other words, we found 319 common targets of KNAT1 with KN1 and OSH1. Next, we performed a Gene Ontology (GO) enrichment analysis of the shared targets with agriGO (37) and visualized it with REVIGO (38), which forms clusters of related terms and facilitates the identification of enriched categories (Figure 4.18.B). These datasets and the REVIGO table can be found in the Supplemental File 1.

As it can be seen in Figure 4.18.B, among the enriched GO functional categories, a great variety of biological processes can be found. These include metabolic and catabolic processes such as the metabolism of hormones, lipids, nitrogen compounds, glycosides and carbohydrates. Also, response to stimulus categories such as defense response, immune system processes, response to light, stress and hormones (regulation of hormone levels). Other processes highlighted are growth, cell wall modification, xylem and phloem formation, cell death, photosynthesis, lipid localization and reproduction. These results suggest that these biological processes can be commonly regulated by KNOX genes in different species, constituting key targets of KNOX function.

To further investigate this issue, we repeated the analysis taking the up- and down-regulated targets found in our RNA-seq separately and comparing each group with the same three published datasets (Table 4.2). For example, among the 125 shared targets of our dataset with the ChIP-seq in rice, 47 were upregulated in our experiment and 78 (more than $60 \%$ of the total shared targets) were down-regulated. See Supplemental File 2. Similar proportions were obtained in the three comparisons, indicating that the targets more conserved among species are mainly down-regulated by KNOX. 


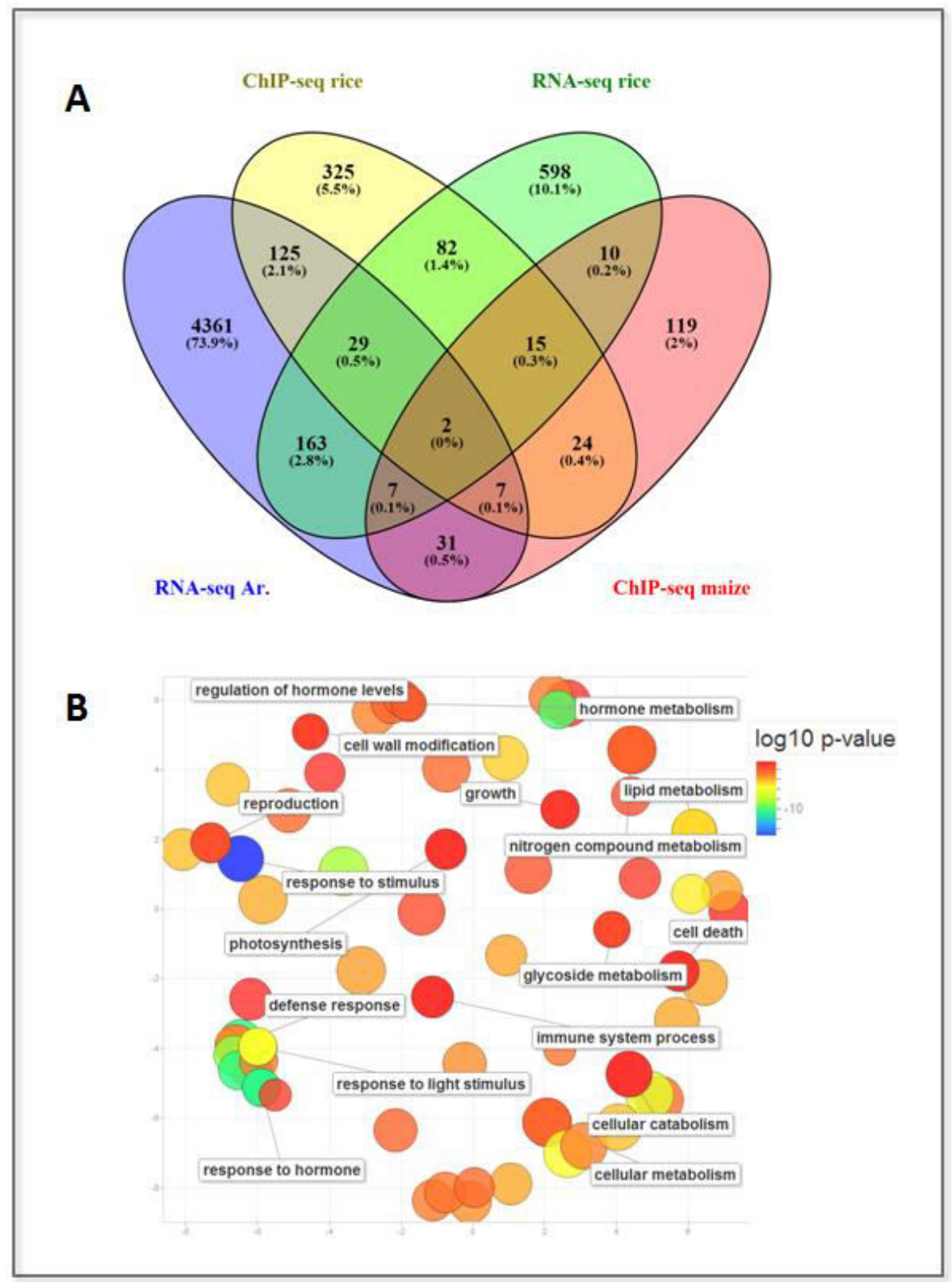

Figure 4.18. KN1, OSH1 and KNAT1 common targets. (A) Venn diagram showing the overlapping or unique targets among all 4 datasets. Numbers in the different sections indicate the number of targets and the percentage respect to the total amount of data. (B) REVIGO visualization of the $\mathrm{GO}$ analysis for the common targets clustered by biological process. Each circle is a category representative and its size reflects the level in the hierarchy (the smaller, the more specific). Different colors reflect the logarithmic $p$-value (legend). 


\begin{tabular}{|cc|ccc|}
\hline \multicolumn{5}{|c|}{ Table 4.2. KNOX common targets } \\
\hline \multirow{2}{*}{ Maize } & ChIP-seq & Total shared targets & UP shared targets & DOWN shared targets \\
\hline \multirow{2}{*}{ Rice } & RNA-seq & 31 & $7(22,5 \%)$ & $24(77,5 \%)$ \\
& ChIP-seq & 163 & $64(39 \%)$ & $99(61 \%)$ \\
& 125 & $47(37,6 \%)$ & $78(62,4 \%)$ \\
\hline
\end{tabular}

Furthermore, taking into account that ChIP-seq analysis in rice and maize were available, we decided to look for likely direct targets of KNAT1 among the targets found in our RNA-seq experiment. To do so, we searched for the overlapping targets among our dataset and both published ChIP-seq experiments and performed a GO enrichment analysis (Figure 4.19, Supplemental File 3). The 154 and 38 targets shared with rice and maize respectively are genes altered in our analysis by KNAT1 over-expression and they could be direct targets of the KNOX gene KNAT1, as they are KNOX direct targets in other species. As for the enriched GO categories found, although most of them were also obtained in the previous analysis, new biological processes can be observed. Importantly, processes related to development and morphogenesis are highlighted, such as tissue and shoot system development, shoot system morphogenesis, regulation of anatomical structure size and regulation of cellular component size. These enriched GO categories are in line with observations in the literature of the developmental role of KNAT1, and remarkably, with our findings that KNAT1 plays a relevant role in the modulation of meristem size. Further evaluation of these specific targets might be needed to unravel the underlying molecular mechanism in this regulation. 
A

RNA-seq Ar. ChIP-seq rice

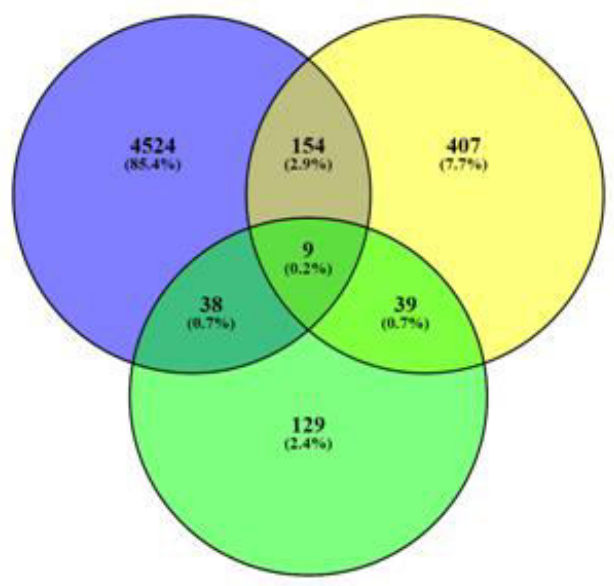

ChIP-seq maize

B

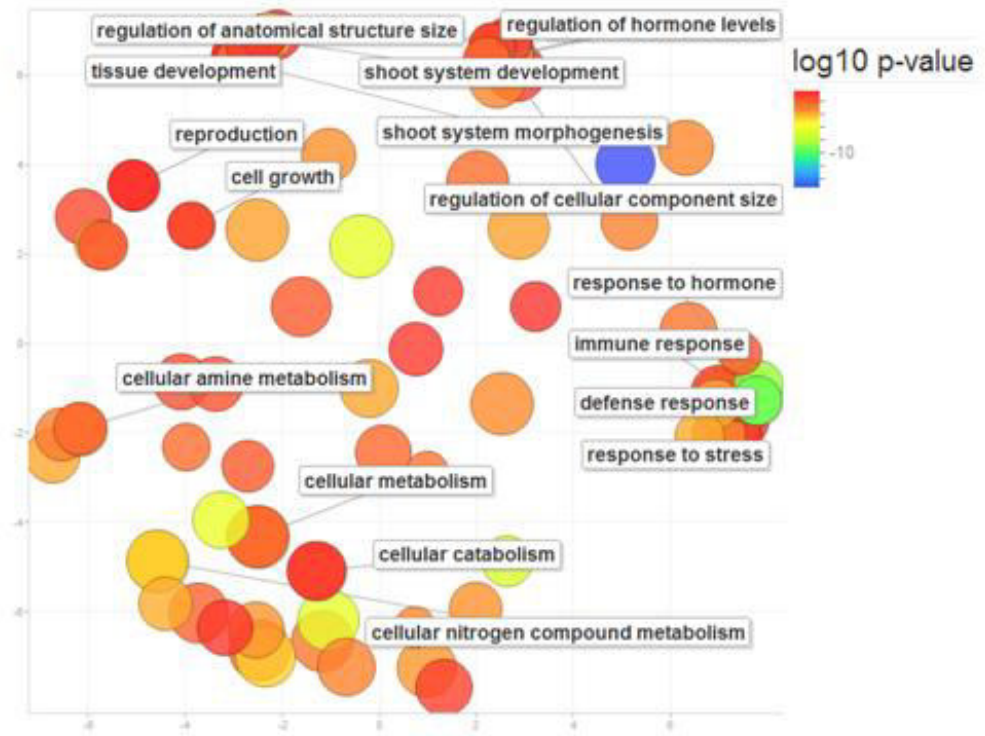

Figure 4.19. Processes regulated by likely direct targets of KNAT1. (A) Venn diagram showing the overlapping or unique targets among 3 datasets. Numbers in the different sections indicate the number of targets and the percentage respect to the total amount of data. (B) REVIGO visualization of the $\mathrm{GO}$ analysis for the common targets clustered by biological process. Each circle is a category representative and its size reflects the level in the hierarchy. Different colors reflect the logarithmic $p$-value (legend). 
Notably, only two articles in the literature have investigated on the specific targets regulated by KNAT1 in Arabidopsis. Both of them performed microarray analysis of gene expression profiling comparing wild type plants with the KNAT1 mutants $b p-101$ (39) and bp-9 (40), obtaining 56 and 64 differentially expressed genes respectively. With the aim to unravel KNAT1 specific functions in Arabidopsis, we looked for common targets among the three datasets and carried out a GO enrichment analysis of them (Figure 4.20, Supplemental File 4).

Despite the microarray datasets being extremely small, we found 9 and 24 shared targets among our data and the microarrays for $b p-9$ and $b p-101$ respectively; and outstandingly, the agriGO and REVIGO analysis rendered significant highlighted GO categories. Among them, metabolism processes (glucosinolate, sulfur compound and carbohydrate), development and response to stimulus such as stress, chemical compounds or abiotic stimulus. These results suggest that KNAT1 specific targets must be related with these processes, being these the processes more directly regulated by KNAT1 in Arabidopsis. A close view of these targets is required to further unravel the molecular mechanisms controlled by this gene. In this line, 6 genes of the lignin pathway have been found to be direct targets of KNAT1 in Arabidopsis by electrophoretic mobility shift assays (EMSA) (40). However, only one of them, AT4G35160 (COMT2), that encodes a cytosolic $\mathrm{N}$-acetylserotonin $\mathrm{O}$-methyltransferase involved in melatonin synthesis, was found in our RNA-seq data. 
A

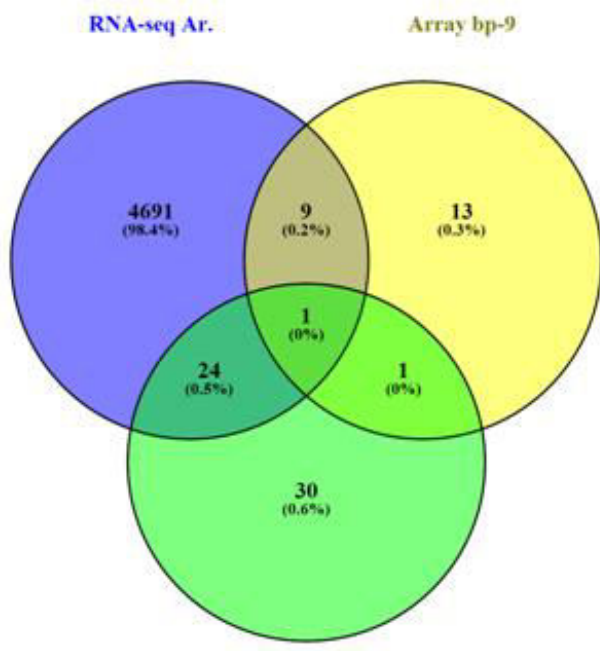

Array bp-101

B

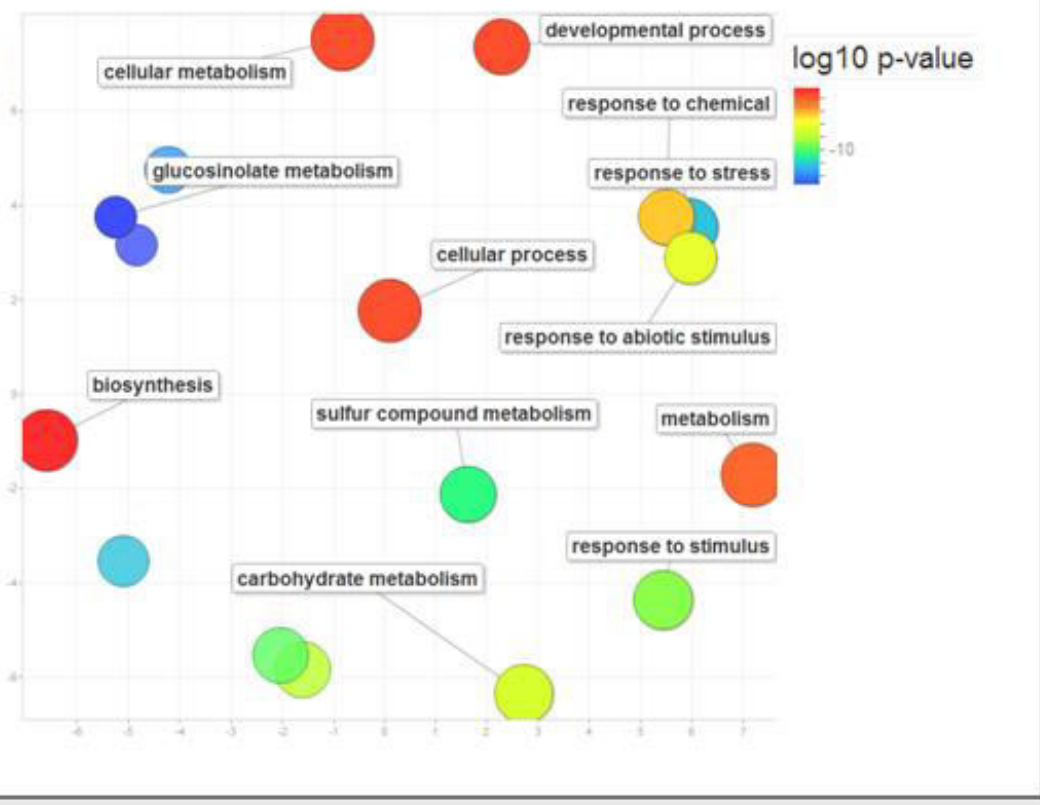

Figure 4.20. Specific KNAT1 targets in Arabidopsis. (A) Venn diagram showing the overlapping or unique targets among 3 datasets. Numbers in the different sections indicate the number of targets and the percentage respect to the total amount of data. (B) REVIGO visualization of the $\mathrm{GO}$ analysis for the common targets clustered by biological process. Each circle is a category representative and its size reflects the level in the hierarchy. Different colors reflect the logarithmic $p$-value (legend). 


\subsection{Analysis of the KNAT1 targets found in the RNA-sequencing experiment}

Focusing now on our RNA-seq experiment, we decided to analyze first the targets which regulation by KNAT1 is independent of the presence or absence of DELLAs. This dataset consists in 1321 up-regulated and 1647 down-regulated genes in response to KNAT1 over-expression, that is, 2968 total genes (Figure 4.17). First, we performed a GO enrichment analysis of the total dataset (2968 genes), that brought out several interesting $\mathrm{GO}$ categories. Besides, we carried out the same analysis with the up-regulated and down-regulated genes separately. Comparing the results obtained in these three tests, a general overview of the biological processes presumably promoted and inhibited by KNAT1 can be observed (Table 4.3, Supplemental File 5).

In the table, the GO categories highlighted in the three analysis performed ("All", "UP"- and "DOWN"-regulated targets of KNAT1) can be observed, and they are indicated with a green, mauve or blue mark, respectively. Outstandingly, several processes seem to be either specifically promoted by KNAT1 or specifically inhibited by this gene.

Among the processes favored by KNAT1 over-expression, we can find some important metabolic processes and, interestingly, the seed germination category. Besides, some of these enriched categories seem to be functionally linked, as they are related to response to biotic stress. In this line, not only apoptosis is induced by KNAT1, but also immune system and some specific defense responses, such as callose deposition in the cell wall and cell wall thickening. These cell-wall-related processes are also enriched independently of the defense response, suggesting a developmental role of KNAT1 controlling cell wall function. Interestingly, KNAT1 has been found to regulate lignin biosynthesis (28) and to bind the promoters of some lignin-pathway-related genes (40). As for the biological processes downregulated by KNAT1, light-related processes are emphasized. Photosynthesis, chlorophyll biosynthesis and electron transport chain are accentuated, and also response to light categories, such as response to light intensity, blue, red and far red response categories. These observations suggest a role of KNAT1 integrating external light sensing with endogen molecular cues that regulate photosynthesisrelated processes. 


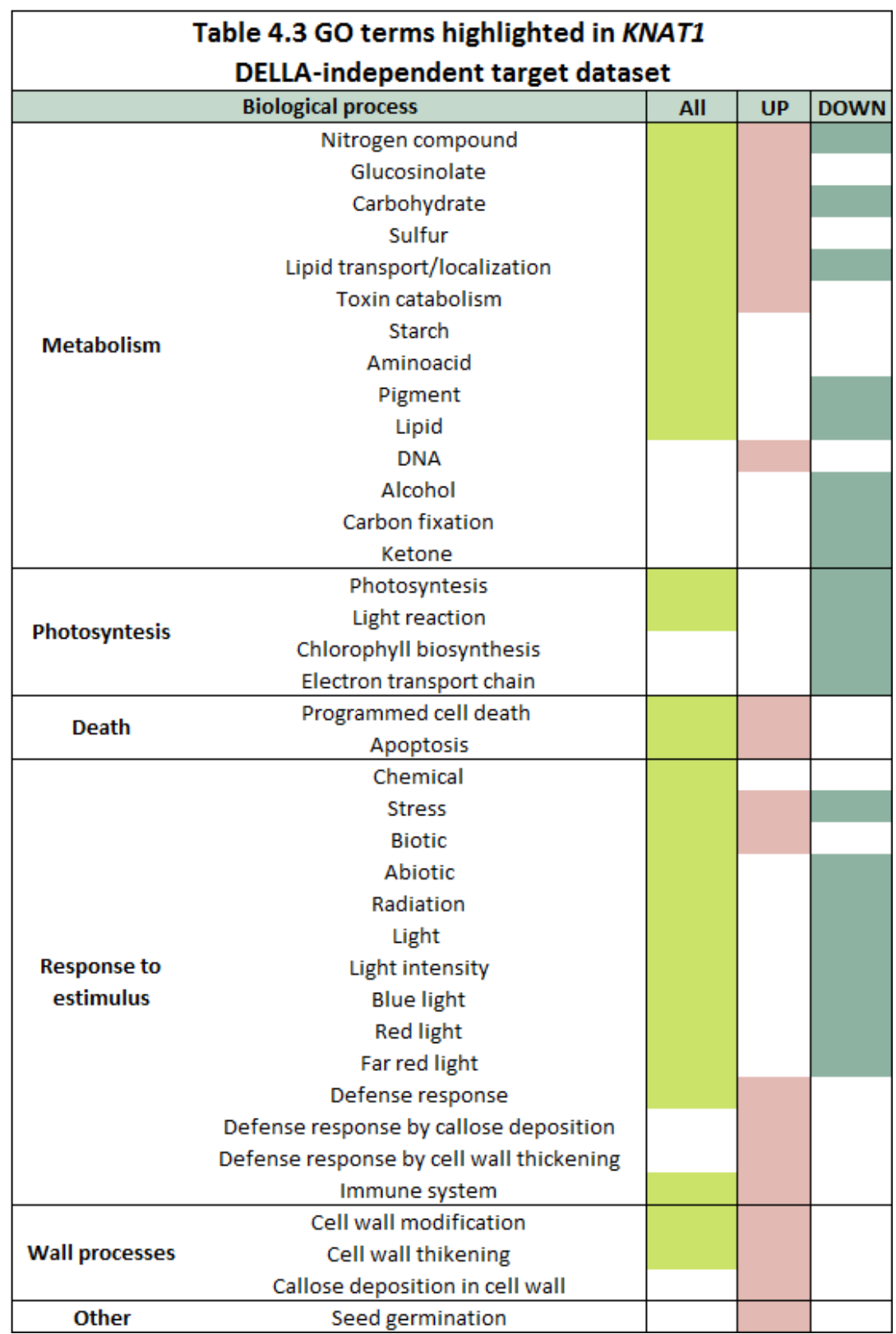

Notably, our RNA-seq results show that there are some targets of KNAT1 that are exclusively modulated by this gene when DELLAs are present (Figure 4.17). In particular, this dataset consists in 504 up-regulated and 480 down-regulated genes in response to KNAT1 over-expression in the presence of DELLA. Given this 
observation, our next aim was to evaluate those biological processes regulated by KNAT1 in a DELLA-dependent way. To do so, we performed a GO enrichment analysis of all the dataset and the up- and down-regulated subsets separately (Supplemental File 6). We found the most represented categories were related to metabolism, photosynthesis, response to stimulus, hormone regulation, and, interestingly, categories related to structural organization and development, and more specifically meristem organization (Table 4.4). Strikingly, almost all the categories highlighted are enriched in the subset of down-regulated genes in response to KNAT1 over-expression in the presence of DELLAs, indicating that KNAT1 could be a repressor TF.

Comparing these results with the ones obtained for KNAT1 over-expression in a DELLA-independent manner (Table 4.3), it can be seen that the study renders some common processes, although DELLA presence seem to influence KNAT1 in the control of some specific biological processes not present in the previous DELLA-independent study (Table 4.3). Among these processes targeted by KNAT1 exclusively in the presence of DELLA, a new class of categories is emphasized, related to structural and developmental features. In this line we can find categories such as morphogenesis, shoot, leaf and tissue development and meristem organization and development (Table 4.4). Other specific categories are related to hormones, such as regulation of hormone levels, response to hormones and hormone transport. Remarkably, although these hormone categories are highlighted also when comparing our data to the published studies (section 9.1), this group is not highlighted in our dataset of DELLA-independent KNAT1 targets; indicating that the regulation of these processes could be dependent of DELLA presence.

The fact that DELLA presence influences KNAT1 regulatory activity despite being expressed from a constitutive promoter opens up the suggestive possibility that DELLAs could regulate KNAT1 through a post-transcriptional mechanism. As it has been previously introduced, DELLAs perform their regulatory activity by protein-protein interaction (15). For this reason, we hypothesize that DELLAs could be modulating KNAT1 activity by physical binding. 
Results and Discussion of Chapter I

\begin{tabular}{|c|c|c|c|c|}
\hline Biological proces & & All & UP & DOWN \\
\hline \multirow[t]{12}{*}{ Metabolism } & Nitrogen compound & & & \\
\hline & Lignin & & & \\
\hline & Glucosinolate & & & \\
\hline & Glicoside & & & \\
\hline & Carbohydrate & & & \\
\hline & Sulfur & & & \\
\hline & Amine & & & \\
\hline & Aromatic compound & & & \\
\hline & Nucleotide & & & \\
\hline & Oxidation/reduction & & & \\
\hline & Ribonucleoprotein complex biogenesis & & & \\
\hline & Ribisome biognesis & & & \\
\hline \multirow[t]{5}{*}{ Photosyntesis } & Photosyntesis & & & \\
\hline & Light reaction & & & \\
\hline & Cellular respiration & & & \\
\hline & Electron transport chain & & & \\
\hline & Precursor metabolites and energy & & & \\
\hline \multirow[t]{10}{*}{ Structure } & Developmental growth involved in morphogenesis & & & \\
\hline & Anatomical structure arrangement & & & \\
\hline & Anatomical structure morphogenesis & & & \\
\hline & Shoot system morphology & & & \\
\hline & Shoot development & & & \\
\hline & Leaf development & & & \\
\hline & Tissue development & & & \\
\hline & Meristem structural development & & & \\
\hline & Meristem structural organization & & & \\
\hline & System development & & & \\
\hline \multirow[t]{6}{*}{ Response to } & Chemical & & & \\
\hline & Abiotic & & & \\
\hline & Radiation & & & \\
\hline & Light stimulus & & & \\
\hline & Hormone & & & \\
\hline & Gravity & & & \\
\hline \multirow[t]{2}{*}{ Hormone } & Regulation of hormone levels & & & \\
\hline & Hormone transport & & & \\
\hline \multirow[t]{2}{*}{ Other } & Cell wall modification & & & \\
\hline & Chromatin assembly and disassembly & & & \\
\hline
\end{tabular}

\subsection{Supplemental material}

Next, an enumeration of the supplemental files derived of the RNA-seq experiment is listed. The documents (in PDF and Excel versions) are available on the following website http://www.ibmcp.upv.es/BlazquezAlabadiLab/, in the Download section. 


\begin{tabular}{|c|c|}
\hline \multicolumn{2}{|c|}{ Supplemental files derived of the RNA-seq experiment } \\
\hline Folder & Document \\
\hline \multirow{2}{*}{ Folder "Cluster 1" } & Cluster 1314 genes \\
& Cluster 1505 genes \\
& Cluster 11321 genes \\
\hline \multirow{2}{*}{ Folder "Cluster 2" } & Cluster 2462 genes \\
& Cluster 2480 genes \\
\hline PLAZA & Cluster 21647 genes \\
\hline & PLAZA orthologs \\
\hline \multirow{2}{*}{ Supplemental Files } & Supplemental File 1 \\
& Supplemental File 2 \\
& Supplemental File 3 \\
& Supplemental File 4 \\
& Supplemental File 5 \\
& Supplemental File 6 \\
\hline
\end{tabular}

\section{GAl and RGA interact with KNAT1}

We tested our hypothesis first by performing $\mathrm{Y} 2 \mathrm{H}$ assays and results indicate that KNAT1 is able to interact with the GRAS domains of GAI and RGA (Figure 4.21.A-B). To determine the protein regions involved in the interaction, we used deleted versions of the GAl protein (separating the different regulatory domains of the protein) and tested their ability to interact with KNAT1 (Figure 4.21.C). As it can be seen in the figure, only M5GAl and deletion 1 are able to interact, suggesting that complete removal of the LHR1 motif of GAI does not impair interaction with KNAT1, whereas it is prevented by further deletion of the VHIID motif (del2). These results are similar to the interaction with ARR1 (12) and contrast with the requirement of the LHR1 motif to sustain interaction of GAI or RGA with BZR1, PIF4, and JAZ1 $(4,5,7,8)$. Besides, it seems to be a requirement for the region close to the C-terminus to support DELLA interactions. Indeed, it has been seen that point mutations in DELLA genes that create a premature stop codon close to the very end of the coding sequence, therefore producing truncated proteins, represent loss-of-function alleles most likely because of their incapacity to interact with downstream partners (41). 


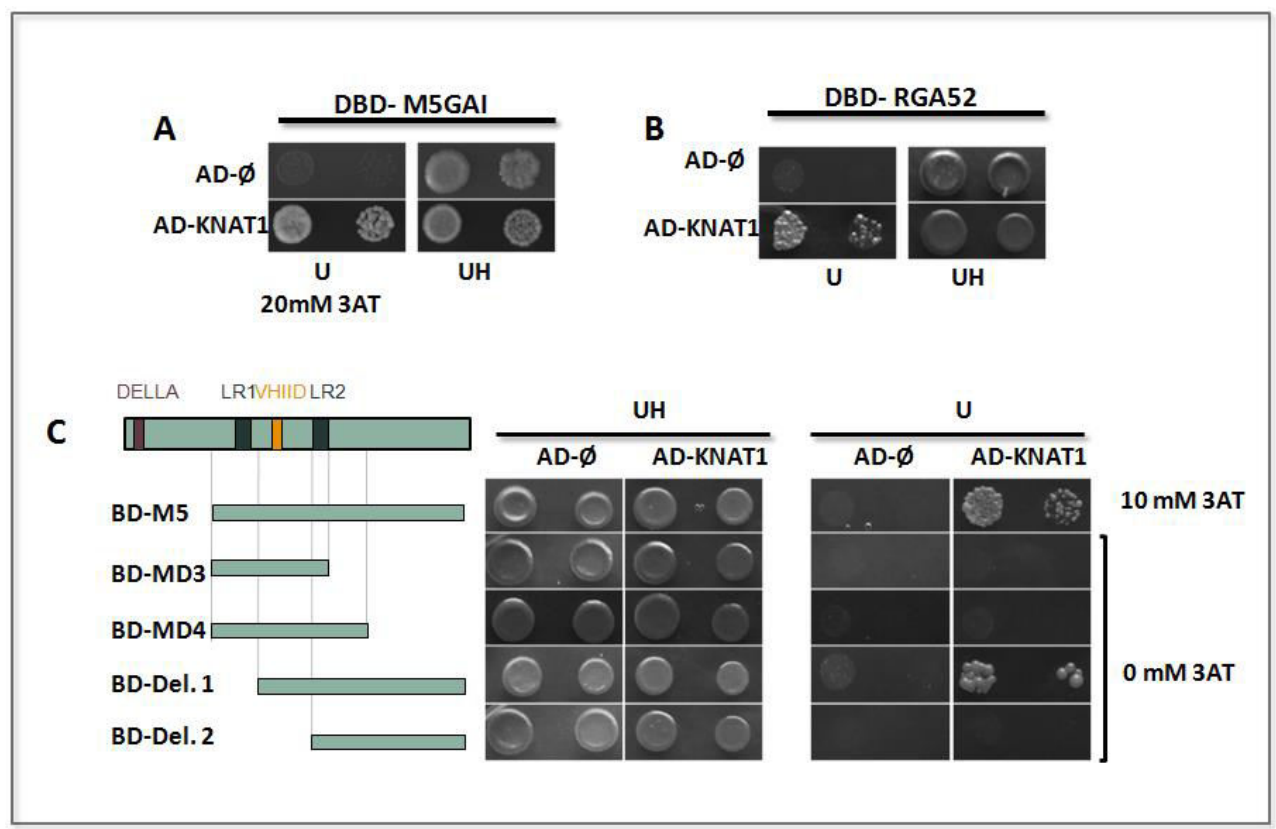

Figure 4.21. DELLA proteins interact with KNAT1. Y2H assay of the interaction between (A) a truncated version of GAI (M5GAI) and KNAT1 and (B) a truncated version of RGA (RGA52) and KNAT1. (C) Domains of GAI involved in the KNAT1-DELLA interaction. Y2H assay of the interaction between KNAT1 and truncated versions of GAI. The different_domains are indicated in colored boxes and their names specified. (DBD, DNA binding domain; $A D$, activation domain; $A D-\phi$, activation domain empty vector; $U$, uracil; $H$, histidine; 3-AT, 3-aminotriazol).

To confirm that the interaction between GAI and KNAT1 also occurs in planta, we performed a co-IP assay in $N$. benthamiana leaves transiently expressing HA-KNAT1 and c-myc-M5GAI (Figure 4.22). As it can be seen in the figure, the HA-tagged version of KNAT1 was co-immunoprecipitated with c-mycM5GAl, using an anti-c-myc antibody, therefore verifying that DELLA-KNAT1 interaction takes place in planta.

These results provide a possible alternative mechanism by which DELLAs modulate KNAT1 activity, which will need to be further investigated. Indeed, by electrophoretic mobility shift assay (EMSA) technique, KNAT1 has been found to bind the promoter of some components of the lignin pathway (40). Using these promoters in transient luciferase assays would clarify the effect of this DELLAKNAT1 interaction on KNAT1 transcriptional activity. Besides, this molecular mechanism would explain our results of the RNA-seq assay, showing that there are some genes that depend on DELLA presence for their regulation by KNAT1. 


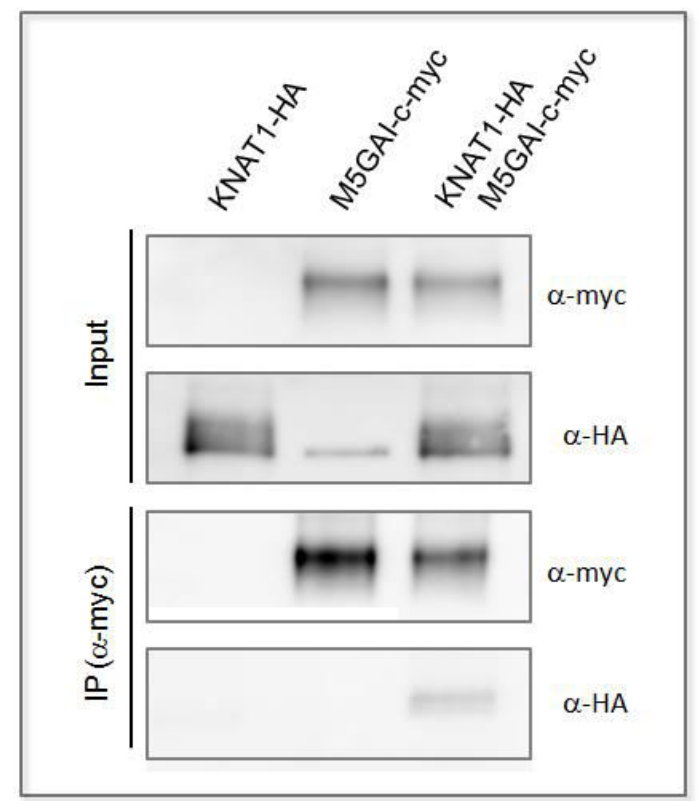

Figure 4.22. KNAT1 and DELLA proteins interact in planta. Co-immunoprecipitation of M5GAI-myc and KNAT1-HA expressed in N. benthamiana leaves. M5GAl was immunoprecipitated using anti-myc ( $\alpha$-myc) conjugated paramagnetic beads, and M5GAI and KNAT1 were detected in immunoblots using anti-myc and anti-HA, respectively. Note that KNAT1 was coimmunoprecipitated with M5GAI. The sizes of the bands correspond to the expected sizes of the fusion proteins.

\section{References}

1. Marin-de la Rosa N, Sotillo B, Miskolczi P, Gibbs DJ, Vicente J, Carbonero $P$, et al. Large-scale identification of gibberellin-related transcription factors defines group VII ETHYLENE RESPONSE FACTORS as functional DELLA partners. Plant physiology. 2014;166(2):1022-32.

2. Daviere JM, Achard P. A Pivotal Role of DELLAs in Regulating Multiple Hormone Signals. Molecular plant. 2015.

3. Daviere JM, Wild M, Regnault T, Baumberger N, Eisler H, Genschik P, et al. Class I TCP-DELLA interactions in inflorescence shoot apex determine plant height. Current biology : CB. 2014;24(16):1923-8.

4. Feng S, Martinez C, Gusmaroli G, Wang Y, Zhou J, Wang F, et al. Coordinated regulation of Arabidopsis thaliana development by light and gibberellins. Nature. 2008;451(7177):475-9. 
5. de Lucas $M$, Daviere JM, Rodriguez-Falcon $M$, Pontin $M$, Iglesias-Pedraz $\mathrm{JM}$, Lorrain $\mathrm{S}$, et al. A molecular framework for light and gibberellin control of cell elongation. Nature. 2008;451(7177):480-4.

6. Martin-Trillo M, Cubas P. TCP genes: a family snapshot ten years later. Trends in plant science. 2010;15(1):31-9.

7. Gallego-Bartolome J, Minguet EG, Grau-Enguix F, Abbas M, Locascio A, Thomas SG, et al. Molecular mechanism for the interaction between gibberellin and brassinosteroid signaling pathways in Arabidopsis. Proceedings of the National Academy of Sciences of the United States of America. 2012;109(33):13446-51.

8. Chini A, Fonseca S, Fernandez G, Adie B, Chico JM, Lorenzo O, et al. The JAZ family of repressors is the missing link in jasmonate signalling. Nature. 2007;448(7154):666-71.

9. Hou X, Lee LY, Xia K, Yan Y, Yu H. DELLAs modulate jasmonate signaling via competitive binding to JAZs. Developmental cell. 2010;19(6):884-94.

10. Fernandez-Calvo P, Chini A, Fernandez-Barbero G, Chico JM, GimenezIbanez S, Geerinck J, et al. The Arabidopsis bHLH transcription factors MYC3 and MYC4 are targets of JAZ repressors and act additively with MYC2 in the activation of jasmonate responses. The Plant cell. 2011;23(2):701-15.

11. Wild M, Daviere JM, Cheminant S, Regnault T, Baumberger N, Heintz D, et al. The Arabidopsis DELLA RGA-LIKE3 is a direct target of MYC2 and modulates jasmonate signaling responses. The Plant cell. 2012;24(8):3307-19.

12. Marin-de la Rosa N, Pfeiffer A, Hill K, Locascio A, Bhalerao RP, Miskolczi P, et al. Genome Wide Binding Site Analysis Reveals Transcriptional Coactivation of Cytokinin-Responsive Genes by DELLA Proteins. PLOS genetics. 2015;11(7):e1005337.

13. Alabadi D, Gallego-Bartolome J, Orlando L, Garcia-Carcel L, Rubio V, Martinez C, et al. Gibberellins modulate light signaling pathways to prevent Arabidopsis seedling de-etiolation in darkness. The Plant journal : for cell and molecular biology. 2008;53(2):324-35.

14. Gallego-Bartolome J, Alabadi D, Blazquez MA. DELLA-induced early transcriptional changes during etiolated development in Arabidopsis thaliana. PloS one. 2011;6(8):e23918.

15. Daviere JM, Achard P. Gibberellin signaling in plants. Development. 2013;140(6):1147-51.

16. Hyun Y, Richter R, Vincent C, Martinez-Gallegos R, Porri A, Coupland G. Multi-layered Regulation of SPL15 and Cooperation with SOC1 Integrate Endogenous Flowering Pathways at the Arabidopsis Shoot Meristem. Developmental cell. 2016;37(3):254-66.

17. Kosugi S, Ohashi Y. DNA binding and dimerization specificity and potential targets for the TCP protein family. The Plant journal : for cell and molecular biology. 2002;30(3):337-48. 
18. Palatnik JF, Allen E, Wu X, Schommer C, Schwab R, Carrington JC, et al. Control of leaf morphogenesis by microRNAs. Nature. 2003;425(6955):257-63.

19. Koyama T, Mitsuda N, Seki M, Shinozaki K, Ohme-Takagi M. TCP transcription factors regulate the activities of ASYMMETRIC LEAVES1 and miR164, as well as the auxin response, during differentiation of leaves in Arabidopsis. The Plant cell. 2010;22(11):3574-88.

20. Luo L, Ando S, Sasabe M, Machida C, Kurihara D, Higashiyama T, et al. Arabidopsis ASYMMETRIC LEAVES2 protein required for leaf morphogenesis consistently forms speckles during mitosis of tobacco BY-2 cells via signals in its specific sequence. Journal of plant research. 2012;125(5):661-8.

21. Lodha M, Marco CF, Timmermans MC. The ASYMMETRIC LEAVES complex maintains repression of KNOX homeobox genes via direct recruitment of Polycomb-repressive complex2. Genes \& development. 2013;27(6):596-601.

22. Guo M, Thomas J, Collins G, Timmermans MC. Direct repression of KNOX loci by the ASYMMETRIC LEAVES1 complex of Arabidopsis. The Plant cell. 2008;20(1):48-58.

23. Iwakawa $H$, Iwasaki $M$, Kojima S, Ueno $Y$, Soma $T$, Tanaka $H$, et al. Expression of the ASYMMETRIC LEAVES2 gene in the adaxial domain of Arabidopsis leaves represses cell proliferation in this domain and is critical for the development of properly expanded leaves. The Plant journal : for cell and molecular biology. 2007;51(2):173-84.

24. Ori N, Eshed Y, Chuck G, Bowman JL, Hake S. Mechanisms that control knox gene expression in the Arabidopsis shoot. Development. 2000;127(24):552332.

25. Gallego-Giraldo C, Hu J, Urbez C, Gomez MD, Sun TP, Perez-Amador MA. Role of the gibberellin receptors GID1 during fruit-set in Arabidopsis. The Plant journal : for cell and molecular biology. 2014;79(6):1020-32.

26. Hake S, Smith HM, Holtan H, Magnani E, Mele G, Ramirez J. The role of knox genes in plant development. Annual review of cell and developmental biology. 2004;20:125-51.

27. Eriksson S, Bohlenius H, Moritz T, Nilsson O. GA4 is the active gibberellin in the regulation of LEAFY transcription and Arabidopsis floral initiation. The Plant cell. 2006;18(9):2172-81.

28. Tsuda K, Hake S. Diverse functions of KNOX transcription factors in the diploid body plan of plants. Current opinion in plant biology. 2015;27:91-6.

29. Venglat SP, Dumonceaux T, Rozwadowski K, Parnell L, Babic V, Keller W, et al. The homeobox gene BREVIPEDICELLUS is a key regulator of inflorescence architecture in Arabidopsis. Proceedings of the National Academy of Sciences of the United States of America. 2002;99(7):4730-5.

30. Serrano-Mislata A, Schiessl K, Sablowski R. Active Control of Cell Size Generates Spatial Detail during Plant Organogenesis. Current biology : CB. 2015;25(22):2991-6. 
31. Winter D, Vinegar B, Nahal H, Ammar R, Wilson GV, Provart NJ. An "Electronic Fluorescent Pictograph" browser for exploring and analyzing largescale biological data sets. PloS one. 2007;2(8):e718.

32. Lincoln C, Long J, Yamaguchi J, Serikawa K, Hake S. A knottedl-like Homeobox Gene in Arabidopsis 1s Expressed in the Vegetative Meristem and Dramatically Alters Leaf Morphology When Overexpressed in Transgenic Plants. The Plant cell. 1994;6:1859-76.

33. Tsuda K, Kurata N, Ohyanagi H, Hake S. Genome-wide study of KNOX regulatory network reveals brassinosteroid catabolic genes important for shoot meristem function in rice. The Plant cell. 2014;26(9):3488-500.

34. Bolduc N, Yilmaz A, Mejia-Guerra MK, Morohashi K, O'Connor D, Grotewold E, et al. Unraveling the KNOTTED1 regulatory network in maize meristems. Genes \& development. 2012;26(15):1685-90.

35. Proost $S$, Van Bel $M$, Vaneechoutte $D$, Van de Peer $Y$, Inze $D$, MuellerRoeber B, et al. PLAZA 3.0: an access point for plant comparative genomics. Nucleic acids research. 2015;43(Database issue):D974-81.

36. Oliveros JC. Venny. An interactive tool for comparing lists with Venn's diagrams. http://bioinfogp.cnb.csic.es/tools/venny/index.html. 2007.

37. Du Z, Zhou X, Ling $Y$, Zhang Z, Su Z. agriGO: a GO analysis toolkit for the agricultural community. Nucleic acids research. 2010;38(Web Server issue):W6470.

38. Supek F, Bosnjak M, Skunca N, Smuc T. REVIGO summarizes and visualizes long lists of gene ontology terms. PloS one. 2011;6(7):e21800.

39. Xiao-Qun Wang W-HX, Li-Geng Ma, Zhi-Ming Fu, Xing-Wang Deng,, Wang J-YLaY-H. Requirement of KNAT1/BP for the Development of Abscission Zones in Arabidopsis thaliana. Journal of integrative plant biology. 2006;48(1):15-26.

40. Mele G, Ori N, Sato $\mathrm{Y}$, Hake S. The knotted1-like homeobox gene BREVIPEDICELLUS regulates cell differentiation by modulating metabolic pathways. Genes \& development. 2003;17(17):2088-93.

41. Silverstone AL, Jung HS, Dill A, Kawaide H, Kamiya Y, Sun TP. Repressing a repressor: gibberellin-induced rapid reduction of the RGA protein in Arabidopsis. The Plant cell. 2001;13(7):1555-66. 


\section{Introduction of Chapter II:}

\section{DELLAs' role on the germination process}





\section{The germination process}

Seed germination is a major developmental transition in a plant's life that mostly consists on resuming embryo growth after a long quiescence imposed during seed maturation. In this section, a brief view of the key aspects of this process is depicted.

\subsection{Seed structure and germination}

In angiosperms such as Arabidopsis, the diploid embryo is surrounded by two different, protective layers. The inner is the triploid endosperm, formed by a single cell layer of nutritive tissue and mostly living cells; and in the outer layer, the diploid testa (also named seed coat) that is formed by maternal tissue and mostly dead cells. In Arabidopsis seeds most nutrients are translocated to and stored in the embryonic leaves, the cotyledons. The micropylar endosperm is the endosperm zone covering the radical tip (Figure 5.1) (1).

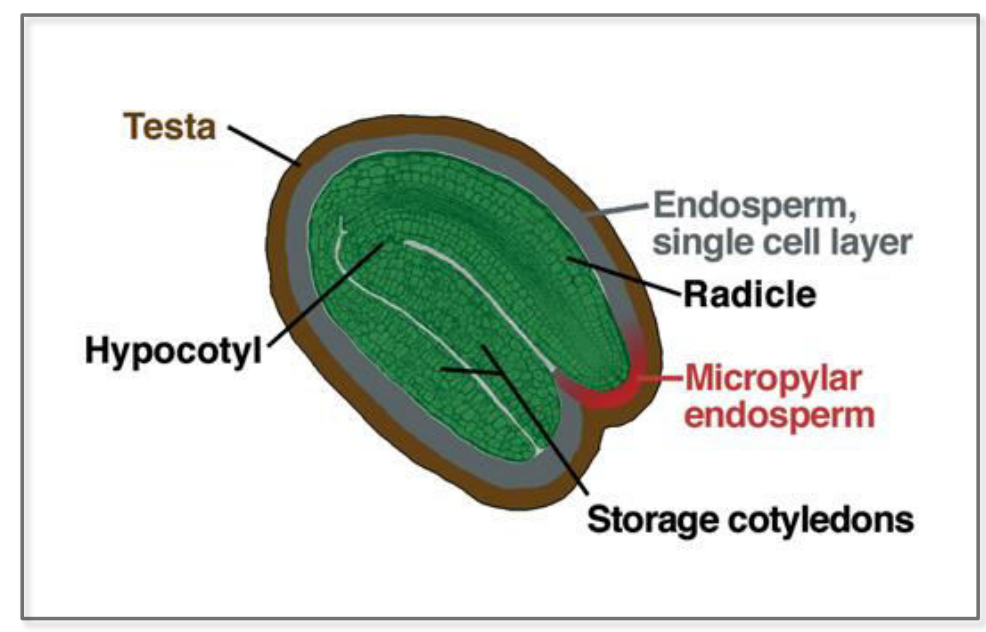

Figure 5.1. Mature seed of Arabidopsis thaliana. Different parts of the embryo and its two covering layers are depicted. The micropylar endosperm is shown in red. Extracted from FinchSavage and Leubner-Metzger, 2006 (1).

The germination process involves the concerted action of several genetic and physiological pathways, where the environmental conditions play a determinant role (2). These internal and external cues determine the dormancy status 
(incapacity of a viable seed to germinate under favourable conditions) and the potential for germination (percentage of emergence of the radicle through surrounding structures) (2).

Seed germination is sensitive to environmental conditions such as water, oxygen, temperature, light and nitrate. Only when these conditions are favorable, the germination commences with the uptake of water by imbibition by the dry seed, followed by embryo expansion. As a result, the embryo axis elongates and breaks through the covering layers to germinate (1). In particular, Arabidopsis thaliana seed germination is developed in two steps: testa rupture followed by endosperm rupture (see following section, Figure 5.1) (2). Cell elongation and division is also necessary for the completion of radicle protrusion (visible germination) (3).

\subsection{Dormancy and dormancy releasing mechanisms}

There are two different mechanisms imposing dormancy to the seed: embryo dormancy and coat dormancy, and their sum and interaction determine the degree of physiological dormancy (PD) $(4,5)$.

Embryo dormancy is characterized by a block that inhibits the inherent growth of the embryo (cell elongation and cell division). This dormancy is independent from the coat-induced one, and thus, embryos excised from their protective layers are not able to germinate. Importantly, in the case of Arabidopsis, its PD is classified as nondeep (1). That means that embryos excised from these seeds produce normal seedlings. In other words, their embryos are not dormant and the PD is imposed by the coat dormancy only. Remarkably, GA treatment, scarification and cold stratification can break this dormancy.

On the other hand, coat dormancy is conferred by the covering layers, and is the result of two forms of mechanical constraints to the protrusion of the radicle: the dormancy imposed by the testa and the endosperm. Germination requires that the embryo growth potential increases to overcome the mechanical resistance imposed by both layers. Besides, this resistance is reduced during germination by different releasing mechanisms (1). Two mechanisms release the dormancy in the testa: predetermined breaking points in the testa that facilitate 
tissue rips and the hydrolytic enzymes released by the endosperm and/or the radicle, which promote cell-wall hydrolysis (6-8). The endosperm dormancy is characterized by other releasing mechanism called endosperm weakening, which is promoted by GA and inhibited by ABA. It consists in the decline of the mechanical resistance of the micropylar endosperm (the endosperm zone covering the radicle tip, Figure 5.1) and is required for radicle protrusion during seed germination (5).

\section{GA involvement in germination}

A handful of evidences demonstrate the implication of GA signaling in the germination process. First, the GA deficient mutant ga1-3 is unable to germinate, but $G A$ treatment rescues this defect (9). In this line, seeds lacking GA receptors also fail to germinate $(10,11)$. Second, the biosynthetic enzymes GA3ox1 and GA3ox2 are essential for GA-regulated germination, as mutations in both genes reduce germination $(12,13)$. In addition, both genes are expressed in the axis of the embryo during initial imbibition before germination. As for DELLA proteins, several reports show that RGL2 have a major role in regulating germination potential, although other DELLAs also influence (14). rgl2 mutant seeds are known to be non-dormant (15), and insensitive to paclobutrazol (PAC, an inhibitor of GA synthesis (16)) repression of germination (17). Besides, the lack of RGL2 function in a ga1 mutant restores germination, showing that RGL2 represses germination in the absence of GA biosynthesis $(17,18)$. Interestingly, DELLAs are thought to integrate environmental signals in germination, as seeds lacking four DELLAs show light-independent and cold-independent germination (14).

In the following sections, an overview of the involvement of GAs in the germination process is depicted. In this Thesis, we focus on the influence of GAs on cell cycle and cell division in the RAM of germinating embryos (section 3 of this Introduction), as it is the aspect that DELLAs and TCP proteins might co-regulate.

\subsection{The ABA:GA balance}

Among the internal cues required for seed germination, plant hormones play a central role in dormancy induction and maintenance and the promotion of germination. A major conclusion from recent studies is that the abscisic acid (ABA) 
and GAs are the main contributors to the process. ABA is a positive regulator of seed maturation and dormancy, while GAs counteract the effects of ABA by releasing dormancy and promoting germination (2). Importantly, a dynamic balance of the ABA:GA ratio is established in the seed to direct signalling pathways that drive the replacement of maturation genetic programs (high ABA) with the ones promoting germination (high GA). In fact, in the seed, there is an intimate interplay between $\mathrm{ABA}$ and GA biosynthesis (NCED and GA3ox1 gene expression) and catabolism (GA2ox2 and CYP707A2 expression) to determine active hormone levels and sensitivity to these hormones that is influenced by the environmental conditions. For example, sensitivity of the seeds to light and GA increases as PD is progressively released. When these requirements overlap with favorable environmental conditions, germination will take place (1).

In this context, taking in to account the influence of these hormones in dormancy, we can re-interpret the dormancy as follows:

A dormant embryo is characterized by a high ABA:GA ratio, with high $A B A$ sensitivity and low GA sensitivity. As embryo dormancy is released, there is a remodeling of hormone biosynthesis and degradation towards a low ABA:GA ratio, decreasing and increasing $A B A$ and $G A$ sensitivity, respectively. $A$ nondormant embryo has increased growth potential, increased capacity for cell extension growth and increased cell division, as well as its ability to induce the release of coat dormancy. As for coat dormancy, it has been demonstrated that GAs can release it by increasing the embryo growth potential and/or by reducing the mechanical constraint of the covering layers, and ABA again plays the opposite role. Besides, as the endosperm is living tissue, it actively participates in influencing both the ABA:GA ratio and sensitivity to these hormones (1). A more detailed view of germination and GAs involvement in this process in exposed in the following section.

\subsection{GA implication in the molecular networks regulating germination following seed imbibition}

The transition between dormancy and germination is a critical stage in the life cycle of plants. Since the formation of the seed, different developmental phases occur: seed maturation, after-ripening and imbibition, when germination starts. After seed imbibition in suitable environmental conditions, the germination 
is induced, and this is the stage when GAs are more important (2). Next, we will briefly present several aspects of the germination process in which GAs are known to play a determinant role. Finally, in the next section, we present the influence of GAs on cell cycle and cell division in the RAM of germinating embryos, which is a key aspect in this Thesis.

\section{Endosperm weakening}

Endosperm weakening is the decline of the physical resistance of the mycropilar endosperm by the action of hydrolytic enzymes released by the own endosperm and/or the embryo, and is required for radicle protrusion during seed germination (5). Endosperm weakening has been demonstrated in Arabidopsis and other Brassicaceae seeds (19). Remarkably, GAs induce this weakening, and this process is regulated by the GA:ABA ratio (see part 2.1 of this section) (19). In the embryo, several GA-related factors induce endosperm weakening. It has been reported that a signal originating from the embryo promotes endosperm weakening, and this signal can be replaced by exogenous GA (19). Other work demonstrates that GA is synthesized de novo in the embryo, as the biosynthetic genes GA3ox1 and GA3ox2 are strongly expressed in the axis of the imbibed embryo (13). Besides, the TF Blue Micropylar End 3 (BME3) is known to be a positive regulator of germination, and is expressed in the embryo at the radicle tip. It is required to facilitate endosperm rupture, as seeds mutant in BME3 lacked endosperm rupture, although it could be restored by exogenous GA treatment $(20,21)$. On the other hand, GAs have been found to induce the expression of cell wall remodeling enzymes in the micropylar zone of the endosperm, which weakens the strength of the micropylar endosperm cell walls, thus facilitating endosperm rupture by the radicle $(22,23)$.

\section{Repression of embryonic traits}

During and after germination, it has been reported that genes that promote embryonic identity are repressed by the chromatin remodelling factor PICKLE (PKL) and the TFs VP1/ABI3-LIKE (VAL) in a GA-dependent manner (24-27). 


\section{Interaction with the environment}

It has been described that low temperatures and exposure to light are the major environmental factors that release seed dormancy and allow the completion of germination. Cold temperatures $\left(4{ }^{\circ} \mathrm{C}\right)$ are known to induce the biosynthetic GA3ox1 gene in dark imbibed seeds (12) and repress the catabolic GA2ox2. Thus, GA level increases in these conditions. Also red light and GA deficiency increase the amount of GA3ox1 transcript, suggesting a complex regulation integrating multiple signals. It has also been reported that the synergistic interaction of light and stratification regulates some bHLH TFs which, in turn, control GA3ox1, GA3ox2, GAI and RGA expression $(2,28)$.

\section{Transcriptomic changes}

Several publications indicate that there are very large changes in genome expression associated with the transition from dormancy to germination. Germination completion is associated with higher expression of GA3ox1 in the presence of light. It is also known that the transcriptome of GA-treated ga1-3 mutant seeds identified 230 genes up-regulated in response to this hormone (9). Interestingly, many of these genes are also induced in the after-ripening stage, indicating that GAs regulate the expression of these genes also at that stage. Remarkably, DELLAs have been involved in these transcriptomic changes as well, as half of the GA-regulated genes were regulated in a DELLA-dependent manner (29). This report suggests that there are GA-regulated genes in a DELLAindependent or DELLA-partially dependent manner.

\section{GAs role in cell division in the RAM during germination}

Among all the aspects of germination in which GAs are involved, we decided to focus on the regulation of cell division in the RAM of germinating embryos. This is due to the fact that class I TCPs have been found to regulate cell proliferation (30), so it is likely that GAs and TCPs regulate jointly this aspect of germination (see part 5 of this section).

It has been described in the literature that the activation of cell division in the embryo is an integral part of germination that precedes the protrusion of the root through the seed coat. In Arabidopsis, this activation has been linked to 
significant early changes in the expression of cell-cycle elements (3). In the dry Arabidopsis seed, embryonic cells are arrested in the G1 phase of the cell cycle. After imbibition, germination is initiated by water uptake and metabolic activity re-starts. This is followed by directional cell expansion, leading to radicle elongation and protrusion (3). In some species, cell division activation has been observed before root protrusion $(31,32)$. In fact, in Arabidopsis it has been demonstrated that cells transit from $\mathrm{G} 1$ into $\mathrm{S}$ phase and cell division is activated in a subset of cells in the root meristem just before radicle protrusion. Masubele et al., 2005 (3) demonstrated using a pCYCB1;1::GUS transgenic line (CYCB1;1 is a mitotic marker that marks G2/M phase of the cell cycle (33)) that cell division initiates in the RAM, where its cells undergo mitotic cycles before root protrusion. This activation of division is then extended to the cotyledons, SAM, and secondary meristems after the embryo have been released from the coat. Besides, they describe that a high increment in the expression of cyclins (CYC) precede root emergence. Seeds with loss-of-function in these cyclins showed reduced division and delayed root emergence, whereas higher expression of CYCs increases cell cycle activation in the RAM and promotes embryonic radicle protrusion. Thus, CYCs regulate cell cycle reentry during RAM activation to promote cell division, radicle growth and germination (3).

Outstandingly, several publications demonstrate that in the RAM, GAs regulate cell division $(34,35)$. Before describing this role of GAs in detail, an overview of root structure and growth is presented.

Root length is determined by the number of dividing cells originated by the RAM and their final cell size (35). Root cell division is first originated within a population of stem cells surrounding the quiescent center (QC) at the root apex (36); being the QC a small group of organizing cells defining together with the stem cells the stem cell niche (Figure 5.2). Daughter cells that remain in contact with the QC still maintain stem cell identity (37). However, those daughter cells that lose contact with the QC undergo repeated rounds of mitotic divisions in the proximal meristem as they are displaced and reach the elongation zone, where they experience rapid cell expansion to definitely differentiate and acquire a determinate cell identity (35).

The Arabidopsis RAM structure can be appreciated in figure 5.2. It is composed of lateral root cap, epidermis, cortex, endodermis, and stele tissues 
(35). Meristem size is considered to be the length of the meristematic zone and the number of cortex cells in a file between the $Q C$ and the first elongated cell exhibiting vacuolization (38) after the transition zone (TZ) (34). Importantly, root growth is maintained and regulated by the activity of the RAM, where a balance between cell production (cell division) and differentiation needs to be coordinated to allow the formation of a meristem of stable size $(34,38)$.

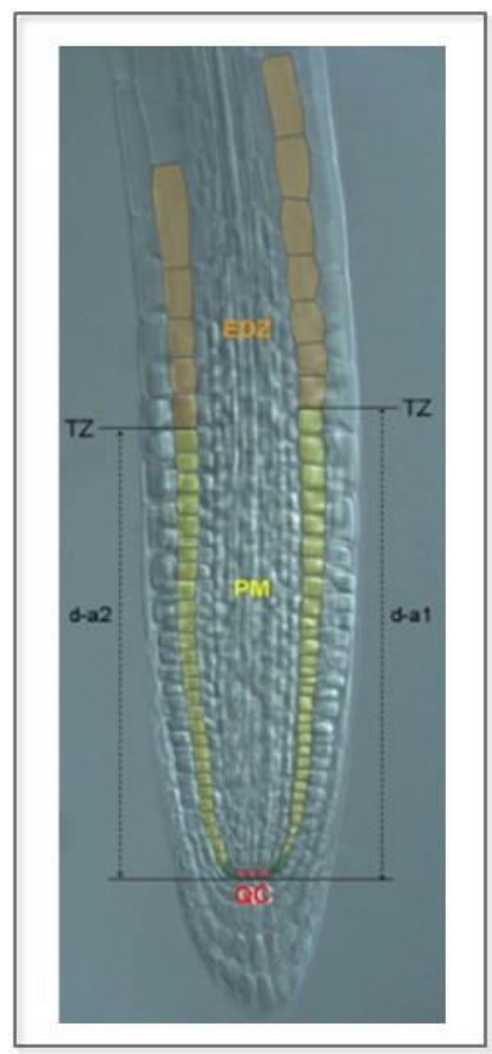

Figure 5.2. Structure of Arabidopsis root meristem. Bright-field microscopy image depicting the different zones of the Arabidopsis RAM: proximal meristem (PM) (with cortical cell files in yellow); elongation-differentiation zone (EDZ) (with cortical cell files in orange); transition zone (TZ); and quiescent center (QC) (cells in red). The distance ( $\mathrm{d}-\mathrm{a} 1$ and $\mathrm{d}-\mathrm{a} 2$ ) between the $\mathrm{TZ}$ and the $\mathrm{QC}$ is the meristem size $(\mu \mathrm{m})$. Extracted from Ubeda-Tomás et al., 2009 (35).

In this context, GAs have been reported to regulate cell division in the RAM $(34,35)$. It has been established that root growth rate is proportional to the rate of root cell production (cell division of the RAM), RAM size and the number of 
meristematic cells (35). Several evidences implicate the GA signaling pathway in the regulation of these processes.

First, plants treated with PAC or GA biosynthetic mutants show reduced cell production and root growth rate and a smaller meristem size compared to wildtype. Interestingly, GA treatment was able to rescue RAM size (35). Furthermore, using transgenic lines with the mitotic marker cyclin $C Y C B 1 ; 1$ fused to the GUS reporter, it has been demonstrated that PAC treatment significantly decreases mitotic cell number, and this phenotype is rescued by GA addition. These results indicate that GAs regulate RAM size by promoting mitotic activity. Thus, they are required to promote and maintain meristem size and therefore, root growth (35)

Second, it has been demonstrated that GAs promote root cell division in a DELLA-dependent manner, as the reduced cell division of the GA-deficient mutant ga1-3 could be restored by mutating the DELLA proteins RGA and GAI (35). Redundantly, Achard et al., 2009 (34) showed that GAs modulate cell cycle activity in the RAM through DELLAs by visualizing the cell cycle marker CYCB1;1::GUS in GA-signaling mutants. In accordance, targeting the expression of the dominant gai-1 in the RAM disrupts cell proliferation, because it reduced drastically the number of dividing cells and root growth (34).

Third, one of the molecular mechanisms DELLAs use to restrain cell production has been unraveled, as it has been reported that DELLAs enhance the levels of the cell cycle inhibitors Kip-related protein 2 (KRP2) and SIAMESE (SIM) (34). Nevertheless, GAs repress the expression of KRP2 and members of the SIM family by overcoming DELLA-mediated promotion.

Thus, it seems clear that GA signaling controls cell division and meristem size in the RAM, at least in part by modulating the expression levels of cell cycle inhibitors, and therefore, root growth. Specifically, DELLAs restrain root growth by enhancing the accumulation of cell cycle inhibitors and so, cell proliferation. Besides, these results point out the importance of GAs during root development to maintain a correct root meristem size, by regulating cell proliferation through DELLA protein degradation. In the next section, we address the involvement of TCPs in germination, and specifically in cell proliferation. 


\section{Class I TCPs involvement in germination}

As it is explained in section 7.1 of the General Introduction, one of the objectives of this Thesis is to unravel the role of DELLAs in germination trough their interaction with class I TCPS (TCP14 and TCP15). In this sense, the involvement of TCP14 in germination has been investigated by Tatematsu et al., 2008 (39). By transcriptomic analysis, they found that the transcript levels of 12 $T C P$ genes are up-regulated during seed germination, suggesting a redundant function of TCPs in this process. Interestingly, they found out that among all the up-regulated genes prior to seed germination, the site II motif, a known cis element target of TCP TFs is over-represented. This indicates that induction of TCPs after imbibition could implicate the activation of their downstream pathways (39). Among the up-regulated TCP genes, TCP14 transcript levels greatly increased after imbibition and it was the most abundantly expressed family member in $24 \mathrm{~h}$ imbibed seed, so it was chosen for further studies. Indeed, germination of freshly harvested tcp14 mutant seeds was significantly delayed (39), indicating that TCP14 is involved in the regulation of seed germination.

Expression analysis of TCP14 in dissected embryos and its surrounding tissues (endosperm and testa) and in situ and reporter gene analysis at $24 \mathrm{~h}$ of imbibition revealed that the transcript and protein was mostly present in embryos, specifically in the vascular tissues of hypocotyls. This indicates that TCP14 acts primarily in the embryo rather than the endosperm. Remarkably, in the same article, it is reported the induction of site II motif-containing genes (putative targets of TCPs) in the root tip during germination. This could indicate that these genes in the root tip might be activated by other TCPs, or that TCP14 regulates radicle growth in a non-cell-autonomous manner.

In this sense, they examined whether loss-of-function of TCP14 affects gene expression in embryo radicles, and notably, they analyzed the expression pattern of a CYCB1;1::GUS reporter gene (direct target of TCP14 (40)) in the tcp14 mutant after imbibition. As it has already mentioned, this CYC is widely used as a mitotic marker, since it marks $\mathrm{G} 2 / \mathrm{M}$ phase of the cell cycle. Thus, the experiment also tests the involvement of TCP14 in cell division in the root tip. They found GUS staining in the radicle of wild-type seedlings, whereas very weak signal was detectable in the tcp14 mutant (39), indicating that TCP14 regulates embryonic 
growth potential, possibly by positively regulating cell division in the radicle even though it does not seem to be expressed in this region.

As a matter of fact, the role of class I TCPs, and specifically TCP14 and TCP15, in the regulation of cell proliferation has been further addressed in the literature $(30,40)$.

Interestingly, disruption of TCP14 and TCP15 affects plant stature by reducing stem internode elongation as well. tcp14, tcp15 and double tcp14 tcp15 mutants display a significant reduction in inflorescence height and shorter internodes (30). This defect is associated with a reduction of cell proliferation, as TCP14 and TCP15 are expressed in the internodes, where they are found to repress the expression of five effectors of cell division. Specifically, the expression of the mitosis markers CYCB1;1, CYCB1;2, CYCA1;1, CDC20 and CDKB2;1 was reduced in double mutant apices relative to the wild-type (30). These results show that TCP14 and TCP15 act redundantly to promote cell proliferation in young stem internodes, and together modulate plant stature.

During the course of this Thesis, an article depicting class I TCPs regulation of cell proliferation in shoot apices was published (40). In this article, Davière et al., 2014, showed that DELLAs modulate cell division by directly binding and regulating the activity of class I TCPs (TCP14 and TCP15) in Arabidopsis inflorescence shoot apices. As the results of this article overlap the results of this Thesis, we will discuss it in the General Discussion.

Therefore, it seems clear that class I TCPs, and especially TCP14 and TCP15 promote cell cycle progression in different contexts on the plant, including root growth $(30,39,40)$. On the other hand, cell division in the embryo RAM before radicle protrusion has been identified as one of the processes required for germination (39). In Chapter II of this Thesis we address the possibility that TCP14 and TCP15 regulate cell division in the RAM before germination and whether this aspect is modulated by DELLAs, given the physical interaction of both factors. 


\section{Proposal of the hypothesis: DELLAs function in the RAM}

As previously presented, GAs have a crucial role promoting germination. In this process, the activation of cell division in the RAM of the embryonic radicle before germination is an integral part of germination, as it promotes embryo growth and radicle protrusion through the seed coat. In Arabidopsis, this activation implies the activation of cell-cycle elements (3). Although GAs have been found to regulate cell division in the $\operatorname{RAM}(3,34,35)$, the underlying molecular mechanism is still unknown. In this line, the Class I TCPs TCP14 and TCP15 have been involved in the control cell proliferation in root growth and other contexts of the plant $(30,39,40)$. Moreover, the activity of TCP14 is necessary to undergo seed germination (39). The finding that DELLA proteins physically interact with TCP14 and TCP15 suggests that DELLAs could restrain germination by inhibiting the activity of these TCPs activating cell cycle genes. This way, GAs could promote germination by releasing this inhibitory mechanism.

Therefore, we hypothesize that TCP14 and TCP15 mediate the GA-dependent activation of the cell cycle during germination by their physical interaction with DELLA proteins.

\section{References}

1. Finch-Savage WE, Leubner-Metzger G. Seed dormancy and the control of germination. The New phytologist. 2006;171(3):501-23.

2. Holdsworth MJ, Bentsink L, Soppe WJ. Molecular networks regulating Arabidopsis seed maturation, after-ripening, dormancy and germination. The New phytologist. 2008;179(1):33-54.

3. Masubelele NH, Dewitte W, Menges M, Maughan S, Collins C, Huntley R, et al. D-type cyclins activate division in the root apex to promote seed germination in Arabidopsis. Proceedings of the National Academy of Sciences of the United States of America. 2005;102(43):15694-9.

4. Bewley JD. Seed Germination and Dormancy. The Plant cell. 1997;9(7):1055-66.

5. Kucera B, Cohn MA, Leubner-Metzger G. Plant hormone interactions during seed dormancy release and germination. Seed Science Research. 2005;15(4):281-307. 
6. Debeaujon I, Koornneef M. Gibberellin requirement for Arabidopsis seed germination is determined both by testa characteristics and embryonic abscisic acid. Plant physiology. 2000;122(2):415-24.

7. Koornneef $M$, Bentsink $L$, Hilhorst $H$. Seed dormancy and germination. Current opinion in plant biology. 2002;5(1):33-6.

8. Rajjou L, Gallardo K, Debeaujon I, Vandekerckhove J, Job C, Job D. The effect of alpha-amanitin on the Arabidopsis seed proteome highlights the distinct roles of stored and neosynthesized mRNAs during germination. Plant physiology. 2004;134(4):1598-613.

9. Ogawa M. Gibberellin Biosynthesis and Response during Arabidopsis Seed Germination. The Plant Cell Online. 2003;15(7):1591-604.

10. Griffiths J, Murase K, Rieu I, Zentella R, Zhang ZL, Powers SJ, et al. Genetic characterization and functional analysis of the GID1 gibberellin receptors in Arabidopsis. The Plant cell. 2006;18(12):3399-414.

11. Willige BC, Ghosh S, Nill C, Zourelidou M, Dohmann EM, Maier A, et al. The DELLA domain of GA INSENSITIVE mediates the interaction with the GA INSENSITIVE DWARF1A gibberellin receptor of Arabidopsis. The Plant cell. 2007;19(4):1209-20.

12. Yamauchi $Y$, Ogawa $M$, Kuwahara A, Hanada A, Kamiya $Y$, Yamaguchi S. Activation of gibberellin biosynthesis and response pathways by low temperature during imbibition of Arabidopsis thaliana seeds. The Plant cell. 2004;16(2):367-78. 13. Mitchum MG, Yamaguchi S, Hanada A, Kuwahara A, Yoshioka Y, Kato T, et al. Distinct and overlapping roles of two gibberellin 3-oxidases in Arabidopsis development. The Plant journal : for cell and molecular biology. 2006;45(5):80418.

14. Cao D, Hussain A, Cheng H, Peng J. Loss of function of four DELLA genes leads to light- and gibberellin-independent seed germination in Arabidopsis. Planta. 2005;223(1):105-13.

15. Carrera E, Holman T, Medhurst A, Peer W, Schmuths H, Footitt $S$, et al. Gene expression profiling reveals defined functions of the ATP-binding cassette transporter COMATOSE late in phase II of germination. Plant physiology. 2007;143(4):1669-79.

16. Olszewski N, Sun TP, Gubler F. Gibberellin signaling: biosynthesis, catabolism, and response pathways. The Plant cell. 2002;14 Suppl:S61-80.

17. Lee $S$, Cheng $H$, King KE, Wang $W, H e ~ Y$, Hussain A, et al. Gibberellin regulates Arabidopsis seed germination via RGL2, a GAl/RGA-like gene whose expression is up-regulated following imbibition. Genes \& development. 2002;16(5):646-58.

18. Tyler L, Thomas SG, Hu J, Dill A, Alonso JM, Ecker JR, et al. Della proteins and gibberellin-regulated seed germination and floral development in Arabidopsis. Plant physiology. 2004;135(2):1008-19. 
19. Muller K, Tintelnot S, Leubner-Metzger G. Endosperm-limited Brassicaceae seed germination: abscisic acid inhibits embryo-induced endosperm weakening of Lepidium sativum (cress) and endosperm rupture of cress and Arabidopsis thaliana. Plant \& cell physiology. 2006;47(7):864-77.

20. Liu PP, Koizuka N, Homrichhausen TM, Hewitt JR, Martin RC, Nonogaki H. Large-scale screening of Arabidopsis enhancer-trap lines for seed germinationassociated genes. The Plant journal : for cell and molecular biology. 2005;41(6):936-44.

21. Liu PP, Koizuka N, Martin RC, Nonogaki H. The BME3 (Blue Micropylar End 3) GATA zinc finger transcription factor is a positive regulator of Arabidopsis seed germination. The Plant journal : for cell and molecular biology. 2005;44(6):960-71. 22. Dubreucq B, Berger N, Vincent E, Boisson M, Pelletier G, Caboche M, et al. The Arabidopsis AtEPR1 extensin-like gene is specifically expressed in endosperm during seed germination. The Plant journal : for cell and molecular biology. 2000;23(5):643-52.

23. Penfield S, Li Y, Gilday AD, Graham S, Graham IA. Arabidopsis ABA INSENSITIVE4 regulates lipid mobilization in the embryo and reveals repression of seed germination by the endosperm. The Plant cell. 2006;18(8):1887-99.

24. Ogas J, Cheng JC, Sung ZR, Somerville C. Cellular differentiation regulated by gibberellin in the Arabidopsis thaliana pickle mutant. Science. 1997;277(5322):91-4.

25. Ogas J, Kaufmann S, Henderson J, Somerville C. PICKLE is a CHD3 chromatin-remodeling factor that regulates the transition from embryonic to vegetative development in Arabidopsis. Proceedings of the National Academy of Sciences of the United States of America. 1999;96(24):13839-44.

26. Eshed Y, Baum SF, Bowman JL. Distinct mechanisms promote polarity establishment in carpels of Arabidopsis. Cell. 1999;99(2):199-209.

27. Dean Rider S, Jr., Henderson JT, Jerome RE, Edenberg HJ, RomeroSeverson J, Ogas J. Coordinate repression of regulators of embryonic identity by PICKLE during germination in Arabidopsis. The Plant journal : for cell and molecular biology. 2003;35(1):33-43.

28. Oh E, Yamaguchi S, Hu J, Yusuke J, Jung B, Paik I, et al. PIL5, a phytochrome-interacting bHLH protein, regulates gibberellin responsiveness by binding directly to the GAI and RGA promoters in Arabidopsis seeds. The Plant cell. 2007;19(4):1192-208.

29. Cao D, Cheng H, Wu W, Soo HM, Peng J. Gibberellin mobilizes distinct DELLA-dependent transcriptomes to regulate seed germination and floral development in Arabidopsis. Plant physiology. 2006;142(2):509-25.

30. Kieffer M, Master V, Waites R, Davies B. TCP14 and TCP15 affect internode length and leaf shape in Arabidopsis. The Plant journal : for cell and molecular biology. 2011;68(1):147-58. 
31. Barroco RM, Van Poucke K, Bergervoet JH, De Veylder L, Groot SP, Inze D, et al. The role of the cell cycle machinery in resumption of postembryonic development. Plant physiology. 2005;137(1):127-40.

32. de Castro RD, van Lammeren AA, Groot SP, Bino RJ, Hilhorst HW. Cell division and subsequent radicle protrusion in tomato seeds are inhibited by osmotic stress but DNA synthesis and formation of microtubular cytoskeleton are not. Plant physiology. 2000;122(2):327-36.

33. Ferreira PC, Hemerly AS, Engler JD, van Montagu M, Engler G, Inze D. Developmental expression of the arabidopsis cyclin gene cyc1At. The Plant cell. 1994;6(12):1763-74.

34. Achard P, Gusti A, Cheminant S, Alioua M, Dhondt S, Coppens F, et al. Gibberellin signaling controls cell proliferation rate in Arabidopsis. Current biology :CB. 2009;19(14):1188-93.

35. Ubeda-Tomas S, Federici F, Casimiro I, Beemster GT, Bhalerao R, Swarup $\mathrm{R}$, et al. Gibberellin signaling in the endodermis controls Arabidopsis root meristem size. Current biology : CB. 2009;19(14):1194-9.

36. Scheres B. Stem-cell niches: nursery rhymes across kingdoms. Nature reviews Molecular cell biology. 2007;8(5):345-54.

37. van den Berg C, Willemsen V, Hendriks G, Weisbeek P, Scheres B. Shortrange control of cell differentiation in the Arabidopsis root meristem. Nature. 1997;390(6657):287-9.

38. Dello loio R, Linhares FS, Scacchi E, Casamitjana-Martinez E, Heidstra R, Costantino $P$, et al. Cytokinins determine Arabidopsis root-meristem size by controlling cell differentiation. Current biology : CB. 2007;17(8):678-82.

39. Tatematsu K, Nakabayashi K, Kamiya Y, Nambara E. Transcription factor AtTCP14 regulates embryonic growth potential during seed germination in Arabidopsis thaliana. The Plant journal : for cell and molecular biology. 2008;53(1):42-52.

40. Daviere JM, Wild M, Regnault T, Baumberger N, Eisler H, Genschik P, et al. Class I TCP-DELLA interactions in inflorescence shoot apex determine plant height. Current biology : CB. 2014;24(16):1923-8. 

6. Results and Discussion of Chapter II: Regulation of the root apical meristem by DELLAs trough Class I-TCPs 

Seed germination involves the coordination of several genetic and physiological pathways (1) and hormones play important roles in the switch from dormant to germinating seeds. During seed maturation, a quiescent state is imposed on the embryo. One of the mechanisms that repress germination at this stage is the one controlled by abscisic acid (ABA). This way, the seed is able to resist adverse environmental conditions. Only when these conditions are favorable, the mechanisms that promote germination (such as GA biosynthesis and a decrease in ABA level) start working to resume embryo growth. This process implies the activation of cell division in the embryo and early changes in the expression of cell-cycle elements (2), that eventually leads to the protrusion of the root through the seed coat. GAs play an essential role in this process, given that they regulate cell division in the $\operatorname{RAM}(3,4)$ and had been found to be required for the rupture of the testa and the endosperm (5).

Interestingly, the Class I TCP transcription factors TCP14 and TCP15 have been proposed to regulate cell proliferation (6) and TCP14 activity has been highly linked with the germination process (7).

Taking all these observations into account, we hypothesized that TCP14 and TCP15 could have a role mediating GA-dependent activation of the cell cycle during germination.

\section{TCP14 and TCP15 are required for the promotion of the germination by gibberellin}

TCP14 activity had been previously demonstrated to be needed for germination. It was shown that freshly harvested tcp14 mutant seeds present a delay in germination. Furthermore, TCP14 is involved in the hormonal regulation of seed germination; given that its expression level is reduced in imbibed seeds of the ga1-3 mutant and tcp14 mutants are hypersensitive to the negative effects on germination of paclobutrazol (7). These observations suggest a functional relationship between this TF and GAs in this process.

In this sense, it has been proposed in the literature that TCP14 and TCP15 are closely related phylogenetically and can operate together in some processes (8), 
such as internode length and leaf development (6). For this reason, we wanted to evaluate if TCP15 activity is also necessary for seed germination.

First, we performed a germination assay with freshly harvested seeds of wild type, two different loss-of-function mutants in TCP14 and TCP15, and the tcp14 tcp15 double mutants. As shown in Figure 6.1, the percentage of germination of both tcp15-2 and tcp15-3 was greatly reduced (52\% and $41.5 \%$ respectively) 4 days after sowing, even more than the single tcp14 mutants. Remarkably, the germination capacity in the double mutants is even smaller. These results suggest that both TCPs may act redundantly promoting germination.

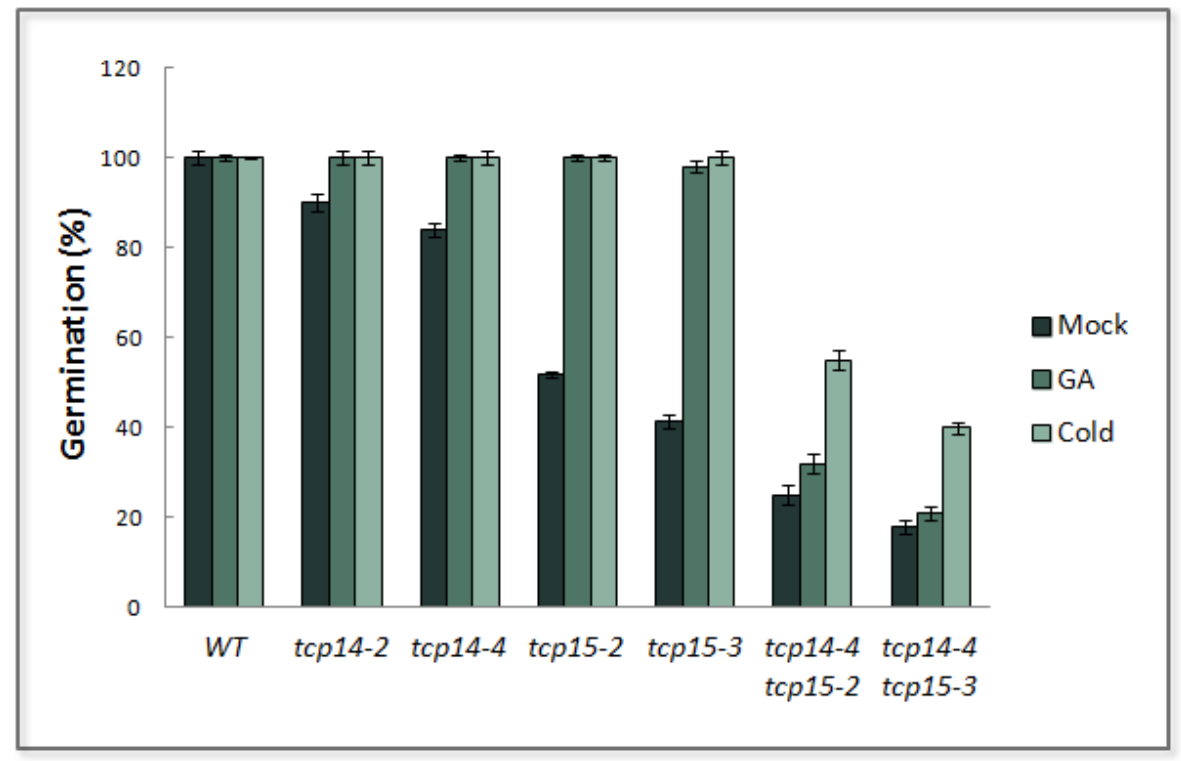

Figure 6.1. TCP14 and TCP15 are needed for Arabidopsis germination. Percentage of germination of wild type, simple and double mutants of TCP14 and TCP15 in three different conditions: mock (black bars), $1 \mathrm{mM} \mathrm{GA}_{3}$ treatment (dark green bars) and stratification treatment, 5 days in dark at $4{ }^{\circ} \mathrm{C}$ (light green bars). Freshly harvested seeds were used in these assays.

To assess whether these TCPs and GAs are promoting seed germination in the same molecular pathway, we carried out germination assays of the same genotypes exposed to different treatments. On the one hand, we added $1 \mathrm{mM}$ $\mathrm{GA}_{3}$ to the medium, and on the other hand we maintained seeds in dark at 4 o $\mathrm{C}$ for 5 days before the exposure to light, since it had been previously demonstrated that cold triggers the accumulation of transcripts encoding GA biosynthetic enzymes (9) and enhances GA accumulation (10). Results in Figure 6.1 show that 
neither GA application nor exposure to cold were able to efficiently overcome this defect in the double mutants while a full recovery was obtained in the case of single mutants. These results are compatible with the idea that GAs promote germination through the redundant activity of TCP14 and TCP15.

\section{TCP15 is expressed in developing embryos}

It had been previously demonstrated that TCP14 is expressed in developing embryos and in seeds (7). In particular, TCP14 is the most abundantly expressed TCP family member in 24 hour-imbibed seeds and is expressed preferentially in embryos rather than in the endosperm or testa (7). In situ hybridization and GUS staining assays in $24 \mathrm{~h}$-imbibed seeds show that the transcript is mainly detected in the vascular tissues of hypocotyls and, in a lesser extent, in the vascular tissues of cotyledons and roots (7).

Given the relevance of TCP15 in germination, where it would act redundantly with TCP14, we decided to compare the expression patterns of TCP14 and TCP15 in Arabidopsis embryos. 


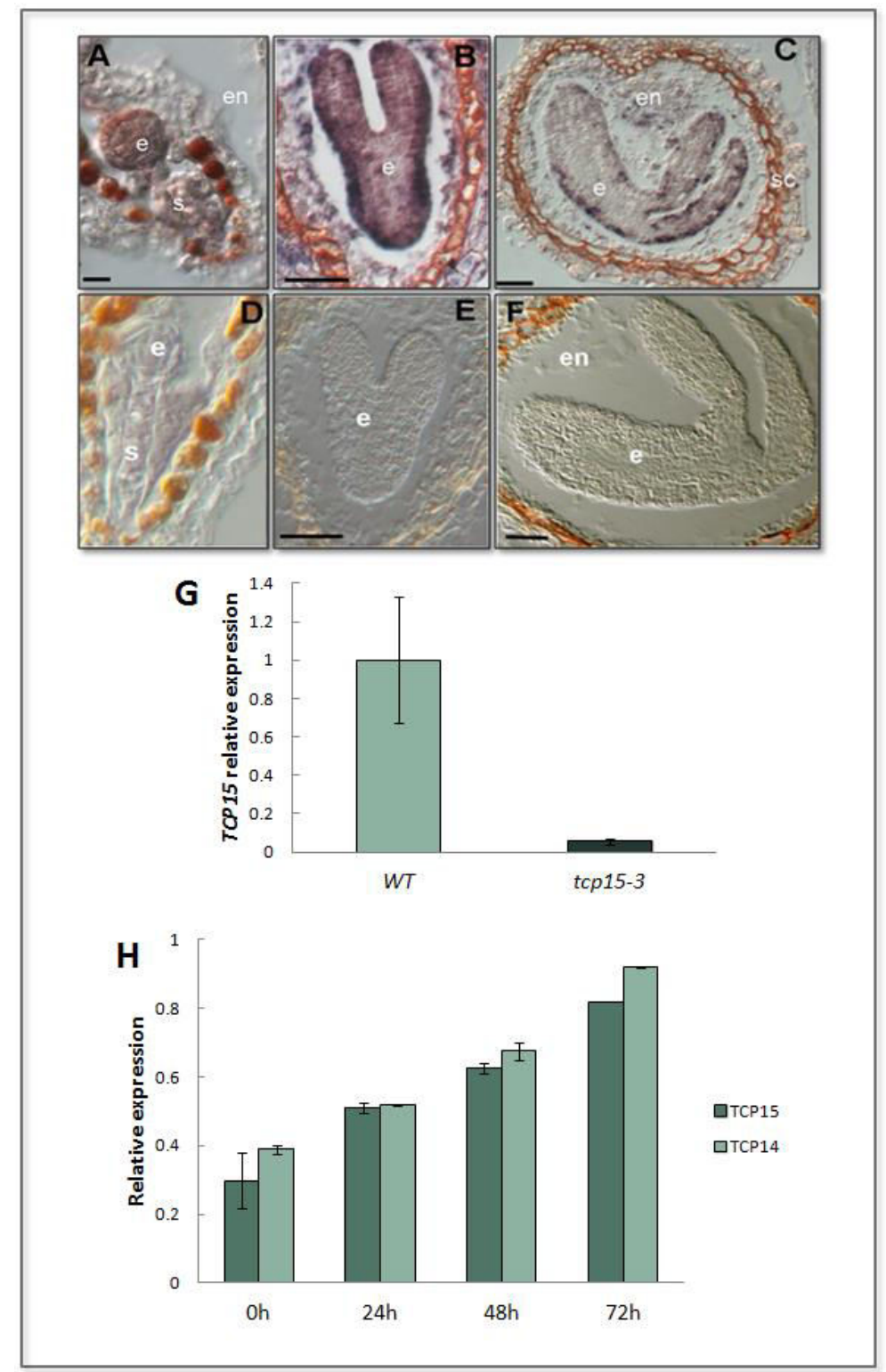

Figure 6.2. TCP14 and TCP15 are expressed in developing embryos. (A-F) In situ hybridizations of TCP15 in Arabidopsis wild type (A-C) and tcp15-3 seeds (D-F). Antisense probe was used in transversal sections of embryos in different developmental stages: globular $(A, D)$, late heart/torpedo $(B, E)$ and cotiledonary or mature (C, F). Scale bars: $20 \mu \mathrm{M}(A, D) ; 50 \mu M(B, C, E, F)$. Letters: e, embryo; en, endosperm; s, suspensor; sc, seed coat. (G) Quantitative RT-PCR showing TCP15 expression level in wild type and tcp15-3 seeds imbibed for 24 hours (H) RT-qPCR experiment indicating TCP14 and TCP15 mRNA level at several time points during the germination of imbibed wild type seeds. Actin 2-8 is used as control gene. 
We carried out in situ hybridization assays of TCP15 in wild type and tcp15-3 embryos at different developmental stages (Figure 6.2A-F). In wild type, TCP15 mRNA was detected in developing embryos since globular stage, although its expression decreases in mature embryos. It is also expressed in the endosperm from the torpedo stage on. On the other hand, TCP15 antisense probe was not detected in tcp15 mutant embryos, indicating that the probe is specific. The very low TCP15 expression level in the mutant was confirmed by RT-qPCR in tcp15-3 seeds (Figure 6.2G).

The role of TCP14 and TCP15 in the germinating embryo was also supported by the observation that the level of expression of both genes increased progressively during at least the first three days after seed imbibition (Figure $6.2 \mathrm{H})$.

\section{DELLAs do not regulate TCP14 and TCP15} transcriptionally

Given that GAs seem to promote germination via TCP14 and TCP15 (Figure 6.1), we decided to investigate the mechanism by which these hormones would regulate TCP activity.

To test if TCP gene expression was under the control of GA signaling, we analyzed mRNA levels of both TFs in response to an increasing level of the DELLA protein GAI. To this end, we chose a genetic approach by using the HS::gai-1 transgenic line (11) that expresses the dominant version of the DELLA protein GAI (gai-1) under the control of a temperature-inducible promoter. In this line a heatshock treatment leads to gai-1 accumulation. 
A

37 으 $1 \mathrm{~h}$
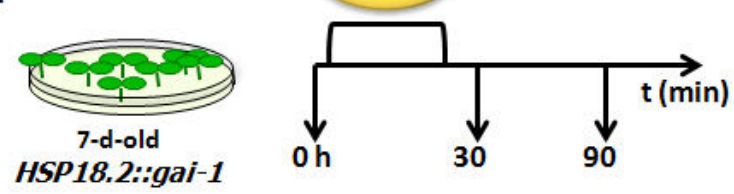

$37 \stackrel{0}{ } \mathrm{C}$ h

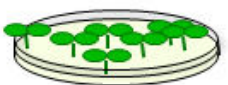

7-d-old

WT (Col-0)

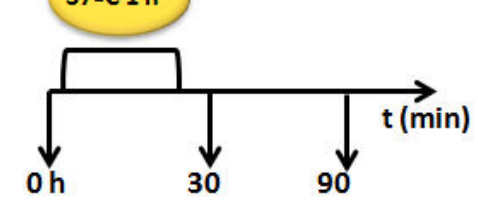

B

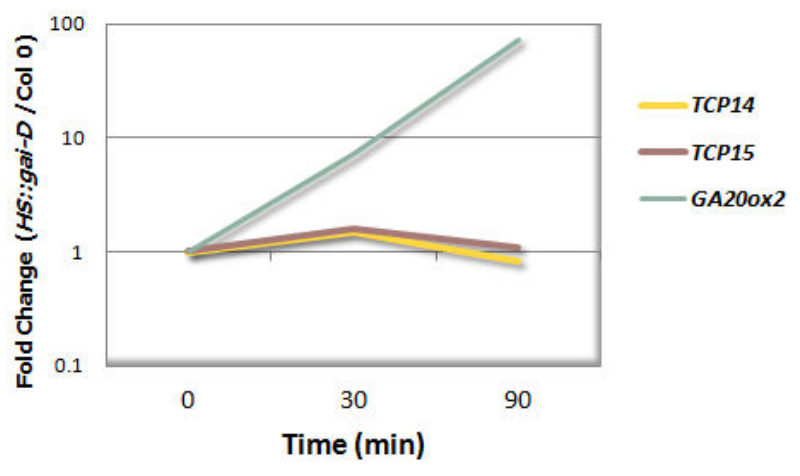

Figure 6.3. DELLA induction does not affect TCP14 and TCP15 mRNA levels in roots.

(A) Diagram of the experimental setting. In the transgenic line (HSP18.2::gai-1), the dominant version of the DELLA protein GAI (gai-1) is induced by a heat shock (1 hour at $37^{\circ} \mathrm{C}$ ). Seven day-old seedlings of each genotype were used for the experiment. Root samples were collected at several time points before and after de heat shock and RT-qPCR analysis was performed. Wild-type (Col-0) plants followed the same procedure as a control. (B) RT-qPCR experiment showing the fold change of the mRNA level of TCP14 (yellow) and TCP15 (mauve) within all the time-course. GA20ox2 (green) gene was used as a positive control.

As shown in Figure 6.3, the mRNA levels of TCP14 and TCP15 was not altered after the induction of gai-1, whereas the control gene GA20ox1 was clearly induced even 30 minutes after the treatment. These results suggest that if DELLAs regulate TCP14 and TCP15 activity, it should be at the post-transcriptional level. 


\section{DELLAs interact with TCP14 and TCP15}

It is widely acknowledged that DELLAs modulate multiple signaling pathways through protein-protein interaction with many TFs (reviewed for instance in Locascio et al., 2013 (12)). Therefore, the possibility that GAs promote germination by affecting DELLA-TCP14 and DELLA-TCP15 interactions was a very likely possibility.

Although the functions of the five DELLAs of Arabidopsis have been usually described as redundant, two DELLAs have been demonstrated to have a more relevant role in the regulation of germination: GAI and RGL2 (5). Consequently, we carried out yeast two hybrid assays to test the ability of these two DELLA proteins to interact with TCP14 and TCP15 (Figure 6.4). We found that both GAI and RGL2 are able to bind physically TCP14 and TCP15, indicating that a posttranscriptional regulation of these TF by DELLAs is plausible.

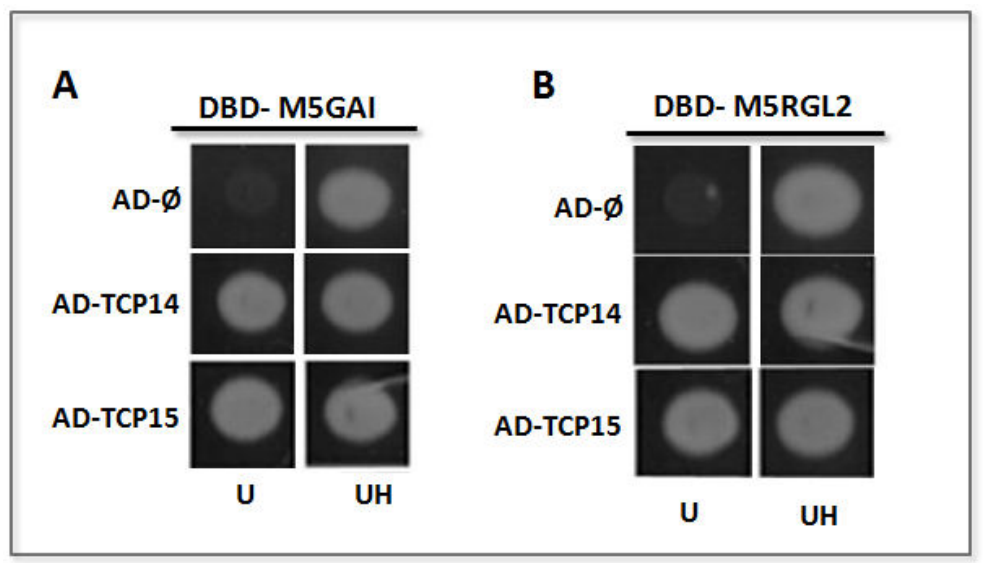

Figure 6.4. DELLA proteins interact with TCP14 and TCP15. Yeast two-hybrid assay of the interaction between truncated versions of GAI (M5GAI) (A) and RGL2 (M5RGL2) (B) with TCP14 and TCP15. (DBD, DNA binding domain; $A D$, activation domain; AD- $\phi$, activation domain empty vector; $\mathrm{U}$, uracil; $\mathrm{H}$, histidine).

To test if the interactions would also take place in planta, we first performed Bimolecular Fluorescence Complementation assays (BiFC) in Nicotiana benthamiana leaves. This analysis showed that the fluorescence from the reconstituted YFP appeared in the nuclei of epidermal cells of leaves co-infiltrated with YFN-TCP14 or YFN-TCP15, and YFC-GAI or YFC-RGL2, whereas fluorescence in the control leaves was below the threshold level (Figure 6.5A). Similarly, myc-GAI 
was efficiently pulled down with anti-HA antibodies in Nicotiana benthamiana leaves that co-expressed HA-TCP14, confirming the interaction between the TCPS and GAI and RGL2 (Figure 6.5B).

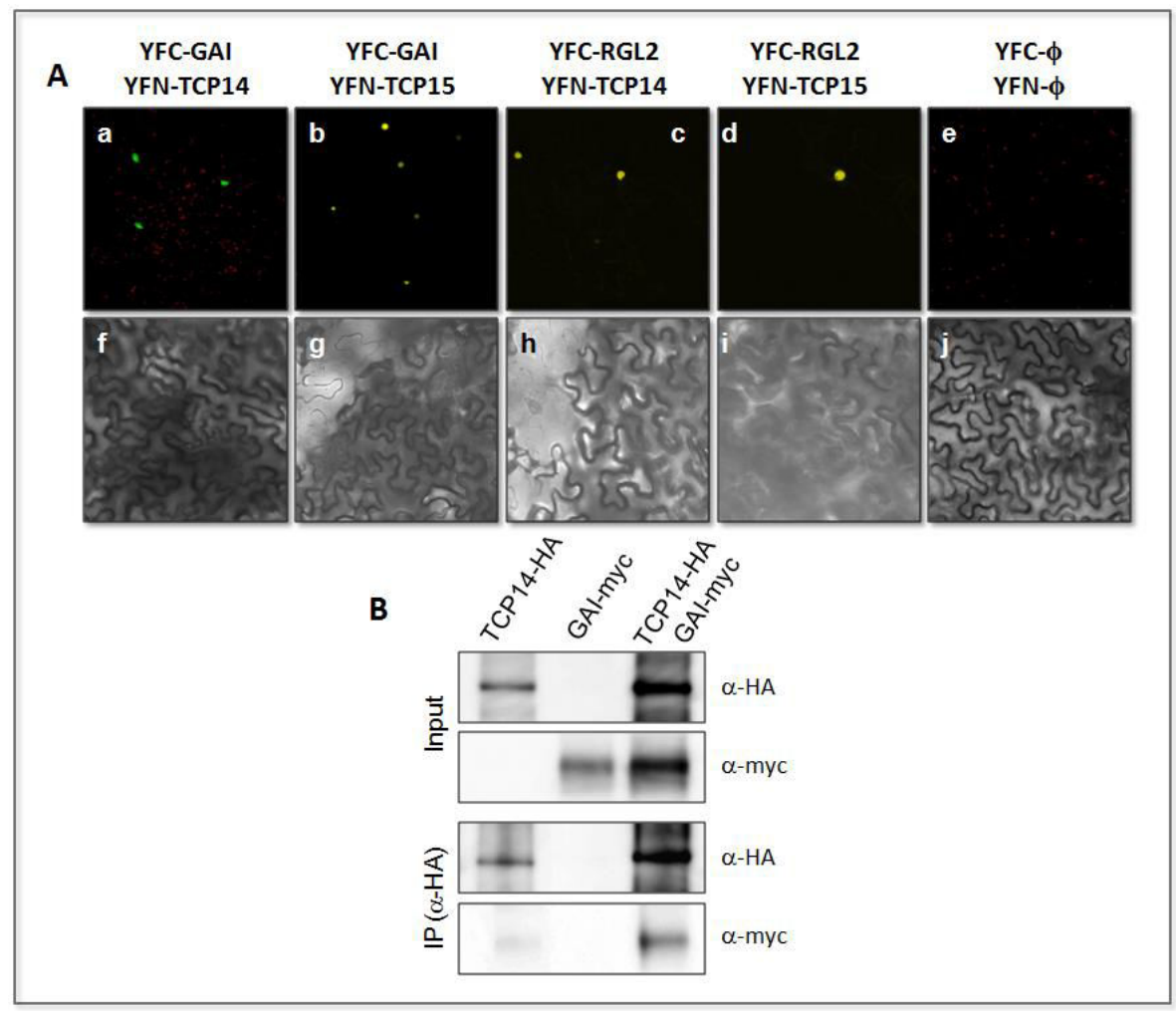

Figure 6.5. TCP14 and TCP15 interact with DELLA proteins in planta. (A) Bimolecular fluorescence complementation analysis showing the interaction of $\operatorname{TCP} 14(a, c)$ and $\operatorname{TCP} 15(b, d)$ proteins with GAI $(a, b)$ and RGL2 $(c, d)$ in nuclei of $N$. benthamiana epidermal leaf cells. The empty vectors of each construction were used as a negative control (e). The lower panel shows the visible chanel of each picture. (B) Co-immunoprecipitation of myc-GAI and HA-TCP14 expressed in N. benthamiana leaves. TCP14 was immunoprecipitated using anti-HA ( $\alpha-\mathrm{HA})$ conjugated paramagnetic beads, and TCP14 and GAI were detected in immunoblots using anti-HA and anti-myc, respectively. Note that GAI was co-immunoprecipitated with TCP14. The sizes of the bands correspond to the expected molecular weight of the fusion proteins.

As a matter of fact, in the course of this Thesis work, it was reported that TCP14 is able to interact with the five DELLAs from Arabidopsis, and TCP15 was proved to interact with at least RGA (13). Further co-immunoprecipitation analysis demonstrated that TCP14 and RGA also interact in planta. Besides, a recent $\mathrm{Y} 2 \mathrm{H}$ screen using the GRAS domain of GAI as bait against an arrayed library containing 
approximately 1,200 TFs from Arabidopsis showed that DELLAs can interact with 12 members of the TCP family (14). Among them, TCP14, TCP15 and four other members of the Class I TCPs (TCP8, TCP16, TCP19 and TCP23).

\section{GAl inactivates TCP14 upon interaction}

DELLAs have been reported to operate by at least two different mechanisms. They can either repress their targets by binding to TFs and impairing their capacity to activate transcription (sequestration mechanism) or they can function in the chromatin either as transactivation factors (15) or as co-repressors (16).

As it is indicated in the introduction, TCP transcription factors have a bHLHlike domain that is very similar to the one of PIFs and other bHLH proteins (17) and it is well established in the literature that DELLAs are able to interact with and sequestrate this family of transcription factors $(18,19)$. Therefore, our hypothesis would be that DELLAs bind physically TCPs and inhibit their transcriptional activity, rather than acting as transactivation factors.

In order to test this hypothesis, we performed transactivation assays in $N$. benthamiana leaves. To this end, we prepared a synthetic promoter consisting of six repeated copies of the Class I TCP consensus binding site (GTGGGCCCAC) (20) separated by a 6-nucleotide spacer (AAAAAA), and placed it upstream of a minimal $35 \mathrm{~S}$ promoter and the translational enhancer omega to control the expression of the Luciferase reporter gene (Figure 6.6A).

Next, we expressed this synthetic promoter alone and in the presence of a construct carrying a translational fusion of TCP14 with the transcriptional activator VP16, which caused an increase in the luciferase activity with respect to the control (Figure 6.6B). Remarkably, this activation was partially reversed when GAl was co-expressed, whereas GAl alone did not affect the activity of the reporter. In addition, we checked by western blot that the protein levels of TCP14 and GAI in all the conditions are comparable (Figure 6.6C).

In this context, our results are in line with the exhaustive studies made in the laboratory of Patrick Achard (13), where they performed electrophoretic mobility shift assay (EMSA), chromatin immunoprecipitation (ChIP) and transient expression assays and they demonstrated that DELLA-Class I TCP interaction inhibit TCP DNA-binding activity and therefore, its transcriptional function. 
Moreover, they also give a mechanistic explanation for these results. It is well known that the TCP domain is responsible of the DNA-binding capacity of TCPs. They show that the DELLAs prevent TCP DNA-binding activity by interacting with their TCP domain, in a similar manner that they act with bHLH proteins such as PIF3 or PIF4 $(18,19)$.

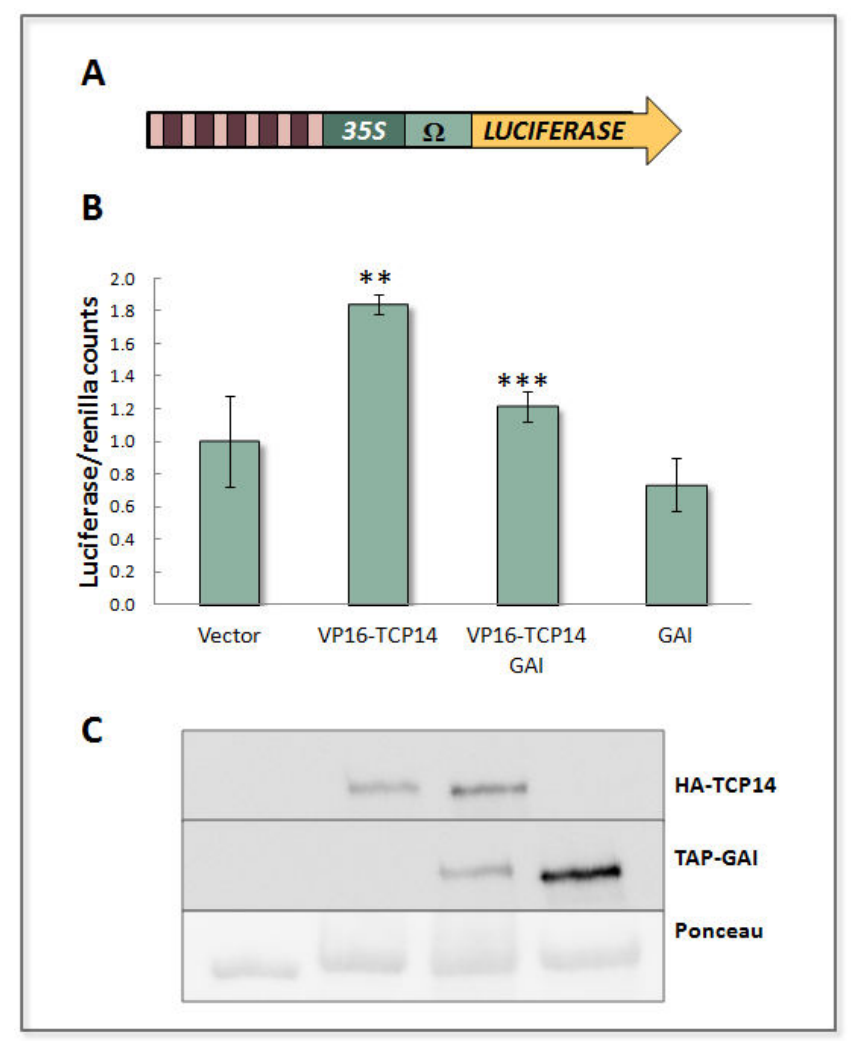

Figure 6.6. GAI inactivates TCP14 upon interaction. (A) Design of the synthetic promoter used for the transient expression assays in $N$. Benthamiana leaves. It consist of six repeated copies of the Class I-TCP consensus binding site (pink boxes) separated by a 6-nucleotide spacer (AAAAAA, red boxes) placed upstream of a minimal $35 \mathrm{~S}$ promoter (dark green box) and the translational enhancer omega (light green box) to control the expression of the Luciferase reporter gene (orange arrow). Renilla Luciferase under $35 \mathrm{~S}$ promoter in the same construct was used as control. (B) Transient expression assays for TCP14 (Vector, infiltration with the synthetic promoter alone used as a negative control; VP16, transcriptional activator). (C) Western blot corresponding to the transient expression assay for TCP14. TCP14 and GAI were detected in immunoblots using anti-HA and antimyc, respectively. Ponceau was used as a load control. Statistic differences are shown (Pvalue<0.05). 


\section{Role of TCP14 and TCP15 regulating cell division in the root apical meristem}

The physiological observation that TCP14 and TCP15 act downstream of GAs in the promotion of germination provides a possible biological framework to test the relevance of the molecular interaction between DELLAs and TCPs. But which aspect of germination would be directly regulated by the GA-TCP module?

It is well established that Class I TCPs stimulate cell proliferation by activating the transcription of several cell-cycle genes. This was first indicated by Kosugi et al. in 1997 (21), showing that two TCP proteins of rice, PCF1 and PCF2, bind a conserved region (GGNCCCAC) in the promoter of the PROLIFERATING CELL NUCLEAR ANTIGEN (PCNA) gene (21). Further research demonstrate that these TFs interact with promoters of several cell-cycle genes such as the cyclins CYCA2;3 and CYCB1;1, PCNA2, and RETINOBLASTOMA-RELATED 1 (RBR1) (22-25). In fact, TCP14 and TC15 have been found to jointly regulate plant stature by promoting cell proliferation in young internodes (6) and in the inflorescence shoot apex (13). What is more, TCP14 have been demonstrated to positively regulate CYC1 in the radicle of 48 hours-imbibed seedlings (7).

Remarkably, the germination process requires active cell division at embryonic root tips to cause root protrusion (2), followed by a sequential activation of cell division in cotyledons, SAM and secondary meristems. In the dry seed, cells of the embryo are arrested in the G1 phase of the cell cycle, and activation of cell division is essential for the success of the germination. Moreover, transcriptional studies demonstrate that several cyclins (CYCs) are greatly induced in the RAM before root emergence and these early activated CYCS play key roles in regulating the extent of cell cycle activation and root emergence. In other words, CYCs regulate cell cycle reentry during RAM activation to promote radicle growth, root protrusion and a successful germination.

Taking all these data into account, we hypothesized that TCP14 and TCP15 could mediate the activation of cell-cycle genes in the RAM early in the germination process and this would lead to root emergence. Therefore, we investigated whether these two TCPs are able to regulate cell division at the root apex of germinating embryos. 


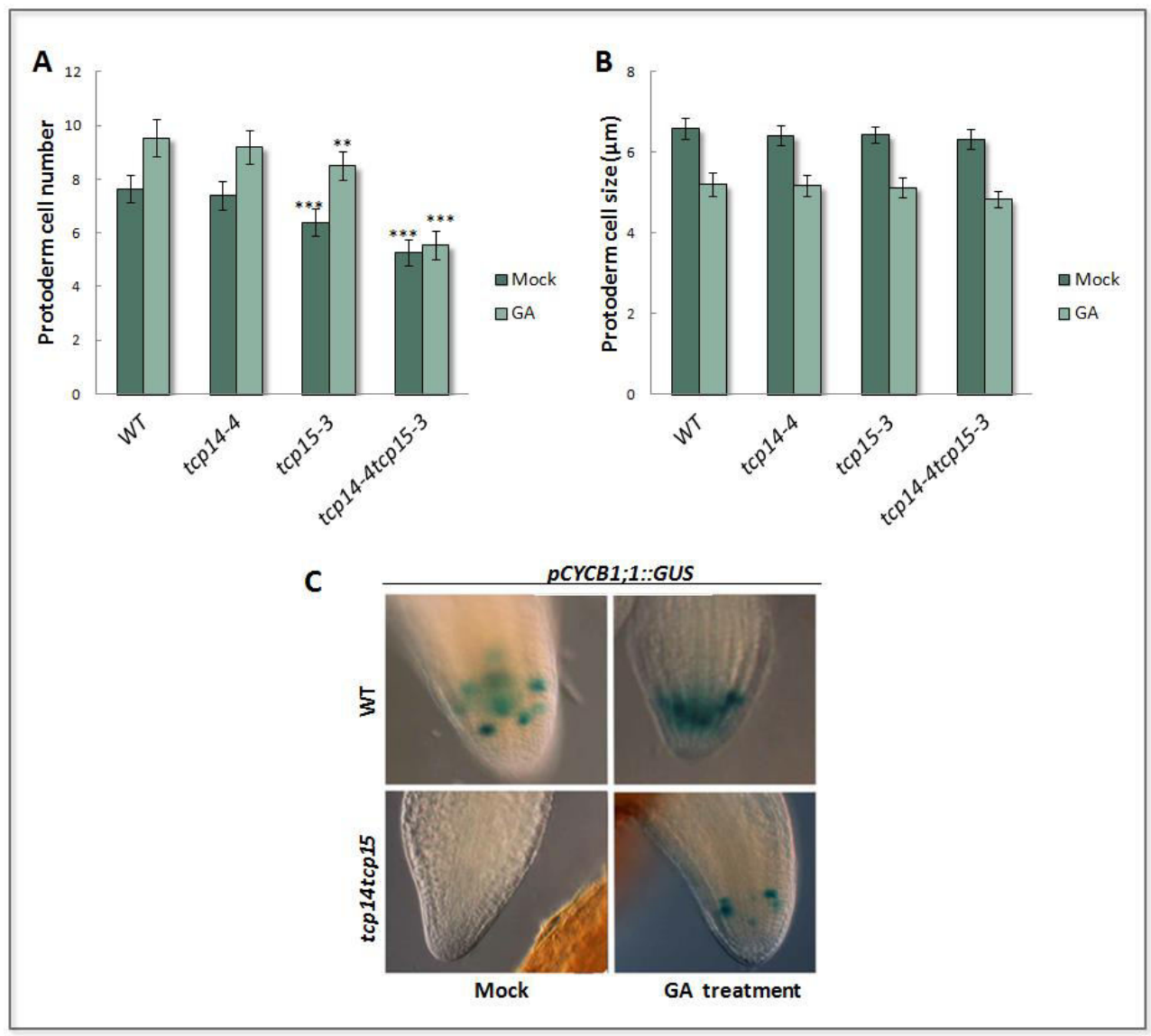

Figure 6.7. TCP14 and TCP15 regulate cell division but not cell expansion in the

RAM. Graphs showing cell number (A) and cell size (B) of protoderm cells of the RAM at mature embryos in wild type, single and double mutants in two different conditions: mock (dark green bars) and $1 \mu \mathrm{M} \mathrm{GA}$ treatment (light green bars). Statistic differences according with $t$ test analysis are shown (***, $\left.\mathrm{P}<0.0001 ;{ }^{* *}, \mathrm{P}=0.0023\right)$. (C) The transgenic line $p C Y C B 1 ; 1:: G U S$ in wild type and tcp144 tcp15-3 double mutant genetic backgrounds is used to carry out GUS staining assays in embryos. The expression pattern is evaluated in two different conditions: mock and $1 \mu \mathrm{M} \mathrm{GA}$ treatment, as indicated.

We measured the number and size of protoderm cells in the RAM (Figure 6.7 $A$ and B, dark green bars) of wild type, single and double mutants of TCP14 and TCP15 mature embryos. Whereas cell size was similar in all genotypes, cell number was greatly and significantly decreased in the double mutant tcp14-4 tcp15-3 and, to a lesser extent, in the tcp15-3 mutant. These results indicate that TCP15 and also TCP14 (its important role is depicted by the great reduction of cell number in the double mutant) are relevant factors promoting cell division and 
proliferation in the RAM during germination and they act jointly constituting a specific module of regulation in the germination process. Remarkably, the module DELLAs/TCPs seems to exert its control specifically over cell proliferation but not over cell size.

To further evaluate the involvement of GA signaling in this module of regulation, we repeated the measurements after GA application (Figure 6.7 A and $B$, light green bars). Interestingly, GA application greatly increased the cell number in the tcp15-3 mutant RAM, although it was not sufficient to restore it to control level. Moreover, GA treatment had no effect in the double mutant and does not affect cell size in the RAM.

Interestingly, transgenic lines such as $p C Y C B 1 ; 1:: G U S$ have been extensively used as cell division reporters (26). In particular, this line maks cells at the G2/M phase of the cell cycle. Therefore, to further support the role of TCP14 and TCP15 controlling cell division and proliferation at the embryonic RAM, we assessed the activity of CYCB1;1::GUS in different genetic backgrounds and conditions (Figure 6.7C). Results show that GUS staining is completely abolished in the double mutant background in normal conditions, in accordance with our previous observations. When plants are exposed to a GA treatment, it is clearly seen an increase in cell division in the wild type background, and the ability of GAs to promote this increase in CYCB1;1 activity was mostly suppressed in double mutant embryos.

These results are in agreement with the independent observation by the Achard group that TCP14 binds TCP binding motives in the promoter of CYCA2;3, CYCB1;1, PCNA2, and RBR1 (13). What is more, in the same study, an in silico analysis defined the most probable Class I TCP consensus motif (KHGGGVC) and it was found that $39 \%$ of the core cell-cycle genes ( 29 of 74 genes) have at least one TCP consensus motif within their $1 \mathrm{~kb}$ promoter sequences.

In other words, TCP14 and TCP15 constitute an essential module of regulation of the germination process by promoting cell division and proliferation in the RAM, and DELLAs inhibit this activity most likely by a sequestration mechanism, given their physical interaction. This model is in agreement with the observation that GA application did not restore cell number in the double mutant. 
Nevertheless, this DELLA-TCP module seems to exert its control specifically over cell proliferation, and not cell size. The fact that a little number of cells is stained in the double mutant in response to GA might be due to other GA-dependent mechanisms involved in the promotion of cell cycle progression. Therefore, TCP14 and TCP15 seem to promote cell division in the RAM of germinating embryos as opposed to the situation in the quiescent state of the seed previous to germination, where DELLAs impair TCP function by their physical interaction.

Regarding to this subject, we have to take into account again recent studies made in Arabidopsis inflorescences by the group of Dr. Achard (13), which are closely related to our subject. They showed that TCP14 capacity to bind the promoter of several cell-cycle genes (CYCA2;3, CYCB1;1, PCNA2, and RBR1) decreased in inflorescences accumulating DELLAs (after PAC treatment) in comparison with GA-treated inflorescences. Furthermore, they performed transient expression assays in Nicotiana benthamiana leaves using a pCYCB1;1::GUS construct as a reporter for TCP14 transcriptional activity. They showed an increase in the reporter activity by TCP14 expression, whereas this induction is inhibited by RGA co-expression. In addition, they measured the expression levels of CYCA2;3, CYCB1;1, PCNA2, and RBR1 in dissected inflorescence shoot apices treated and not treated with PAC of wild type, tcp14-4 tcp15-3 double mutant and a transgenic line mutant in TCP14 and TCP15 and with reduced expression of TCP8 and TCP22. Upon PAC treatment, they found an expression decrease in all cell-cycle genes in wild type and the double mutant, whereas the transgenic line lost a great deal of sensibility to the treatment. These results further confirm our hypothesis that DELLAs repress cell-cycle genes by sequestrating Class I TCPs. Also, this mechanism seems to be universal, given that it is taking place in developmental moments so different such as roots of germinating seeds and in inflorescences.

\section{Role of TCP14 and TCP15 regulating root growth in later} stages of development

To investigate whether the regulation of cell division at the RAM by the GATCP module would also extend beyond germination, we also measured the lengths of roots of young seedlings of wild type, tcp14 and tcp15 single mutants and the double mutant, since this trait might be affected as a consequence of a defect in the cell division at the RAM (Figure 6.8 A and B, dark green bars). 
Both the single and the double mutants presented a shorter root than that of the wild type in early stages of the development (four days after germination, Figure 6.8A). However, in the case of the single mutants, this difference in root length decreased with the age of the plant, becoming non significant in the case of tcp14 (Figure 6.8B). Interestingly, the roots of the double mutant were still significantly shorter than wild-type roots even seven days after germination.

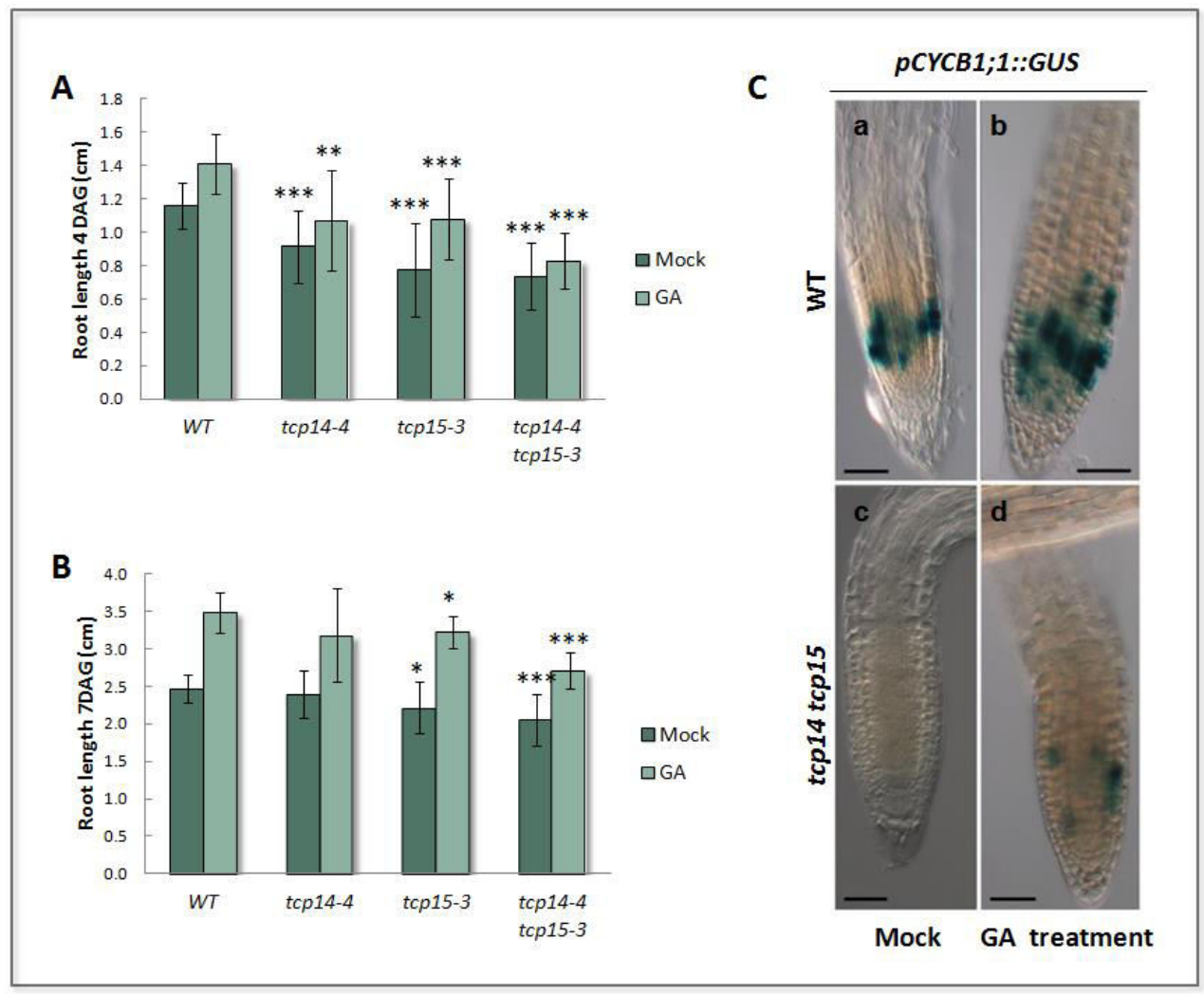

Figure 6.8. TCP14 and TCP15 regulate root growth. (A, B) Graphs showing root length of wild type, single and double mutant seedlings at 4 (A) and 7 (B) days after germination (DAG) in two different conditions: mock (dark green bars) and $1 \mu \mathrm{M} \mathrm{GA}$ treatment (light green bars). Asterisks indicate significant statistical differences respect to the WT control according to the test (P-value<0.05) (C) $p C Y C B 1 ; 1:: G U S$ expression in 7 day-old seedling roots in wild type $(\mathrm{a}, \mathrm{b})$ and tcp14-4 tcp15-3 double mutant (c,d) backgrounds. Staining of the mock $(a, c)$ and $1 \mu \mathrm{M} \mathrm{GA}_{3}$ treatment $(b, d)$ are shown (Scale $=100 \mu \mathrm{M})$.

Next, we evaluated the role of GA in this process, so we treated the plants with GA and performed the same experiment (Figure 6.8, light green bars). As it can be seen, GAs promoted root elongation in all the cases, especially in the single 
mutants, and its effect was more notorious in later stages of root growth (seven days after germination), when GA application completely restored the phenotype in tcp14 and the difference between tcp15 and the control was reduced. It is important to remark that the double mutant was less sensitive to the treatment and its final root length was significantly shorter and seriously compromised even seven days after germination. The fact that there was a slight increase in root length in the double mutant after GA application could be due to additional mechanisms by which GAs facilitate this trait.

In agreement with the effect of GAs on root length, the expression of the pCYCB1;1::GUS marker was induced after GA application in the RAM of wild-type seedlings, but not in the tcp14 tcp15 double mutant, also indicating that final root size is strongly influenced by cell divisions at the RAM (Figure 6.8C).

All in all, these results indicate that the TCP14/TCP15 module supports cell division in the Arabidopsis RAM by activating cell-cycle genes and is required for GAs to promote root growth post-embrionically, as well as embrionically. In recent years several works have provided genetic support for the involvement of the interactors of DELLAs in the control of seed germination $(27,28)$. Moreover, control of DELLAs over cell-cycle progression at the RAM has also been reported $(3,4)$. Nonetheless, a molecular mechanism explaining the action of DELLAs on seed germination has not been proposed. Work in this Thesis provide evidence for such a mechanism, showing that the transcriptional regulators DELLAs maintain the embryo in a quiescent state by restricting cell-cycle progression in the embryonic RAM through the inhibition of TCP14 and TCP15 activities upon interaction. Given the strong influence of environmental conditions on DELLA levels (29), the DELLA-TCP module acts as a relay for environmental information into the cell cycle at the RAM to coordinate root emergence with other events during seed germination.

\section{References}

1. Holdsworth MJ, Bentsink L, Soppe WJ. Molecular networks regulating Arabidopsis seed maturation, after-ripening, dormancy and germination. The New phytologist. 2008;179(1):33-54.

2. Masubelele NH, Dewitte W, Menges M, Maughan S, Collins C, Huntley R, et al. D-type cyclins activate division in the root apex to promote seed 
germination in Arabidopsis. Proceedings of the National Academy of Sciences of the United States of America. 2005;102(43):15694-9.

3. Achard P, Gusti A, Cheminant S, Alioua M, Dhondt S, Coppens F, et al. Gibberellin signaling controls cell proliferation rate in Arabidopsis. Current biology : CB. 2009;19(14):1188-93.

4. Ubeda-Tomas S, Federici F, Casimiro I, Beemster GT, Bhalerao R, Swarup $R$, et al. Gibberellin signaling in the endodermis controls Arabidopsis root meristem size. Current biology : CB. 2009;19(14):1194-9.

5. Lee $S$, Cheng $H$, King KE, Wang W, He $Y$, Hussain A, et al. Gibberellin regulates Arabidopsis seed germination via RGL2, a GAI/RGA-like gene whose expression is up-regulated following imbibition. Genes \& development. 2002;16(5):646-58.

6. Kieffer M, Master V, Waites R, Davies B. TCP14 and TCP15 affect internode length and leaf shape in Arabidopsis. The Plant journal : for cell and molecular biology. 2011;68(1):147-58.

7. Tatematsu K, Nakabayashi K, Kamiya Y, Nambara E. Transcription factor AtTCP14 regulates embryonic growth potential during seed germination in Arabidopsis thaliana. The Plant journal : for cell and molecular biology. 2008;53(1):42-52.

8. Danisman S, van Dijk AD, Bimbo A, van der Wal F, Hennig L, de Folter S, et al. Analysis of functional redundancies within the Arabidopsis TCP transcription factor family. Journal of experimental botany. 2013;64(18):5673-85.

9. Curaba J, Moritz T, Blervaque R, Parcy F, Raz V, Herzog M, et al. AtGA3ox2, a key gene responsible for bioactive gibberellin biosynthesis, is regulated during embryogenesis by LEAFY COTYLEDON2 and FUSCA3 in Arabidopsis. Plant physiology. 2004;136(3):3660-9.

10. Yamauchi Y, Ogawa M, Kuwahara A, Hanada A, Kamiya Y, Yamaguchi S. Activation of gibberellin biosynthesis and response pathways by low temperature during imbibition of Arabidopsis thaliana seeds. The Plant cell. 2004;16(2):367-78.

11. Alabadi D, Gallego-Bartolome J, Orlando L, Garcia-Carcel L, Rubio V, Martinez $C$, et al. Gibberellins modulate light signaling pathways to prevent Arabidopsis seedling de-etiolation in darkness. The Plant journal : for cell and molecular biology. 2008;53(2):324-35.

12. Locascio A, Blazquez MA, Alabadi D. Genomic analysis of DELLA protein activity. Plant \& cell physiology. 2013;54(8):1229-37.

13. Daviere JM, Wild M, Regnault T, Baumberger N, Eisler $H$, Genschik $P$, et al. Class I TCP-DELLA interactions in inflorescence shoot apex determine plant height. Current biology : CB. 2014;24(16):1923-8.

14. Marin-de la Rosa N, Sotillo B, Miskolczi P, Gibbs DJ, Vicente J, Carbonero $P$, et al. Large-scale identification of gibberellin-related transcription factors defines group VII ETHYLENE RESPONSE FACTORS as functional DELLA partners. Plant physiology. 2014;166(2):1022-32. 
15. Daviere JM, Achard P. Gibberellin signaling in plants. Development. 2013;140(6):1147-51.

16. Hyun Y, Richter R, Vincent C, Martinez-Gallegos R, Porri A, Coupland G. Multi-layered Regulation of SPL15 and Cooperation with SOC1 Integrate Endogenous Flowering Pathways at the Arabidopsis Shoot Meristem. Developmental cell. 2016;37(3):254-66.

17. Martin-Trillo M, Cubas P. TCP genes: a family snapshot ten years later. Trends in plant science. 2010;15(1):31-9.

18. de Lucas $M$, Daviere JM, Rodriguez-Falcon $M$, Pontin $M$, Iglesias-Pedraz $\mathrm{JM}$, Lorrain $\mathrm{S}$, et al. A molecular framework for light and gibberellin control of cell elongation. Nature. 2008;451(7177):480-4.

19. Feng S, Martinez C, Gusmaroli G, Wang Y, Zhou J, Wang F, et al. Coordinated regulation of Arabidopsis thaliana development by light and gibberellins. Nature. 2008;451(7177):475-9.

20. Viola IL, Reinheimer R, Ripoll R, Manassero NG, Gonzalez DH. Determinants of the DNA binding specificity of class I and class II TCP transcription factors. The Journal of biological chemistry. 2012;287(1):347-56.

21. Kosugi S, Ohashi Y. PCF1 and PCF2 specifically bind to cis elements in the rice proliferating cell nuclear antigen gene. The Plant cell. 1997;9(9):1607-19.

22. Tremousaygue D, Garnier L, Bardet C, Dabos P, Herve C, Lescure B. Internal telomeric repeats and 'TCP domain' protein-binding sites co-operate to regulate gene expression in Arabidopsis thaliana cycling cells. The Plant journal : for cell and molecular biology. 2003;33(6):957-66.

23. Li C, Potuschak T, Colon-Carmona A, Gutierrez RA, Doerner P. Arabidopsis TCP20 links regulation of growth and cell division control pathways. Proceedings of the National Academy of Sciences of the United States of America. 2005;102(36):12978-83.

24. Herve C, Dabos P, Bardet C, Jauneau A, Auriac MC, Ramboer A, et al. In vivo interference with AtTCP20 function induces severe plant growth alterations and deregulates the expression of many genes important for development. Plant physiology. 2009;149(3):1462-77.

25. Li ZY, Li B, Dong AW. The Arabidopsis transcription factor AtTCP15 regulates endoreduplication by modulating expression of key cell-cycle genes. Molecular plant. 2012;5(1):270-80.

26. Colon-Carmona A, You R, Haimovitch-Gal T, Doerner P. Technical advance: spatio-temporal analysis of mitotic activity with a labile cyclin-GUS fusion protein. The Plant journal : for cell and molecular biology. 1999;20(4):503-8.

27. Zhang ZL, Ogawa M, Fleet CM, Zentella R, Hu J, Heo JO, et al. Scarecrowlike 3 promotes gibberellin signaling by antagonizing master growth repressor DELLA in Arabidopsis. Proceedings of the National Academy of Sciences of the United States of America. 2011;108(5):2160-5. 
28. Park J, Nguyen KT, Park E, Jeon JS, Choi G. DELLA proteins and their interacting RING Finger proteins repress gibberellin responses by binding to the promoters of a subset of gibberellin-responsive genes in Arabidopsis. The Plant cell. 2013;25(3):927-43.

29. Claeys H, Skirycz A, Maleux K, Inze D. DELLA signaling mediates stressinduced cell differentiation in Arabidopsis leaves through modulation of anaphase-promoting complex/cyclosome activity. Plant physiology. 2012;159(2):739-47. 

7. General Discussion 

Plant development is a repetitive process of organ initiation from primary meristems (SAM and RAM). As plants are sessile organisms, they need to adjust their growth and developmental processes according to environmental conditions to guarantee their survival. To achieve this plasticity, plants perceive and integrate environmental conditions, and translate these signals to the intrinsic genetic programs of the plant (1). A paradigmatic example of the mechanisms that support this interplay between the plant and the environment is the regulation of DELLA stability by environmentally modulated GA metabolism, such that cellular DELLA levels turn out to be directly dependent on light, temperature and other external cues. Through physical interaction with a wide variety of TFs, DELLAs can modulate for instance the balance between growth and defense when plants are subjected to adverse conditions, such as cold, salt and osmotic stress (2). This is a critical issue for plants, since the ability to adaptively restrain or resume growth ensures plant survival. In this context, the results shown in this Thesis provide an initial molecular framework to study how the activity of primary meristems is regulated by the environment:

(i) GAs influence the size of the SAM by interfering with the mutual regulation between DELLAs and KNOX factors.

(ii) GAs trigger cell divisions in the RAM that permit root protrusion during germination, by relieving DELLA-dependent repression of Class I TCPs in the embryos.

\section{DELLA-TCP interaction, an example of tissue specific signaling}

The discovery the DELLAs can interact with multiple TFs in higher plants represented a molecular mechanism by which a single hormone could exert different effects in different spatial and temporal contexts. In other words, DELLAs would have access to different partner TFs in different tissues or developmental stages, and physical interaction with them would consequently affect very different transcriptomes. Here we have provided new evidence for differential effects of DELLAs in shoot and root tips, depending on the type of TCP transcription factors expressed in each region of the plant. Importantly, the molecular mechanism by which DELLAs act in both cases is the same: the inhibition of TCPs' ability to regulate their downstream targets. However, the 
consequence of this regulation in the shoot apex is the control of meristematic cell size and the contribution to the establishment of boundaries between differentiated and undifferentiated regions of the meristem, while in the root apex the consequence is the regulation of cell divisions $(3,4)$.

With respect to the molecular mechanism by which DELLAs regulate TCP activity, we favour the model in which the interaction prevents TCP binding to target promoters for several reasons. Curiously, modelling studies of the threedimensional structure of the DNA binding domain of TCPs conclude that it resembles the structure of bHLH domains with high confidence (5). This suggests that similar motifs recognized by DELLAs are present in the DNA binding domains of both TF families. Moreover, in support of our transactivation assays in $N$. benthamiana, the group of Dr. Patrick Achard found during the course of this Thesis using electrophoretic mobility shift assays (EMSA) and chromatin immunoprecipitation (ChIP) that the DELLA-Class I TCP interaction inhibits TCP DNA-binding activity (6).

\section{DELLA function in meristems: a possible link with the} environment

It has been widely documented how plant developmental decisions and growth rate are tightly influenced by the environment. Here we propose that DELLAs would transduce environmental information to the activity of at least the primary meristems. Indications that plant meristems change their activity depending on environmental cues are very clear. For instance, cell division at the RAM is triggered by exposure of seeds to germination-promoting signals such as the presence of water and particular light wavelengths (7). And cell division rate at the SAM and the size of the apical dome increase during the transition from the vegetative to the reproductive phase of growth, which is triggered by the inductive photoperiodic signals (8). Moreover, stress signals also modify the homeostasis of the primary meristems, to allow better adaptation to the different circumstances encountered by the plants. This is for example the case of high temperatures, which arrest the activity of the SAM while the plant undergoes physiological reprogramming to cope with these factors (9). Similarly, it has been shown that the RAM transiently decreases its activity upon exposure to high salt concentration, but later resumes growth even if the stress factor is still present (10). And phosphate availability critically alters the activity of the dormant RAMs 
of secondary roots, thereby promoting changes in the root architecture that favour phosphate detection and assimilation $(11,12)$.

Does the interaction between DELLAs and TCPs mediate environmental signaling in the primary meristems, as we propose? In this Thesis, we have not explored experimentally the direct implication of DELLAs in the transduction of environmental signals specifically to meristematic cells. However, at least three lines of evidence support this hypothesis, which should be tested in the future.

First, dellaKO mutants have been shown to elude the growth arrest imposed by different types of stress, such as exposure to salt (13). In this case, most of the growth of the plant is supported by cell divisions at the meristems, so it is quite reasonable that DELLAs participate in this particular process depending on the environmental situation. Although other unidentified interactors of DELLAs might be the target for stress-imposed growth arrest, the observation that TCPs participate in the regulation of key cell-cycle genes seems to indicate that this particular interaction is probably critical for the control of meristematic activity under stress.

Second, our transcriptomic analysis of DELLA-dependent KNAT1 targets shows that this category of genes largely includes those involved in environmental regulation, or in processes directly regulated by the environment (such as response to light and abiotic stresses in Table 4.4), suggesting that the DELLA-TCPKNOX module probably mediates adaptation of SAM activity to environmental conditions.

Third, the observation that GA levels increase dramatically (over 100-fold) at the Arabidopsis shoot apex during the transition to flowering (8) suggests that a mechanism to maintain SAM homeostasis must be in place, involving DELLAs. Remarkably, transcriptional analysis in the shoot apex demonstrated that the transcription of GA-negative feedback-regulated GA20OX and GA3OX genes were unchanged when the $\mathrm{GA}_{4}$ levels started to increase, and expression of positively regulated GA2OX genes was increased (8). Importantly, the increase in size of the meristem during flowering is accompanied not only by an increase in GA input (8), but also by an increase in KNOX genes (KNAT1 and STM) expression (eFP Browser (14)), that could explain the increase in GA2OX transcription. The observation that GA and KNAT1 levels increase in parallel during this stage supports that our model of KNAT1/GA balance might be also important during the transition from 
vegetative to reproductive SAMs to guarantee a controlled growth at this temporal window and even later in the reproductive phase.

Finally, it will be interesting to test if the DELLA-TCP-KNOX module is also operating at the cambium during secondary growth. Unpublished observations in our lab have shown that DELLA genes are expressed in cambial cells, and $b p$ mutants have been shown to display defects in vascular development (15). Considering that secondary growth (both in woody species and in herbaceous plants like Arabidopsis) is highly influenced by the environment, it is quite likely that at least DELLAs will participate in this regulation. If eventually proven, DELLAs would confirm and expand their role as regulatory players for environmental control of development.

\section{References}

1. Casal JJ, Fankhauser C, Coupland G, Blazquez MA. Signalling for developmental plasticity. Trends in plant science. 2004;9(6):309-14.

2. Colebrook EH, Thomas SG, Phillips AL, Hedden P. The role of gibberellin signalling in plant responses to abiotic stress. The Journal of experimental biology. 2014;217(Pt 1):67-75.

3. Manassero NG, Viola IL, Welchen E, Gonzalez DH. TCP transcription factors: architectures of plant form. Biomolecular concepts. 2013;4(2):111-27. 4. Martin-Trillo M, Cubas P. TCP genes: a family snapshot ten years later. Trends in plant science. 2010;15(1):31-9.

5. Aggarwal P, Das Gupta M, Joseph AP, Chatterjee N, Srinivasan N, Nath U. Identification of specific DNA binding residues in the TCP family of transcription factors in Arabidopsis. The Plant cell. 2010;22(4):1174-89.

6. Daviere JM, Wild M, Regnault T, Baumberger N, Eisler H, Genschik P, et al. Class I TCP-DELLA interactions in inflorescence shoot apex determine plant height. Current biology : CB. 2014;24(16):1923-8.

7. Masubelele NH, Dewitte W, Menges M, Maughan S, Collins C, Huntley R, et al. D-type cyclins activate division in the root apex to promote seed germination in Arabidopsis. Proceedings of the National Academy of Sciences of the United States of America. 2005;102(43):15694-9.

8. Eriksson $\mathrm{S}$, Bohlenius $\mathrm{H}$, Moritz T, Nilsson O. GA4 is the active gibberellin in the regulation of LEAFY transcription and Arabidopsis floral initiation. The Plant cell. 2006;18(9):2172-81.

9. Ma W, Wu F. The LBD12-1 Transcription Factor Suppresses Apical Meristem Size by Repressing Argonaute 10 Expression. 2017;173(1):801-11. 
10. Dinneny JR. Traversing organizational scales in plant salt-stress responses. Current opinion in plant biology. 2015;23:70-5.

11. Peret B, Desnos T. Root architecture responses: in search of phosphate. 2014;166(4):1713-23.

12. Niu YF, Chai RS, Jin GL, Wang H, Tang CX, Zhang YS. Responses of root architecture development to low phosphorus availability: a review. Annals of botany. 2013;112(2):391-408.

13. Achard P, Cheng H, De Grauwe L, Decat J, Schoutteten H, Moritz T, et al. Integration of plant responses to environmentally activated phytohormonal signals. Science. 2006;311(5757):91-4.

14. Winter D, Vinegar B, Nahal H, Ammar R, Wilson GV, Provart NJ. An "Electronic Fluorescent Pictograph" browser for exploring and analyzing largescale biological data sets. PloS one. 2007;2(8):e718.

15. Liebsch D, Sunaryo W, Holmlund M, Norberg M, Zhang J, Hall HC, et al. Class I KNOX transcription factors promote differentiation of cambial derivatives into xylem fibers in the Arabidopsis hypocotyl. Development. 2014;141(22):43119. 

8. Conclusions 

Results in this Thesis provide new evidence of the role of GAs controlling two different aspects of Arabidopsis primary meristems, cell expansion and cell division. In particular, GAs exert their action by releasing the inhibitory effect of DELLAs over two sub-classes of TCP TFs:

1. DELLAs inhibit CIN-TCP activity in the boundaries of the shoot apical meristem, guaranteeing KNAT1 expression in that zone. KNAT1 and GAs promote cell expansion and, therefore, the balance between both activities is relevant to control meristem size.

2. The promotion of cell division by TCP14 and TCP15 in the root apical meristem before radicle protrusion is essential for germination, and, in later stages of development, for root growth. DELLAs impair cell division in the root meristem by inhibiting the activity of these TFs. 

9. Materials and Methods 



\section{Plant material and growth conditions}

\section{Plant material}

Arabidopsis thaliana accessions Col-0, Ler and No-O were used as wild-types as indicated. A list of the previously described lines used in this work can be found in Tables I and II.

\begin{tabular}{|cccc|}
\hline & \multicolumn{2}{c|}{ Table I: Previously generated lines used in Chapter I } \\
\hline Genotype & Background & Vector/Mutation & Reference \\
\hline HS::gai-1/HSP18.2::gai-1 & Col-0 & pTT101 & Alabadi et al, The Plant Journal (2008) \\
pAS1::GUS & Col-0 & pGreen & Iwakawa et al, The Plant Journal (2007) \\
pKNAT1::GUS & Col-0 & Not described & Ori et al, Development (2000) \\
pGAl::GUS & Col-0 & pBI101.1 & Gallego-Giraldo et al, The Plant Journal (2014) \\
pRGA::GUS & Col-0 & pOCA28 & Gallego-Giraldo et al, The Plant Journal (2014) \\
pRGA::GFP-RGA & Col-0 & pRG51 & Provided by Dr. Salomé Prat \\
pKNAT1::KNAT1-CFP & Col-0 & pMLBART & Rast-Somssich et al, Genes and Dev (2015) \\
bp-1 & Ler & hyl methanesulfona & Venglat et al, PNAS (2001) \\
p35S:::KNAT1 & No-0 & pBIN19 & Lincoln et al, The Plant Cell (1994) \\
\hline
\end{tabular}

\begin{tabular}{|cccc|}
\hline & Table II: Previously generated lines used in Chapter II \\
\hline Genotype & Background & Vector/Mutation & Reference \\
\hline HS::gai-1/HSP18.2::gai-1 & Col-0 & pTT101 & Alabadí et al, The Plant Journal (2008) \\
tcp14-2 & Col-0 & T-DNA & Provided by Dr. Brendan Davies \\
tcp14-4 & Col-0 & T-DNA & Krysan et al, The Plant Cell (1999) \\
tcp15-2 & Col-0 & T-DNA & Provided by Dr. Brendan Davies \\
tcp15-3 & Col-0 & T-DNA & Alonso and Stepanova, Plant Functional Genomics (2003) \\
tcp14-4 tcp15-3 & Col-0 & T-DNA & Provided by Dr. Brendan Davies \\
tcp14-4 tcp15-2 & Col-0 & T-DNA & Provided by Dr. Brendan Davies \\
pCYCB1;1::GUS & Col-0 & PCDG & Colon-Carmona et al, The Plant Journal (1999) \\
\hline
\end{tabular}

\section{Seedling growth conditions}

Seeds were surface sterilized with $70 \%(\mathrm{v} / \mathrm{v})$ ethanol and $0.01 \%(\mathrm{v} / \mathrm{v})$ Triton X-100 for $10 \mathrm{~min}$, followed by $96 \%(\mathrm{v} / \mathrm{v})$ ethanol for another $10 \mathrm{~min}$. Then, seeds were sown on plates of growing medium ( $1 / 2 \mathrm{MS}$ medium (Duchefa) $2.2 \mathrm{~g} / \mathrm{L}$, agar $0.8 \%(\mathrm{w} / \mathrm{v})$, sucrose 20 $\mathrm{g} / \mathrm{L}$, at $\mathrm{pH} 5,7)$, and stratified at $4^{\circ} \mathrm{C}$ in darkness for 3-5 days. Plates were then moved to a Percival E-30B growth cabinet (Percival) under white fluorescent light $\left(55-200 \mu \mathrm{mol} \mathrm{m} \mathrm{s}^{-2}\right.$ ${ }^{1}$ ) at $22^{\circ} \mathrm{C}$ for 8 hours. Seedlings were grown at $22^{\circ} \mathrm{C}$ under continuous light (55-65 $\mu \mathrm{mol}$ $\mathrm{m}^{-2} \mathrm{~s}^{-1}$ ) the indicated time in most cases.

\section{Plant growth conditions}

Arabidopsis thaliana and Nicotiana Benthamiana plants were grown in the greenhouse, in $12 \mathrm{~cm}$ pots or in polystyrene growing pots. The soil was a mixture of peat moss, perlite and vermiculite in a 1:1:1 proportion. Plants were watered twice a week with the nutritive solution described in Table III. The photoperiod was long day (LD) with 16 hours light $\left(22^{\circ} \mathrm{C}, 130 \mu \mathrm{mol} \mathrm{m}-2 \mathrm{~s}-1\right)$ and 8 hours dark (19ㅇ). Seeds were harvested when 
plants had ceased flowering and siliques start to dehisce and stored in the dark at $4^{\circ} \mathrm{C}$ and $30 \%$ relative humidity.

\begin{tabular}{|c|c|}
\hline \multicolumn{2}{|c|}{$\begin{array}{c}\text { Table III. Composition of the } \\
\text { nutritive solution. }\end{array}$} \\
\hline Compound & Dose $(\mathrm{g} / \mathrm{L})$ \\
\hline $\mathrm{H}_{3} \mathrm{PO}_{4}$ & 0.15 \\
\hline $\mathrm{Ca}\left(\mathrm{NO}_{3}\right)_{2}$ & 0.82 \\
\hline $\mathrm{KNO}_{3}$ & 0.2 \\
\hline $\mathrm{K}_{2} \mathrm{SO}_{4}$ & 0.35 \\
\hline $\mathrm{MgSO}_{4}$ & 0.24 \\
\hline BMX (Micronutrients) & 0.1 \\
\hline
\end{tabular}

\section{Hormonal treatments}

Chemical treatments with $\mathrm{GA}_{3}$ (Sigma) and the inhibitor of GA biosynthesis Paclobutrazol (PAC, Duchefa) were performed as indicated in each case (Results and Discussion). For long treatments, the compound was added to the solid growing medium in the moment of plate preparation, before it solidifies; whereas for short time treatments the chemical is added in the liquid growing medium, where plants were incubated.

\section{Genetic engineering}

During the course of this Thesis, several DNA constructs have been generated with different purposes. For this reason, diverse DNA manipulation and cloning techniques have been carried out.

\subsection{Bacteria manipulation}

The bacterial strains used in this Thesis are depicted in Table IV. They were grown at the indicated temperature in LB (Luria-Bertani) medium ( $1 \%$ tryptone, $0.5 \%$ yeast extract and $1 \% \mathrm{NaCl}$ at $\mathrm{pH}$ 7). For solid medium, 1.5\% Bacteriological Agar (Pronadisa) was added.

\begin{tabular}{|c|c|c|c|}
\hline \multicolumn{3}{|c|}{ Table IV: Bacterial strains used } \\
\hline \multirow{2}{*}{ Mscherichia coli } & Strain & Transformation method & \multicolumn{1}{|c|}{ Growth temperature } \\
\hline & TOP10 & Termo-competent & \multirow{2}{*}{$37 \circ \mathrm{C}$} \\
& DH5 $\alpha$ & & \\
& DB3 & Electro-competent & \\
Agrobacterium tumefaciens & C58 & & $28 \circ \mathrm{C}$ \\
\hline
\end{tabular}

For bacteria transformation, approximately $200 \mathrm{ng}$ of DNA were added to a frozen aliquot of competent cells $(40 \mu \mathrm{L})$. Then, transformation of the microorganisms was 
carried out. For termo-competent cells, the protocol of the manufacturer (Invitrogen ${ }^{\circledR}$ ) was followed. In the case of the electro-competent strains, cells were transferred to an electroporation bucket (BioRad ${ }^{\circledR}$ ) placed in ice and an electric pulse was applied (200 $\Omega$, $25 \mu \mathrm{F}$ and $1.5 \mathrm{kV}$ for $E$. coli and $440 \Omega, 25 \mu \mathrm{F}$ and $1.44 \mathrm{kV}$ for A. tumefaciens). Cells were recovered with $700 \mu \mathrm{L}$ of liquid LB medium without antibiotics and placed at the growth temperature in continuous agitation for 1 hour, or in the case of $A$. tumefaciens, 4 hours. After incubation, cells (50-200 $\mu \mathrm{L}$ ) were plated in solid LB medium supplemented with the selective combination of antibiotics to be later on incubated at the corresponding growth temperature. One day later (or three in the case of $A$. tumefaciens), resistant colonies carrying the desired plasmid were selected and inoculated in a $3 \mathrm{~mL}$ culture of liquid LB with the selection antibiotic. After 1-2 days, the culture was used for DNA extraction, or plant infiltration, in the case of $A$. tumefaciens.

\subsection{Plasmid DNA extraction}

For plasmid extraction, $3 \mathrm{~mL}$ of liquid cultures of the transformed bacteria grown in LB supplemented with the selective antibiotic were centrifuged 1 minute at 13.000 revolutions per minute (r.p.m.) and then the protocol of the E.Z.N.A plasmid miniprep Kit OMEGA BIO-tek was followed. DNA concentration, $A_{260 / 280}$ and $A_{260 / 230}$ was evaluated with a NanoDrop® ND-1000 spectrophotometer.

\subsection{Plant genomic DNA extraction}

For genomic extraction, $300 \mathrm{mg}$ of fresh tissue were grinded and incubated in $500 \mu \mathrm{L}$ of Extraction Buffer (0.2 M Tris-HCl pH 9.0, 0.4 M LiCl, $25 \mathrm{mM}$ EDTA and 1\% v/v SDS) for 5 minutes. After a 5 minutes centrifugation at 13.000 r.p.m., $350 \mu \mathrm{L}$ of the supernatant were transferred to a new tube containing $350 \mu \mathrm{L}$ of isopropanol. After a short shaking, the mixture was centrifuged for 10 minutes and the supernatant was discarded. The pellet was washed with ethanol $70 \%(\mathrm{v} / \mathrm{v})$ twice and let dry for 20 minutes. The dried pellet was resuspended in $200 \mu \mathrm{L}$ of distillated de-ionizated water $\left(\mathrm{ddH}_{2} \mathrm{O}\right)$ and the quantification of genomic DNA was made using a NanoDrop® ND-1000 spectrophotometer.

\subsection{DNA engineering}

Different techniques for DNA manipulation were employed. Enzymes used to this purpose are depicted in Table V. 


\begin{tabular}{|c|c|c|c|c|}
\hline \multicolumn{5}{|c|}{ Table V. Enzymes used for DNA engineering } \\
\hline Application & Enzyme & Brand & Proof-reading & Ends generated \\
\hline \multirow{3}{*}{ PCR-Cloning } & Pfu DNA Polymerase & Biotools & Yes & blunt-ended products \\
\hline & Ex Taq & Takara & Yes & 3'-terminal adenosine \\
\hline & Phusion ${ }^{\ominus}$ High-Fidelity DNA Polymerase & NEB & Yes & blunt-ended products \\
\hline \multirow{2}{*}{ PCR-Genotyping } & Taq DNA Polymerase & Quiagen & No & 3'-terminal adenosine \\
\hline & MyTaq $^{\mathrm{TM}}$ DNA Polymerase & Bioline & No & Not specified \\
\hline \multirow{5}{*}{$\begin{array}{c}\text { Digestion } \\
\text { Ligation } \\
\text { De-Phosphorylation } \\
\text { Gateway Technology }\end{array}$} & Digestion enzymes & ThermoFisher & & \\
\hline & T4 DNA Ligase & Promega & & \\
\hline & Shrimp Alkaline Phosphatase (SAP) & Takara & & \\
\hline & pCR8/GW/TOPO TA & Invitrogen & & \\
\hline & LR Clonase & Invitrogen & & \\
\hline
\end{tabular}

\subsubsection{DNA amplification}

Polymerase Chain Reaction (PCR) was used to amplify DNA fragments. Different commercial DNA polymerases (Table V) were used to amplify 50 ng of DNA according to the protocol of the manufacturer and depending on the application. Proof-reading polymerases were used to amplify fragments destined to be cloned in different constructs, whereas enzymes lacking this activity were used for genotyping or colony-PCR applications, for example. Reactions were carried out in thermocyclers following, in general, these conditions: initial denaturation step at 94으 for $2 \mathrm{~min}, 30-35$ cycles of amplification and final extension at the extension temperature of the given polymerase during 10 minutes.

\subsubsection{DNA digestion, ligation and phosphorylation}

For regular DNA restriction pattern by enzymatic digestion, 5-10 $U$ of the restriction enzyme per $\mu$ g of DNA were used (ThermoFisher, Table V). For normal cloning applications, the number of enzyme units was calculated with Formula 1. The protocol specified for the manufacturer was followed for each enzyme.

$$
\text { Units for } 1 \text { h digestion }=\left(\frac{48.5}{k b \text { of target } D N A}\right) *\left(\frac{\text { cuts in target } D N A}{\text { cuts in reference } D N A}\right) * \mu g \text { of target DNA }
$$

\section{Formula 1. Units of restriction enzyme needed for one hour of digestion} reaction.

For DNA ligation and de-phosphorylation of the ends of the DNA molecule, the commercial T4 Ligase and SAP phosphatase (Table V) were used respectively, and the manufacturer protocol was followed in each case. For the ligation reaction, Promega recommends using a 1:1, 1:3 or 3:1 molar ratio of insert: vector DNA when cloning a fragment into a plasmid vector. The ng needed of insert can be obtained by using Formula 2. Usually, ligation is performed with $100 \mathrm{ng}$ of destination vector. Ligation varied from 3 hours at room temperature to over-night at $4 \stackrel{\circ}{ } \mathrm{C}$. SAP phosphatase catalyzes the release of 
5'- and 3'-phosphate groups from DNA. It dephosphorylated all types of DNA ends in 10 minutes at $37^{\circ} \mathrm{C}$. The enzyme was inactivated in 5 minutes at $75^{\circ} \mathrm{C}$.

$$
\operatorname{Insert}(n g)=\left(\frac{\text { Vector }(n g) * \operatorname{Insert}(\mathrm{kb})}{\operatorname{Vector}(\mathrm{kb})}\right) * \text { Molar Ratio of Insert } / \text { Vector }
$$

\section{Formula 2. Nanograms of insert needed for the ligation reaction.}

\subsubsection{DNA-end modification}

For some applications, modification of DNA ends becomes indispensable. For example, Gateway technology requires the presence of a 3'-terminal adenosine $(A)$ in the insert; or in some ligation reactions there is a requirement for the insert and vector to have blunt ends.

For the addition of adenosines in the 3 '-terminal, $1 \mu \mathrm{l}$ of a $1 \mathrm{mM}$ dNTPs solution, 0.5 $U$ of DNA polymerase and the required quantity of its buffer were added to the product of the PCR and incubated in a thermocycler for 10-30 min at the extension temperature of the DNA polymerase.

To transform DNA overhangs in blunt ends, we used the protocol for the Klenow enzyme. First, $0.2-5 \mu \mathrm{g}$ of DNA were digested with the appropriate restriction enzyme in a final volume of $20 \mu \mathrm{l}$, then $1 \mu \mathrm{l}$ of a $1 \mathrm{mM}$ dNTPs solution and $1 \mathrm{U}$ of Klenow enzyme per $\mu \mathrm{g}$ of DNA were added and the mixture is incubated for 1 hour at room temperature. Finally, both the Klenow and the restriction enzyme were inactivated for 1 hour at $65^{\circ} \mathrm{C}$.

\subsection{Electrophoresis and fragment purification}

DNA fragments were separated by agarose gel electrophoresis $0.8-2 \%(w / v)$ in TBE 1X Buffer (Tris $0.89 \mathrm{M}$, boric acid 0.89 M, EDTA $2 \mathrm{mM}(\mathrm{pH}=8)$ ), used as electrophoresis buffer as well. Samples were mixed with Loading Buffer 6X (bromophenol blue 0.25\% $(w / v)$, xylencyanol blue $0.25 \%(w / v)$, glycerol $30 \%(v / v))$ to a $1 X$ final concentration. Electrophoresis run at constant voltage. Gels contained $0.5 \mu \mathrm{g} / \mathrm{ml}$ of ethidium bromide, so DNA could be observed by exposing it to UV light in a transilluminator.

To DNA fragment purification, the selected DNA bands observed under UV light were excised from the agarose gel and the QIAquick Gel Extraction Kit ${ }^{\circledR}$ system was used following the manufacturer protocol.

\subsection{Gateway Technology}

This technology is based on the site-specific recombination properties of the lambda phage, which includes well characterized recombination sites such as att (site-specific 
ATTachment). First, the selected insert is cloned in an entry vector, the pCR8/GW/TOPO $\mathrm{TA}^{\circledR}$ (Invitrogen ${ }^{\mathrm{TM}}$ ), which contains the recombination sites attL1 and attL2 flanking the fragment that will be replaced by the insert. After transformation, selection of clones and digestion to verify the orientation of the insert, the selected construct was sequenced. Once selected the correct entry plasmid, a second reaction (LR reaction) catalyzed by the LR Clonase (Invitrogen ${ }^{\mathrm{TM}}$ ) was made to transfer the fragment that includes the insert to a destination vector containing two recombination sites, attR1 and attR2.

\subsection{Sequencing}

Sequencing of the fragments was carried out in the sequencing service of the Instituto de Biología Molecular y Celular de Plantas (Universidad Politécnica de ValenciaCESIC), where a capilar sequenciator ABI 3100 (Applied Biosystems) was used.

\subsection{Constructs and oligos used in the Thesis}

In this work, several genetic constructs were used for different purposes. The ones used for Yeast two Hybrid are depicted in Table VI, whereas the ones for in planta expression are showed in Table VII. A list of the primers used according to their application can be found in Table VIII.

\begin{tabular}{|c|c|c|c|c|}
\hline \multicolumn{5}{|c|}{ Table VI: Plasmid constructs for $\mathrm{Y} 2 \mathrm{H}$} \\
\hline \multicolumn{5}{|c|}{ Constructs generated in this Thesis } \\
\hline Chapter & Construct & Vector & Origin & Technology \\
\hline \multirow{10}{*}{ Chapter I } & pADH1::GAL4 AD-TCP2 & \multirow{10}{*}{ pDEST22 } & pENTR223.1-Sfi-Orf-TCP2 & \multirow{8}{*}{$\begin{array}{c}\text { Gateway (LR } \\
\text { reaction) }\end{array}$} \\
\hline & pADH1::GAL4 AD-TCP2 Del1 & & pENTR223.1-Sfi-Orf-TCP2 & \\
\hline & pADH1::GAL4 AD-TCP2 Del2 & & pENTR223.1-Sfi-Orf-TCP2 & \\
\hline & pADH1::GAL4 AD-TCP3 & & pENTR223.1-Sfi-Orf-TCP3 & \\
\hline & pADH1::GAL4 AD-TCP4 & & pENTR223.1-Sfi-Orf-TCP4 & \\
\hline & pADH1::GAL4 AD-TCP5 & & PENTR223.1-Sfi-Orf-TCP5 & \\
\hline & pADH1::GAL4 AD-TCP10 & & PENTR223.1-Sfi-Orf-TCP10 & \\
\hline & pADH1::GAL4 AD-TCP13 & & PENTR223.1-Sfi-Orf-TCP13 & \\
\hline & pADH1::GAL4 AD-TCP24 & & Per8 GW TCP24 & $\begin{array}{c}\text { PCR amplification, } \\
\text { then Gateway }\end{array}$ \\
\hline & pADH1::GAL4 AD-KNAT1 & & pENTR223.1-Sfi-Orf-KNAT1 & \multirow{3}{*}{$\begin{array}{l}\text { Gateway (LR } \\
\text { reaction) }\end{array}$} \\
\hline \multirow{2}{*}{ Chapter II } & $\begin{array}{l}\text { pADH1::GAL4 AD-TCP14 } \\
\text { pADH1::GAL4 AD-TCP15 }\end{array}$ & pGADT7 & $\begin{array}{l}\text { pDONR207TCP14 } \\
\text { pDONR207TCP15 }\end{array}$ & \\
\hline & $\begin{array}{l}\text { pADH1::GAL4 DBD-M5GAI } \\
\text { pADH1::GAL4 DBD-M5RGL2 }\end{array}$ & pGBKT7 & $\begin{array}{l}\text { pDONR207 M5GAI } \\
\text { pDONR207 M5RGL2 }\end{array}$ & \\
\hline \multicolumn{5}{|c|}{ Constructs previously described } \\
\hline Chapter & Construct & Vector & \multicolumn{2}{|c|}{ Reference } \\
\hline Chapter I and II & $\begin{array}{c}\text { pADH1::GAL4 DBD-M5GAl } \\
\text { pADH1::GAL4 DBD-RGA52 } \\
\text { pADH1::GAL4 DBD-MD3 GAI } \\
\text { pADH1::GAL4 DBD-MD4 GAl } \\
\text { pADH1::GAL4 DBD-Del1 GAl } \\
\text { pADH1::GAL4 DBD-Del2 GAl }\end{array}$ & pDEST32 & \multicolumn{2}{|c|}{ Gallego-Bartolomé et al., 2012} \\
\hline
\end{tabular}




\begin{tabular}{|c|c|c|c|c|}
\hline \multicolumn{5}{|c|}{ Table VII: Plasmid constructs for expression in plant } \\
\hline \multicolumn{5}{|c|}{ Constructs generated in this Thesis } \\
\hline Application & Construct & Vector & Origin & Technology \\
\hline \multirow{5}{*}{$\mathrm{BiFC}$} & p35S:: YFN-TCP2 & & pENTR223.1-Sfi-Orf-TCP2 & \multirow{8}{*}{$\begin{array}{l}\text { Gateway (LR } \\
\text { reaction) }\end{array}$} \\
\hline & p35S:: YFN-TCP4 & & pENTR223.1-Sfi-Orf-TCP4 & \\
\hline & p35S:: YFN-TCP14 & PIMDC43-YFN & PDONR207TCP14 & \\
\hline & p35S:: YFN-TCP15 & & PDONR207TCP15 & \\
\hline & p35S:: YFC-RGL2 & pMDC43-YFC & PDONR207RGL2 & \\
\hline \multirow{3}{*}{ Colp } & p35S:: HA-TCP2 & \multirow{3}{*}{ pEarleyGate201 } & pENTR223.1-Sfi-Orf-TCP2 & \\
\hline & p35S:: HA-KNAT1 & & PENTR223.1-Sfi-Orf-KNAT1 & \\
\hline & p35s:: HA-ТCP14 & & PDONR207TCP14 & \\
\hline \multirow{4}{*}{ Luciferase } & \multirow{4}{*}{$\begin{array}{c}\text { p35Sm-Syn. Class II TCPbs::LUC } \\
\text { p35Sm-Syn. Class I TCPbs::LUC } \\
\text { p35S::HA-VP16-TCP2 } \\
\text { p35S::HA-VP16-TCP4 } \\
\text { p35S::HA-VP16-TCP14 }\end{array}$} & pGreenII 0800-LUC & \multirow{4}{*}{$\begin{array}{c}\text { pUC57 GeneScript } \\
\text { pENTR223.1-Sfi-Orf-TCP2 } \\
\text { pENTR223.1-Sfi-Orf-TCP4 } \\
\text { pDONR207TCP14 } \\
\end{array}$} & $\begin{array}{l}\text { Traditional } \\
\text { cloning }\end{array}$ \\
\hline & & \multirow{3}{*}{ pAlligator } & & \multirow{4}{*}{$\begin{array}{l}\text { Gateway (LR } \\
\text { reaction) }\end{array}$} \\
\hline & & & & \\
\hline & & & & \\
\hline Transgenic plants & p35S:: HA-GAI & pEarleyGate201 & pDONR201 GAI & \\
\hline \multicolumn{5}{|c|}{ Constructs previously described } \\
\hline Application & Construct & Vector & \multicolumn{2}{|l|}{ Reference } \\
\hline \multirow[b]{2}{*}{$\mathrm{BiFC}$} & \multirow{2}{*}{$\begin{array}{c}\text { p35S::YFC-GAI } \\
\text { p35S::YFC } \\
\text { p35s::YFN }\end{array}$} & pMDC43-YFC & \multirow{2}{*}{\multicolumn{2}{|c|}{$\begin{array}{c}\text { Provided by Antonella Locascio } \\
\text { Provided by Dr Alejandro Ferrando-IBMCP }\end{array}$}} \\
\hline & & & & \\
\hline \multirow{2}{*}{ ColP/ Luciferase } & p35S::myc-M5GAl & \multirow{2}{*}{$\begin{array}{l}\text { pEarleyGate } 203 \\
\text { pC- TAPa }\end{array}$} & \multirow{2}{*}{\multicolumn{2}{|c|}{$\begin{array}{l}\text { Provided by Antonella Locascio } \\
\text { Provided by David Alabadí }\end{array}$}} \\
\hline & p35S::GAI-TAP & & & \\
\hline \multirow{2}{*}{ Transgenic plants } & \multirow{2}{*}{$\begin{array}{l}\text { pTCP2::TCP2-GFP } \\
\text { pTCP4::TCP4-GFP } \\
\text { pTCP2:::TCP2-GFP } \\
\text { pTCP4::rTCP4-GFP }\end{array}$} & CHF3 & \multicolumn{2}{|c|}{ Provided by Ignacio Rubio Somoza } \\
\hline & & pXW74 & Provided by Javier & alatnik \\
\hline
\end{tabular}




\begin{tabular}{|c|c|c|c|}
\hline \multicolumn{4}{|c|}{ Table VIII. Oligos used in this Thesis. } \\
\hline Experiment & Gene & Forward & Reverse \\
\hline \multirow{12}{*}{ RT-PCR } & TCP2 & GCATCACAATTCTTCCCGGAT & TTACCACCGGAAGGTCGTG \\
\hline & TCP3 & TTCTCCGGCCAGAGCAATAA & GCTTGCCGTCGATGAGTCA \\
\hline & TCP4 & CACTCACAAGCCGTCCTCTG & TTCGATTGTCAATGGCGAGA \\
\hline & TCP5 & GGTCCTACTCCTCCGGCAAT & AAACGAAGGGTATGTCGGGAA \\
\hline & TCP10 & GACGCAAAGACCGTCATAGCA & GGTCACGTGGACCCTTTGAT \\
\hline & TCP13 & CTTCGTGGATGAAATCCAAGG & AGGCGCGTGAAACCCTAAC \\
\hline & TCP24 & TCATGGCTACACCTCCACCTC & AGTCTCCGGAAGCTGGTGGT \\
\hline & TCP14 & CCAACATGATCAAATCGGAGG & CGCCACCAGTACCAATAGAA \\
\hline & TCP15 & СTCTCCAGCTTCTTGATTC & CGAAGAATGTGACTCGTTC \\
\hline & AS1 & GTTAGACAGTTCGGTCCGAGAGA & TGATCCCTGGCTTAAGATAATTCTTC \\
\hline & GA20ox1 & GATCCATCCTCCACTITAGA & GTGTATTCATGAGCGTCTGA \\
\hline & Actines & AGTGGTCGTACAACCGGTATT & GAGGATAGCATGTGGAAGTGA \\
\hline \multirow{2}{*}{ Deletions for $\mathrm{Y} 2 \mathrm{H}$} & TCP2 Del1 & ATGATTGGAGATCTAATGAAG & TCACGACCCGAGAATTAAACCCG \\
\hline & TCP2 Del2 & ATGACAACAGTTGCTGCTAATTC & TCAGTTCTTGCCTTTACCCTTA \\
\hline \multirow{5}{*}{ Genotyping } & GUS & CAACGTCTGGTATCAGCGCGAAGT & TATCCGGTTCGTTGGCAATACTCC \\
\hline & GFP & ATGAGTAAAGGAGAAGAACTTTTC & GTATAGTTCATCCATGCCATGTG \\
\hline & $\operatorname{tcp} 14-4$ & GTTGTTGATGATGATGATGTCTCTGTG & GACGACAACCATCAACAACAACCTTC \\
\hline & tcp15-3 & СTCTCCAGCTTCTTGATTC & CGAAGAATGTGACTCGTTC \\
\hline & SALKT-DNA & CGATTTCGGAACCACCATCAAACAGGA & \\
\hline \multirow{4}{*}{ Sequencing } & M13 & GTAAAACGACGGCCAGT & CAGGAAACAGCTATGAC \\
\hline & YFN & TCATGGCCGGTGGAGGTGGATCTGG & \\
\hline & pGreen & CTAAAATCCAGATCGATAACATTAACG & GAACCAGGGCGTATCTCTTCATAGC \\
\hline & Alligator & CGATCTGGACATGTTGGGGGA & GTAACATAGATGACACCGCGCGCG \\
\hline
\end{tabular}

\section{Genetic transformation}

During this Thesis, stable and transitory genetic transformation of Arabidopsis thaliana and Nicotiana benthamiana was carried out, respectively. In both cases, a liquid culture in selective medium (Gentamicin, Rifampicine and the selection antibiotic) of the Agrobacterium tumefaciens C58 strain carrying the selected construct in each case was used (see Section 2.1 of Materials and Methods).

\section{Transgenic Arabidopsis plants}

For generation of Arabidopsis transgenic plants, the protocol of floral dip described by Clough and Bent (1998) (1) was used, with some modifications (2). First, 20 seeds of the selected genotype were sown in $12 \mathrm{~cm}$ of diameter pots ( 6 seeds per pot) grown in the greenhouse at long day (LD) conditions. After 4 weeks, when the first inflorescence appears, is the moment of the transformation.

Three days before the transformation, a pre-culture in selective medium of $5 \mathrm{ml}$ of $A$. tumefaciens carrying the desired construct was prepared and incubated over-night at 
28 ․ C. The following day, the pre-culture was inoculated in a flask containing $300 \mathrm{ml}$ of selective medium and is incubated at $28^{\circ} \mathrm{C}$ for 16 hours in agitation. In the moment of plant transformation, that culture must reach an $\mathrm{OD}_{600}$ of 0.6 , corresponding to an inoculate concentration of $10^{-2}-10^{-3} \mathrm{CFU} / \mathrm{ml}$. When the culture reached this $\mathrm{OD}_{600}$ value, it was centrifuged at 6000 r.p.m. for $20 \mathrm{~min}$ and the pellet was resuspended in $300 \mathrm{ml}$ of infiltration medium (sucrose $5 \%(w / v)$, MES $0.5 \mathrm{~g} / \mathrm{L}$, Silwet L-77 0.03\%, at pH 5,7). Plants were submerged upside-down in the culture for $15-60 \mathrm{~s}$, and then the pots were deposited horizontally in trays with absorbent tissue. These trays were covered with plastic to preserve high humidity conditions favorable for infection and they were placed in the dark for a day. After a day, the plastic was removed and the pots were deposited vertically in the trays. Plants were grown in the greenhouse under LD conditions until seed harvesting. The collected seeds were dried at $37^{\circ} \mathrm{C}$ for 2 days (except heat-shock lines) and saved.

For selection of the transformants, the collected seeds were surface-sterilized and sown in plates containing growing medium supplemented with the selection antibiotic of the vector at $100 \mathrm{mg} / \mathrm{L}$ (see Section 1 of Materials and Methods) and subjected to 3-7 days of stratification. Then the plates were moved to growing chambers in LD conditions. After 7-10 days, the antibiotic-resistant seedlings were transferred to pots containing soil and they were grown in the greenhouse until seed collection. Each one of these antibioticresistant plants was considered an independent transgenic line (T1).

In order to select transgenic lines carrying a unique insertion of T-DNA, 100 seeds of each T1 plant were sterilized and sown in selection medium. After 10 days, a ratio of Resistant: Sensitive seedlings was calculated for each T1 offspring and lines presenting a 3:1 Resistant: Sensitive segregation were selected. Approximately 12 resistant seedlings for each line (T2) were transferred to the greenhouse to obtain their seeds.

A third round of selection was performed to choose homozygous transgenic lines. 100 seeds of each $\mathrm{T} 2$ were sown in selective medium and followed the same protocol than in the previous step. In this case, only lines with $100 \%$ of resistant seedlings were selected (T3). In Table IX, a list of the transgenic lines generated in this Thesis can be found. In the case of the TCP transgenic lines, the constructs were provided by Dr. Javier Palatnik.

\begin{tabular}{|cc|c|}
\hline \multicolumn{3}{|c|}{ Table IX: Transgenic lines generated in this Thesis } \\
\hline Genotype & Background & Vector \\
\hline pTCP2::TCP2-GFP & Col-0 & CHF3 \\
pTCP4::TCP4-GFP & Col-0 & \\
pTCP2::rTCP2-GFP & Ler & \multirow{2}{*}{ pXW74 } \\
pTCP4::rTCP4-GFP & Ler & \\
pAS1::GUS;; p35S::HA-GAI & Col-0, pAS1::GUS & \multirow{2}{*}{ pEarleyGate201 } \\
pKNAT1::GUS;; p35S::HA-GAI & Col-0, pKNAT1::GUS & \\
\hline
\end{tabular}




\section{Transitory expression in N. benthamiana}

Transitory expression in 3 week old $N$. benthamiana leaves was used in this Thesis for different purposes such as Bimolecular Fluorescence Complementation (BiFC), coimmunoprecipitation or transient expression assays with the Luciferase reporter gene.

A day before the infiltration, we refreshed a pre-culture in $5 \mathrm{ml}$ of selective medium of $A$. tumefaciens carrying the desired construct and we incubated it over-night at $28^{\circ} \mathrm{C}$. A pre-culture per each construct is needed. The following day, cultures were centrifuged at 3000 r.p.m. for $20 \mathrm{~min}$ and the pellet was resuspended in $15 \mathrm{ml}$ of infiltration buffer $(1 \mathrm{mM}$ MES pH 5.7, $0.1 \mathrm{mM} \mathrm{MgCl} 2,200 \mu \mathrm{M}$ acetosyringone). Then, cultures were incubated in dark and agitation at $28^{\circ} \mathrm{C}$ for 2 hours. After this time, the $\mathrm{OD}_{600}$ was measured for each culture, and calculations are made to reach the desired concentration for each construct. Once the mixture of constructs was made, 3 leaves of $N$. benthamiana were agroinfiltrated per plant and combination of constructs, in the presence of the P19 protein (except BiFC assays) to suppress gene silencing. The third day after infiltration, samples can be obtained for the different applications previously mentioned.

\section{Genetic crosses}

Several genetic crosses were made to obtain different genotypes. In the case of the pAS1::GUS pTCP2::rTCP2-GFP genotype, the constructs to be crossed carry different selection genes, so it facilitates the posterior genotyping. In the transgenic line pAS1::GUS (3), the pGreen vector carries the bar gene, that confers resistance to the glufosinate herbicide. Pollen of $p A S 1:: G U S$ (masculine parental) was used to fertilize flowers of the pTCP2::rTCP2-GFP line generated by us. Then, the F1 seeds were sown in growth medium supplemented with glufosinate $(100 \mathrm{mg} / \mathrm{L})$ to discard self-pollinated $p T C P 2:: r T C P 2-G F P$ seeds. Posterior selection combined the resistance to glufosinate and genotyping by PCR of the GFP gene (see Table VIII) to obtain plants homozygous for both transgenes in the F3 generation. For generating the pRGA::RGA-GFP pKNAT1::KNAT1-CFP transgenic line, crosses using pollen of the $p R G A:: R G A-G F P$ line (Col-0 background, provided by Dr. Salomé Prat, CNB, Madrid) to fertilize pKNAT1::KNAT1-CFP flowers (provided by Dr. Miltos Tsiantis (4)) and viceversa were made and F1 seeds were used for microscopy observations. Finally, to obtain the tcp14-4 tcp15-3 pCYCB1;1::GUS genotype genetic crosses of the double mutant and the transgenic line were performed and the homozygous line was selected by genotyping GUS and both mutant alleles with primers depicted in Table XII. 


\section{Germination assays}

Wild type and mutant seeds were collected simultaneously from plants grown under the same conditions. Storage conditions were $22^{\circ} \mathrm{C}$ and $30 \%$ relative humidity in the dark for 1 week for freshly harvested seeds. For each genotype, approximately 100 seeds were placed onto filter papers (Whatman $\mathrm{N}^{\circ} 3$ ), moistened with $2 \mathrm{ml}$ of sterile water or aqueous solution of $\mathrm{GA}_{3} 1 \mu \mathrm{M}$ (Duchefa) in $6 \mathrm{~cm}$ diameter Petri dishes and then transferred in a climate room $\left(25^{\circ} \mathrm{C}, 16 \mathrm{~h}\right.$ light $/ 8 \mathrm{~h}$ dark). The percentage of germination was counted after 4 days (96 hours). Assays were carried out in triplicate with at least two independent seed batches.

\section{Yeast two hybrid assays}

For the yeast two hybrid assays $(\mathrm{Y} 2 \mathrm{H})$, the genetic constructs depicted in Table VI were used. Deleted versions of GAI (M5GAI, MD3, MD4, Del1 and Del2), RGA (RGA52) and RGL2 (M5RGL2) fused to the DNA binding domain of the GAL4 (DBD) were used to avoid the self-activation effect that confers de $\mathrm{N}$-terminal region of the protein. On the other hand, the Class I TCPS TCP14 and TCP15, CIN-TCPs and KNAT1 were fused to the activation domain of GAL4 (AD). Constructs were co-transformed by pairs (one DBD and one AD) in the yeast strain $\mathrm{AH} 109$ according to the protocol of the manufacturer (Clontech). The HIS3 reporter gene is stably integrated at the yeast genome of the AH109 strain, which is characterized by the presence of GAL4 binding sites in its promoter region.

The basis of the assay is the fact that if the tested proteins physically interact, the DBD and AD of GAL4 are in enough proximity and there is an induction of the HIS3 reporter gene by two-hybrid-dependent transcriptional activation, which allows AH109 cells (auxotroph for histidine) growth on plates lacking histidine. The analysis of the interaction was made in an SD medium and positive colonies were selected in the absence of tryptophan, leucine and histidine. In some cases, the medium was supplemented with 3-amino-1, 2, 4 triazole (3AT, Sigma-Aldrich), an inhibitor of the reporter gene HIS3 to test the strength of the interaction. As a control, each bait (the protein fused to the DBD of GAL4) was also co-transformed into the yeast strain with the empty AD vector.

\section{Bimolecular Fluorescence Complementation assay}

To perform the bimolecular fluorescence complementation assay (BiFC), the DELLAs $R G L 2$ and GAl were cloned in the PMDC43-YFC vector, whereas TCP2, TCP4, TCP14 and TCP15 were introduced in the PMDC43-YFN (Table VII). These vectors, pMDC43-YFN and pMDC43-YFC, constitutively express the selected proteins fused to the $\mathrm{N}$-terminal and Cterminal of the yellow fluorescent protein (YFP), respectively. This way, when the tested 
proteins are co-expressed, only if they physically interact both parts of the YFP proteins are close enough to reconstitute its fluorescence that can be observed by confocal miscroscopy.

Each construct was introduced in the A. tumefaciens C58 strain (section 2.1 of Material and Methods) and $N$. benthamiana leaves were agroinflitrated (section 3.2 of Material and Methods). Co-infiltration of the empty vectors was used as a negative control. Three days after infiltration, disks of leaves were taken and fluorescence was analyzed in the confocal microscope (section 12 of Material and Methods). Complementation was confirmed in two independent assays.

\section{Co-immunoprecipitation assays}

\section{Preparation of the samples}

To evaluate the physical interaction between two target proteins in planta, we performed co-immunoprecipitation (Co-IP) assays. First, we cloned the selected genes in specific vectors for expression in plants with different tags, the pEarlyGate (Table VII, (5)). Second, the constructs are introduced in the C58 A. tumefaciens strain and leaves of $N$. benthamiana were agroinfiltrated. Three conditions were tested, two with each one of the proteins to be tested alone (used as controls) and one co-expressing both constructs. Bacteria concentration was adjusted to guarantee that the expression of both proteins was similar. Three days after infiltration, leaves were collected and frozen in liquid nitrogen $\left(\mathrm{N}_{2}(\mathrm{I})\right)$.

\section{Protein extraction and immunoprecipation}

The frozen tissue was grinded in a cold mortar to obtain a thin powder of each sample. Then $1 \mathrm{ml}$ of the powder was mixed with the same volume of an extraction buffer that maintains the proteins in native conditions [Tris- $\mathrm{HCl}(\mathrm{pH} 7.5) 50 \mathrm{mM}$, glycerol 10\%, Nonidet P-40 0.1\%] supplemented with Complete Protease Inhibitors $1 \mathrm{X}$ (Roche). After incubation in ice for 15-120 minutes, samples were centrifuged at $4{ }^{\circ} \mathrm{C}$ and $13000 \mathrm{~g}$ for 15 minutes twice and supernatant was transferred to a new tube. $250 \mu \mathrm{l}$ of this supernatant were saved in a different tube, to serve as input. Then, the denaturing protein extraction buffer Laemli (1x) [Tris- $\mathrm{HCl}$ (pH 7.5) 50 mM, NaCl 150 mM, EDTA 1 mM, DTT $1 \mathrm{mM}$, glycerol 10\%] was added, heated to $100^{\circ} \mathrm{C}$ for $5 \mathrm{~min}$ and stored at $-80^{\circ} \mathrm{C}$. The rest of the extract was incubated between 30 minutes and overnight in slow agitation at 4 으 with paramagnetic beads (Miltenyi Biotec) with antibodies that recognize the corresponding epitope tag. This step allows the beads to bind specifically to the epitope of the target protein (one of the both tested). After incubation, samples were loaded at room temperature in $\mu$ columns (Miltenyi Biotec) previously washed with extraction buffer. The 
magnetically-labeled proteins are retained on the $\mu$ column placed in the magnetic field of a $\mu$ MACS Separator. Then, two washing steps were made, one with $800 \mu$ l of extraction buffer without protease inhibitors and other with $100 \mu \mathrm{l}$ of the washing buffer 2 provided by the manufacturer. Immunoprecipitated proteins in each one of the samples were eluted in $50 \mu$ l of pre-heated denaturing elution buffer (Miltenyi Biotec).

\section{Western blot}

The six samples (three inputs and three IPs) were heated at 95을 5 minutes, centrifuged at $13000 \mathrm{~g}$ for another 5 minutes and loaded in separation SDS-PAGE $8.5 \%$ gels (Pierce). After protein separation, proteins were transferred to a PVDF membrane (Bio-Rad), stained with Ponceau Red to check that protein level in the different input samples were comparable and de-stained with water. Then, membranes were saturated with blocking buffer [TBS 0.1\%, Tween-20 (0.1\%), Blocking Reagent 20\% (Roche $\left.{ }^{\circledR}\right)$ ] one hour at room temperature and incubated with the selected primary antibody diluted in blocking reagent overnight at 4 으. The anti-myc (clone 9E10; Roche ${ }^{\circledR}$ ) and anti-HA-HRP (clone 3F10; Roche ${ }^{\circledR}$ ) antibodies were used. The following day, three washing steps of 15, 10 and 5 minutes with washing buffer (TBS 0.1\%, Tween-20 (0.1\%)) were performed. Incubation for 1 hour at room temperature with a secondary antibody followed by another three washing steps was needed in the case of non-conjugated antibodies. The SuperSignal West Femto Chemiluminiscent Substrate (ThermoFisher) was used and the signal was detected with a LAS 3000 imaging system.

\section{Real-time quantitative RT-PCR}

To analyze the expression level of different genes, real-time quantitative RT-PCR was performed. Preparation of the samples is specified in each case in Results and Discussion and at least two biological replicates were used. Once samples were collected in $N_{2}(\mathrm{I})$ and grinded in a mortar, total RNA was extracted following the protocol of the Plant RNA Mini Kit (Omega Biotek). These RNA samples were subjected to a treatment with the DNase Kit (Ambion) to further eliminate genomic DNA. Then, RNA concentration in the samples was measured with a NanoDrop ${ }^{\circledR}$ ND-1000 spectrophotometer and CDNA was synthesized from $2 \mu \mathrm{g}$ of total RNA using the PimeScript ${ }^{\mathrm{TM}}$ II Reverse Transcriptase kit (Takara).

Quantitative PCR reactions were prepared in MicroAmp ${ }^{\circledR}$ Fast Optical 96-Well Reaction plates (Applied Biosystems) using SYBR Green PCR Master Mix (Applied Biosystems). Three technical replicates were performed for each condition and the primers employed are depicted in Table VIII. Reactions were carried out in the 7500 FastReal Time (Applied Biosystems) quantitative PCR thermocycler. Quantitative PCR program was as follows: initial incubation for 2 minutes at 50ㄷ , initial denaturation step at 95ㅇ for 10 minutes and 40 amplification cycles of 15 seconds at $95^{\circ} \mathrm{C}$ and 1 minute at $60^{\circ} \mathrm{C}$. 
Data analysis was performed with the 7500 Software v2.0.6 (Applied Biosystems) using the CT comparative method $(\triangle \Delta C T)$. The expression levels obtained for the different genes were normalized respect to the expression levels obtained for the control gene, ACTINE8 (ACT8).

\section{Transactivation assays}

For the transactivation assays in $N$. benthamiana leaves, we decided to use specific synthetic promoters for each class of TCPs studied: class I TCPs and Class II TCPs. To this purpose, we designed a synthetic promoter consisting of six copies of either the Class I TCP (GTGGGCCCAC) (6) or Class II TCP (GTGGTCCCA) (7) consensus binding site separated by a 6-nucleotide spacer (AAAAAA) upstream of a minimal 355 promoter and the translational enhancer omega $(\Omega)$. We ordered the synthesis of these constructs to Genescript who provided each one of them in a pUC57 vector, with our synthetic promoters flanked by Pst and Ncol restriction sites. Therefore, we digested the pUC57 vectors and cloned the fragment of interest in a pGreenll 0800-LUC vector (8) by traditional cloning techniques (Table VII). This way, the synthetic promoter controls the expression of the Luciferase reporter gene.

The next step was to generate the constructs for expression in planta of the proteins to be tested. In particular, TCP2, TCP4 and TCP14 were cloned in the Alligator vector, to obtain a translational fusion of the TCP with the transcriptional activator VP16 and the 3xHA molecular tag. On the other hand, we used the previously generated constructs p35S::myc-M5GAl and p35S::GAI-TAP to express this DELLA protein in planta (Table VII).

The C58 A. tumefaciens strain was transformed to incorporate all constructs and 3 leaves of each $N$. benthamiana plant were infiltrated for each combination of constructs, as described in sections 2.1 and 3.2 of Material and Methods. Firefly and the control Renilla LUC activities were assayed from leaf extracts (made with the Lysis Buffer of Promega) with the Dual-Glo Luciferase Assay System (Promega) following the protocol of the manufacturer and quantified with a GloMax 96 Microplate Luminometer (Promega). To verify that protein levels were similar in all conditions, Western Blot analysis were performed with proteins extracted from the same experiment using the specific antibody required for each molecular tag (Section 8 of Material and Methods).

\section{Analysis of the B-glucoronidase activity}

$\beta$-glucoronidase (GUS) staining assays were carried out as established in Zadnikova et al, 2010 (9). Samples were collected and immediately fixed in cold, 90\% acetone for $10-20$ minutes at $4 \stackrel{\circ}{ } \mathrm{C}$ [in the case of developing seeds (Chapter II of Results and Discussion), they were cleared before fixation according to Yadegari et al., 1994 (10)]. Then, they were 
subjected to a brief vacuum pulse of 1-3 minutes and a washing step with the staining solution (Table $X$ ) without the substrate (X-gluc) for 20 minutes. After this time, the substrate was added to the solution to allow the staining reaction to start. Substrate concentration, temperature and time of incubation in each case are depicted in Table XI. After incubation, samples were de-stained with serial ethanol washing steps $(15,30,50$ and $70 \%$ ). At this point, samples can follow a final incubation in chlorhydrate (Sigma) for 2 days and be directly observed in the microscope.

\begin{tabular}{|c|c|c|}
\hline Compound & \multicolumn{2}{|c|}{ Concentration } \\
\hline $\mathrm{NaPO}_{4} \mathrm{pH} 7$ & \multicolumn{2}{|c|}{$50 \mathrm{mM}$} \\
\hline Titron X-100 (Sigma) & \multicolumn{2}{|c|}{$0.1 \% \mathrm{v} / \mathrm{v}$} \\
\hline Potassium Ferrocyanide & $0.5 \mathrm{mM}$ & \multirow{2}{*}{$\mathrm{K}_{3} \mathrm{~K}_{4} \mathrm{Fe}(\mathrm{CN})_{6} 1 \mathrm{mM}$} \\
\hline Potassium Ferricyanide & $0.5 \mathrm{~mm}$ & \\
\hline EDTA & \multicolumn{2}{|c|}{$10 \mathrm{Mm}$} \\
\hline X-Gluc & \multicolumn{2}{|c|}{ Table XI } \\
\hline
\end{tabular}

\begin{tabular}{|c|c|c|c|c|}
\hline \multicolumn{5}{|c|}{ Table XI. GUS staining conditions. } \\
\hline Experiment & Transgenic line & [X-Gluc] (mM) & $\begin{array}{l}\text { Incubation } \\
\text { time }\end{array}$ & $\begin{array}{l}\text { Incubation } \\
\text { temperature }\end{array}$ \\
\hline $\begin{array}{l}\text { Chapter I } \\
\text { Section } 4\end{array}$ & $\begin{array}{c}\text { pAS1::GUS } \\
\text { pAS1::GUS;; } \\
\text { p35S::HA-GAI } \\
\text { pAS1::GUS;; } \\
\text { pTCP2::rTCP2-GFP }\end{array}$ & 0.5 & $30 \mathrm{~min}$ & Room T./3790 \\
\hline $\begin{array}{l}\text { Chapter I } \\
\text { Section } 5\end{array}$ & $\begin{array}{c}\text { pKNAT1::GUS } \\
\text { pKNAT1::GUS;; } \\
\text { p35S::HA-GAI }\end{array}$ & \multirow[b]{2}{*}{2} & Overnight & Room $\mathrm{T}$. \\
\hline $\begin{array}{l}\text { Chapter I } \\
\text { Section } 7\end{array}$ & $\begin{array}{c}\text { pKNAT1::GUS } \\
\text { pGAl::GUS } \\
\text { pRGA::GUS }\end{array}$ & & $\begin{array}{c}1-3 \text { hours non } \\
\text { saturated, } \\
0 / n \text { saturated }\end{array}$ & $37^{\circ} \mathrm{C}$ \\
\hline $\begin{array}{l}\text { Chapter II } \\
\text { Section } 6\end{array}$ & pCYCB1;1::GUS & 2 & Overnight & $377^{\circ} \mathrm{C}$ \\
\hline $\begin{array}{l}\text { Chapter II } \\
\text { Section } 7\end{array}$ & рСYCB1;1::GUS & 2 & Overnight & $377^{\circ} \mathrm{C}$ \\
\hline
\end{tabular}




\section{Histological cuts and microscopy}

\section{Histological cuts}

Once samples are in $70 \%$ ethanol, they were introduced in the tissue processor (Leica TP1020) that was programmed following the instructions of the manufacturer. This processor performed two different functions: first, samples were subjected to several dehydration steps and then they were included in paraffin. For sample de-hydration, samples were incubated with sequential $70 \%, 95 \%$ and $100 \%$ ethanol (in the second of these incubations, they also were stained with Eosina- $Y$ 0.2\%) and different concentrations of a Histo-Clear ${ }^{\circledR}$ (National Diagnostics): ethanol solution [25:75, 50:50, 75:25 and 100:0 (\%v/v)]. Finally, samples were included in 100\% paraffin Paraplast ${ }^{\circledR}$ Plus (McCormick Scientific) at $58^{\circ} \mathrm{C}$ in vacuum. After the inclusion, samples were placed in aluminium moulds with liquid paraffin, covered with plastic pieces and let solidify at 4 으.

Longitudinal cuts of the samples (10 $\mu \mathrm{m}$ thickness) were made with the Microm HM330 microtom, placing them in polilysine coated slides. Next, paraffin was removed with histoclear. In the case of samples used for in situ hybridization assays, the slices were then re-hydrated with decreasing quantities of ethanol (100\%, $75 \%, 50 \%$ and $25 \%$ ) and water. This last step is important if samples are destined to be hybridized or stained.

\section{Optical microscopy}

Stained fresh tissue was observed with the Nikon Eclipse E600 optic microscope. Bright field illumination and Normaski technique (D.I.C., differential interface contrast) were used. Images were captured with a Nikon Digital-Sight (DS-Fi1) camera connected to the microscope and processed with the NIS-Elements F3.0 image analysis software.

In the case of the CYCB1;1::GUS transgenic line and TCP15 in situ hybridization assay in Chapter II of Results and Discussion, the experiments were performed in collaboration with Drs. Masiero and Resentini. Therefore, the samples were observed using a Zeiss Axiophot D1 microscope (Zeiss) equipped with DIC optics. Images were recorded with an Axiocam MRc5 camera (Zeiss) using the Axiovision program (4.1).

\section{Confocal microscopy}

For confocal microscopy observations, the Leica TCS SL (Leica) was used. This microscope consists in an inverted DMIR2 microscope and a confocal spectral unit SL with two simultaneous detectors of fluorescence and four laser lines (458 nm, 488 nm, $514 \mathrm{~nm}$ and $534 \mathrm{~nm}$ ). To excite the YFP or GFP protein a laser of $488 \mathrm{~nm}$ was used and the emission was absorbed between $500 \mathrm{~nm}$ and $520 \mathrm{~nm}$ (maximum of emission: $509 \mathrm{~nm}$ ). Chlorophyll was excited with the same laser and its emission was absorbed between 660 
$\mathrm{nm}$ and $690 \mathrm{~nm}$. Signal identity was confirmed in all cases by a scan of wavelengths ( $\lambda$ scan), to visualize the intensity of the emission within all the range of wavelengths.

In the case of the experiments made in collaboration with Drs. Serrano-Mislata and Sablowski in the John Innes Centre, in UK, samples were treated differently. For colocalization of $p R G A:: R G A-G F P$ and $p K N A T 1:: K N A T 1-C F P$, vegetative meristems of 9 day old seedlings were dissected and stained with FM4-64 (30 ug/ml) for 20 minutes. Next, the images were obtained with a Zeiss LSM780 confocal microscope, where the localization of pRGA::RGA-GFP and pKNAT1::KNAT1-CFP was sequentially obtained with a $488 \mathrm{~nm}$ laser followed by a $405 \mathrm{~nm}$ laser. For cell measurements, apices were dissected and left to recover in GM medium ( $0.1 \%$ glucose; $0.44 \%$ MS medium including vitamins, $0.9 \%$ agar [pH 5.7]) for 24 hours at $16 \circ \mathrm{C}$, continuous light. Then, they were stained with FM4-64 30 $\mathrm{mg} / \mathrm{ml}$ (Invitrogen) for 10 minutes and imaged with the same Zeiss LSM780 confocal microscope with excitation at $488 \mathrm{~nm}$, emission filter set to 572-625 nm for FM4-64.

\section{Cell measurements in the shoot apical meristem}

The experiment to measure cell number, cell volume and meristem volume was made in collaboration with the laboratory of Dr. Sablowski, and we used a novel technique implemented in his laboratory (11). It combines confocal microscopy with a package of Python scripts and Fiji macros to process the images to landmark, segment, locate and measure cells in 3D, covering all the volume of the meristem. This was followed by another step of manual treatment of the data to delete cells that were incorrectly segmented.

First, the preparation of the samples and imaging was made as described in section 12 of this Material and Methods. Second, the image analysis was performed. For 3D segmentation and cell measurements, confocal image stacks were processed using scripts written in Python 2.7.3 and Fiji macros were used to visualize images, select landmark points, and select cells to be removed from the analysis during manual quality control. Next, statistics of the measurements were calculated. For each treatment, measurements from three to five replicates per apex were pooled after filtering by cell layer and region of interest (meristem). The raw data were processed in a Python shell using the functions defined in Serrano-Mislata, 2015 (11) and the obtained measures were then analyzed statistically with a Student test. 


\section{Root length and cell measurements in the root apical meristem}

To measure the root length, seedlings were grown for one week in continuous light at $22^{\circ} \mathrm{C}$ in a vertical orientation on plates containing half strength MS medium (Duchefa) with $0.8 \%(\mathrm{w} / \mathrm{v})$ phytoagar and without sucrose, and supplemented with either mock solution or $1 \mu \mathrm{M}$ GA3 (Duchefa). Root length was measured using Image J software.

To measure the size of protoderm cells in the RAM, the modified pseudo-Schiff propidium iodide staining technique (mPS-PI) was performed as described in Truernit et al., 2008 (12). In brief, the basis of this technique is the covalent labeling of fluorophores (in our case propidium iodide) to the cell wall, followed by clearing of the tissue with chloral hydrate. This results in samples with highly fluorescent cell walls for the visualization of internal tissue structures (such as the vasculature) that can be easily observed by confocal microscopy and render high resolution images. After capturing the images in the confocal microscope with excitation at $488 \mathrm{~nm}$ and emission collected at 520 to $720 \mathrm{~nm}$ (section 12 of Material and Methods), cell number and length in the protoderm was measured with the Image J software.

\section{RNA-sequencing}

\section{Preparation of the samples}

Three biological replicates for each condition were taken. Extraction and purification of the RNA samples was performed according to section 9 of this materials and methods. Samples were collected in $\mathrm{N}_{2}(\mathrm{I})$ and grinded, and total RNA was extracted with the Plant RNA Mini Kit (Omega Biotek). These RNA samples were then treated with the DNase Kit (Ambion) to further eliminate genomic DNA. Following isolation, RNA concentration, quality and integrity was checked using a NanoDrop ${ }^{\circledR}$ ND-1000 spectrophotometer and an Agilent Technologies 2100 Bioanalyzer. All samples had an RNA Integrity Number (RIN) value bigger than 8 . Additionally, a $1 \%$ agarose gel was carried out and RNA integrity was corroborated, as the $28 \mathrm{~S}$ and $18 \mathrm{~S}$ ribosomal RNA bands can be seen (Figure 9.1). Concentrations of all samples were equalized and adjusted to $4 \mathrm{ng}$. 


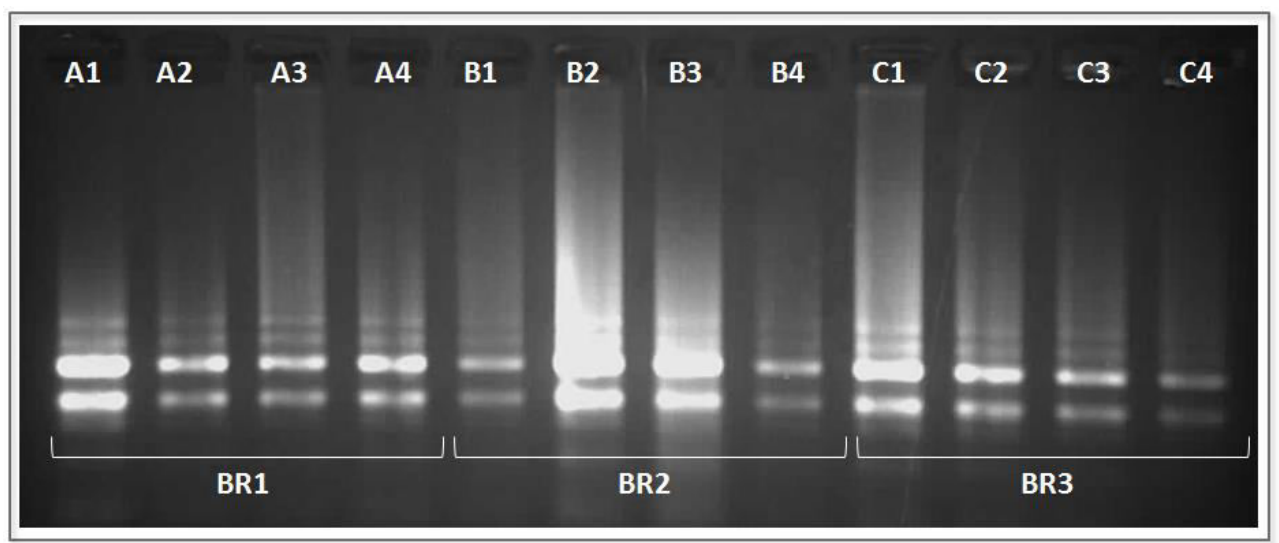

Figure 9.1. Agarose gel showing the $28 \mathrm{~S}$ and $18 \mathrm{~S}$ ribosomal RNA bands of the 12 samples analyzed. Samples are named from 1 to 4 (section 9 of Chapter I). Three biological replicates were used for the analysis: biological replicate 1 (BR1, A), biological replicate $2(B R 2, B)$ and biological replicate 3 (BR3, C).

\section{CDNA library preparation for RNA-Sequencing}

RNA-sequencing (RNA-seq) library preparation was done in the Genomic Service of the University of Valencia following the TruSeq Stranded mRNA Sample Preparation Low Sample (LS) Protocol from Illumina. Next, an overview of the process is depicted.

The first step involves the purification of the poly-A containing mRNA molecules using poly-T oligo attached magnetic beads. After purification, the mRNA was fragmented using divalent cations at high temperature. The cleaved RNA fragments were retrotranscribed into first strand cDNA using reverse transcriptase and random primers, and the original RNA template was removed. The second CDNA strand was then synthesized, in a process that incorporates dUTP instead of dTTP to quench the second strand during amplification, because the polymerase used does not incorporate past this nucleotide. At the end of this process, blunt-ended double stranded cDNAs were generated. After, a single adenine nucleotide was added to the $3^{\prime}$ ends of the blunt fragments to prevent concatenation during the adapter ligation reaction. Then, multiple indexing adapters were ligated to the ends of the ds CDNA, purified and enriched with PCR to create the final cDNA library.

\section{Sequencing and in silico analysis}

At the Genomic Service of the University of Valencia, libraries were sequenced on a NextSeq 500 sequencer from Illumina and the reads of $10 \mathrm{M}$ deep and 75 nucleotides in length (paired-end) were pre-processed (edition and elimination of adapters) using the package Trim.fastq. All processed reads were mapped to the Arabidopsis thaliana genome 
using the TopHat.v2.1.0 program, retrieving the results depicted in Table XII. Statistical analysis was also performed. Then, data was subjected to a quality control with QC program and the differential expression analysis was performed using DESeq2, SeqMonk 0.32.1 and EdgeR packages.

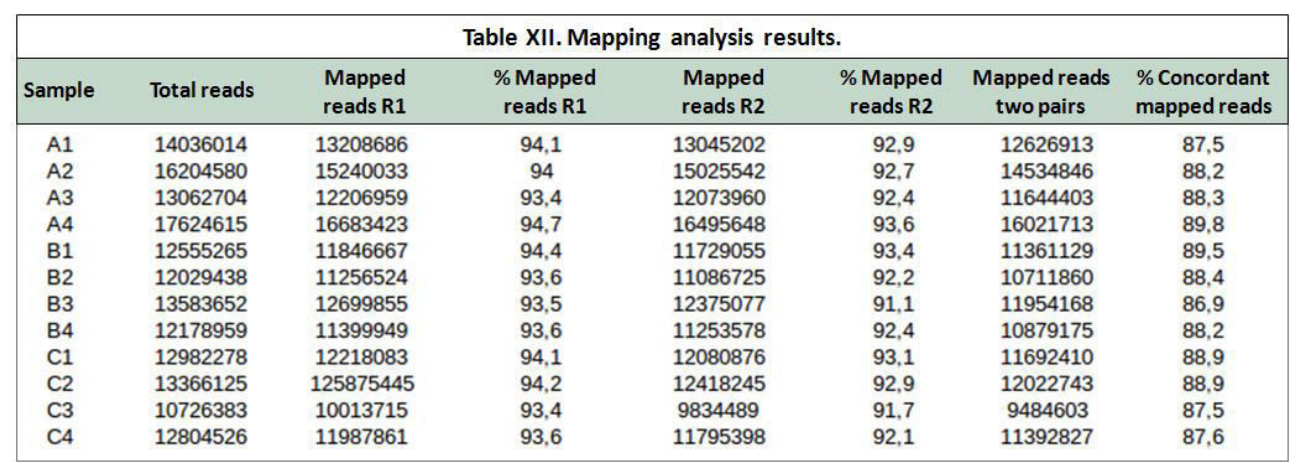

\section{In situ hybridization}

\section{Generation of the digoxigenin (DIG) labeled RNA probe}

Genomic DNA of Col-0 Arabidopsis plants was extracted and amplified with the GAI and TCP15 primers specified in Table VIII to generate a 782 and 469 bp fragment, respectively, belonging to specific zones in the gene that constitute the mould for the RNA probe. These fragments were cloned in the $p G E M^{\circledR}-T$ vector (Promega) that contains T7 and SP6 RNA polymerase transcription initiation sites flanking the insert. On both sides of the T7 and SP6 initiation sites, the vector contains specific primer sites M13 forward and M13 reverse, allowing the amplification of the fragment of interest by PCR (Table VIII). After the PCR, in vitro transcription with $\mathrm{T7}$ provided the antisense probe, whereas with SP6 the sense probe was generated.

For the in vitro transcription reaction, a $20 \mu \mathrm{l}$ mix was prepared with $200 \mathrm{ng}$ of mould DNA, $2 \mu$ I of DIG RNA Labeling Mix (10 mM ATP, 10 mM CTP, 10 mM GTP, 6.5 mM UTP, 3.5 mM DIG-11-UTP. Roche ${ }^{\circledR}$ ), $2 \mu$ l of Protector RNase Inhibitor (Roche ${ }^{\circledR}$ ), $2 \mu$ l of T7 RNA polymerase (or SP6 polymerase) and $2 \mu$ of 10X Buffer (Roche ${ }^{\circledR}$ ). Reaction was incubated at $37^{\circ} \mathrm{C}$ for 2 hours and then it was treated with $1 \mu$ I RNase-free DNase I (Roche ${ }^{\circledR}$ ) at 37으 for 15 minutes. To stop the reaction, $2 \mu$ of $0.2 \mathrm{M}$ EDTA were added and $1 \mu \mathrm{l}$ of yeast tRNA $\left(10 \mu \mathrm{g} / \mu \mathrm{l}\right.$, Roche $\left.{ }^{\circledR}\right)$. Precipitation was made in $10 \mu \mathrm{l}$ of $1 \mathrm{M} \mathrm{LiCl}$ and $75 \mu \mathrm{l} 100 \%$ ethanol and it was deposited in a freezer at $-20^{\circ} \mathrm{C}$ over night. The following day, probes were centrifuged at 13000 r.p.m. for 15 minutes, washed in $80 \%$ ethanol and let them dry around one hour. Probes were resuspended in $10 \mu \mathrm{l}$ of RNase-free $\mathrm{ddd}_{2} \mathrm{O}$ and $1 \mu \mathrm{l}$ was 
used for quantification. The remaining $9 \mu \mathrm{l}$ were resuspended in $91 \mu \mathrm{l}$ of hybridization buffer and saved at $-20 \circ \mathrm{C}$.

\section{Probe quantification}

The quantification of the probe was made with the nucleic acid hybridization technique or dot blot. Taking $1 \mu \mathrm{l}$ of the synthesized probe, different dilutions were made $(1 / 25,1 / 100$ and $1 / 250)$ and $1 \mu l$ of each dilution was deposited in a nylon membrane (Hybond $\mathrm{N}+$ ), dried and crosslinked with UV light. The same procedure was performed for the control of the quantification, a DIG labeled RNA of known concentration (Roche ${ }^{\circledR}$ ). The membrane was incubated in TBS $1 \mathrm{X}$ (TBS 10X: Tris- $\mathrm{HCl} 1 \mathrm{M}, \mathrm{NaCl} 4 \mathrm{M}$ at $\mathrm{pH}$ 7.5) for 2 minutes, blocked for 10 minutes in Blocking Reagent $0.5 \%$ (Roche ${ }^{\circledR}$ ) diluted in TBS $1 \mathrm{X}$, and washed in BSA solution (BSA 1\%, Triton X-100 0.3\%; in TBS 1X) for 5 minutes. Then, the membrane was incubated for 20 minutes with a 1:3000 dilution of the anti-DigoxigeninAP, Fab fragments antibody (Roche ${ }^{\circledR}$ ) diluted in BSA solution. The trace of antibody was washed twice for 4 minutes with BSA solution and detection buffer was added (Tris 100 $\mathrm{mM}, \mathrm{NaCl} 100 \mathrm{mM}, \mathrm{MgCl}_{2} 50 \mathrm{M}$, at $\mathrm{pH}$ 9.5). The membrane was revealed by incubation in dark for 12 minutes in $2.5 \mathrm{ml}$ of detection buffer $1 \mathrm{X}$ with substrate [3.75 $\mu \mathrm{l}$ of NBT $(100 \mathrm{mg} / \mathrm{ml})$ and $3.75 \mu \mathrm{l}$ of BCIP $(50 \mathrm{mg} / \mathrm{ml})$, Roche $\left.{ }^{\circledR}\right)$. Then the membrane was washed with $\mathrm{ddH}_{2} \mathrm{O}$ and let dry.

\section{Deparaffinization, antigen retrieval and hybridization}

Samples were included in paraffin and longitudinally cut as described in section 12 of Material and Methods. The slides were de-paraffinated with histoclear, re-hydrated with decreasing quantities of ethanol (100\%, 75\%, 50\% and $25 \%$ ) and water ( 2 minutes of incubation in each solution), and hydrolyzed in $\mathrm{HCl} 0.2 \mathrm{M}$ for 20 minutes. Then, samples were subjected to 4 washing steps of 5 minutes each: ultrapure water, twice with SSC $2 X$ (SSC 20X: sodium citrate $0.3 \mathrm{M}, \mathrm{NaCl} 3 \mathrm{M}$, at $\mathrm{pH}$ 7) and again ultrapure water. After that, they were incubated with Proteinase $\mathrm{K}(1 \mu \mathrm{g} / \mathrm{ml}$ in buffer: Tris $100 \mathrm{mM}$, EDTA $50 \mathrm{mM}$, at $\mathrm{pH} 8$ ) at $37^{\circ} \mathrm{C}$ for 18 minutes. After incubation, the slides were washed with PBS $1 \mathrm{X}$ (PBS 20X: $\mathrm{NaCl} 2.75 \mathrm{M}, \mathrm{KCl} 50 \mathrm{mM}, \mathrm{Na}_{2} \mathrm{HPO}_{4} 200 \mathrm{mM}, \mathrm{KH}_{2} \mathrm{PO}_{4}$, at $\mathrm{pH} 7.4$ ) for 2 minutes and incubation in glycine $0.2 \%(2 \mathrm{mg} / \mathrm{ml}$ in PBS $1 \mathrm{X})$ for 2 minutes followed by 2 washes of 2 minutes each in PBS $1 \mathrm{X}$ was used to block the Proteinase $\mathrm{K}$. For the re-fixation of the tissue, slides were incubated for 10 minutes in a dilution of $4 \%$ formaldehyde in PBS $1 X$. After incubation, slides were washed with PBS and de-hydrated in 2 minutes incubation with ultrapure water, $30 \%, 50 \%, 70 \%, 95 \%$ and $100 \%$ ethanol and let them dried.

For the hybridization, probes were diluted in hybridization buffer (HB: SSC 6X, SDS $1.5 \%$, formamide $50 \%$, yeast tRNA $100 \mu \mathrm{g} / \mathrm{ml}$ ) in the following relation: $4 \mu$ l of the probe in $50 \mu \mathrm{l}$ de HB. Probes were de-naturalized at $80^{\circ} \mathrm{C}$ for 2 minutes, added in each slide 
$(50 \mu \mathrm{l} / \mathrm{slide})$ and covered with slide covers. Hybridization was carried out over night in a wet chamber at 50 으.

\section{Washing and colorimetric immunodetection}

The excess of probe was removed with 3 washing steps in SSC $2 \mathrm{X}$ with formamide $50 \%(\mathrm{v} / \mathrm{v})$ at hybridization temperature $(50 \mathrm{O} \mathrm{C})$ : the first one for 30 minutes and the other two one hour and a half each. After washing, the slides were incubated in TBS $1 \mathrm{X}$ for 5 minutes and blocked in Blocking Reagent (Roche ${ }^{\circledR}$ ) $0.5 \%$ in TBS $1 X$ for 1 hour. Then, the slides were washed in BSA solution for 30 minutes and incubated with anti-DigoxigeninAP, Fab fragments (Roche ${ }^{\circledR}$ ) diluted in BSA solution (1:3000). After that, slides were washed with BSA solution three times (20 minutes each). Next, they were submerged for 5 minutes in detection buffer without the substrate (Tris $100 \mathrm{mM}, \mathrm{NaCl} 100 \mathrm{mM}, \mathrm{MgCl}_{2} 50 \mathrm{M}$, at $\mathrm{pH} 9.5)$ and then incubated in $50 \mathrm{ml}$ of detection buffer supplemented with the substrate $\left[75 \mu \mathrm{l}\right.$ of NBT $(100 \mathrm{mg} / \mathrm{ml})$ and $75 \mu \mathrm{l}$ of BCIP $(50 \mathrm{mg} / \mathrm{ml})$, Roche $\left.{ }^{\circledR}\right]$ until the signal was observed, in our case, more than 18 hours. Finally, the reaction was stopped by placing the slides in water and let them dry. For the visualization of the signal, slides were prepared with Merckglass (Merck) and observed with the optical microscope (section 12 of Material and Methods).

\section{References}

1. Clough SJ, Bent AF. Floral dip: a simplified method for Agrobacterium-mediated transformation of Arabidopsis thaliana. The Plant journal : for cell and molecular biology. 1998;16(6):735-43.

2. Bechtold N, Pelletier G. In planta Agrobacterium-mediated transformation of adult Arabidopsis thaliana plants by vacuum infiltration. Methods in molecular biology. 1998;82:259-66.

3. Iwakawa H, Iwasaki M, Kojima S, Ueno Y, Soma T, Tanaka H, et al. Expression of the ASYMMETRIC LEAVES2 gene in the adaxial domain of Arabidopsis leaves represses cell proliferation in this domain and is critical for the development of properly expanded leaves. The Plant journal : for cell and molecular biology. 2007;51(2):173-84.

4. Rast-Somssich M, Broholm S, Jenkins H, Canales C, Vlad D, Kwantes M, et al. Alternate wiring of a KNOXI genetic network underlies differences in leaf development of A. thaliana and C. hirsuta. GenDev. 2015;29:2391-404.

5. Earley KW, Haag JR, Pontes O, Opper K, Juehne T, Song K, et al. Gatewaycompatible vectors for plant functional genomics and proteomics. The Plant journal : for cell and molecular biology. 2006;45(4):616-29.

6. Viola IL, Reinheimer R, Ripoll R, Manassero NG, Gonzalez DH. Determinants of the DNA binding specificity of class I and class II TCP transcription factors. The Journal of biological chemistry. 2012;287(1):347-56.

7. Kosugi S, Ohashi Y. DNA binding and dimerization specificity and potential targets for the TCP protein family. The Plant journal : for cell and molecular biology. 2002;30(3):337-48. 
8. Hellens RP, Allan AC, Friel EN, Bolitho K, Grafton K, Templeton MD, et al. Transient expression vectors for functional genomics, quantification of promoter activity and RNA silencing in plants. Plant methods. 2005;1:13.

9. Zadnikova P, Petrasek J, Marhavy P, Raz V, Vandenbussche F, Ding Z, et al. Role of PIN-mediated auxin efflux in apical hook development of Arabidopsis thaliana. Development. 2010;137(4):607-17.

10. Yadegari R, Paiva G, Laux T, Koltunow AM, Apuya N, Zimmerman JL, et al. Cell Differentiation and Morphogenesis Are Uncoupled in Arabidopsis raspberry Embryos. The Plant cell. 1994;6(12):1713-29.

11. Serrano-Mislata A, Schiessl K, Sablowski R. Active Control of Cell Size Generates Spatial Detail during Plant Organogenesis. Current biology : CB. 2015;25(22):2991-6.

12. Truernit E, Bauby H, Dubreucq B, Grandjean O, Runions J, Barthelemy J, et al. High-resolution whole-mount imaging of three-dimensional tissue organization and gene expression enables the study of Phloem development and structure in Arabidopsis. The Plant cell. 2008;20(6):1494-503. 



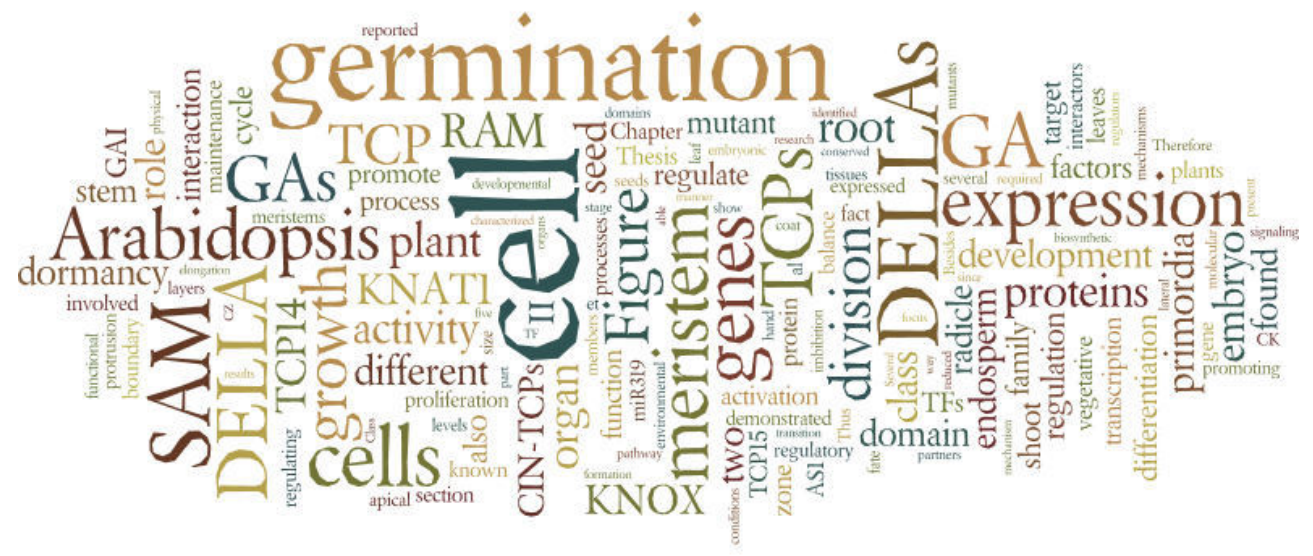

Esta tesis se llevó a cabo gracias a una beca de Formación de Personal Investigador (FPI) del Ministerio de Economía, Industria y Competitividad, Gobierno de España. 



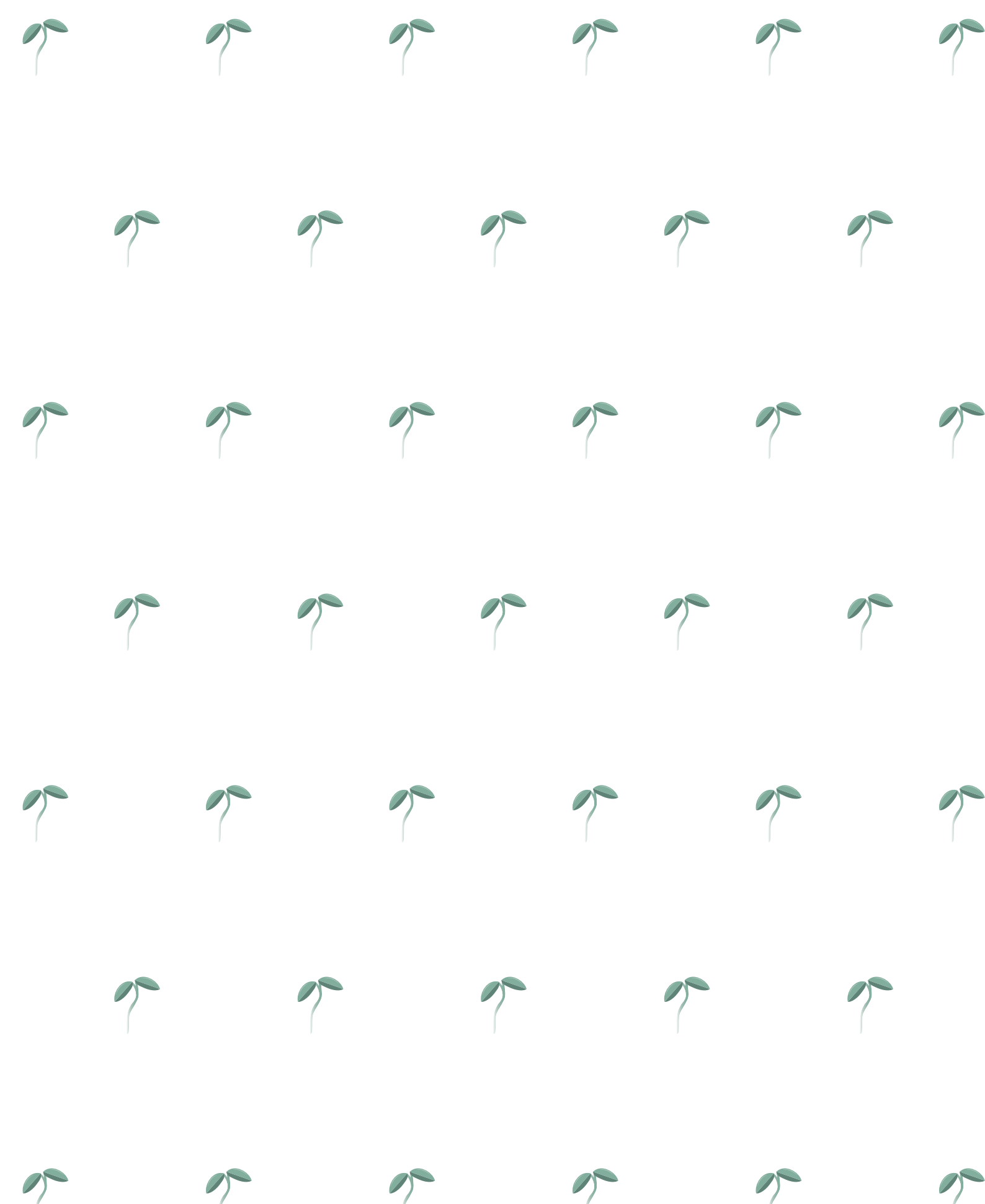

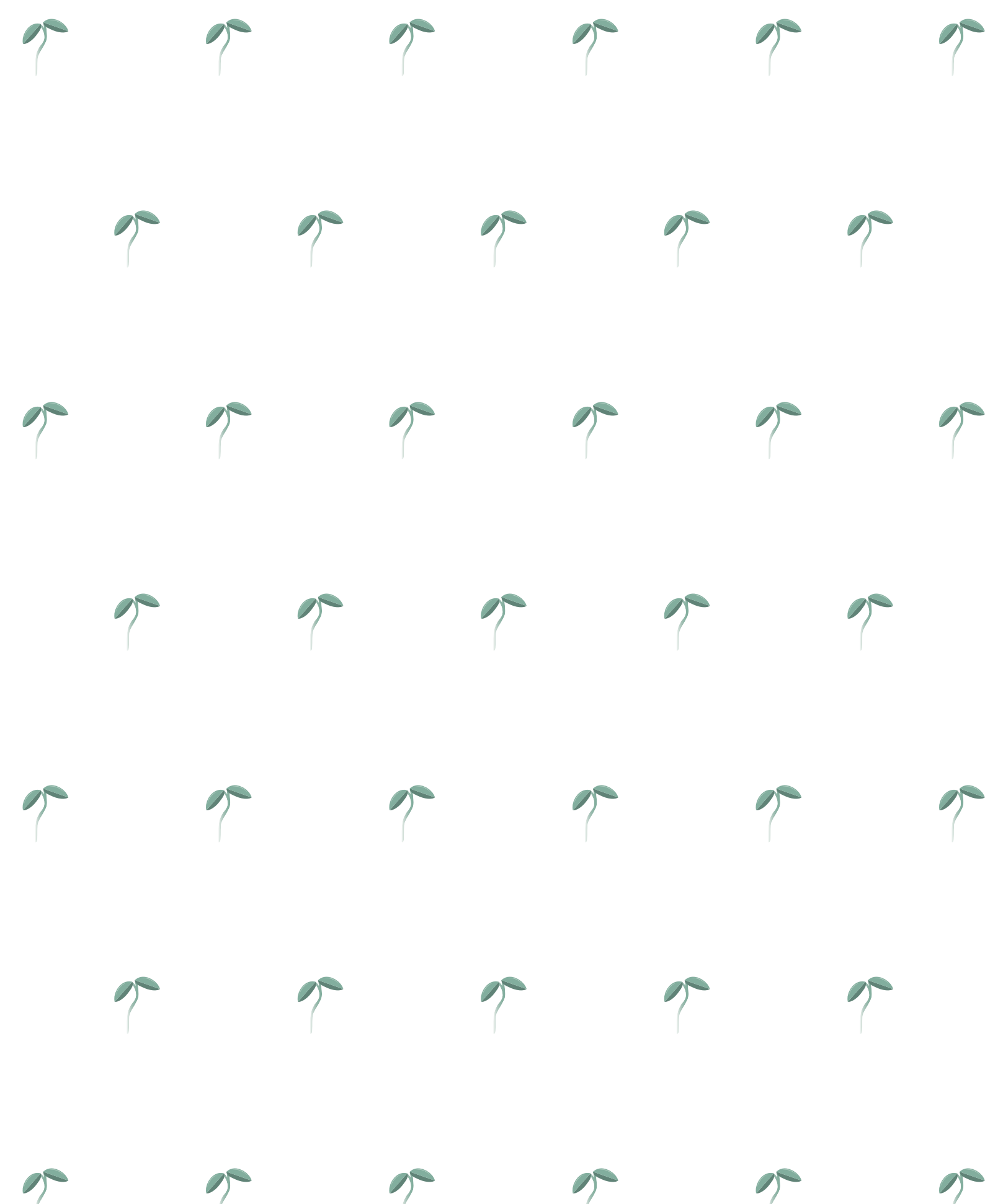
网 